AISI/DOE Technology Roadmap Program

Final Report

\title{
Technology of Low Coal Rate and High Productivity of RHF Ironmaking
}

\author{
by
}

W-K. LU

September 15, 2002

Work Performed under Cooperative Agreement No. DE-FC07-97ID13554

Prepared for

U.S. Department of Energy

Prepared by

American Iron and Steel Institute

Technology Roadmap Program Office

Pittsburgh, PA 15220 


\section{DISCLAIMER}

"Any opinions, findings, and conclusions or recommendations expressed in this material are those of the author(s) and do not necessarily reflect the views of the US Department of Energy."

Number of pages in this report: 184

DOE and DOE contractors can obtain copies of this report FROM: Office of Scientific and Technical Information, P. O. Box 62, Oak Ridge, TN 37831. (615) 576-8401.

This report is publicly available from the Department of Commerce, National Technical Information Service, 5285

Port Royal Road, Springfield, VA 22161. (703) 487-4650. 


\section{TABLE OF CONTENTS}

Table of Contens $\quad$ iii

$\begin{array}{ll}\text { List of Figures } & \text { iv }\end{array}$

$\begin{array}{ll}\text { List of Tables } & \text { vii }\end{array}$

Executive Summary $\quad$ xi

$\begin{array}{ll}\text { Acknowledgement } & \text { xiv }\end{array}$

$\S 1$ Introduction $\quad 1$

$\S 2$ Raw Materials and Laboratory Equipment $\quad 8$

$\S 3 \quad$ Fundamentals of Ironmaking Based on Ore/Coal Composites 21

$\S 4 \quad$ Reduction Experiments in the Natural Gas-Fired Furnace $\quad 41$

$\S 5 \quad$ Pilot Plant Trials at CSM, Genova, Italy 57

$\$ 6$ Systematic Experimentation and Mathematical Analysis for Technology Transfer 92

§7 Energy Consumption and Environment Protection 99

$\S 8$ The New Heath Furnace for the New Technology 115

$\S 9$ Conclusions and Recommendations $\quad 121$

$\begin{array}{lll}\S 10 & \text { Reference } & 124\end{array}$

$\begin{array}{lll}\S 11 & \text { Appendices } & 125\end{array}$ 


\section{LIST OF FIGURES}

Figure No.

Title of Figure

Page

1-1 The rising gas stream pushes back the combustion products which contains $\mathrm{CO}_{2}, \mathrm{H}_{2} \mathrm{O}$ and possibly $\mathrm{O}_{2}$

2-1 Appearance of the muffle furnace used for the experimental study

$2-2 \mathrm{a}$

Experimental Set-up in the Muffle Furnace

12

$2-2 b \quad$ The special crucible for the reduction of ore/coal pellets in the muffle furnace

2-3 Design and appearance and of the natural gas- fired furnace

The combustion and control system

2-7 The Appearance and design of the discharging and cooling device 19

2-8 Appearance of the pelletizing disk 20

3-1 Direct measurement of temperature and gas composition at top of pellet bed of $60 \mathrm{~mm}$ height.(Green ball: Taconite + coal\#3, C/O-0.9)

3-2 The influence of processing temperature on the reduction of bed of ore/coal pellet (Total heating time $25 \mathrm{~min}$., Bed height $60 \mathrm{~mm}$, green ball conditions see Table 4-1)

3-3 The influence of processing temperature on the reduction process (bed height $60 \mathrm{~mm}$, green ball conditions see Table 4-2)

3-4 The relation of degree of metallization of DRI to total heating time with different $\mathrm{C} / \mathrm{O}$ ratio different total heating time

3-6 The effect of volatile matter of carbonaceous reductant in the pellets on the reduction of ore/coal pellets

3-7 The reduction of ore/coal pellets and re-oxidation of DRI in pellet bed of different heights in a muffle furnace in air atmosphere

3-8 The effect of pellet size on the reduction of ore/coal pellet 


\section{LIST OF FIGURES (continued)}

Figure No.

Title of Figure

Page

3-9 Comparison of effects of hot and cold hearth surface on the reduction of ore/coal pellets

3-10 The relationship between productivity and height of pellet bed

3-11 Changes in atomic ratio of combined oxygen and carbon in pellet beds of different heights

3-12 The relationship between density of DRI and total heating time (green balls: taconite + coal $\# 3, \mathrm{C} / \mathrm{O}=0.9$, size $=14 \mathrm{~mm}$, bed height $=60 \mathrm{~mm}$ )

3-13 The relationship between density of DRI and the $\mathrm{C} / \mathrm{O}$ ratio (green balls: taconite + coal $\# 3$, size $=14 \mathrm{~mm}$, bed height $=60 \mathrm{~mm}$, total heating time $=30$ minutes)

4-1 A typical direct measurement of temperatures and gas compositions at the top of the crucible (Green ball: Taconite + Marfork coal, $\mathrm{C} / \mathrm{O}=0.9$, bed height $120 \mathrm{~mm}$ )

4-2 A typical direct measurement of temperatures and gas compositions of exit gas (Green ball: Taconite + Marfork coal, $\mathrm{C} / \mathrm{O}=0.9$, bed height $120 \mathrm{~mm})$

4-3 Appearance of DRI "cake" made from taconite concentrate at McMaster University

5-1 The configuration of the natural gas fired furnace used for reduction experiments

5-2 The appearance of the natural gas fired furnace used for reduction experiments

5-3 A record of the air and gas flow rate during an experiment at the pilot plant

5-4 Appearance of the pelletizing disk at the pilot plant

Appearance of the crucible made in the pilot plant after one experiment

5-6 The charger at CSM for the trials

5-7 The carbon soot was burned off by the leaked-in air through the door 66

5-8 Temperature profiles and CO concentration of Trial \#2 (Taconite) 71

5-9 Temperature profiles and CO concentration of Trial \#6 (BOF Sludge) 72

5-10 Temperature profiles and CO concentration of Trial \#8 73 


\section{LIST OF FIGURES (continued)}

Figure No.

Title of Figure

Page

5-11 DRI cake made from Taconite Concentrate

5-12 DRI cake made from Brazilian hematite concentrate (Carajas) 75

5-13 DRI cake made from mill scale $\quad 76$

5-14 DRI cake made from BOF sludge $\quad 77$

5-15 DRI cake made from BOF sludge and EAF dust $\quad 78$

5-16 The Effects of the turbulence of the flue gas on the top of the pellet bed 79

5-17 The metallograph photos of the specimens of DRI made of iron ore 81

5-18 The metallograph photos of the specimens of DRI made of waste oxides 82 $(\times 32)$

5-19 The metallograph photos of the specimens of DRI made of BOF sludge and EAF dust $(\times 32)$

5-20 The degree of metallization of three portions of every DRI cake made from iron ores. The average values of DRI cakes are also included

5-21 The degree of metallization of three portions of every DRI cake made from waste oxides. The average values of DRI cakes are also included.

6-1 The furnace temperatures and gas composition at the top of crucible in Experiment No.1

6-2 Productivity vs. Degree of Metallization $(\mathrm{C} / \mathrm{O}=0.9) \quad 97$

7-1 Coal rate for the reduction of taconite concentrate based on heat and mass 104 balance

7-2 Coal rate for the reduction of hematite concentrate based on heat and mass 105 balance

7-3 A schematic diagram of a melting operation 109

7-4 A schematic diagram of a melting operation(electric) 112

8-1 Likely situations at outer edge of a rotary hearth furnace with a tall pellet $\quad 117$

8-2 The top view of a PSH furnace and the movements of solids and gas $\quad 119$

8-3 The structure of pallets of PSH furnace 119

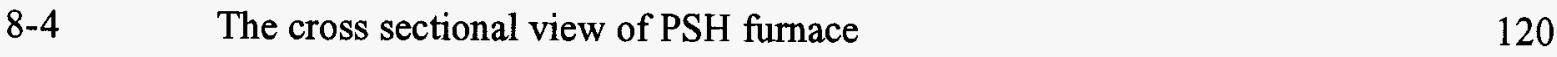




\section{LIST OF TABLES}

Table No.

Title of Figure

Page

1-1 Absolute theoretical minimum carbon and energy requirements per tonne of liquid iron at $1600^{\circ} \mathrm{C}$

2-1 Major Chemical Composition of Taconite concentrate(wt.\%)

2-2 Major Chemical Composition of Carajas concentrate(wt.\%)

The Chemical Composition of BOF Sludge from Dofasco (wt.\%)

The Chemical Composition of Mill Scale from Dofasco (wt.\%)

The Chemical Composition of EAF Dust from Dofasco (wt.\%)

The Chemical Composition of EAF Dust from SMS Demag (wt.\%) .\%)

[for the pilot plant trials in CSM Italy only]

2-7 the Total Carbon content and Proximate Analyses of Coals (wt.\%)

The Major Properties of the Muffle Furnace

3-1 The Influence of Furnace Temperature on the Reduction Process in a Pellet Bed of $60 \mathrm{~mm}$

3-2 The Influence of Heating Time on the Reduction in a Pellet Bed of 60 $\mathrm{mm}$

3-3 The relationship between metallization degree and total heating time $\left(\mathrm{C} / \mathrm{O}=1.1,(\mathrm{C} / \mathrm{O})_{\text {ext }}=0\right.$, Bed Height $\left.=60 \mathrm{~mm}\right)$

3-4 The relationship between metallization degree and total heating time $\left(\mathrm{C} / \mathrm{O}=1.0,(\mathrm{C} / \mathrm{O})_{\text {ext } .}=0\right.$, Bed Height $\left.=60 \mathrm{~mm}\right)$

3-5 The relationship between metallization degree and total heating time $\left(\mathrm{C} / \mathrm{O}=0.9,(\mathrm{C} / \mathrm{O})_{\text {ext }}=0.1\right.$, Bed Height $\left.=60 \mathrm{~mm}\right)$

3-6 The relationship between metallization degree and total heating time $\left(\mathrm{C} / \mathrm{O}=0.8,(\mathrm{C} / \mathrm{O})_{\text {ext }}=0.2\right.$, Bed Height $\left.=60 \mathrm{~mm}\right)$

3-7 The relationship between metallization degree and total heating time $\left(\mathrm{C} / \mathrm{O}=0.7,(\mathrm{C} / \mathrm{O})_{\text {ext }}=0.3\right.$, Bed Height $\left.=60 \mathrm{~mm}\right)$

3-8 The relationship between metallization degree and total heating time $\left(\mathrm{C} / \mathrm{O}=0.6,(\mathrm{C} / \mathrm{O})_{\text {ext. }}=0.4\right.$, Bed Height $\left.=60 \mathrm{~mm}\right)$ 


\section{LIST OF TABLES (continued)}

Table No.

Title of Figure

Page

3-9 The effect of volatile matter on reduction of ore/coal pellets $(\mathrm{C} / \mathrm{O}=1.05$,

Bed Height $=60 \mathrm{~mm}$, Pellets Size: $14 \mathrm{~mm}$ )

3-10 The relationship between metallization degree and total heating time $\left(\mathrm{C} / \mathrm{O}=0.9,,(\mathrm{C} / \mathrm{O})_{\text {ext. }}=0.1\right.$, Bed Height $\left.=20 \mathrm{~mm}\right)$

3-11 The relationship between metallization degree and total heating time $\left(\mathrm{C} / \mathrm{O}=0.9,(\mathrm{C} / \mathrm{O})_{\text {ext }}=0.1\right.$, Bed Height $\left.=40 \mathrm{~mm}\right)$

3-12 The relationship between metallization degree and pellet size (Bed Height $=60 \mathrm{~mm}$ )

3-13 The relationship between metallization degree and total heating time when the pellets are placed on cold hearth (Bed Height $=60 \mathrm{~mm}$ )

4-1 Chemical Analysis and Density of DRI of Series A 46

4-2 Chemical Analysis and Density of DRI of Series B 47

4-3 Weighted Average of Degree of Metallization, Productivity and Density 48 of DRI of Series A

4-4 Weighted Average of Degree of Metallization, Productivity and Density of DRI of Series B

4-5 Chemical analysis of DRI in the layers and performance of the whole bed

4-6 Chemical analysis of DRI in the three layers and the performance of the whole bed

5-1 Specifics of the Natural Gas-fired Furnace used for reduction experiments

5-2 Compositions of Green Balls, wt.\% (dry basis). All Green Balls Contain $1 \%$ Bentonite, the Diameter is in a Range of 16 19 mm

5-3 Compression strength of dried green balls $(\mathrm{kg} / \mathrm{pellet})$

5-4 Reduction Conditions

5-5 Metallographic Examination

5-6 The chemical analyses of DRI made of iron ores in the pilot plant 86

5-7 The chemical analyses of DRI made of waste oxides in the pilot plant $\quad 88$

5-8 The chemical analyses of DRI made of iron ores in the pilot plant 89

6-1 The Central Composite Design for 3 Factors 94

6-2 The Arrangement of the systematic experimentation 95 


\section{LIST OF TABLES (continued)}

Table No.

Title of Figure

Page

6-3

Chemical Analysis and Density Measurement of DRI in Experiment No. 196

$6-4$

Recommended Conditions for Producing DRI of high Metallization

98

Degree at High Productivity

6-5 Recommended Conditions for Producing DRI of High Quality

Typical RHF Processes Inputs

100

$7-2$

Chemical Compositions

100

Mass and Heat Balance with Natural Gas Burners

102

$7-4$

Chemical Composition of Products

102

Mass and Heat Balance with Coal Burners

103

The coal rate under different operations for taconite concentrate reduction, from Fig. 8-1

7-7 The computation of the cases shown in Table 8-3 and Table 8-5 with lower temperature of exit gas

7-8 Chemical Compositions (case of oxygen melter)

108

7-9 Heat and Mass Balance for the Hearth Furnace

7-11 Chemical Compositions (case of electric melter) 112

7-12 Heat and mass balance for the hearth furnace (case of electric melter) 113

7-13 Heat and mass balance of the electric melter 113

8-1 The volume ratios and area ratios, $\mathrm{H}=120 \mathrm{~mm} \quad 117$

8-2 The volume ratios and area ratios, $\mathrm{H}=25 \mathrm{~mm} \quad 118$ 


\section{EXECUTIVE SUMMARY}

The project objective as stated in the original research proposal was to develop a coatbased and coke-free ironmaking process based on RHF and a melting/refining unit to provide high quality/inexpensive hot metal for BOF steelmaking. This objective has been substantially achieved in about one-half of the time, due to the very diligent work of highly qualified staff and of course, the absence of breakdown of the equipment. As guided by representatives of sponsoring companies and AISI TRP officials the objective of the project was enlarged and the budget increased to include a series of experiments in a pilot plant in Genoa, Italy, and the extension of the project duration by three months.

After completion of the pilot plant work two very important tasks which were not a part of the expanded objective, were given to the staff of this project:

(a)The assessment of major materials handling equipment in the existing plant and its compatibility with the new technology being developed.

(b)The development of a reliable method for chemical analysis of high temperature DRI, with which the standard method failed.

Developmental work was conducted with the use of a specially designed furnace with a capacity of $6.0 \mathrm{kgs}$. of pellets, a step up from the current 230 grams. It was aimed to find the optimum operating conditions to increase the productivity by at least a factor of three and to decrease the carbon rate by $50 \%$ in comparison with current practice in industry.

The following table compares the achieved productivity and carbon rate of the new hearth furnace with a commercial RHF plant: 
The comparison of productivity and carbon rate of the new hearth furnace with a commercial RHF plant

\begin{tabular}{|l|c|c|c|}
\hline \multicolumn{1}{|c|}{ Process } & $\begin{array}{c}\text { McMaster } \\
\text { University }\end{array}$ & $\begin{array}{c}\text { Commercial } \\
\text { Plant A* }\end{array}$ & $\begin{array}{c}\text { Ratio for } \\
\text { Comparison }\end{array}$ \\
\hline Degree of Metallization (\%) & 95 & 66 & \\
\hline Metallic Iron $\left(\mathrm{Fe}^{\circ}\right)(\mathrm{wt} \%$ \%) & 79.2 & 46 & \\
\hline Prod. (kg-DRI $\left./ \mathrm{m}^{2} \mathrm{~h}\right)$ & 125 & 56 & \\
\hline Prod. (kg-Fe $\left./ \mathrm{m}^{2} \mathrm{~h}\right)$ & $\mathbf{9 9}$ & $\mathbf{2 6}$ & $\mathbf{3 . 8}$ \\
\hline $\mathrm{kg}-\mathrm{C}($ fixed) $/ \mathrm{t}-\mathrm{DRI}$ & 146 & 193 & \\
\hline $\mathrm{kg}-\mathrm{C}\left(\right.$ fixed) $/ \mathrm{t}-\mathrm{Fe}^{\circ}$ & $\mathbf{1 8 4}$ & $\mathbf{4 2 1}$ & $\mathbf{0 . 4 4}$ \\
\hline
\end{tabular}

* Monthly average values

It is evident from this table that the new process produced DRI with higher degree of metallization (95\%), lower coal rate, and higher productivity compared to an existing commercial RHF plant.

Pilot plant trials in Genoa, Italy were conducted:

(1) To confirm experimental results obtained on campus in an industrial setting, i.e., carrying out all tasks by steel workers supervised by company staff, and

(2)To test the viability of the proposed new technology for waste oxide recycling in a carbon steel plant.

For a period of five weeks, in an old steel works, a team of four workers led by two combustion engineers have modified a high temperature furnace and conducted nine experiments, according to McMaster University team's instructions. Data obtained on campus were successfully repeated in the pilot plant. The validity of the methodology and equipment at McMaster University has been confirmed. 
BOF sludge, BOF sludge/EAF dust mixtures and millscale were successfully processed. DRIproduced was of high quality, about $95 \%$ degree of metallization of iron oxides and essentially complete removal of zinc and lead was achieved.

In comparison with other commercial RHF practices, this process is different in atmosphere (fully oxidized, at $1600^{\circ}$ to $1650^{\circ} \mathrm{C}$ ), in bed height $(120 \mathrm{~mm}$ instead of $20-25 \mathrm{~mm}$ ) and in pellet composition (much less coal, but higher in volatile matters). The combined effect leads to three times higher furnace productivity, lower coal consumption and superior DRI quality.

An assessment on the possibility of operating the existing plants with tall pellet bed $(120 \mathrm{~mm}$ height) and high flame temperature $\left(1600^{\circ}\right.$ to $1650^{\circ} \mathrm{C}$ ) was made as regards retrofitting.In existing RHF plants, a water-cooled metallic screw is used to discharge hot DRI from a shallow bed in the radial direction. The metallic screw discharger with long flights for the tall bed of very hot DRI (in the range from $1200^{\circ}$ to $1500^{\circ} \mathrm{C}$ ) is very unlikely to have an acceptable service life. Furthermore, the presence of the discharger in the radial direction prevents the building of a retaining wall to hold pellets in the tall bed. The conceptual design of a simple furnace which resembles the straight grate for pellet induration at mines, sinter machine in steel plants and tunnel furnace in the ceramic industry is outlined in the main body of the report.

Very large errors were found in the determination of the content of metallic iron, in the DRI produced at high temperatures, by commercial laboratories using the standard method. These errors were due to incomplete extraction of metallic iron by bromine solution which was probably hindered by the presence of slag coating. A method based on copper sulfate was tested and recommended.

In comparison with typical blast furnace operations, this new technology together with a melter would have a lower coal rate by $200 \mathrm{Kg} / \mathrm{THM}$. The elimination of cokemaking and high temperature agglomeration steps, and an inherent simpler gas handling system would lead to a lower capital and operating costs. 


\section{ACKNOWLEDGEMENTS}

The writer of this report wishes to express his appreciation to three institutions: McMaster University, the American Iron and Steel Institute and the US Department of Energy for their support of this project. In the early stage, guidance from Mr. William A. Obenchain of AISI was timely and helpful.

When the project was in progress, we appreciated very much the Monitoring and Supervisory Committee for its encouragement and support. This friendly, informal, competent and sometimes demanding committee was made up of the following individuals representing their institutions: Joe Vehec (AISI), Tom Stackrow (AISI), Ken Grieshabar (BOC Gases), Clara van Aswegan (BOC Gases), Jack Bajaj (US Steel), John Ellis (Heckett Multiserve), Otto Metelmann (SMS Demag), Rolf Degel (SMS Demag), Prakash Hegde (LTV Steel), Stanley Sun (Dofasco Inc.), and Russ Bleakney (INMETCO).

For the successful pilot plant trials, we wish to thank Dr. P. Fontana of SMS Demag S.P.A. for his leadership and Dr. D. Nelli, Director, CSM Experimental Station of Combustion and his crew for yheir effort in responding to our needs with a very short time of notice.

At McMaster University, we wish to thank the Office of Research Contracts and Intellectual Properties and the Department of Materials Science and Engineering for their guidance and support. There is one individual without whom this project could not have been completed as successfully as it was. He is Dr. Dianbing (Frank) Huang, who was responsible for all experimental activities on campus. Frank designed experiments based on scientific facts. He also designed laboratory devices and went ahead to make them in the machine shop himself. During the pilot plant trials in Genoa, Italy, Frank played the role of quality control person very well, even though he can neither speak Italian nor hold alcohol. Frank has clearly contributed beyond the call of duty. We wish to thank Ken Du and Annette Boudreau who always provided a helping hand when needed. 


\title{
Report Documentation Page Information
}

\section{Title and Subtitle:}

AISI/DOE Technology Roadmap Program

Technology of Low Coal Rate and High Productivity of RHF Ironmaking

Author:

Wei-Kao Lu

Performing Organization Names, Address:

Department of Materials Science and Technology

McMaster University

1280 Main Street West

Hamilton, Ontario, CANADA

L8S 2N6

\begin{abstract}
An economical and environment-friendly ironmaking process based on heating the chemically self-sufficient green balls of iron ore and coal in a hearth furnace was developed with financial support from AISI members and DOE. DRI, which is hot $\left(1400^{\circ} \mathrm{C}\right)$, dense $\left(>3.2 \mathrm{~g} / \mathrm{cm}^{3}\right)$ and of high degree of metallization $(95 \%)$, has been produced in laboratory and in a pilot plant in Genoa, Italy. Products of such quality have been made from American and Brazilian ores, BOF sludge, EAF dust/BOF sludge mixtures and millscale. The removal of zinc and lead from green balls by this process is essentially complete.
\end{abstract}

In comparison with typical blast furnace operation, the new technology with a melter would have a lower total coal rate by $200 \mathrm{~kg} / \mathrm{THM}$. The elimination of cokemaking and high temperature agglomeration steps, and a simpler gas handling system would lead to lower capital and operating costs.

In comparison with commercial RHF practice it is different in atmosphere (fully oxidized at $1600^{\circ}$ to $1650^{\circ} \mathrm{C}$ ), in bed height $(120 \mathrm{~mm}$ instead of $20-25 \mathrm{~mm}$ ) and in pellet composition (much less coal but of higher VM). The combined effect leads to three times higher furnace productivity, lower coal consumption and superior DRI quality. The risk of re-oxidation (slag formation) and dusty operation are practically eliminated. The process is stable, tolerant and independent of the size, shape and movement of the hearth. However, materials handling (e.g., discharge of hot DRI) and the exact energy savings have to be established in a larger furnace, straight or rotary, and in a continuous mode of operation. 


\section{§1. INTRODUCTION}

$\S 1.1$ Brief Description of Major Events $\quad 2$

$\S 1.2$ The Absolute Theoretical Minimum Carbon and Energy Requirements for 3 Making Liquid Iron

$\S 1.3$ Hearth-Type Furnaces for Ironmaking 5

$\S 1.4$ Scale-Up of McMaster Process and Modification of Current RHF 6

$\S 1.5$ Steps Towards Commercialization of McMaster Process $\quad 7$ 


\section{§1. INTRODUCTION}

For another decade to come, the blast furnace will very likely remain the dominant ironmaking reactor in North America and in the world. There have been continuing efforts all over the world in the search for alternative processes because of high capital investment and environmental concerns associated with preparatory steps of raw materials for blast furnaces. Furthermore, it is a mature process, i.e., there is little opportunity for pleasant surprises in the future development, for example, the efficiency of using carbon as the reductant. The $\mathrm{CO}$ to $\mathrm{CO}_{2}$ ratio in blast furnace top gas is limited by thermodynamic equilibrium of wustite and gas in the stack. On the other hand, the counter-current flows of gas and solid streams and the massive scale of operation keep the blast furnace in such a powerful position that none of the previously proposed alternative ironmaking processes can have better efficiency in the utilization of reductants and energy (theoretically and practically), with the present work the only exception The importance of this project must be emphasized in that the technology which is being developed at McMaster University has the basic features in the savings in energy consumption and in capital investment, as well as fundamental changes in environment protection to replace blast furnace as the coat fired ironmaking process.

When this project began in May 1999, there were several rotary hearth furnaces (RHFs) in operation for processing waste oxides from stainless steel plants and on-site processing of waste oxides in carbon steel plants. There is one RHF plant which was designed to produce DRI from iron ore and subsequently melted electrically as a source of liquid iron in an arc furnace steelmaking shop. At the present time, a large fraction of RHF plants in North America is not in operation for various reasons, including quality of product, high energy cost and low furnace productivity. This situation will be part of the discussion in this Report.

\section{$\S 1.1 \quad$ Brief Description of Major Events}

This project officially started on April 22, 1999, and Dr. Dianbing (Frank) Huang was given the responsibility of all laboratory activities. Reduction experiments were conducted in the electrically heated muffle furnace and simultaneously, negotiations with University and government regulatory offices and a contractor started for the installment of a burner in the natural gas fired furnace.

The scientific basis of our research proposal, that taller bed, higher temperature and higher volatile matter in coal will lead to operational efficiency and superior product quality, was confirmed by experiments in the muffle furnace with pellet bed in the range of 25 to $80 \mathrm{~mm}$. Upon completion of the installment of the burner and other instruments, the experimental work was switched to the new and larger furnace. The heat size in terms of the weight of green balls in each reduction experiment increased from 230 grams to 6000 to 7000 grams for a bed of $120 \mathrm{~mm}$ height. The reduction of taconite ore under a fully oxidized flame of $1600-1650^{\circ} \mathrm{C}$ and various American coals was extensively investigated. Early in the year 2000, representatives of sponsoring companies and AISI Project Managers shared our assessment that there is no doubt in our mind that this 
project will be successfully concluded as promised in this proposal. The question was: should we take on new challenges to accelerate the development of this technology?

The primary goals for the pilot plant trials (combustion laboratory of CSM, Genoa, Italy) in the summer of 2000 were (i) to repeat experiments conducted at McMaster under an "industrial setting", (ii) to conduct experiments for the recycling of waste oxides which we could not do on campus due to lack of environmental protection equipment. The work was carried out by a team of four workers and two junior combustion engineers, with Dr. Huang of McMaster University as the quality control person. The heat size was 17 kilograms of green balls in each experiment. The results were excellent based on the monitoring instruments and observation of the DRI, visual and under the microscope, except the chemical analysis of metallic iron. Erroneous results of metallic iron contents of DRI were reported by well established commercial laboratories, both in Italy and in Canada, and the standard method (designed for Midrex type DRI) was used in both cases. Over a period of four months, Dr. Huang demonstrated how the error in the standard method was due to incomplete extraction of metallic iron and established the method of "copper sulfate" to be reliable for DRI made at high temperatures. Looking back to those days, we are very proud to say that excellent results were obtained in an industrial setting (inside an old steel works), and in a relaxed environment of a seaside location, and further, that Murphy's Law was alive and kicking over the period of five weeks immediately before the summer holidays.

At meetings with representatives of sponsoring companies and AISI managers in early 2001, we all recognized that the next challenge will be "technology transfer". Work should be done on two fronts:

(i) systematic documentation of the characteristics of this technology with improved equipment and aided by mathematical analysis.

(ii) contemplation of modification of existing RHF plants and possible new designs for the application of this new technology.

These tasks were completed on budget in the end of 2001.

\section{\$1.2 The Absolute Theoretical Minimum Carbon and Energy Requirements for Making Liquid Iron}

In our proposal, the expected lower coal rate of the McMaster Process in comparison with that of a blast furnace and smelting reduction was illustrated in terms of energy content (chemical and thermal) of off-gas leaving the reactor. In the theoretical analysis shown below, the approach adopted in the documents of the Office of Industrial Technologies of the US Department of Energy is used ${ }^{[1]}$. The comparisons between the blast furnace and the McMaster Process are based on the following assumptions:

(i) Pure iron oxide and pure carbon which serves as the reductant as well as the fuel, react at $298^{\circ} \mathrm{K}$ without any energy loss.

(ii) Metallic iron is heated to $1873^{\circ} \mathrm{K}\left(1600^{\circ} \mathrm{C}\right)$

(iii) Stoichiometries of chemical reactions 


\section{Blast Furnace:}

Reduction: $\mathrm{Fe}_{2} \mathrm{O}_{3}+2 \mathrm{C} \rightarrow 2 \mathrm{Fe}+\mathrm{CO}+\mathrm{CO}_{2}$

Heat Generation: $2 \mathrm{C}+3 / 2 \mathrm{O}_{2} \rightarrow \mathrm{CO}+\mathrm{CO}_{2}$

Gas composition reflects the limitation due to thermodynamic equilibrium between wustite and gas in the stack.

\section{McMaster Process:}

Reduction: $\mathrm{Fe}_{2} \mathrm{O}_{3}+3 / 2 \mathrm{C} \rightarrow 2 \mathrm{Fe}+3 / 2 \mathrm{CO}_{2}$

Heat Generation: $\mathrm{C}+\mathrm{O}_{2} \rightarrow \mathrm{CO}_{2}$

Gas composition reflects the fact that there is no $\mathrm{CO}$ in the main gas stream in the hearth furnace.

\section{Taconite:}

In North America the important iron ore deposits are around the Great Lakes in the form of Taconite, consisting mainly of magnetite; therefore, for using taconite in the McMaster Process the stoichiometry of reduction reaction is: $\mathrm{Fe}_{3} \mathrm{O}_{4}+2 \mathrm{C} \rightarrow$ $3 \mathrm{Fe}+2 \mathrm{CO}_{2}$.

(iv). Computations are carried out based on data listed in the JANAF Table ${ }^{[2]}$.

The comp utational results are shown in Table 1-1.

Table 1-1: Absolute theoretical minimum carbon and energy requirements per tonne of liquid iron at $1600^{\circ} \mathrm{C}$

\begin{tabular}{|l|c|c|c|}
\hline \multirow{2}{*}{ Process } & \multirow{2}{*}{ Blast Furnace } & \multicolumn{2}{c|}{ McMaster Process } \\
\cline { 3 - 4 } & & Hematite & Magnetite \\
\hline Carbon Rate, kg/T.Fe & 404 & 259 & 238 \\
\hline Energy Requirement, MJ/T.Fe & $8673^{*}$ & 8482 & 8387 \\
\hline
\end{tabular}

* From Ref. \#1 with accuracy of $\pm 3 \%$.

It should be noted that the source of carbon in the McMaster Process is coal and that for blast furnaces is mostly coke. The advantage of using taconite ore from the Great Lakes region is not only in lower carbon requirement but also in lower swelling during reduction. 


\section{\$1.3 Hearth-Type Furnaces for Ironmaking ${ }^{[3]}$}

The chemically self-sufficient green agglomerates, which contain carbonaceous reductants, are the prepared raw materials in the present work as well as in current rotary hearth furnace practices in the industry. These agglomerates are mechanically weak and need only heat to convert green balls to DRI.

The common causes of operational problems in RHF plants are often due to contradictory requirements of the process. The newly formed sponge iron needs protection from reoxidation by the furnace atmosphere which is usually oxidizing for metallic iron. In order to improve the energy efficiency, gases formed should be fully oxidized in the reduction zone of RHF to liberate energy for the process. By trial-and-error, the following rules-ofthumb as the compromise of contradictory requirements have been established in the current commercial practice in RHF plants:

(ii) The bed height of the agglomerates (pellets or briquettes) is about $20-25 \mathrm{~mm}$.

(iii) The flame temperature aimed for is in the $1300-1350^{\circ} \mathrm{C}$ range. The chemical composition of the flame is kept at $\mathrm{CO} / \mathrm{CO}_{2}$ ratio equal to or larger than 2.0 to moderate its oxidizing power with respect to the sponge iron.

(iv) Reductants of low volatile matter content and high in fixed carbon are preferred.

The reason for (i) is based on the experience that the third layer of agglomerates would not be adequately reduced under these conditions. Under practical conditions, the furnace atmosphere would be unavoidably oxidizing with respect to metallic iron. Conditions in (ii) are adopted to moderate the rate of oxidization with tolerable fuel penalty. Higher temperature or lower $\mathrm{CO} / \mathrm{CO}_{2}$ ratio for a gain in energy efficiency would lead to a low degree of metallization and the formation of liquid and corrosive slag. The condition (iii) is for saving the energy for de-volatilization and for more solid carbon availability.

The strategy of the present work, as outlined in the original research proposal, which is based on our earlier work, is to break all three rules listed above simultaneously for fundamental and favourable changes, even though breaking each rule alone would result in operational difficulties in the industry as confirmed in our laboratory.

The McMaster Process ${ }^{[4]}$ is based on "3 Highs", i.e. high bed height $(120 \mathrm{~mm})$, a flame of high temperature $\left(1600^{\circ} \mathrm{C}\right)$ and fully oxidized and high volatile content in carbonaceous reductants. Drastic improvement in productivity and DRI quality (degree of metallization and density) is the result of high temperature in the system. The DRI at the top of the bed at $1500^{\circ} \mathrm{C}$ is protected from re-oxidation by rising gas flow out of a tall bed and enhanced by high volatile coal in the agglomerates over a longer period of time, see Figure 1-1. Therefore, it is safe to keep all the combustibles fully oxidized in the reduction zone of a hearth furnace to gain energy efficiency. 


\section{\$1.4 Scale-Up of McMaster Process and Modification of Current RHF}

The ironmaking process based on heating the chemically self-sufficient agglomerates in a hearth-type furnace is kinetically limited by heat transfer by a radiative mechanism in the vertical direction. The reaction front in the bed, where heat is consumed by endothermic reactions, also moves vertically and downwards. All important thermat-chemical steps proceed in the vertical direction (in $Z$ direction); therefore, the process should be independent of the size (in X-Y plane), shape and the pattern of the movement of the bed or the hearth of the furnace. As it has been confirmed experimentally, there should be very little risk or surprises in the scale-up by enlarging the total area of the hearth.

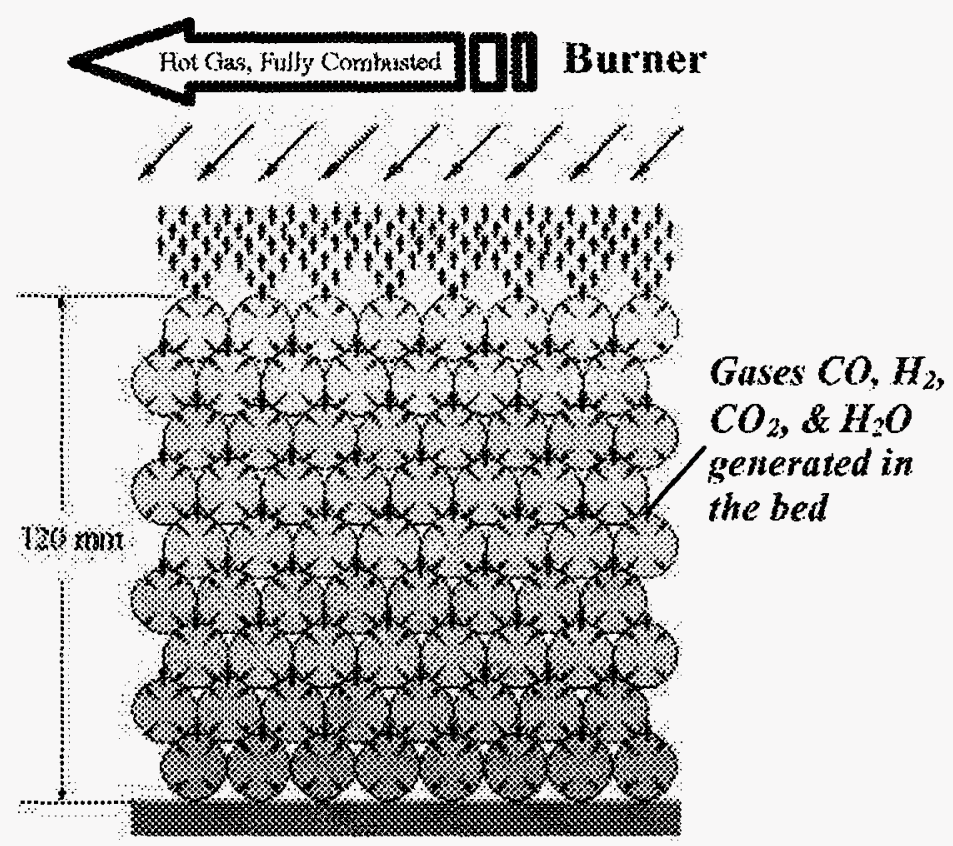

Figure 1-1 The rising gas stream pushes back the combustion products which contains $\mathrm{CO}_{2}, \mathrm{H}_{2} \mathrm{O}$ and possibly $\mathrm{O}_{2}$.

At the present time, hot DRI is discharged from an RHF horizontally in the radial direction by using a screw discharger with its metallic flights cooled from its shaft. By adopting the McMaster Process in an existing RHF plant, the flights would be longer (for taller bed), and the DRI hotter (average temperature about $1400^{\circ} \mathrm{C}$ ), thus the cooling of the actual screw discharger would be very challenging. It might be relatively easier to find another method, for example, the gravity discharging used in sinter plants and pellet plants, instead of fighting a losing battle. Furthermore, discharging products in the direction of moving hearth as in a sinter plant would solve the problem of building a retaining wall at the edge of the hearth for a tall bed at the same time. 


\section{\$1.5 Steps Towards Commercialization of McMaster Process}

For decades, in the ceramic industry, refractory bricks are fired under a fully oxidized flame in a tunnel or rotary kiln at a temperature often higher than $1600^{\circ} \mathrm{C}$. Refractory wares to be fired are placed on top of cars (or sections of the hearth) which are then pushed together (similar to a sintering machine for iron ore agglomeration) to form the floor or the hearth of the furnace. The firing process is complete when each individual car and the ware on top travel from one end to the other along a straight line (tunnel kiln) or a circle (rotary kiln).

Once the idea that the one-piece hearth in an RHF may be replaced by sections or cars on wheels is presented, then solutions of problems related to charging of green balls and discharging hot DRI by gravity automatically will present themselves. Conceptual designs from engineering companies will be discussed later in this report. The risk technically in the commercialization of the McMaster Process is in automatic charging of green balls and discharging of hot DRI because these operations could not be tested in the laboratory nor at the pilot plant in Italy that we used. On the economic side, the energy efficiency, which has very strong impact on operating cost and the capital cost for gas cleaning system, needs to be established in a system larger than what we have used up to the present time.

Hearth furnaces of multiple sections relevant to the effort for the commercialization of the McMaster Process may be of the following sizes listed in the table below:

\begin{tabular}{|c|c|c|c|}
\hline Hearth Furnaces & $\begin{array}{c}\text { Capacity } \\
\text { DRI tonne/year }\end{array}$ & $\begin{array}{c}\text { Hearth Area } \\
\mathrm{m}^{2}\end{array}$ & $\begin{array}{c}\text { Capital Cost in } \\
\text { M \$U.S. }\end{array}$ \\
\hline Pilot & 10,000 & 10 & $2 \sim 3$ \\
\hline On-site recycling & 100,000 & 100 & $5 \sim 14$ \\
\hline $\begin{array}{c}\text { A unit in an integrated } \\
\text { plant }\end{array}$ & $1,000,000$ & 1,000 & 20 \\
\hline
\end{tabular}

It should be noted that the cost of building the hearth furnace is about one-third of the total cost of the plant, including $1 / 3$ for raw material preparation and $1 / 3$ for gas cleaning. The capital cost for the hearth furnaces listed above are essentially independent of hearth design (one-piece or multiple sections) and movement of hearth (straight tunnel or rotary).

The cost of building a pilot plant in a steel works is comparable to replacing the conventional RHF by a hearth furnace of multiple sections using the McMaster Process in a typical waste oxide recycling plant in North America. What would be the best way to proceed, of course, depends on the judgement of the management of steel companies. 


\section{§2. RAW MATERIALS AND LABORATORY EQUIPMENT}

$\S 2.1$ Raw Materials 9

$\S 2.2$ The Electric Muffle Furnace and Experimental Set-Up 11

$\S 2.3 \quad$ Natural Gas-Fired Furnace $\quad 13$

$\$ 2.4$ Pelletizing Disk $\quad 20$ 


\section{§2. RAW MATERIALS AND LABORATORY EQUIPMENT}

\section{\$2.1 Raw Materials}

\section{\$2.1.1 Iron Ore Concentrates}

In this experimental program, two kinds of iron ore concentrates were used, magnetite and hematite. The magnetite concentrate, i.e., Taconite concentrate, was supplied by U S Steel. The major chemical compositions of the Taconite concentrate are listed in Table 21. The hematite ore, Carajas concentrate, was supplied by SMS Demag and CSM (Genoa, Italy). The major chemical compositions of Carajas concentrate are listed in Table 2-2, which was used in pilot plant trials. These results of chemical analysis were provided by the suppliers and confirmed at McMaster University.

Table 2-1 Major Chemical Composition of Taconite concentrate(wt.\%)

\begin{tabular}{|c|c|c|c|c|c|c|c|}
\hline $\mathrm{TFe}$ & $\mathrm{FeO}$ & $\mathrm{SiO}_{2}$ & $\mathrm{Al}_{2} \mathrm{O}_{3}$ & $\mathrm{CaO}$ & $\mathrm{MgO}$ & $\mathrm{S}$ & $\mathrm{P}_{2} \mathrm{O}_{5}$ \\
\hline 66.73 & 30.28 & 4.09 & 1.11 & 0.27 & 0.62 & 0.01 & 0.046 \\
\hline
\end{tabular}

Table 2-2 Major Chemical Composition of Carajas concentrate(wt.\%)

\begin{tabular}{|c|c|c|c|c|c|c|c|}
\hline $\mathrm{TFe}$ & $\mathrm{FeO}$ & $\mathrm{SiO}_{2}$ & $\mathrm{Al}_{2} \mathrm{O}_{3}$ & $\mathrm{CaO}$ & $\mathrm{MgO}$ & $\mathrm{S}$ & $\mathrm{P}_{2} \mathrm{O}_{5}$ \\
\hline 66.41 & 0.5 & 0.78 & 1.55 & 0.1 & 0.1 & 0.01 & 0.03 \\
\hline
\end{tabular}

\section{\$2.1.2 Waste Oxides Generated in Steel Plants}

The waste oxides used in this experimental program were BOF sludge, EAF dust and mill scale supplied by Dofasco, and a EAF dust of Italian Origin was supplied by SMS Demag for the trials in CSM, Italy. The mill scale was ground ( -325 meshes $>80 \%)$ for pelletization. The chemical compositions of these waste oxides are listed in Table 2-3, Table 2-4, Table 2-5, and Table 2-6, respectively. These chemical compositions were analyzed by the supplier, the total $\mathrm{Fe}, \mathrm{Fe}^{0}, \mathrm{FeO}$ and $\mathrm{C}$ content were confirmed at McMaster.

Table 2-3 The Chemical Composition of BOF Sludge from Dofasco (wt.\%)

\begin{tabular}{|c|c|c|c|c|c|c|c|c|}
\hline $\mathrm{TFe}$ & $\mathrm{Fe}$ & $\mathrm{FeO}$ & $\mathrm{SiO}_{2}$ & $\mathrm{Al}_{2} \mathrm{O}_{3}$ & $\mathrm{CaO}$ & $\mathrm{MgO}$ & $\mathrm{K}_{2} \mathrm{O}$ & $\mathrm{MnO}$ \\
\hline 63.53 & 0.90 & 68.20 & 0.90 & 0.01 & 4.79 & 2.02 & 0.01 & 1.03 \\
\hline $\mathrm{TiO}_{2}$ & $\mathrm{P}_{2} \mathrm{O}_{5}$ & $\mathrm{PbO}$ & $\mathrm{ZnO}$ & $\mathrm{Na}_{2} \mathrm{O}$ & $\mathrm{V}_{2} \mathrm{O}_{5}$ & $\mathrm{Cr}_{2} \mathrm{O}_{5}$ & $\mathrm{~S}$ & $\mathrm{C}$ \\
\hline 0.04 & 0.05 & 0.021 & 2.11 & 0.80 & 0.03 & 0.04 & 0.18 & 1.89 \\
\hline
\end{tabular}


Table 2-4 The Chemical Composition of Mill Scale from Dofasco (wt.\%)

\begin{tabular}{|c|c|c|c|c|c|c|c|c|}
\hline $\mathrm{TFe}$ & $\mathrm{Fe}$ & $\mathrm{FeO}$ & $\mathrm{SiO}_{2}$ & $\mathrm{Al}_{2} \mathrm{O}_{3}$ & $\mathrm{CaO}$ & $\mathrm{MgO}$ & $\mathrm{K}_{2} \mathrm{O}$ & $\mathrm{MnO}$ \\
\hline 74.05 & 1.20 & 64.20 & 0.32 & 0.43 & 0.06 & 0.03 & 0.03 & 0.30 \\
\hline $\mathrm{TiO}_{2}$ & $\mathrm{P}_{2} \mathrm{O}_{5}$ & $\mathrm{PbO}$ & $\mathrm{ZnO}$ & $\mathrm{Na}_{2} \mathrm{O}$ & $\mathrm{V}_{2} \mathrm{O}_{5}$ & $\mathrm{Cr}_{2} \mathrm{O}_{5}$ & $\mathrm{~S}$ & $\mathrm{C}$ \\
\hline 0.02 & 0.06 & 0.031 & 0.01 & 0.33 & 0.02 & 0.04 & 2.80 & 0.90 \\
\hline
\end{tabular}

Table 2-5 The Chemical Composition of EAF Dust from Dofasco (wt.\%)

\begin{tabular}{|c|c|c|c|c|c|c|c|c|}
\hline $\mathrm{TFe}$ & $\mathrm{Fe}$ & $\mathrm{FeO}$ & $\mathrm{SiO}_{2}$ & $\mathrm{Al}_{2} \mathrm{O}_{3}$ & $\mathrm{CaO}$ & $\mathrm{MgO}$ & $\mathrm{K}_{2} \mathrm{O}$ & $\mathrm{MnO}$ \\
\hline 32.3 & 0.00 & 2.73 & 2.79 & 0.77 & 8.54 & 5.00 & 0.55 & 3.33 \\
\hline $\mathrm{TiO}_{2}$ & $\mathrm{P}_{2} \mathrm{O}_{5}$ & $\mathrm{PbO}$ & $\mathrm{ZnO}$ & $\mathrm{Na}_{2} \mathrm{O}$ & $\mathrm{V}_{2} \mathrm{O}_{5}$ & $\mathrm{Cr}_{2} \mathrm{O}_{5}$ & $\mathrm{~S}$ & $\mathrm{C}$ \\
\hline 1.64 & 0.16 & 0.93 & 26.04 & 1.64 & N/A & 0.25 & 0.39 & 0.07 \\
\hline
\end{tabular}

Table 2-6 The Chemical Composition of EAF Dust from SMS Demag (wt.\%) [for the pilot plant trials in CSM Italy only]

\begin{tabular}{|c|c|c|c|c|c|c|c|c|}
\hline $\mathrm{TFe}$ & $\mathrm{Fe}^{0}$ & $\mathrm{FeO}$ & $\mathrm{SiO}_{2}$ & $\mathrm{Al}_{2} \mathrm{O}_{3}$ & $\mathrm{CaO}$ & $\mathrm{MgO}$ & $\mathrm{K}_{2} \mathrm{O}$ & $\mathrm{MnO}$ \\
\hline 19.21 & 2.23 & 0.87 & 7.40 & 1.27 & 10.83 & 3.48 & 1.08 & 2.92 \\
\hline $\mathrm{TiO}_{2}$ & $\mathrm{P}_{2} \mathrm{O}_{5}$ & $\mathrm{PbO}$ & $\mathrm{ZnO}$ & $\mathrm{Na}_{2} \mathrm{O}$ & $\mathrm{V}_{2} \mathrm{O}_{5}$ & $\mathrm{Cr}_{2} \mathrm{O}_{5}$ & $\mathrm{~S}$ & $\mathrm{C}$ \\
\hline 0.21 & 0.02 & 1.58 & 20.86 & 0.81 & 0.04 & 13.04 & 0.28 & 0.33 \\
\hline
\end{tabular}

Table 2-7, the Total Carbon content and Proximate Analyses of Coals (wt.\%)

\begin{tabular}{|c|c|c|c|c|c|}
\hline & C $_{\text {Total }}$ & C $_{\text {Fixed }}$ & MV & Ash & S \\
\hline Coke & 92.3 & 92.0 & 0.8 & 6.70 & 0.5 \\
\hline Coal \#3 & 77.54 & 57.34 & 34.53 & 6.90 & 1.23 \\
\hline Myra & 76.35 & 56.91 & 36.00 & 7.16 & 0.65 \\
\hline Marfork & 79.13 & 62.40 & 32.57 & 5.03 & 0.89 \\
\hline Pinnacle & 84.26 & 78.22 & 16.35 & 5.43 & 0.9 \\
\hline
\end{tabular}

\section{§2.1.3 Coal and coke}

The carbonaceous materials used as reductants in the experimental program for this project were four types of coals and one kind of metallurgical coke (for verifying the effects of volatile matters on the reduction process). The total carbon contents and proximate analyses of these materials are list in Table 2-7. The coal \#3, Myra coal and coke are supplied by Dofasco and the rest were supplied by U S Steel, but chemical analyses were done at McMaster University. All the coke and coal were ground down to $100 \%-50$ meshes before mixing with the iron ore or waste oxides . 


\section{\$2.2 The Electric Muffle Furnace and Experimental Set-Up}

For a given time and effort, more experiments can be carried out in the smaller muffle furnace because the heat size in smaller, about 200 grams of green balls. Extensive investigations on the optimum conditions with respect to processing variables such as bed height, amount and type of reductant, temperature, size of green balls, etc. were carried out.

The major properties of the muffle furnace (Figure 2-1) are listed in Table 2-8, and the experimental set-up is illustrated in Figure 2-2a. The special crucible (see Figure 2-2b) for holding the ore/coal pellets in the muffle furnace consists of two parts: the mullite ring to retain the gas flow in vertical direction and the insulating ring to obstruct heat radiation from the sides of the bed of pellets. For the case shown in Figure 2-2b, the inner diameter of the mullite ring is $60 \mathrm{~mm}$. If the bed height is less than $60 \mathrm{~mm}$, the inner diameter is kept at $60 \mathrm{~mm}$, and if the bed height is $80 \mathrm{~mm}$, a bigger mullite ring of inner diameter of $80 \mathrm{~mm}$ is used.

Table 2-8. The Major Properties of the Muffle Furnace

\begin{tabular}{|l|c|}
\hline Full power & $7,500 \mathrm{~W}$ \\
\hline Heating elements & Silicon Carbide \\
\hline Insulating materials & Alumina Insulating Board (Zircar AL-20B) \\
\hline Highest service temperature & $1550^{\circ} \mathrm{C}$ \\
\hline Heating-Up Rate & $40^{\circ} \mathrm{C} /$ minute \\
\hline Furnace atmosphere & Air \\
\hline Working chamber & $260($ long $) \times 280($ wide $) \times 240($ high $) \mathrm{mm}$ \\
\hline
\end{tabular}




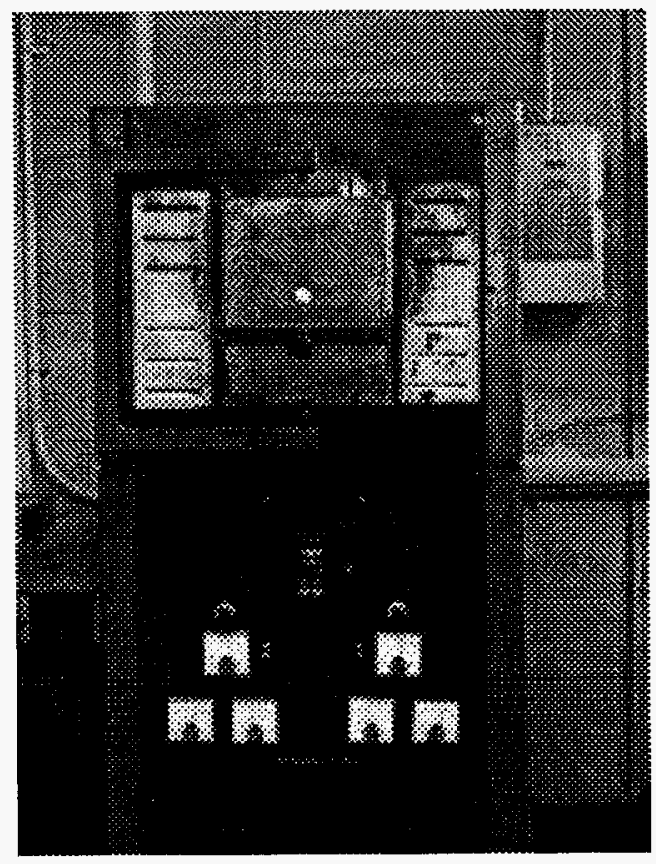

Fig. 2-1. Appearance of the muffle furnace used for the experimental study

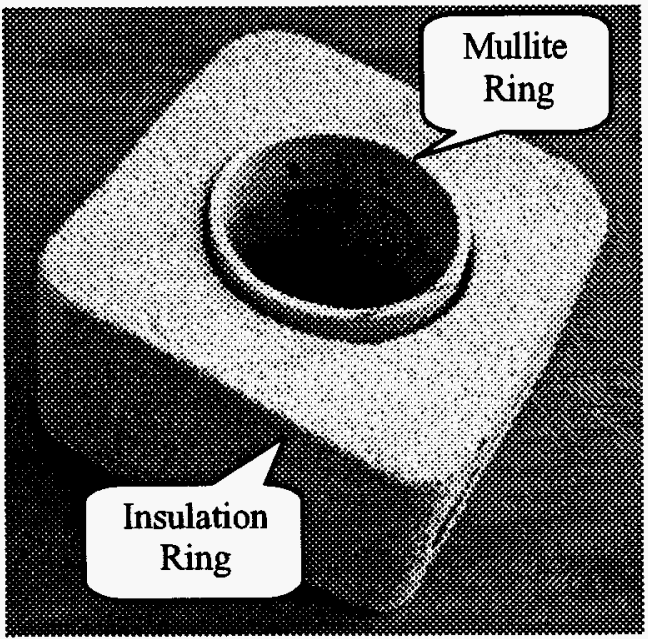

Fig. 2-2b. The special crucible for the reduction of ore/coal pellets in the muffle furnace

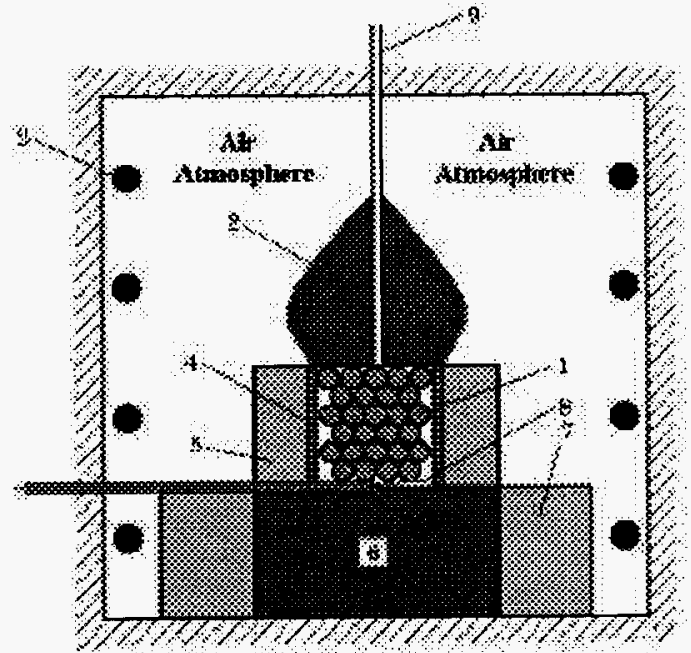

1. Pellet or composite

2. Flame of burning gaseous products from reacting bed

3. Heating elements (SiC)

4. Mullite ring

5. Insulating ring (See Fig. 2-1b)

6. Refractory brick

7. Refractory insulation Brick

8. Thermocouple

9. Alumina Tube for Gas Sampling or Thermocoup le

Fig. 2-2a. Experimental Set-up in the Muffle Furnace 


\section{\$2.3 Natural Gas-Fired Furnace}

\section{\$2.3.1 The system of the natural gas-fired furnace}

The goal of designing and building a natural gas-fired furnace is to heat and to reduce the tall ore/coal pellet bed by radiative heat transfer under conditions of

- fully combusted atmosphere in the free board

- higher flame temperature.

The system of natural gas-fired furnace includes:

- furnace

- burner and control system of natural gas

- crucible to receive charges

- charging device

- discharging and cooling system

- Temperature measurement, gas composition measurement, and data logging system

\section{\$2.3.2 Design and Construction of the furnace}

In early 1998, our group started to design and construct the natural gas-fired furnace system. These tasks included the steel shell and refractory lining of the furnace, the combustion and control system, the selection of refractory materials for the crucibles and the design casting procedure, the charging device, and the discharging system. Blackhawk Combustioneering Ltd of Hamilton, Ontario designed the combustion safety system and completed the construction of combustion system. In the later part of 1999, the construction of natural gas-fired furnace and related auxiliary systems were completed (Figure 2-3). Under the Technical Standards and Safety Authority Field Approval Program, an operating license was granted by TSSA Ontario on Oct. 1, 1999.

\section{\$2.3.3 Specifics of the natural gas-fired furnace}

In order to simulate the moving hearth furnace with a stationary bed operation, it is required that heating and cooling rates of the natural gas-fired furnace should be in the desired ranges. The lighter and high temperature insulating materials were chosen for the lining of the furnace. This furnace is equipped with oxygen enrichment system to enhance the heating rate when it is needed. The major specifications of the natural gasfired furnace are listed in Table 2-9. 
Table 2-9. Properties of the Natural Gas-fired Furnace

\begin{tabular}{|l|c|}
\hline Full power (Burner) & \multicolumn{1}{c|}{$\begin{array}{c}180 \mathrm{kw} \\
\left(18 \mathrm{Nm}^{3} \text {-natural gas/hour) }\right.\end{array}$} \\
\hline Insulating materials & $\begin{array}{l}\text { Alumina Insulating Boards (Kaowool-17C, } \\
\text { Kaowool-2600, Kaowool-S })+ \text { Alumina } \\
\text { insulating Brick (Insalcor Brick) }\end{array}$ \\
\hline Highest service temperature & $1650^{\circ} \mathrm{C}$ \\
\hline Heating-Up Rate & 1200 to $1500^{\circ} \mathrm{C}$ in 25 minutes \\
\hline Furnace atmosphere & Full combustion \\
\hline Heat-Size (depending on the density) & $6-7 \mathrm{~kg}$ green balls, \\
\hline Highest pellet bed & $130 \mathrm{~mm}$ \\
\hline Dimensions of pellet bed & $230(\mathrm{~L}) \times 170(\mathrm{~W}) \times 130(\mathrm{H}) \mathrm{mm}$ \\
\hline
\end{tabular}
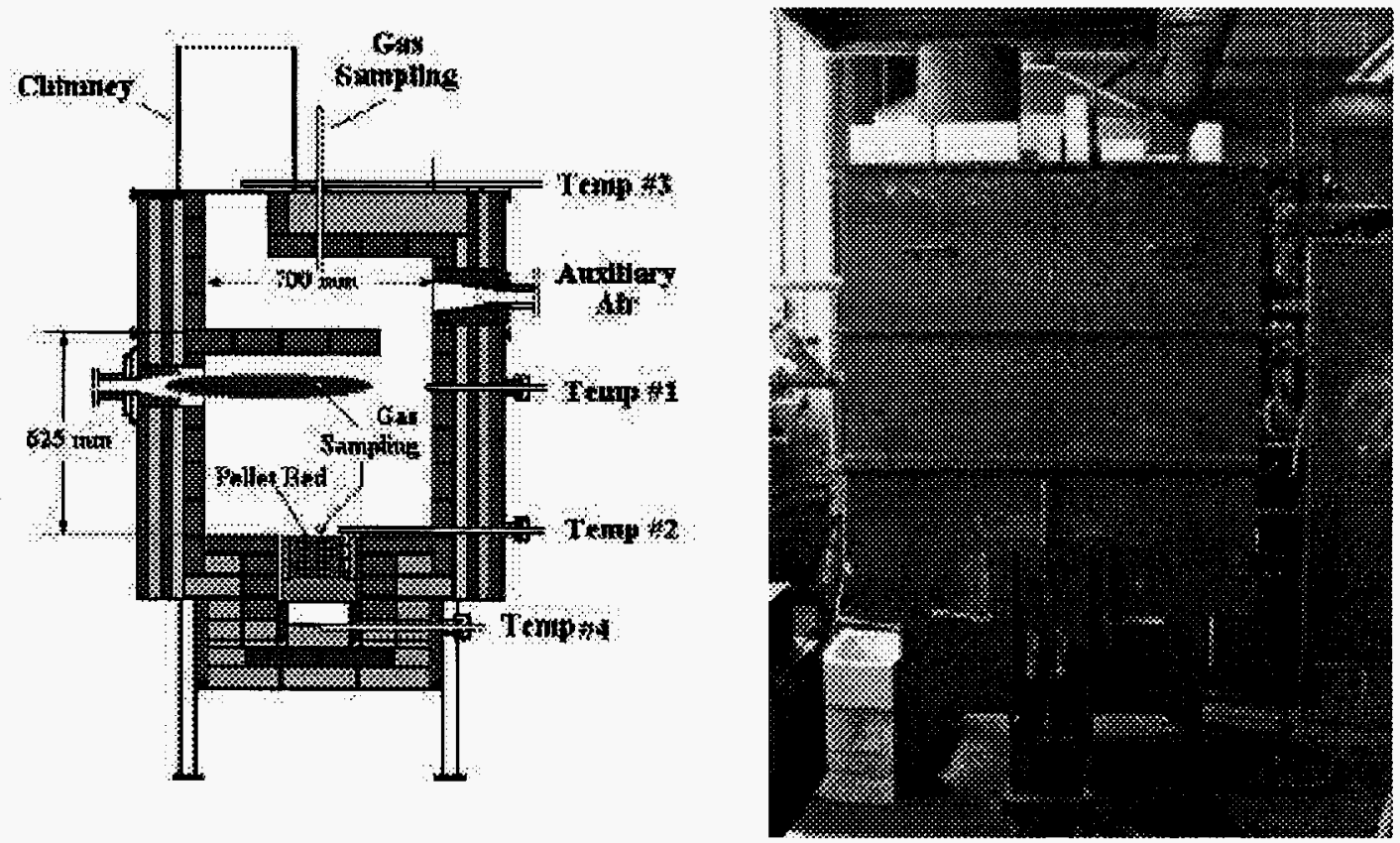

Fig. 2-3. Design and appearance and of the natural gas- fired furnace

\section{§2.3.4 The combustion and control system}

The system of natural gas combustion and control is shown in Figure 2-4. It includes two major sub-systems, the combustion system and control system. Combustion system consists of the aspirator air/gas mixer and burner (North American Nozzle). The control system consists of flow meters (Waukee Flo-Meter) to monitor and control the flow rate of the air, natural gas, and oxygen. The temperature of the furnace is controlled by 
adjusting the gas supply with a proper ratio of air (and oxygen) to gas to maintain the full combustion of all the fuel in the free board of the chamber (including $\mathrm{CO}$ and $\mathrm{H}_{2}$ generated in the ore/coal pellet bed during reduction).

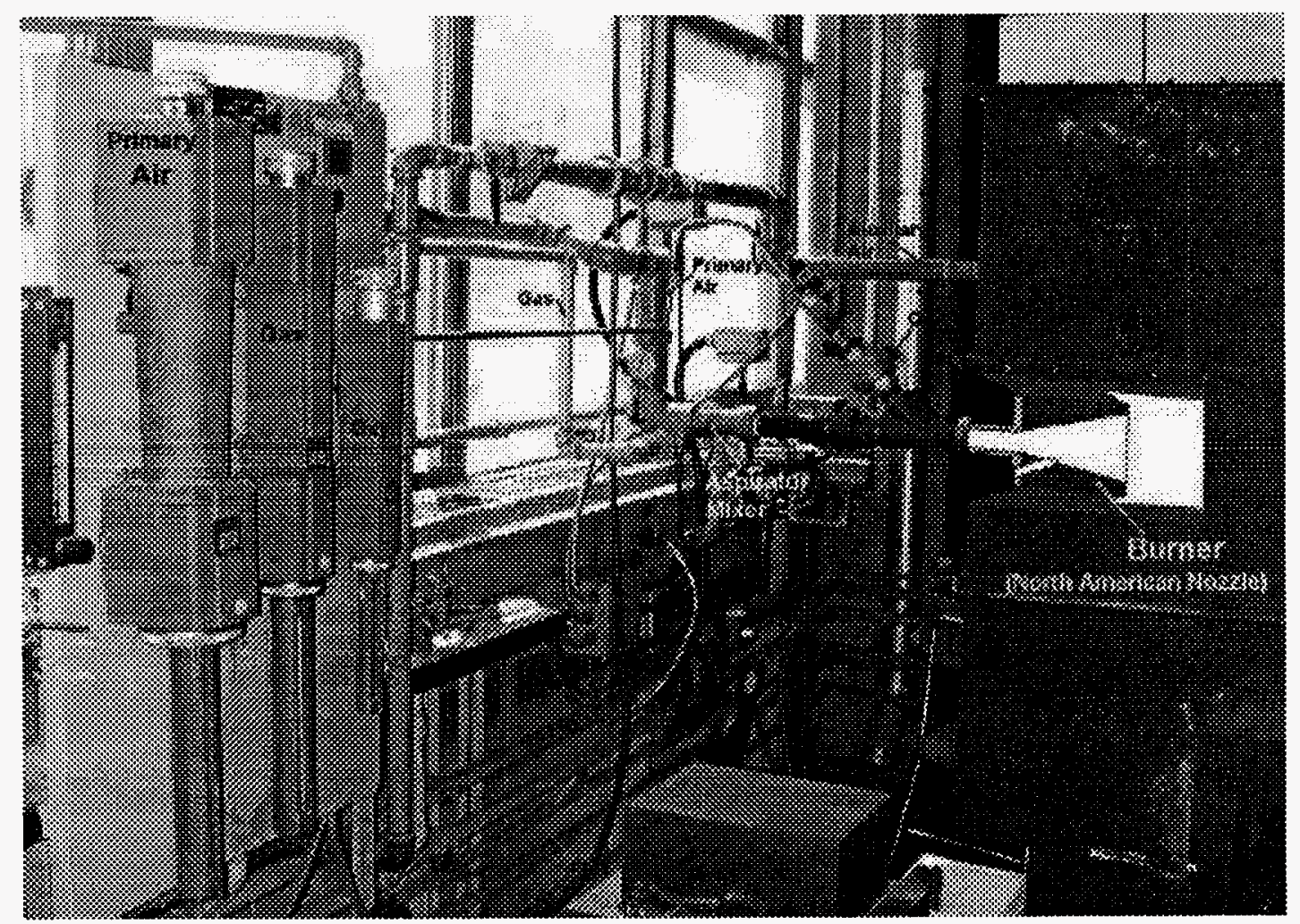

Fig. 2-4. The combustion and control system

\section{\$2.3.5 The crucible and pellet bed}

For convenient charging of ore/coal pellets of certain bed height into and discharging of DRI from the natural gas- fired furnace, special crucibles (Figure 2-5) were designed and made in our laboratory. These crucibles, which are made of castable refractory materials of high alumina, consist of two parts: the ring and the bottom. One ring can be used for tens experiments and the bottom can be used for a very long time. The holding space of the crucible is listed in Table 2-9. The bottom is $85 \mathrm{~mm}$ in thickness. 


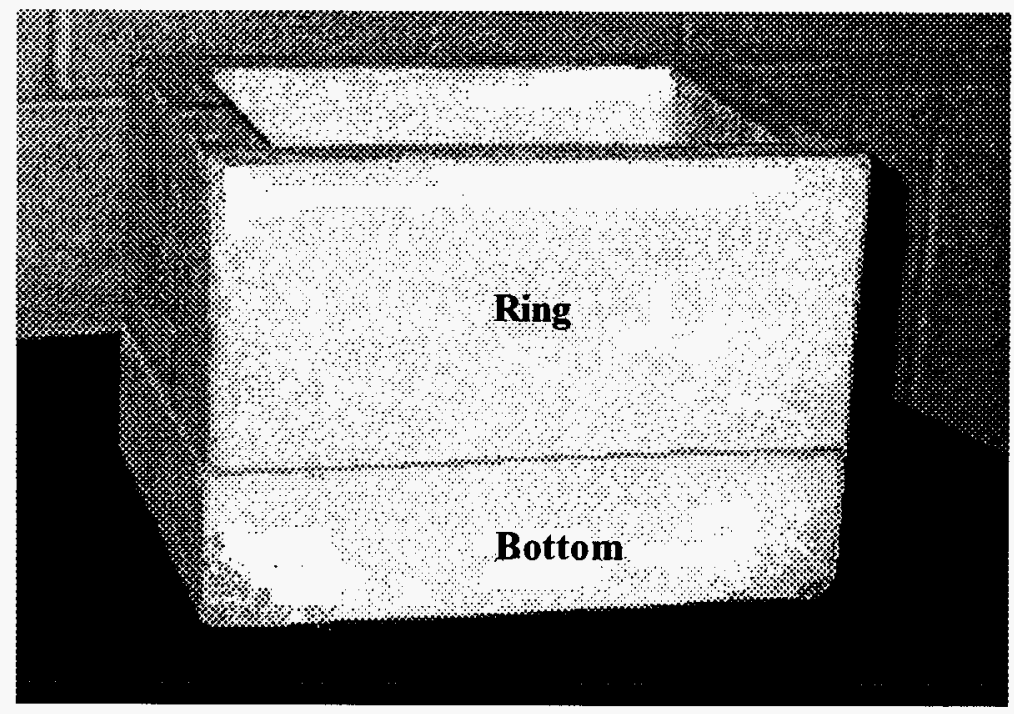

Fig. 2-5. The appearance of crucible

\section{\$2.3.6 Device and the procedure of charging}

In the commercial rotary heath furnace, pellets/briquettes are charged onto the hot hearth. In order to charge pellets into a hot crucible smoothly and safely, we designed a special charger for this project (Figure 2-6a). The charger is essentially a container with a bottom which can be opened to unload the charge. A handle which is connected to a forelock can be used to open or close the bottom, see Figure 2-6b

For charging, a load of pellets of known weight for a given bed height is placed in the charger with bottom closed. The loaded charger is inserted into the hot crucible and placed on the bottom of the crucible. By turning the handle of the charger, by $90^{\circ}$ either to left or right, to unlock the bottom, the pellets are left behind in the crucible when the charger is lifted out. 
(a)
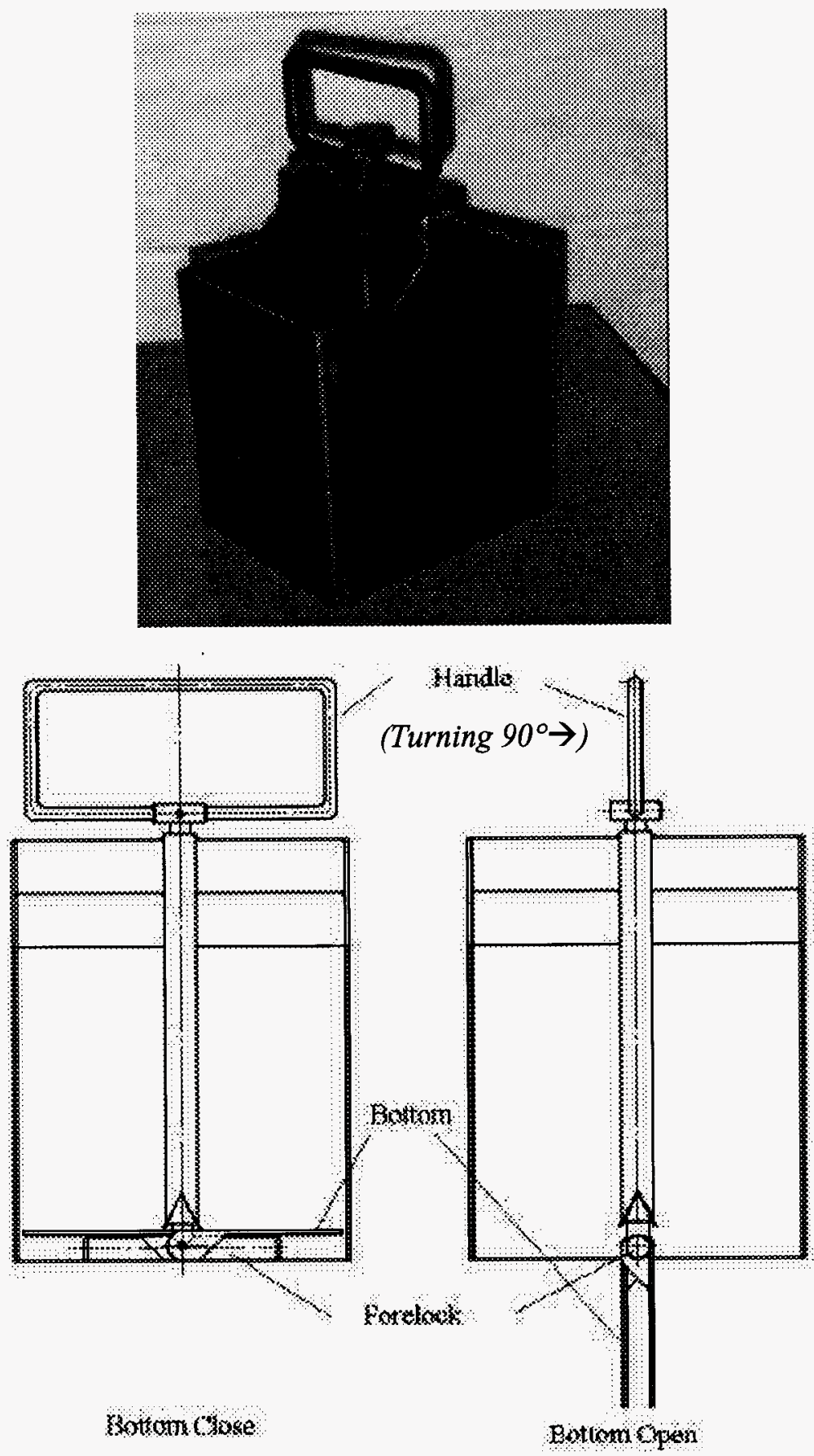

Fig. 2-6 Appearance and design of the charger 


\section{\$2.3.7 The device for discharging and cooling}

In order to interrupt experiments as precise in time as possible, partially reduced ore/coal pellets should be cooled in an inert atmosphere quickly. At McMaster University, we designed and constructed a special device for discharging and cooling (Figure 2-7) for this purpose. This device consists two chambers, the turning chamber and the cooling chamber. The turnable chamber is for separating DRI and crucible, and the cooling chamber is for cooling DRI under nitrogen atmosphere.

For discharging, using a special designed carrier, take the hot crucible with DRI out of the natural gas-fired furnace and insert it into the turnable dumper (see Figure 2-7b), then turn the dumper up-side-down to dump the DRI down to the receiver. The loaded receiver (Figure 2-7c) is detached from the turning chamber and pushed into the cooling chamber, which is cooled by running water in the coil, under nitrogen flow after closing the door of cooling chamber. The emptied hot crucible is put back into the gas-fired furnace by reversing the operation described above without attaching the receiver to the turnable chamber. By using this device, the discharging of DRI from the gas-fired furnace to the cooling chamber can be done in about one minute, and the DRI can be cooled from $1500^{\circ}$ down to $900^{\circ} \mathrm{C}$ within 5 minutes (depending on the total mass of DRI and the nitrogen flow rate).

\section{§2.3.8 Temperature measurement and analysis of gas compositions inside the furnace}

As illustrated in Figure 2-3, temperatures are measured at four locations inside the gasfired furnace by four thermocouples. One thermocouple (Temp\#1) is facing the burner to measure the temperature of flame. The second thermocouple (Temp\#2) is placed on the top of the crucible to measure the temperature which is defined as the processing temperature. The third thermocouple is placed in the center of the exit port of the gasfired furnace to measure the temperature of the exit gas. The last thermocouple (Temp\#4) is placed beneath the bottom of the crucible. 
(a)
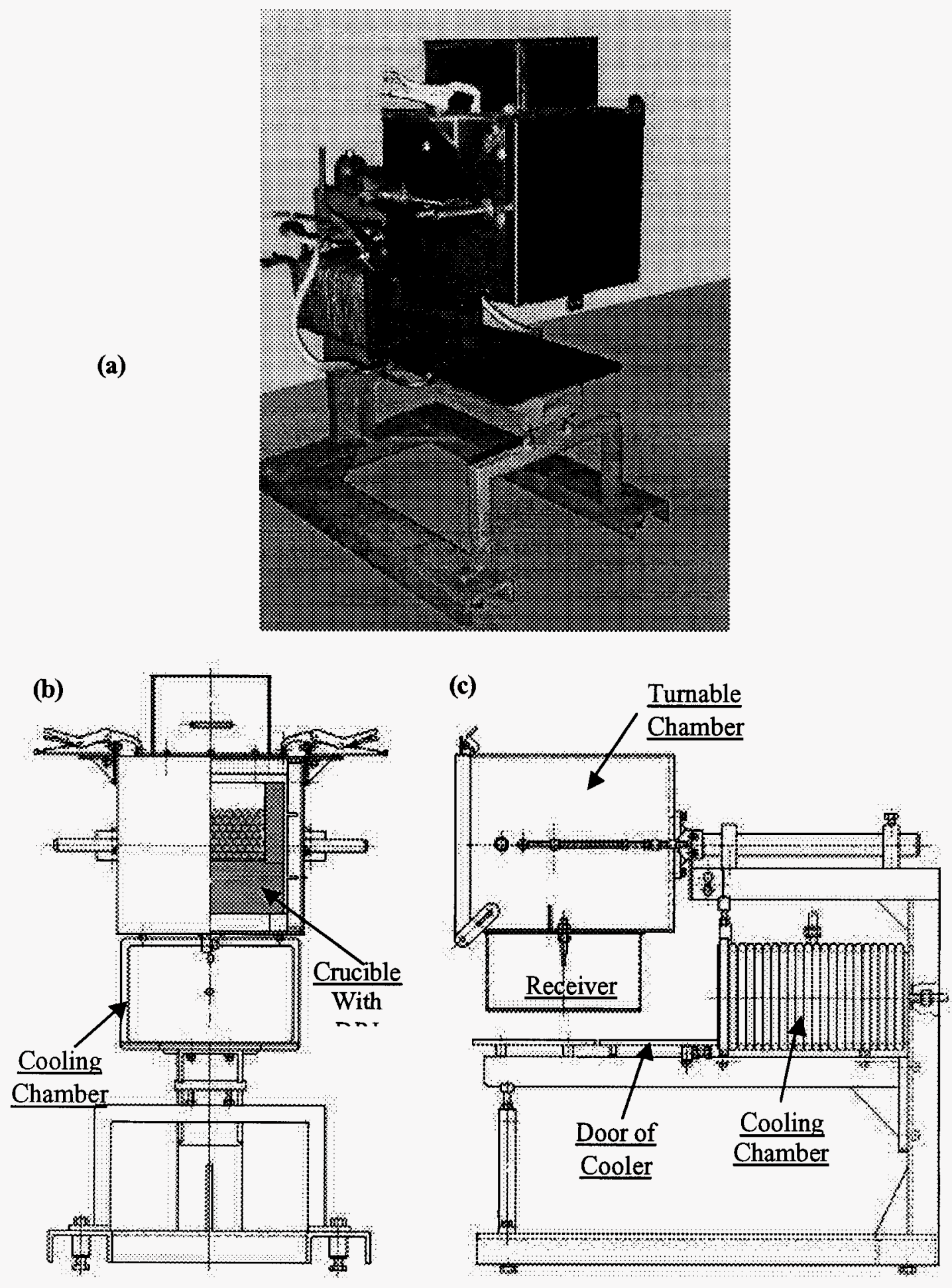

Fig. 2.7. The Appearance and design of the discharging and cooling device 
The gas sample is taken continuously form three position from the gas-fired furnace (see Figure 2-3) to the gas analysers to determine the composition /concentrate of $\mathrm{CO}, \mathrm{CO}_{2}$ and $\mathrm{O}_{2}$. One sampling position is at the center of the crucible and right above the top of the crucible representing the gas flow leaving the pellet bed. The second sampling position is on the axis-line of burner, representing the core of the flame. The third sampling position is for the exit gas.

The gas analyzers for $\mathrm{CO}$ and $\mathrm{CO}_{2}$ are based on infrared absorption. Their models are HORIBA PIR-2000. The oxygen analyzer is a paramagnetic type, HORIBA PMA-200F. All the readings, including four temperature signals and three concentrations are recorded continuously by a data- $\log$ controlled by a PC.

The auxiliary air port was designed (Figure 2-3) to eliminate any trace amount of $\mathrm{CO}$ in the exit gas for safety consideration. However it was hardly used because the flame was fully combusted.

\section{§2.4 Pelletizing Disk}

In our laboratory, the green balls were made by using a pelletizing disk for this project. The pelletizing disk (Figure 2-8) is $380 \mathrm{~mm}$ in diameter(I.D.) and 150 $\mathrm{mm}$ in depth. The running speed is adjustable, and the maximum speed is $50 \mathrm{rpm}$.

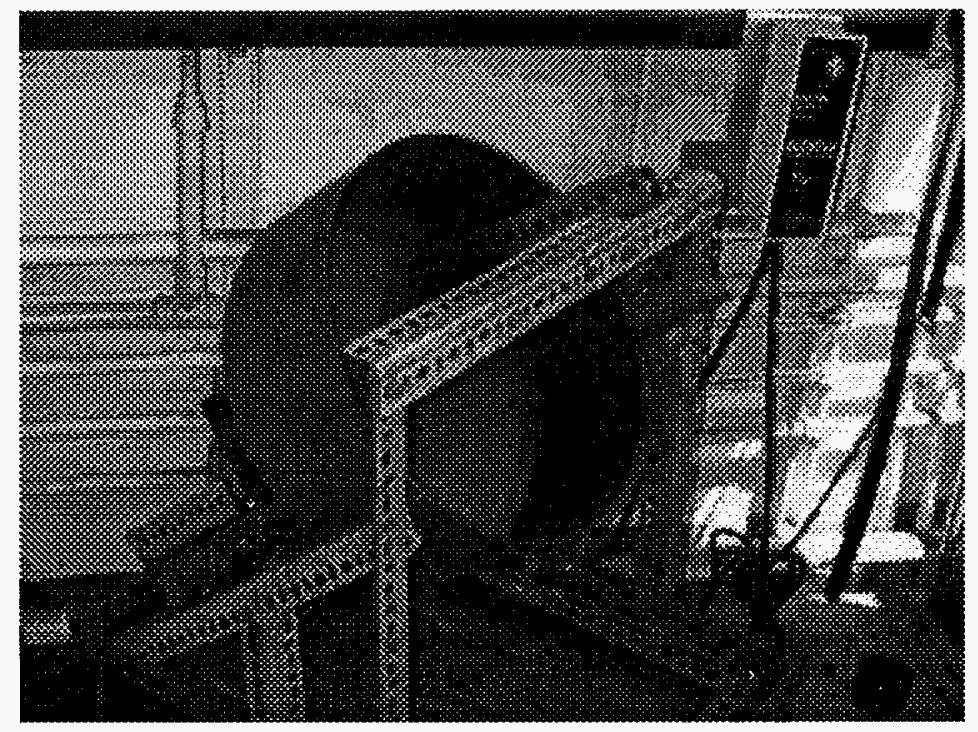

Fig. 2-8. Appearance of the pelletizing disk 


\section{§3 FUNDAMENTALS OF IRONMAKING BASED ON ORE/COAL COMPOSITES}

§3.1 The Background $\quad 22$

\$3.2 The Reduction of Ore/Coal Pellets in Air Atmosphere of High 23 Temperature

\$3.3 Experimental Results and Brief Discussions 24

$\$ 3.4$ Productivity and Efficiency in the Use of Reductant 36

$\S 3.5$ The Apparent Density of DRI 39

$\$ 3.6$ Summary $\quad 40$ 


\section{§3 FUNDAMENTALS OF IRONMAKING BASED ON ORE/COAL COMPOSITES $^{[3,4]}$}

\section{\$3.1 The Background}

The major effort of our research group at McMaster University in the last 20 years was devoted to the development of a new and efficient coal-based and coke-free ironmaking process. It has been concluded, in doctorate theses of H. Gou and S. Sun, that kinetically the overall rate of reduction is limited by heat transfer in a bed of ore/coal composite. Since the late1996, Dr. D. Huang joined our group and started to work on the heat transfer of the following three steps which are connected in series:

(1). The heat transfer from the source of radiative heat to the top of the bed of ore/coal pellet/composite,

(2). The heat transfer from the top of the bed of ore/coal pellet/composite to the bottom of the bed, by a combination of heat radiation and conduction, and

(3). The heat transfer within individual pellets of ore/coal mixtures by heat conduction, a continuation of S. Sun's work.

Through mathematical modeling, Huang's work has concluded that:

From the view point of process control, the second step, the heat transfer from the top of the bed downwards to the bottom is the critical step.

The heat transfer in this step includes: (a) the primary heat radiation (heat radiation from the source above to the bottom of pellet bed directly, through the vertical gaps), (b) the secondary heat radiation (heat radiation emitted/ reflected by the hotter surfaces of the pellet and then is transferred to the surface of the colder pellets, and (c) the heat conduction within a pellet and between pellets across the contact point.

The steps of primary and secondary heat radiation and heat condition, which deliver heat from its source above the bed to the interior of individual pellets where heat is consumed to support endothermic reactions, are sensitive to temperature of the source. The temperature of the source of radiative heat is the most important variable for enhancing the rate of heat transfer in the whole system because (a) the intensity of thermal radiation is proportional to $\mathrm{T}^{4}$ of surface and the effective heat conductivity of DRI increases with the increase of temperature of the process.

In the mathematical modeling of heat transfer through the pellet bed and the reduction of ore by coal inside the bed, a very important phenomena was recognized. It is that the upward-stream of gas flow generated within the pellet bed increases with the reduction rate and the height of pellet bed (see Figure 1-1). It is the basis for our recommendation that process temperature, bed height and volatile matter content in reductants should be increased simultaneously to result in a more efficient process.

This proposed technology of using the upward-stream of gas to prevent DRI at the top of pellet bed from re-oxidation, therefore, would allow the pellet bed to be heated to higher 
temperatures in a fully combusted atmosphere, which is the key to decrease the coal rate in DRI production.

\section{\$3.2 The Reduction of Ore/Coal Pellets in Air Atmosphere of High Temperature}

\section{§3.2.1 The Scope of Study}

In order to see whether using high temperature could speed-up heat transfer through the pellet bed and whether the upward-stream of gas generated in the pellet bed could protect the DRI from re-oxidation effectively, a special experimental set-up was designed (see Figure 2-2) and series of reduction experiments were conducted. Different iron ores and coals were studied in the ordinary muffle furnace (see Figure 2-1 and table 2-7) during 1997 and 1998. In these series of experiments, the effects of following variables on the reduction of ore/coal pellets in a bed were studied:

(1). The processing temperature (the furnace temperature in the muffle furnace) on the reduction

(2). The amount of coal addition, in term of the gram-atomic ratio of the total carbon in the coal added to the combined oxygen in iron oxides, denoted as $\mathrm{C} / \mathrm{O}$ (g-atom/g atom),

(3). The content of volatile matter of coal, denoted as VM (wt.\%)

(4). The height of pellet bed

(5). The size of pellet, in term of diameter of dried green balls.

(6). The effect of the temperature of furnace hearth

\section{§3.2.2 Experimental Procedure}

As an example, experimental procedure for the case of using taconite concentrate (see Table 2-1), coal \#3 and coke (see Table 2-7), consists of the following the steps:

- Place the dried ore/coal pellets into the special crucible (see Figure 2-2b),

- Put the loaded special crucible into the muffle furnace (see Figure 2-1), which has been controlled to stay at $1200^{\circ} \mathrm{C}$, in air atmosphere, on the hot brick (see the item 6 of Figure 2-2a )which has been a part of the furnace chamber.

- Keep the furnace temperature at $1200^{\circ} \mathrm{C}$ for 5 minutes (heating time of step1) and then set the temperature of the furnace to the pre-determined experiment temperature.

- Keep the reacting pellet bed in the muffle furnace for the pre-determined time (heating time of step 2) when the furnace temperature rises to and stay at the predetermined value.

- When the total experimental time (including time for step1 and step 2) is past, the crucible with the DRI is taken out to be cooled under flowing nitrogen.

During the reduction experiments in the muffle furnace, the temperature and gas compositions are monitored continuously. Typical records for the temperature and gas compositions are shown in Figure 3-1. 


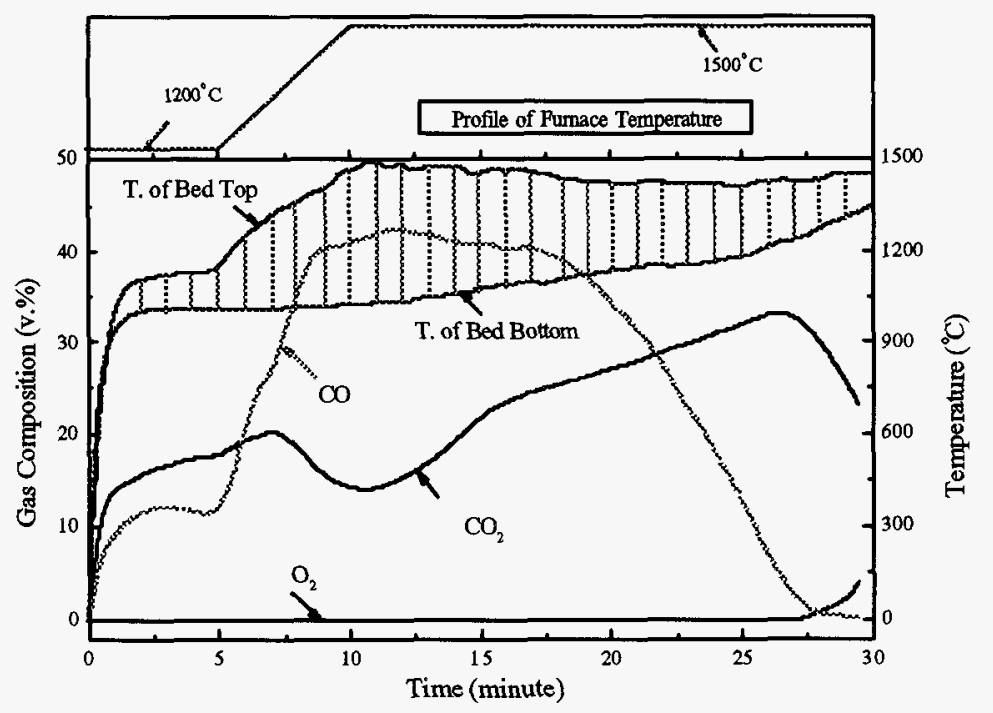

Fig. 3-1. Direct measurement of temperature and gas composition at top of pellet bed of $60 \mathrm{~mm}$ height.(Green ball: Taconite + coal\#3, C/O-0.9)

\section{§3.2.3 DRI sampling and analysis}

The cooled DRI were taken out of the special crucible and separated along the axis of the bed of DRI into two portions. One portion was ground by shatter-box down to -150 mesh for chemical analysis to determine the contents of total iron, metallic iron and residual carbon. The other portion was separated again into top-layer, middle-layers and bottom layer for measuring density and metallographic analysis.

\section{\$3.3 Experimental Results and Brief Discussions}

A number of series of experiments were designed and conducted for the studies of the six items described in \$3.2.1. in order to verify influences of the processing temperature, the amount of coal addition, the content of volatile matter of coal, the height of pellets bed, the size of pellet and temperature of furnace hearth on the reduction of ore/coal pellets in a bed. The results of experiments and related experimental conditions are presented in following sections.

\section{\$3.3.1 The effect of processing temperature on the reduction of ore/coal pellets}

The relationship between the degrees of metallization of DRI and the processing temperature (or furnace temperature) for a constant total heating time is presented in 
Table 3-1 and illustrated in Figure 3-2. The variations of degree metallization of DRI with the total heating time at different processing temperature are listed in Table 3-2 and illustrated in Figure 3-3.

Table 3-1. The Influence of Furnace Temperature on the Reduction Process in a Pellet Bed of $60 \mathrm{~mm}$

\begin{tabular}{|c|c|c|c|c|c|c|c|c|c|}
\hline & \multirow{2}{*}{$\begin{array}{c}\mathrm{C} / \mathrm{O} \\
\text { No. }\end{array}$} & \multirow{2}{*}{$\begin{array}{c}\text { g-atom/ } \\
\text { g-atom) }\end{array}$} & Reductant & \multirow{2}{*}{$\begin{array}{c}\text { Size } \\
(\mathrm{mm})\end{array}$} & & \multicolumn{2}{|c|}{$\begin{array}{c}\text { Temp. }\left({ }^{\circ} \mathrm{C}\right) / \\
\text { Time(min.) }\end{array}$} & \multicolumn{4}{|c|}{ Sponge Iron Composition (wt.\%) } \\
\cline { 5 - 10 } & & & Setp.1 & Step. 2 & TFe & MFe & DM & C \\
\hline 2 & 1.05 & Coal \#3 & 14 & $1200 / 5$ & $1200 / 20$ & 67.38 & 32.15 & 47.70 & 8.04 \\
\hline 3 & 1.05 & Coal \#3 & 14 & $1200 / 5$ & $1300 / 20$ & 73.83 & 61.74 & 83.63 & 7.26 \\
\hline 4 & 1.05 & Coal \#3 & 14 & $1200 / 5$ & $1400 / 20$ & 79.87 & 74.45 & 93.21 & 4.74 \\
\hline 5 & 1.05 & Coal \#3 & 14 & $1200 / 5$ & $1500 / 20$ & 83.97 & 80.13 & 95.43 & 3.40 \\
\hline
\end{tabular}

Table 3-2. The Influence of Heating Time on the Reduction in a Pellet Bed of $60 \mathrm{~mm}$

\begin{tabular}{|c|c|c|c|c|c|c|c|c|c|}
\hline \multirow{2}{*}{ No. } & \multirow{2}{*}{$\begin{array}{c}\mathrm{C} / \mathrm{O} \\
\text { (g-atom/ } \\
\text { g-atom) }\end{array}$} & \multirow[t]{2}{*}{ Reductant } & \multirow{2}{*}{$\begin{array}{l}\text { Pellet } \\
\text { Size } \\
(\mathrm{mm})\end{array}$} & \multicolumn{2}{|c|}{$\begin{array}{l}\text { Temp. }\left({ }^{\circ} \mathrm{C}\right) / \\
\text { Time(min.) }\end{array}$} & \multicolumn{4}{|c|}{ Sponge Iron Composition (wt.\%) } \\
\hline & & & & Setp.1 & Step. 2 & $\mathrm{TFe}$ & $\mathrm{MFe}$ & $\overline{\mathrm{DM}}$ & $\bar{C}$ \\
\hline 11 & 1.05 & Coal \#3 & 14 & $1200 / 5$ & $1300 / 15$ & 68.40 & 27.44 & 40.12 & 10.98 \\
\hline 3 & 1.05 & Coal \#3 & 14 & $1200 / 5$ & $1300 / 20$ & 73.83 & 61.74 & 83.63 & 7.26 \\
\hline 10 & 1.05 & Coal \#3 & 14 & $1200 / 5$ & $1300 / 25$ & 76.19 & 64.00 & 84.00 & 7.80 \\
\hline 9 & 1.05 & Coal \#3 & 14 & $1200 / 5$ & $1300 / 30$ & 84.38 & 79.87 & 94.66 & 4.69 \\
\hline 8 & 1.05 & Coal \#3 & 14 & $1200 / 5$ & $1500 / 15$ & 80.28 & 71.88 & 89.54 & 5.63 \\
\hline 5 & 1.05 & Coal \#3 & 14 & $1200 / 5$ & $1500 / 20$ & 83.97 & 80.13 & 95.43 & 3.40 \\
\hline 1 & 1.05 & Coal \#3 & $\overline{14}$ & $1200 / 5$ & $1500 / 25$ & 87.45 & 85.86 & 98.19 & 1.71 \\
\hline 7 & 1.05 & Coal \#3 & 14 & $1200 / 5$ & $1500 / 30$ & 87.62 & 86.46 & 98.68 & 1.11 \\
\hline
\end{tabular}




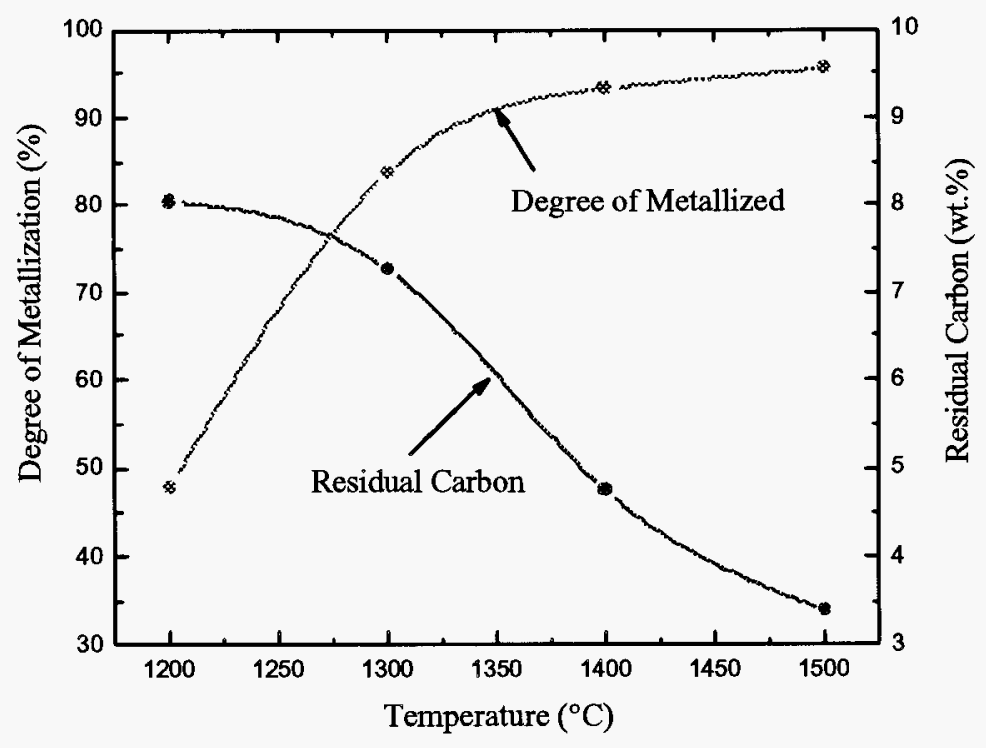

Figure 3-2. The influence of processing temperature on the reduction of bed of ore/coal pellet (Total heating time $25 \mathrm{~min}$., Bed height $60 \mathrm{~mm}$, green ball conditions see Table 3-1)

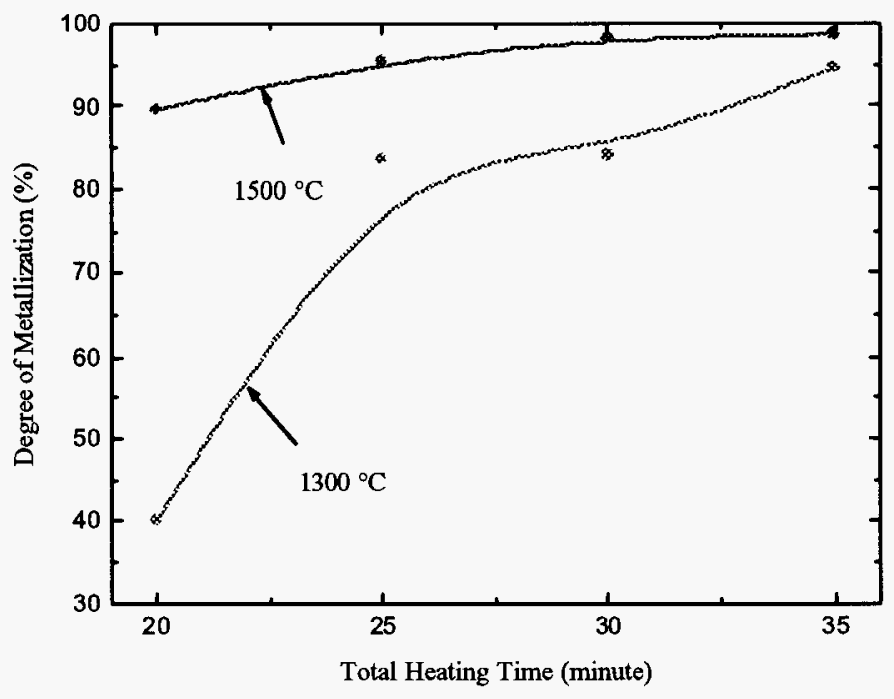

Figure 3-3 The influence of processing temperature on the reduction process (bed height $60 \mathrm{~mm}$, green ball conditions see Table 3-2)

From Table 3-1 and Figure34-2, it is very clear that the reduction rate of a bed of ore/coal pellets increases with the increase of processing temperature. However, the beneficial effect of processing temperature diminishes after $90 \%$ degree of metallization and above 
$1400^{\circ} \mathrm{C}$ in the cases of total heating time of 25 minutes. The critical temperature will move further up from $1400^{\circ} \mathrm{C}$, as shown in Table 3-2 and Figure 3-3. It may be concluded that a higher processing temperature may lead to higher productivity under otherwise constant conditions. For example, under the same conditions, the total heating time for reaching $90 \%$ degree of metallization of DRI can be cut down to 20 minutes from more than 30 minutes (seen Table 3-2 and Figure 3-3).

The obvious explanation of these changes is that higher processing temperature results in higher radiative heat flux to the pellet bed. Furthermore, the heat transfer within the bed is enhanced. The densification and shrinkage of DRI increases with the increase of processing temperature. The consequence is that the void fraction of the DRI bed increases to facilitate radiative heat transfer. There is another contribution of densification of DRI: denser iron phase has higher conductivity. The shrinkage of bed results in a shortening of the height by $50 \%$ at a processing temperature of $1500^{\circ} \mathrm{C}$ after a total heating time of 25 minute. In comparison, a shrinkage of less than $10 \%$ of bed height was observed at a the processing temperature of $1300^{\circ} \mathrm{C}$ under otherwise the same condition.

\section{\$3.3.2 The effects of the amount and method of addition of coal}

Pellet properties vary with amount of coal addition. There are certain advantages for lowing the coal content in the pellets; therefore, the idea of adding coal internally and externally were tested in the following series of experiments. The symbol $\mathrm{C} / \mathrm{O}$ stands for the portion of coal internally added to the pellet; $(\mathrm{C} / \mathrm{O})_{\text {ext }}$. stands for the ratio of the amount of coal added at the floor of the bed and total $\mathrm{C} / \mathrm{O}$ ratio of the pellet bed is $\mathrm{C} / \mathrm{O}+(\mathrm{C} / \mathrm{O})_{\text {ext }}$.

Table 3-3. The relationship between metallization degree and total heating $\operatorname{time}\left(\mathrm{C} / \mathrm{O}=1.1,(\mathrm{C} / \mathrm{O})_{\text {ext. }}=0\right.$, Bed Height $\left.=60 \mathrm{~mm}\right)$

\begin{tabular}{|c|c|c|c|c|c|c|c|c|c|}
\hline \multirow{2}{*}{ No. } & \multirow{2}{*}{$\begin{array}{c}\mathrm{C} / \mathrm{O} \\
\text { (g-atom/ } \\
\text { g-atom) }\end{array}$} & \multirow[t]{2}{*}{ Reductant } & \multirow{2}{*}{$\begin{array}{l}\text { Pellet } \\
\text { Size } \\
(\mathrm{mm})\end{array}$} & \multicolumn{2}{|c|}{$\begin{array}{l}\text { Temp. }\left({ }^{\circ} \mathrm{C}\right) / \\
\text { Time(min.) }\end{array}$} & \multicolumn{4}{|c|}{ Sponge Iron Composition (wt.\%) } \\
\hline & & & & Setp.1 & Step. 2 & TFe & $\mathrm{MFe}$ & $\mathrm{DM}$ & $\bar{C}$ \\
\hline 49 & 1.1 & Coal \#3 & $\overline{14}$ & $1200 / 5$ & $1300 / 10$ & 70.09 & 45.35 & 64.70 & 9.56 \\
\hline 50 & 1.1 & Coal \#3 & 14 & $1200 / 5$ & $1300 / 15$ & 79.39 & 73.02 & 91.98 & 5.63 \\
\hline 51 & $\overline{1.1}$ & Coal \#3 & 14 & $1200 / 5$ & $1300 / 20$ & 86.25 & 85.24 & 98.83 & 3.54 \\
\hline 52 & 1.1 & Coal \#3 & 14 & $1200 / 5$ & $1300 / 25$ & 88.78 & 86.76 & 97.72 & 1.46 \\
\hline 53 & 1.1 & Coal \#3 & $\overline{14}$ & $1200 / 5$ & $1500 / 30$ & 89.79 & 88.13 & 98.09 & 1.22 \\
\hline
\end{tabular}


Table 3-4. The relationship between metallization degree and total heating time $\left(\mathrm{C} / \mathrm{O}=1.0,(\mathrm{C} / \mathrm{O})_{\text {ext } .}=0\right.$, Bed Height $\left.=60 \mathrm{~mm}\right)$

\begin{tabular}{|c|c|c|c|c|c|c|c|c|c|}
\hline & \multirow{2}{*}{$\begin{array}{c}\text { C/O } \\
\text { No.atom/ }\end{array}$} & \multirow{2}{*}{$\begin{array}{c}\text { Reductant } \\
\text { g-atom) }\end{array}$} & & $\begin{array}{c}\text { Sellet } \\
(\mathrm{mm})\end{array}$ & \multicolumn{2}{|c|}{$\begin{array}{c}\text { Temp. }\left({ }^{\circ} \mathrm{C}\right) / \\
\text { Time(min.) }\end{array}$} & \multicolumn{4}{|c|}{ Sponge Iron Composition (wt.\%) } \\
\cline { 5 - 10 } & & & Setp.1 & Step. 2 & TFe & MFe & DM & C \\
\hline 54 & 1.0 & Coal \#3 & 14 & $1200 / 5$ & $1300 / 10$ & 68.28 & 38.78 & 56.80 & 9.02 \\
\hline 55 & 1.0 & Coal \#3 & 14 & $1200 / 5$ & $1300 / 15$ & 80.19 & 73.23 & 91.30 & 4.81 \\
\hline 56 & 1.0 & Coal \#3 & 14 & $1200 / 5$ & $1300 / 20$ & 84.84 & 83.45 & 98.35 & 2.01 \\
\hline 57 & 1.0 & Coal \#3 & 14 & $1200 / 5$ & $1300 / 25$ & 89.69 & 87.26 & 97.30 & 0.53 \\
\hline 58 & 1.0 & Coal \#3 & 14 & $1200 / 5$ & $1500 / 30$ & 90.09 & 88.25 & 97.97 & 0.31 \\
\hline
\end{tabular}

Table 3-5. The relationship between metallization degree and total heating time $\left(\mathrm{C} / \mathrm{O}=0.9,(\mathrm{C} / \mathrm{O})_{\text {ext. }}=0.1\right.$, Bed Height $\left.=60 \mathrm{~mm}\right)$

\begin{tabular}{|c|c|c|c|c|c|c|c|c|c|}
\hline \multirow{2}{*}{ No. } & \multirow{2}{*}{$\begin{array}{c}\mathrm{C} / \mathrm{O} \\
\text { (g-atom/ } \\
\text { g-atom) }\end{array}$} & \multirow[t]{2}{*}{ Reductant } & \multirow{2}{*}{$\begin{array}{l}\text { Pellet } \\
\text { Size } \\
(\mathrm{mm})\end{array}$} & \multicolumn{2}{|c|}{$\begin{array}{l}\text { Temp. }\left({ }^{\circ} \mathrm{C}\right) / \\
\text { Time(min.) }\end{array}$} & \multicolumn{4}{|c|}{ Sponge Iron Composition (wt.\%) } \\
\hline & & & & Setp.1 & Step. 2 & $\mathrm{TFe}$ & $\mathrm{MFe}$ & $\overline{\mathrm{DM}}$ & $\bar{C}$ \\
\hline 59 & 0.9 & Coal \#3 & 14 & $1200 / 5$ & $1300 / 10$ & 70.09 & 35.39 & 50.5 & 8.10 \\
\hline 60 & 0.9 & Coal \#3 & $\overline{14}$ & $1200 / 5$ & $1300 / 15$ & 78.78 & 70.66 & 89.68 & 3.41 \\
\hline 61 & 0.9 & Coal \#3 & 14 & $1200 / 5$ & $1300 / 20$ & 86.86 & 85.08 & 97.95 & 0.89 \\
\hline 62 & 0.9 & Coal \#3 & $\overline{14}$ & $1200 / 5$ & $1300 / 25$ & 88.78 & 86.96 & 97.95 & 0.16 \\
\hline 63 & 0.9 & Coal \#3 & 14 & $1200 / 5$ & $1500 / 30$ & 88.84 & 87.30 & 98.28 & 0.12 \\
\hline
\end{tabular}

Table 3-6. The relationship between metallization degree and total heating time $\left(\mathrm{C} / \mathrm{O}=0.8,(\mathrm{C} / \mathrm{O})_{\mathrm{ext} .}=0.2\right.$, Bed Height $\left.=60 \mathrm{~mm}\right)$

\begin{tabular}{|c|c|c|c|c|c|c|c|c|c|}
\hline \multirow{2}{*}{ No. } & \multirow{2}{*}{$\begin{array}{c}\mathrm{C} / \mathrm{O} \\
\text { (g-atom/ } \\
\text { g-atom) }\end{array}$} & \multirow[t]{2}{*}{ Reductant } & \multirow{2}{*}{$\begin{array}{l}\text { Pellet } \\
\text { Size } \\
(\mathrm{mm})\end{array}$} & \multicolumn{2}{|c|}{$\begin{array}{l}\text { Temp. }\left({ }^{\circ} \mathrm{C}\right) / \\
\text { Time(min.) }\end{array}$} & \multicolumn{4}{|c|}{ Sponge Iron Composition (wt.\%) } \\
\hline & & & & Setp.1 & Step. 2 & $\mathrm{TFe}$ & $\mathrm{MFe}$ & $\mathrm{DM}$ & $\mathrm{C}$ \\
\hline 64 & 0.8 & Coal \#3 & 14 & $1200 / 5$ & $1300 / 10$ & 70.34 & 32.50 & 46.20 & 6.84 \\
\hline 65 & 0.8 & Coal \#3 & 14 & $1200 / 5$ & $1300 / 15$ & 84.13 & 73.20 & 87.00 & 2.58 \\
\hline 66 & 0.8 & Coal \#3 & 14 & $1200 / 5$ & $1300 / 20$ & 86.25 & 82.50 & 95.65 & 0.28 \\
\hline 67 & 0.8 & Coal \#3 & 14 & $1200 / 5$ & $1300 / 25$ & 87.67 & 84.74 & 96.54 & 0.014 \\
\hline 68 & 0.8 & Coal \#3 & 14 & $1200 / 5$ & $1500 / 30$ & 87.87 & 85.49 & 97.30 & 0.01 \\
\hline
\end{tabular}


Table 3-7. The relationship between metallization degree and total heating time $\left(\mathrm{C} / \mathrm{O}=0.7,(\mathrm{C} / \mathrm{O})_{\text {ext }}=0.3\right.$, Bed Height $\left.=60 \mathrm{~mm}\right)$

\begin{tabular}{|c|c|c|c|c|c|c|c|c|c|}
\hline & \multirow{2}{*}{$\begin{array}{c}\mathrm{C} / \mathrm{O} \\
\text { No. }\end{array}$} & \multirow{2}{*}{$\begin{array}{c}\text { g-atom/ } \\
\text { g-atom) }\end{array}$} & Reductant & \multirow{2}{*}{$\begin{array}{c}\text { Size } \\
(\mathrm{mm})\end{array}$} & & \multicolumn{2}{|c|}{$\begin{array}{c}\text { Temp. }\left({ }^{\circ} \mathrm{C}\right) / \\
\text { Time(min.) }\end{array}$} & \multicolumn{4}{|c|}{ Sponge Iron Composition (wt.\%) } \\
\cline { 5 - 10 } & & & Setp.1 & Step. 2 & TFe & MFe & DM & C \\
\hline 69 & 0.7 & Coal \#3 & 14 & $1200 / 5$ & $1300 / 10$ & 71.71 & 31.53 & 43.98 & 5.90 \\
\hline 70 & 0.7 & Coal \#3 & 14 & $1200 / 5$ & $1300 / 15$ & 81.10 & 66.58 & 82.10 & 1.78 \\
\hline 71 & 0.7 & Coal \#3 & 14 & $1200 / 5$ & $1300 / 20$ & 85.75 & 76.70 & 89.45 & 0.10 \\
\hline 72 & 0.7 & Coal \#3 & 14 & $1200 / 5$ & $1300 / 25$ & 85.65 & 77.06 & 89.98 & 0.01 \\
\hline 73 & 0.7 & Coal \#3 & 14 & $1200 / 5$ & $1500 / 30$ & 86.05 & 77.57 & 90.26 & 0.02 \\
\hline
\end{tabular}

Table 3-8. The relationship between metallization degree and total heating time $\left(\mathrm{C} / \mathrm{O}=0.6,(\mathrm{C} / \mathrm{O})_{\text {ext. }}=0.4\right.$, Bed Height $\left.=60 \mathrm{~mm}\right)$

\begin{tabular}{|c|c|c|c|c|c|c|c|c|c|}
\hline \multirow{2}{*}{ No. } & $\begin{array}{c}\text { C/O } \\
\text { (g-atom/ } \\
\text { g-atom) }\end{array}$ & Reductant & \multirow{2}{*}{$\begin{array}{c}\text { Pellet } \\
\text { Size }\end{array}$} & & \multicolumn{2}{|c|}{$\begin{array}{c}\text { Temp. }\left({ }^{\circ} \mathrm{C}\right) / \\
\text { Time(min. }\end{array}$} & \multicolumn{3}{|c|}{ Sponge Iron Composition (wt.\%) } \\
\cline { 5 - 10 } & & & Setp.1 & Step. 2 & TFe & MFe & DM & C \\
\hline 74 & 0.6 & Coal \#3 & 14 & $1200 / 5$ & $1300 / 10$ & 71.71 & 30.81 & 42.95 & 4.89 \\
\hline 75 & 0.6 & Coal \#3 & 14 & $1200 / 5$ & $1300 / 15$ & 80.80 & 61.41 & 76.00 & 1.13 \\
\hline 76 & 0.6 & Coal \#3 & 14 & $1200 / 5$ & $1300 / 20$ & 82.42 & 67.49 & 81.89 & 0.072 \\
\hline 77 & 0.6 & Coal \#3 & 14 & $1200 / 5$ & $1300 / 25$ & 83.83 & 69.08 & 82.41 & 0.013 \\
\hline 78 & 0.6 & Coal \#3 & 14 & $1200 / 5$ & $1500 / 30$ & 84.03 & 69.41 & 82.60 & 0.014 \\
\hline
\end{tabular}

The relation between the degree of metallization of DRI and the total heating time with different values of $\mathrm{C} / \mathrm{O}$ ratio is presented in Figure 3-4. The relationship between the degree of metallization of DRI and $\mathrm{C} / \mathrm{O}$ ratio at different total heating time was shown in Figure 3-5.

From Figure3-.4 and Figure 3-5, it is clear that the degree of metallization of DRI increases strongly with increasing $\mathrm{C} / \mathrm{O}$ ratio inside ore/coal pellets. However the strong influence of $\mathrm{C} / \mathrm{O}$ ratio diminishes after $\mathrm{C} / \mathrm{O}=0.8$ (see Figure 3-5). From data shown here, it is clear that, in order to have a very high degree of metallization in DRI, adequate amount of coal must be provided at the location it is needed. The gaseous flow inside a pellet is outward; thus, it would be very difficult for gaseous reductant to diffuse upstream to reduce iron oxides in the core. 


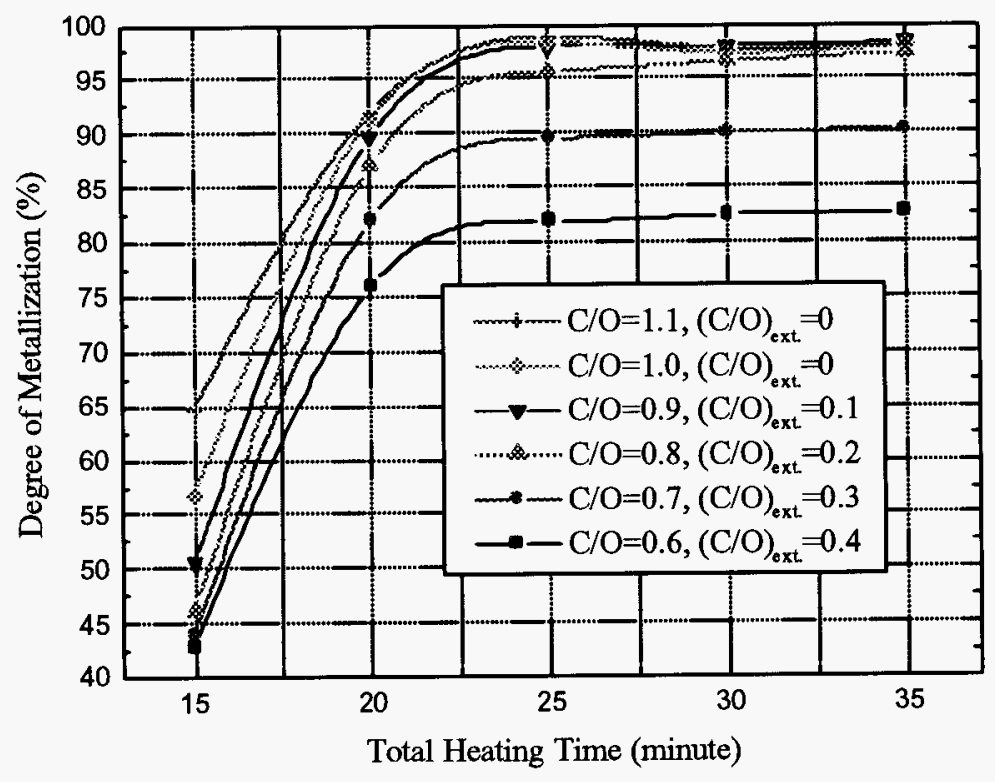

Figure 3-4. The relation of degree of metallization of DRI to total heating time with different $\mathrm{C} / \mathrm{O}$ ratio

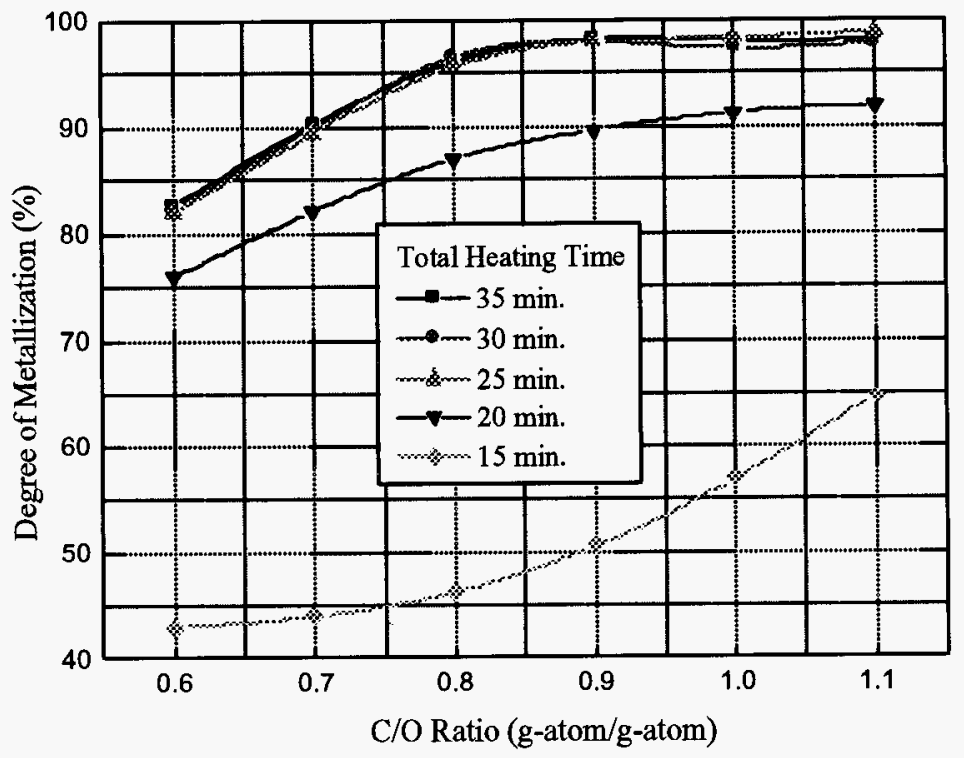

Figure 3-5. The relation between degree of metallization of DRI and $\mathrm{C} / \mathrm{O}$ ratio with different total heating time 
The external coal addition which was placed at the bottom of the bed contributed very little to the reduction of iron oxides in pellets. The presence of char at the bottom of the DRI bed was observed and it was found that only a small portion of the fixed carbon was gasified. Therefore the extra coal addition externally was eliminated in all later experiments (after this section, §3.3).

\section{\$3.3.3 The content of volatile matter of coal}

Table 3-9. The effect of volatile matter on reduction of ore/coal pellets $(C / O=1.05$,

\begin{tabular}{|c|c|c|c|c|c|c|c|c|c|}
\hline \multicolumn{1}{|c|}{ Bed Height $=60 \mathrm{~mm}$, Pellets Size: $14 \mathrm{~mm})$} \\
\hline & $\begin{array}{c}\text { C/O } \\
(\mathrm{g} \text {-atom/ } \\
\text { g-atom) }\end{array}$ & $\begin{array}{c}\text { Reductant } \\
(\text { mixture of } \\
\text { coke \& coal) }\end{array}$ & $\begin{array}{c}\text { Volatile } \\
\text { Matter } \\
(\text { wt.\%) }\end{array}$ & \multicolumn{2}{|c|}{$\begin{array}{c}\text { Temp. }\left({ }^{\circ} \mathrm{C}\right) / \\
\text { Time(min.) }\end{array}$} & \multicolumn{4}{|c|}{$\begin{array}{c}\text { Sponge Iron Composition } \\
(\text { wt. } \%)\end{array}$} \\
\hline 26 & 1.05 & $100 \%$ Coke & 0.8 & $1200 / 5$ & $1400 / 25$ & 78.35 & 55.51 & 70.85 & 4.94 \\
\hline 18 & 1.05 & $\begin{array}{c}46 \% \text { Coke }+ \\
54 \% \text { coal }\end{array}$ & 19.0 & $1200 / 5$ & $1400 / 25$ & 81.51 & 67.89 & 83.29 & 4.38 \\
\hline 19 & 1.05 & $100 \%$ Coal \#3 & 34.5 & $1200 / 5$ & $1400 / 25$ & 83.66 & 80.16 & 95.82 & 3.03 \\
\hline
\end{tabular}

The effect of the amount of volatile matter and carbon reactivity on the reduction of ore/coal pellets is show in Table 3-9 and Figure 3-6. The reductants were coal\#3, coke (Table 2-7) and a mixture of them. The relation between the degree of metallization and the content of volatile matter in the reductant is presented in Figure 3-6. The beneficial effects of volatile matter in coal and possibly more reactive char are very clear.

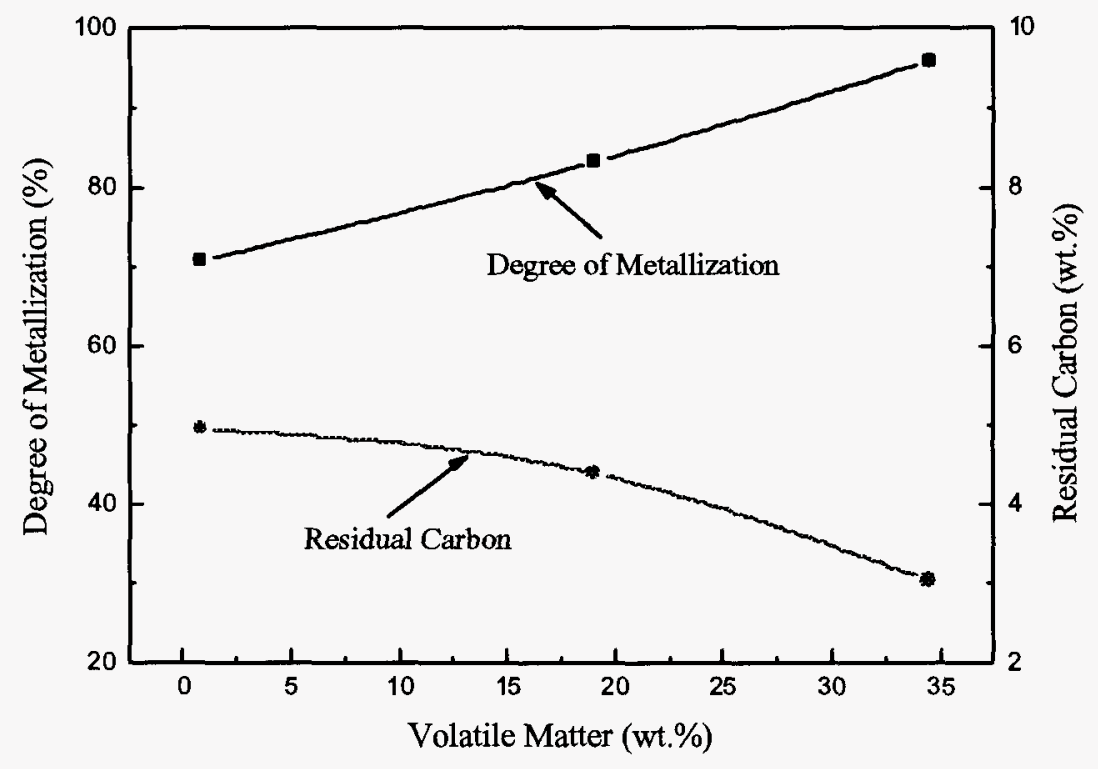

Figure 3-6. The effect of volatile matter of carbonaceous reductant in the pellets on the reduction of ore/coal pellets. 


\section{§3.3.4 The height of pellet bed}

The effects of the height of bed of ore/coal pellets on the reduction of iron oxides are listed in Table 3-10 (bed height $=20 \mathrm{~mm}$ ), Table 3-11 (bed height $=40 \mathrm{~mm}$ ) and Table 35 (bed height $=60 \mathrm{~mm}$ ). The relation between the degree of metallization of DRI and the total heating time for different bed height are shown in Figure 3-7. It shows that, when the height of pellets was $20 \mathrm{~mm}$, the degree of metallization of DRI increased with the total heating time up to metallization of $95 \%$ at about 15 minutes and then decreased obviously. This implies that re-oxidation of DRI will happen if the total heating time is above a certain value for the shallow pellet bed. This re-oxidation problem is common in the production of DRI by using a shallow bed of ore/coal pellet in a rotary hearth furnace process (RHF). But the re-oxidation of DRI became much less obvious when the bed height of pellets was increased to 40 and $60 \mathrm{~mm}$. These experimental results confirm that a taller bed would have less problem for re-oxidation of DRI and reach a higher final value of degree of metallization.

Table 3-10. The relationship between metallization degree and total heating time $\left(\mathrm{C} / \mathrm{O}=0.9,,(\mathrm{C} / \mathrm{O})_{\text {ext }}=0.1\right.$, Bed Height $\left.=20 \mathrm{~mm}\right)$

\begin{tabular}{|c|c|c|c|c|c|c|c|c|c|}
\hline \multirow{2}{*}{ No. } & \multirow{2}{*}{$\begin{array}{c}\mathrm{C} / \mathrm{O} \\
\text { (g-atom/ } \\
\text { g-atom) }\end{array}$} & \multirow[t]{2}{*}{ Reductant } & \multirow{2}{*}{$\begin{array}{l}\text { Pellet } \\
\text { Size } \\
(\mathrm{mm})\end{array}$} & \multicolumn{2}{|c|}{$\begin{array}{l}\text { Temp. }\left({ }^{\circ} \mathrm{C}\right) / \\
\text { Time(min.) }\end{array}$} & \multicolumn{4}{|c|}{ Sponge Iron Composition (wt.\%) } \\
\hline & & & & Setp.1 & Step. 2 & TFe & $\mathrm{MFe}$ & $\overline{\mathrm{DM}}$ & $\mathrm{C}$ \\
\hline 39 & 0.9 & Coal \#3 & 14 & $/ /$ & $1500 / 6$ & 77.19 & 53.84 & 69.74 & 5.61 \\
\hline 40 & 0.9 & Coal \#3 & 14 & $\pi$ & $1500 / 9$ & 88.22 & 82.01 & 92.95 & 1.73 \\
\hline 41 & 0.9 & Coal \#3 & 14 & $/ /$ & $1500 / 12$ & 91.63 & 86.82 & 94.75 & 0.04 \\
\hline 42 & 0.9 & Coal \#3 & 14 & $/ /$ & $1500 / 15$ & 91.23 & 87.72 & 96.15 & 0.05 \\
\hline 43 & 0.9 & Coal \#3 & 14 & // & $1500 / 18$ & 91.03 & 85.01 & 93.37 & 0.06 \\
\hline 44 & 0.9 & Coal\#3 & 14 & $/ /$ & $1500 / 21$ & 89.83 & 81.40 & 90.63 & 0.05 \\
\hline
\end{tabular}




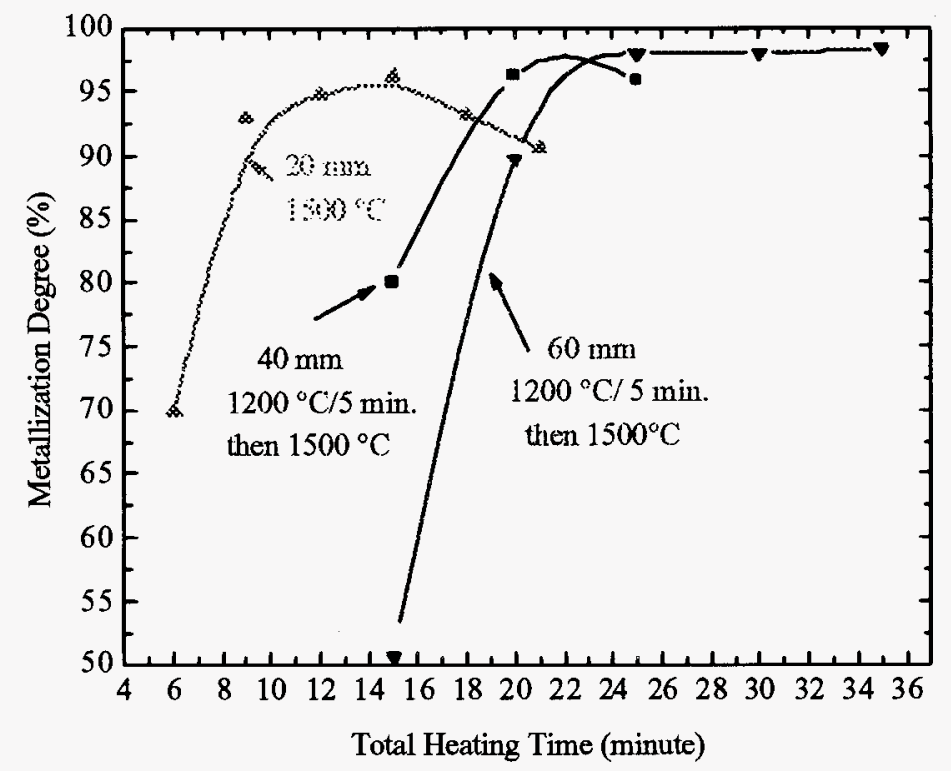

Figure 3-7. The reduction of ore/coal pellets and re-oxidation of DRI in pellet bed of different heights in a muffle furnace in air atmosphere

Table 3-11. The relationship between metallization degree and total heating time $\left(\mathrm{C} / \mathrm{O}=0.9,(\mathrm{C} / \mathrm{O})_{\text {ext } .}=0.1\right.$, Bed Height $\left.=40 \mathrm{~mm}\right)$

\begin{tabular}{|c|c|c|c|c|c|c|c|c|c|}
\hline & \multirow{2}{*}{$\begin{array}{c}\text { C/O } \\
\text { (g-atom/ } \\
\text { g-atom) }\end{array}$} & Reductant & $\begin{array}{c}\text { Pellet } \\
\text { Size } \\
(\mathrm{mm})\end{array}$ & \multicolumn{2}{|c|}{$\begin{array}{c}\text { Temp. }\left({ }^{\circ} \mathrm{C}\right) / \\
\text { Time(min.) }\end{array}$} & \multicolumn{4}{|c|}{ Sponge Iron Composition (wt.\%) } \\
\cline { 5 - 10 } & & & Setp.1 & Step. 2 & TFe & MFe & DM & C \\
\hline 45 & 0.9 & Coal \#3 & 14 & $1200 / 5$ & $1500 / 10$ & 80.20 & 64.16 & 80.00 & 3.87 \\
\hline 46 & 0.9 & Coal \#3 & 14 & $1200 / 5$ & $1500 / 15$ & 86.82 & 84.41 & 96.23 & 0.11 \\
\hline 47 & 0.9 & Coal \#3 & 14 & $1200 / 5$ & $1500 / 20$ & 91.63 & 87.82 & 95.84 & 0.06 \\
\hline
\end{tabular}




\section{§3.3.5 The effect of pellet size}

The effect of pellet size on reduction rate is shown in Table $3-12$ and Figure 3-8. It should be noted that the rate of reduction of the pellet bed, as concluded earlier, is limited by heat transfer. It appears that larger pellets are easier to be reduced. The explanation is that the bed of lager pellets is also of larger space for the passage of radiative heat flux. For larger system and in view of the concern of bulk of the bed, there should be an optimum size in each case. It is our opinion that the optimum size of pellets will be between 14 and $20 \mathrm{~mm}$ in diameter, and it will increase with the height of pellet bed slightly.

Figure 3-8. The effect of pellet size on the reduction of ore/coal pellet

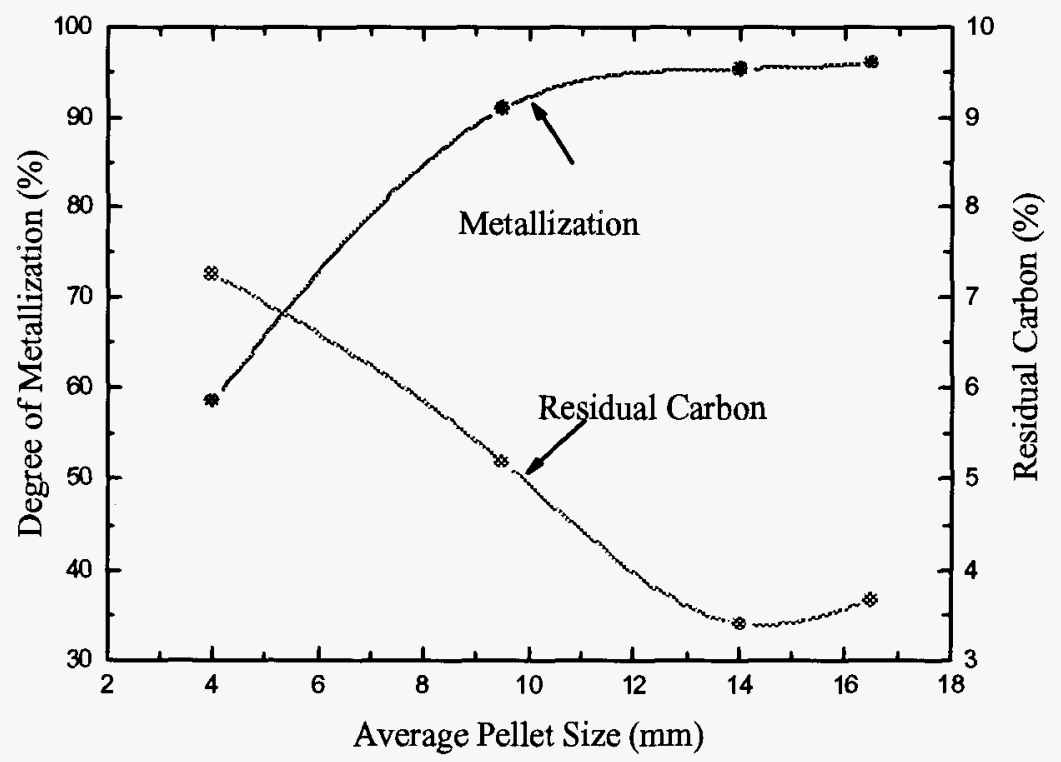

Table 3-12. The relationship between metallization degree and pellet size (Bed Height $=60 \mathrm{~mm}$ )

\begin{tabular}{|c|c|c|c|c|c|c|c|c|c|}
\hline & \multirow{2}{*}{$\begin{array}{c}\mathrm{C} / \mathrm{O} \\
\text { No-atom/ }\end{array}$} & \multirow{2}{\text{g-atom})}{} & Reductant & \multirow{2}{*}{$\begin{array}{c}\text { Pellet } \\
\text { Size } \\
\text { g-ato }\end{array}$} & & \multicolumn{2}{|c|}{$\begin{array}{c}\text { Temp. }\left({ }^{\circ} \mathrm{C}\right) / \\
\text { Time(min. })\end{array}$} & \multicolumn{4}{|c|}{ Sponge Iron Composition (wt.\%) } \\
\cline { 5 - 10 } & & & Setp.1 & Step. 2 & TFe & MFe & DM & C \\
\hline 25 & 1.05 & Coal \#3 & 4.0 & $1200 / 5$ & $1500 / 20$ & 71.34 & 41.74 & 58.50 & 7.25 \\
\hline 13 & 1.05 & Coal \#3 & 9.5 & $1200 / 5$ & $1500 / 20$ & 81.51 & 74.14 & 90.96 & 5.19 \\
\hline 5 & 1.05 & Coal \#3 & 14.0 & $1200 / 5$ & $1500 / 20$ & 83.97 & 80.13 & 95.43 & 3.40 \\
\hline 12 & 1.05 & Coal\#3 & 16.5 & $1200 / 5$ & $1500 / 20$ & 84.38 & 81.10 & 96.11 & 3.66 \\
\hline
\end{tabular}




\section{\$3.3.6 The effect of temperature of hearth surface at the time of charging}

In commercial practice, due to discharging operation the temperature of the surface of hearth drops to various values. It has been recognized that the temperature of hearth, in general, is higher than the ambient temperature which is the temperature of materials to be charged. With the ambient temperature as the reference, the pellet bed is heated from bottom with heat stored in the refractory (in brick or powders form) and in principle the process would be affected by the surface temperature.

In order to verify the effect of temperature of hearth surface on the reduction of ore/coal pellet, two series of experiments were carried out in the muffle furnace. In one series of experiments, the special crucible loaded with green ball was placed on a brick at ambient temperature, before the crucible and the brick were placed into the chamber of the muffle furnace. In the other series, the loaded special crucible was placed onto a brick which has been heated to $1200^{\circ} \mathrm{C}$ and has been inside the chamber of the muffle furnace. The results of these two sets of experiments and experimental conditions are shown in Table 3-2 and Table 3-13. The effects hot and cold hearth surface on reduction of ore/coal pellets are illustrated in Figure 3-9.

It is clear that the hot hearth surface has positive effect for the reduction of ore/coal pellet. The presence of the peak in the lower curve of Figure 3-9 is likely due to reoxidation after 20 minutes, because of inadequate reaction to generate enough gas at lower part of bed, a result of the drainage of heat to the supporting brick.

The benefit of heat stored in the hearth which is of limited amount and slow in its release, may be in preheating of pellets, de-volatilization and pre-reduction, i.e., low temperature reactions.

Table 3-13 The relationship between metallization degree and total heating time when the pellets are placed on cold hearth (Bed Height $=60 \mathrm{~mm}$ )

\begin{tabular}{|c|c|c|c|c|c|c|c|c|c|}
\hline \multirow{2}{*}{ No. } & \multirow{2}{*}{$\begin{array}{c}\text { C/O } / \mathrm{O} \text {-atom/ } \\
\text { g-atom })\end{array}$} & \multirow{2}{*}{ Reductant } & $\begin{array}{c}\text { Pellet } \\
\text { Size } \\
(\mathrm{mm})\end{array}$ & \multicolumn{3}{|c|}{$\begin{array}{c}\text { Temp. }\left({ }^{\circ} \mathrm{C}\right) / \\
\text { Time(min.) }\end{array}$} & \multicolumn{4}{|c|}{ Sponge Iron Composition (wt.\%) } \\
\cline { 5 - 10 } & & & Setp.1 & Step. 2 & TFe & MFe & DM & C \\
\hline 16 & 1.05 & Coal \#3 & 14 & $1200 / 5$ & $1500 / 15$ & 74.75 & 55.30 & 73.98 & 9.64 \\
\hline 15 & 1.05 & Coal \#3 & 14 & $1200 / 5$ & $1500 / 20$ & 75.67 & 67.89 & 89.72 & 8.85 \\
\hline 14 & 1.05 & Coal \#3 & 14 & $1200 / 5$ & $1500 / 25$ & 82.33 & 72.91 & 88.56 & 5.44 \\
\hline 17 & 1.05 & Coal \#3 & 14 & $1200 / 5$ & $1500 / 30$ & 84.79 & 72.70 & 85.74 & 5.14 \\
\hline
\end{tabular}




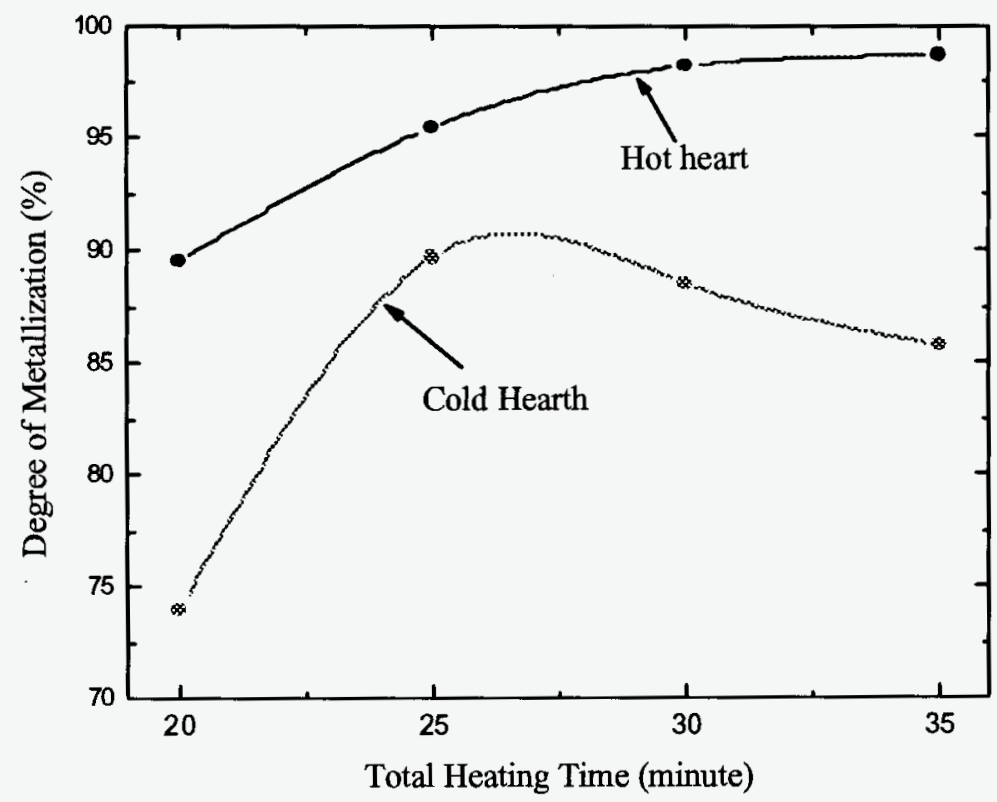

Figure 3.9. Comparison of effects of hot and cold hearth surface on the reduction of ore/coal pellets (hot hearth surface at $1200^{\circ} \mathrm{C}$ and cold hearth surface at ambient temperature).

\section{\$3.4 Productivity and Efficiency in the Use of Reductant}

In a hearth furnace, the productivity is defined as the kilograms of DRI being produced in a unit hearth area per unit processing time $\left(\mathrm{kg}-\mathrm{DRI} / \mathrm{m}^{2}-\mathrm{hr}\right)$. In this term of productivity, based on products of comparable degree of metallization (95 96\%), data shown in Figure 3-10 indicate that the combined effect of taller pellet bed and higher temperature leads to significant increase in productivity. 


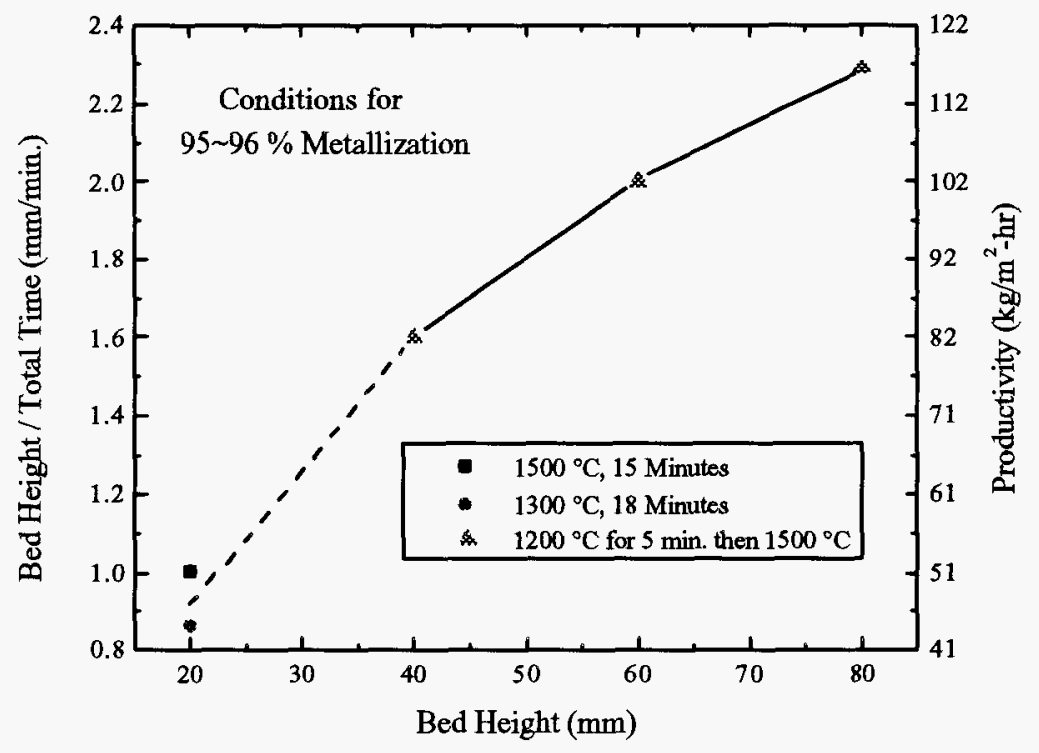

Figure 3-10. The relationship between productivity and height of pellet bed

In the present work, carbon is the main reductant with hydrogen playing a minor role. In the analysis of the efficiency of the use of reductant, carbon consumption is chosen for comparison, in terms of atomic ratio ?(O)/?(C). It stands for the ratio of number of atoms of combined oxygen in iron oxides removed to that of carbon gasificated in a particular time interval.

It is anticipated that, as the flow of upward-stream of gases at the top of the bed weakens, the oxidation of both sponge iron and residual carbon may gradually become significant. In the later stage of reduction, if we assume that carbon is the reductant and wustite is the oxide to be reduced, then we have the following stoichiomertric equation

$$
\mathrm{FeO}(\mathrm{s})+\mathrm{C}(\mathrm{s}) \rightarrow \mathrm{Fe}(\mathrm{s})+\mathrm{CO}(\mathrm{g})
$$

For this reaction in a given period of time, for which changes in chemical composition of the pellet bed are available, the efficiency of the utilization of carbon may be assessed. The average atomic ratio of removed combined oxygen from iron oxide and carbon over a period of time, ?(O)/?(C), may be plotted as functions average reaction time for each period in Figure 3-10. The stoichiometric changes according to the reference reaction shown above may be written as: 


$$
\frac{\Delta(\mathrm{O})}{\Delta(\mathrm{C})}=1.0
$$

for other cases, they have the following implications stoichiometrically,

$$
\begin{aligned}
2.0> & \frac{\Delta(\mathrm{O})}{\Delta(\mathrm{C})}>1.0 ; \text { gaseous product consists of a mixture of } \mathrm{CO} \text { and } \mathrm{CO}_{2} \\
1.0> & \frac{\Delta(\mathrm{O})}{\Delta(\mathrm{C})}>0 ; \text { carbon is oxidized by oxygen from wustite and other sources } \\
& \frac{\Delta(\mathrm{O})}{\Delta(\mathrm{C})}<0 ; \text { simultaneous oxidation of sponge iron and carbon }
\end{aligned}
$$

The average atomic ratio of changes in combined oxygen to carbon for each period is shown in Figure 3-11. The vertical axis on the right is for easier assessment of the situation. The very interesting conclusion from studying these plots is that, in taller beds the utilization of carbon for wustite reduction is more efficient and there is less risk of reoxidation of sponge iron. The practical implication is that lower internally added coal will lead to easier-to-produce, stronger green balls and denser DRI.

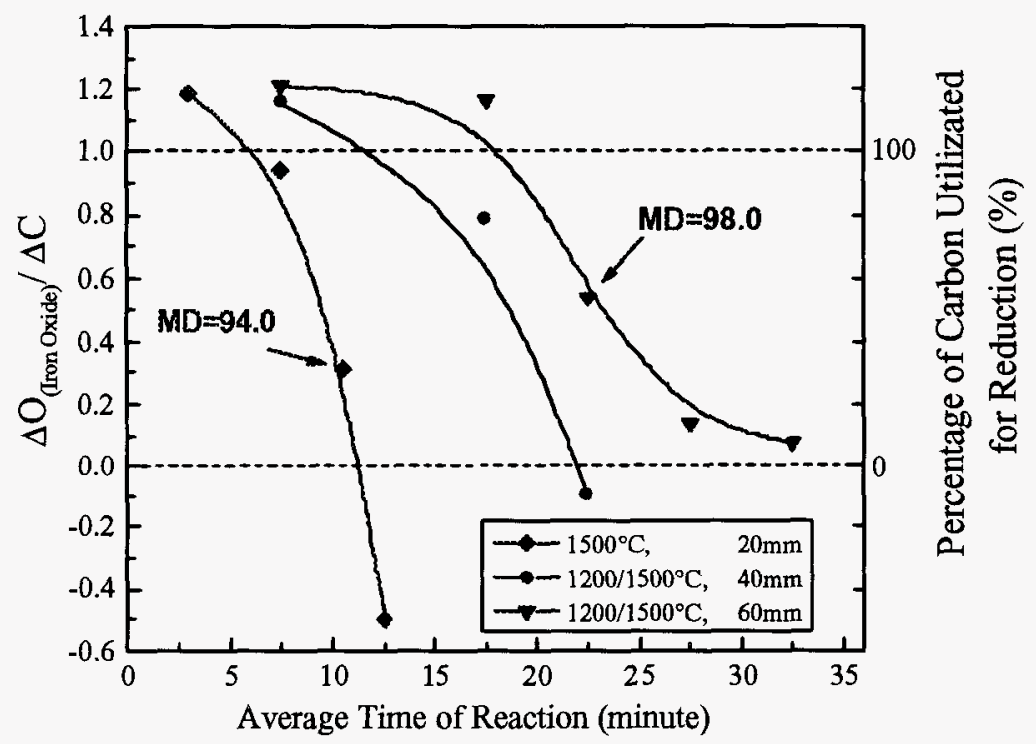

Figure 3-11. Changes in atomic ratio of combined oxygen and carbon in pellet beds of different heights 


\section{\$3.5 The Apparent Density of DRI}

The density of DRI produced from ore/coal pellets varies mainly with the C/O ratio and total heating time. For green balls made of taconite concentrate and coal \#3 with $\mathrm{C} / \mathrm{O}=0.9$ (the other detail conditions was listed in Table 3-5), the relationship between the weighted average apparent density of DRI and the total heating time is illustrated Figure 3-12. It is obvious that the longer heating time made the DRI denser. The relationship between the density of DRI and the amount of coal additions (in term of C/O ratio) is shown in Figure 3-13. This phenomenon was first recognized by our research group, which is very important for control of the density and residual carbon of DRI. Combining the curve of degree of metallization varying with the $\mathrm{C} / \mathrm{O}$ ratio, it is very easy to understand why there exist a peak value of density of DRI vs. C/O ratio.

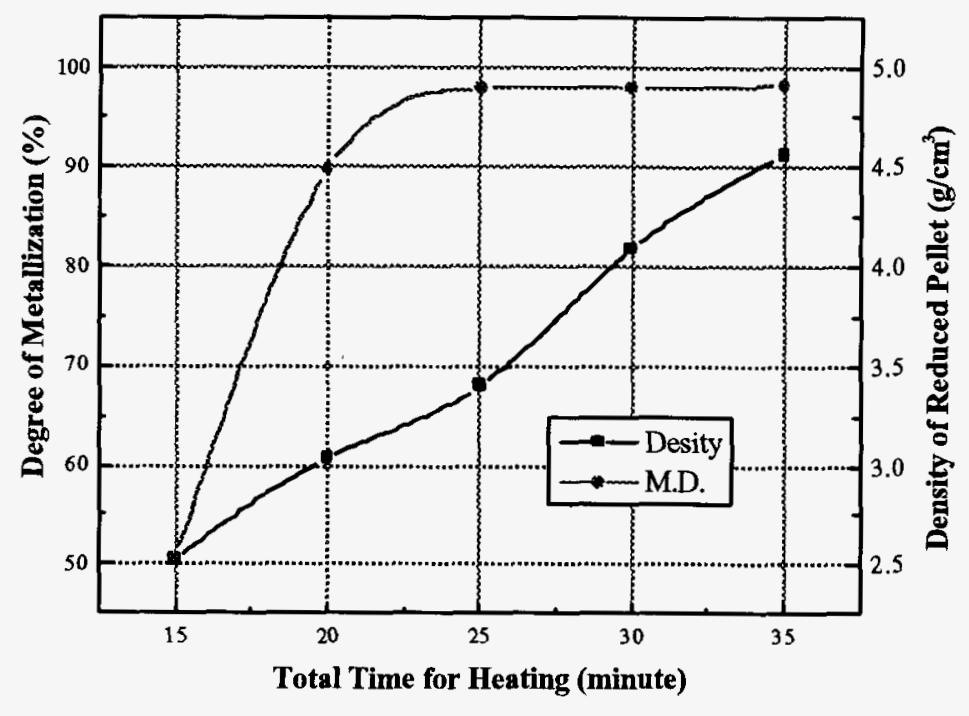

Figure 3-12. The relationship between density of DRI and total heating time (green balls: taconite + coal $\# 3, \mathrm{C} / \mathrm{O}=0.9$, size $=14 \mathrm{~mm}$, bed height $=60 \mathrm{~mm}$ ) 


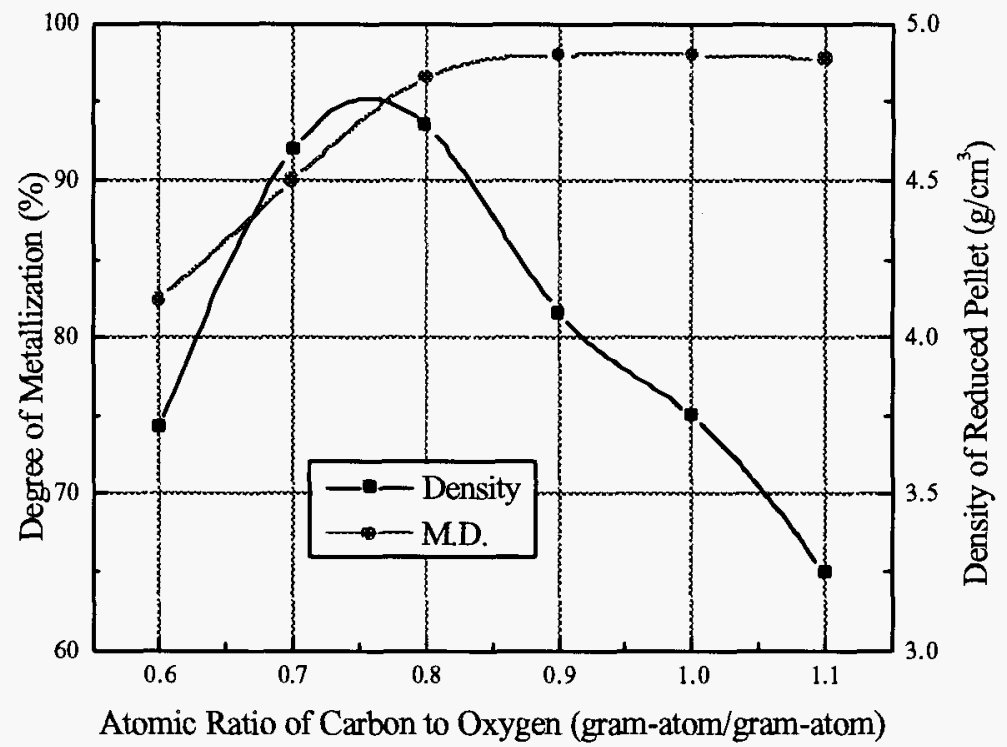

Figure3-13. The relationship between density of DRI and the $\mathrm{C} / \mathrm{O}$ ratio (green balls: taconite + coal $\# 3$, size $=14 \mathrm{~mm}$, bed height $=60 \mathrm{~mm}$, total heating time $=30$ minutes)

From Figure 3-12 and Figure 3-13, it can be seen that the DRI made from ore/coal pellets may be of high degree metallization and high density. The apparent density could be between 3.5 and $5.0 \mathrm{~g} / \mathrm{cm}^{3}$ with the degree of metallization over $90 \%$. The density of commercial DRI/sponge iron produced from shaft furnace is around $2.0 \mathrm{~g} / \mathrm{cm}^{3}$. Higher density of DRI is particularly important if it is denser than molten slag of steelmaking for more efficient melting.

\section{\$3.6 Summary}

A taller pellet (containing high volatile coal) bed coupled with a high processing temperature will generate a sustainable stream which is protective for DRI from reoxidation. It leads to higher furnace productivity and lower reductant requirement. Furthermore, longer residence time at high temperatures and quality of coal added will ensure DRI of high quality, particularly in the degree of metallization and apparent density. 
\$4 Reduction Experiments in the Natural Gas-Fired Furnace

$\S 4.1$ Common Features in All Reduction Experiments $\quad 42$

$\S 4.2$ Bed Height and Coal Type 45

$\S 4.3$ Chemical Compositions of Green Balls $\quad 49$

$\S 4.4$ The Processing of Waste Oxides for Recycling 51

$\S 4.5$ Summary $\quad 56$ 


\section{$\$ 4 \quad$ Reduction Experiments in the Natural Gas-Fired Furnace}

The advantages of the proposed new technology based on taller ore/coal pellet beds as outlined earlier have been confirmed by those experiments reported in $\S 3$. However, critics may argue:

(i). The heat size is too small (about 230 grams of green balls for a bed of $60 \mathrm{~mm}$ height) to claim that it is truly one dimensional system.

(ii). The electric muffle furnace is not a typical hearth furnace for the steel industry, and

(iii). The height of pellet bed $(60 \mathrm{~mm})$ which is limited by the size of furnace chamber, is not tall enough.

Experiments to be carried out in this natural gas-fired furnace were designed to answer these criticisms.

In order to test the viability of the new technology, a natural gas-fired furnace and auxiliary device were designed and built as described in detail in $\S 2$. This furnace, see Figure 2-3, is big enough to give a heat size of 6 to 7 kilo grams of dried green balls in the form of a bed $120 \mathrm{~mm}$ height, but not large enough for proper expansion of the flame. There are strong turbulence in the free board because the flame (gas flow) is stopped and reflected by the wall. It is a very severe test for the effectiveness of the upward-stream of gases generated in the bed in the protection of DRI from re-oxidation by oxidants in the fully oxidized flame. The situation in this furnace is much worse than the case would be in a commercial practice. This protective layer of gas at the top of the bed should let most of radiative heat flux to go through, but not the oxidants $\left(\mathrm{O}_{2}, \mathrm{CO}_{2}\right.$, and $\left.\mathrm{H}_{2} \mathrm{O}\right)$ to arrive at and to penetrate into the bed of DRI. Turbulence in the free board promotes mass transfer of oxidants to the bed of DRI, and therefore, increases the risk of re-oxidation of sponge iron.

The results of four series of reduction experiments are be reported in this Chapter. Series $A$ and $B$ were probing in nature to gain a feeling of system. Series $C$ was based on data of Series A and B with some fine tuning of experimental conditions. In all three sets of experiments, taconite concentrate and various types of coals were used. In Series D, selective waste oxides and a number of mixtures were investigated

\section{\$4.1 Common Features in All Reduction Experiments}

There are two types of laboratory practice which are common to all experiments, and should be explained once for all.

"Two levels" temperature control in the muffle furnace, see Figure 3-1 is relatively simple, and is accomplished by changing the setting of the temperature controller. In the first five minutes it was controlled at $1200^{\circ} \mathrm{C}$, then raised to $1500^{\circ} \mathrm{C}$. In the natural gasfired furnace, the temperature control is done by changing the flow rate of natural gas, 
that is the rate of heat input to the furnace. The volumetric ratio of air to natural gas is fixed at 10 to 1 in the primary combustion chamber all the time to insure that it is more than the stoichiometric requirement for full combustion of the fuel. In view of the amount of air sucked in through the hole for observation and flame detection, there is enough oxygen to burn all $\mathrm{CO}$ and $\mathrm{H}_{2}$ generated in the bed. This situation was confirmed from time to time by gas sampling and analysis. In the section $\$ 2.3$, the locations of thermocouples and gas sampling ports are shown and intended purposes were given. From the data logging, in a typical reduction experiment with taconite concentrate in the pellets, the changes of temperatures and chemical composition of gaseous phases as a function of reduction time are shown in Figure 4-1 and Figure 4-2.

"Three layers" of DRI in the bed are separated and analyzed to sharpen up our examination and evaluation of experimental results. In a shallow bed (20 to $25 \mathrm{~mm}$ height and 1 to 2 layers of agglomerates), as in some commercial practice, it is difficult to take care of the top and the bottom of the bed simultaneously. When the top layer is done and before the re-oxidation begins, the bottom is not ready yet and will become very dusty in subsequent handling. If the residence time is long enough to reduce iron oxides in the pellets at the bottom of the bed and to gain compression strength, then, the top layer DRI would suffer significant re-oxidation. Assuming both types of problems remain when the bed height and process temperature are raised to higher values, the top and the bottom layers will become smaller fractions of the whole bed as the height increases. The consequence is that the properties of the whole bed will be less sensitive to the problem at the top and that at the bottom layers. For the development of the tall bed process, the monitoring of progress at the top and at the bottom of bed are very important for excellence, even though not necessary for adequacy. Samples taken from a DRI bed are classified as (1) the top layer, (2) the bottom portion and (3) the rest of the bed "main body".

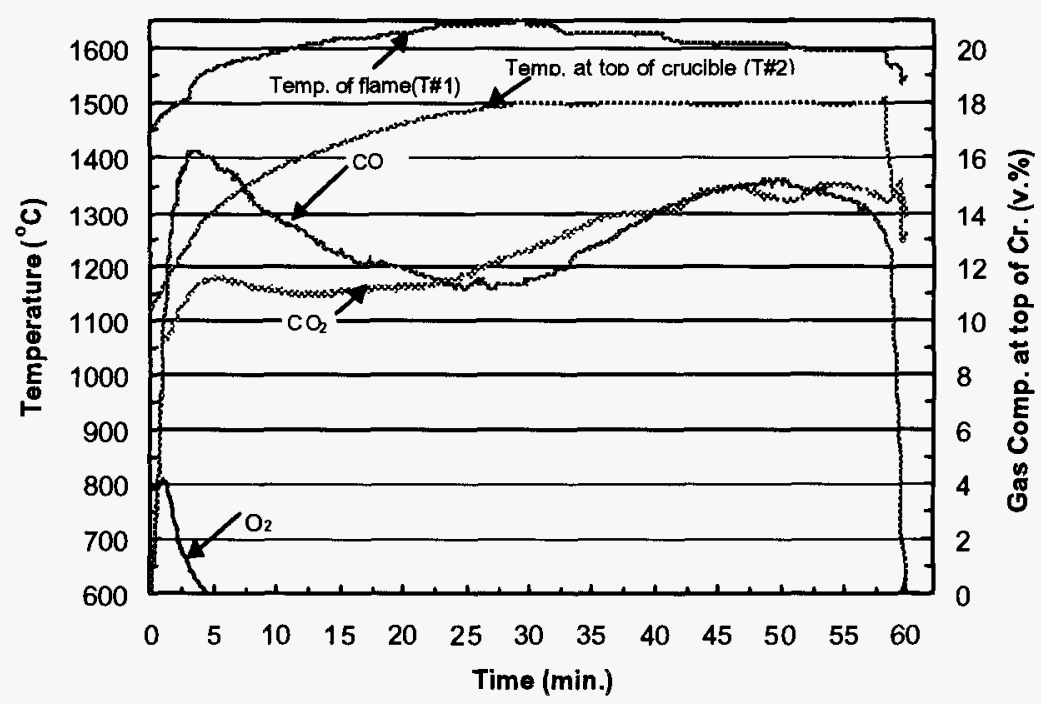

Figure 4-1. A typical direct measurement of temperatures and gas compositions at the top of the crucible (Green ball: Taconite + Marfork coal, $\mathrm{C} / \mathrm{O}=0.9$, bed height $120 \mathrm{~mm}$ ) 


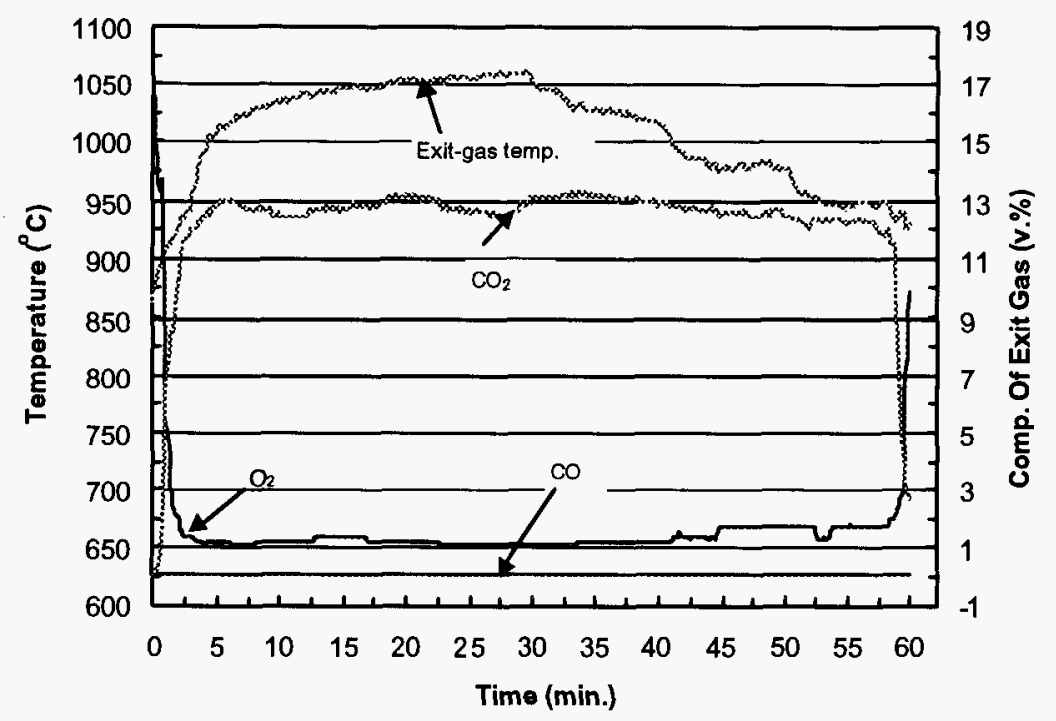

Figure 42. A typical direct measurement of temperatures and gas compositions of exit gas (Green ball: Taconite + Marfork coal, $\mathrm{C} / \mathrm{O}=0.9$, bed height $120 \mathrm{~mm}$ )

During discharging, the DRI-containing crucible is taken out of the natural gas-fired furnace and placed into the discharger to separate the DRI from the crucible and to cool the DRI bed, see Figure 327. The appearance of DRI bed has led people around the laboratory calling it "the cake" (see Figure 4-3). It is very similar to the cake we see at the discharge of indurated pellets at mines and at sinter plants. The cake breaks up in subsequent handling. In the sampling of DRI cake, the first step is to lift the cake to find the loose balls of DRI at the bottom. These loose balls are classified as "the bottom portion" which are weighted and sampled for chemical analysis and density measurement. The top layer DRI of the cake are hand-picked and the weight calculated from the numbers of calibrated pellets in the top layers. The weight of the main body is obtained by subtracting that of top layer from the weight of the cake without those loose balls. The sampling of DRI in the main body is carefully carried out to make sure that DRI at different height in the bed are properly represented.

Procedure of chemical analysis will be given in the next chapter. 


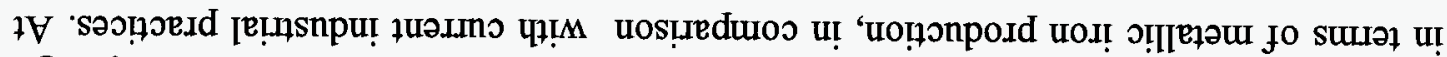

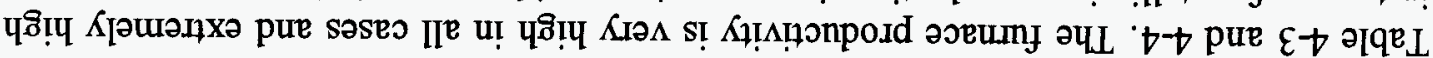

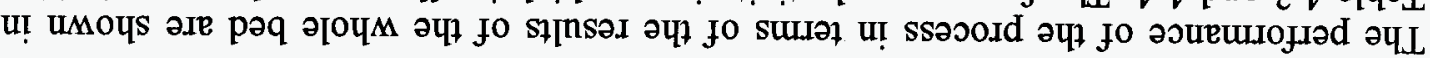

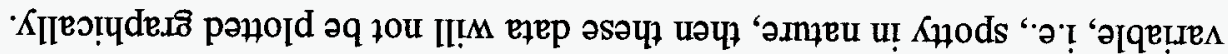

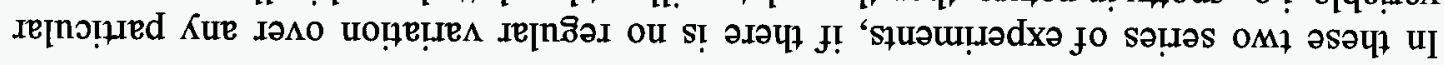

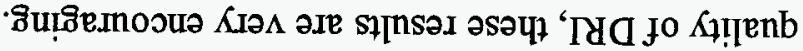

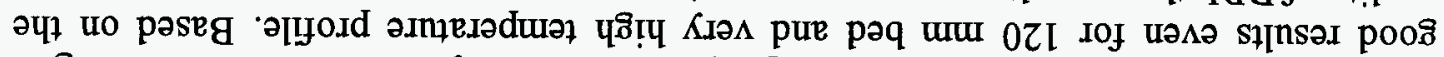

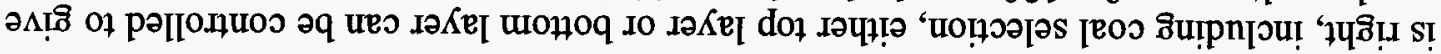

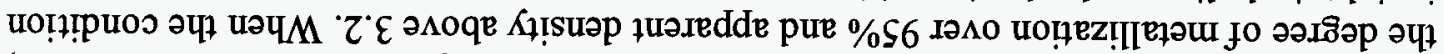

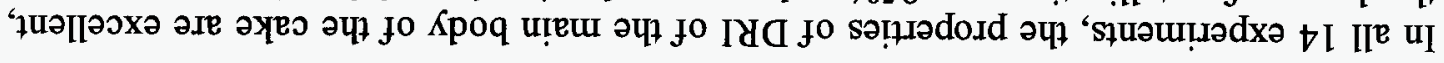

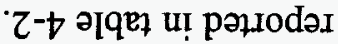

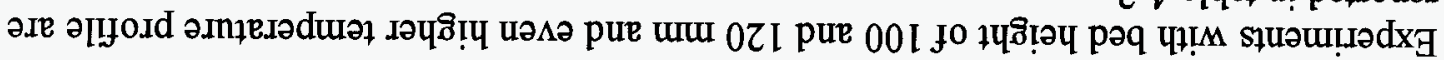

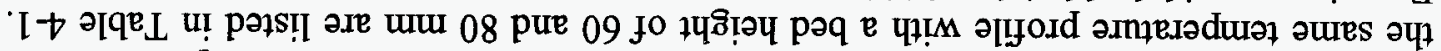

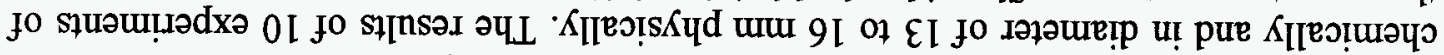

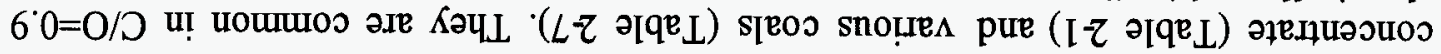

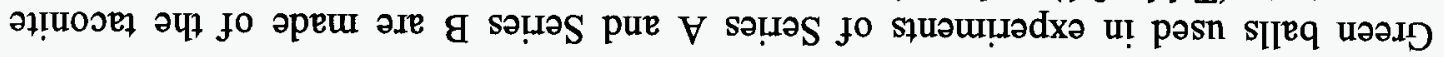

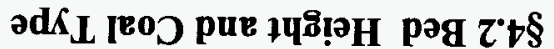

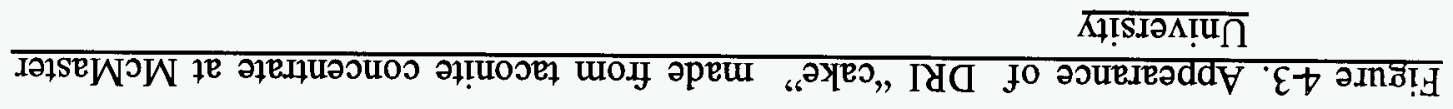

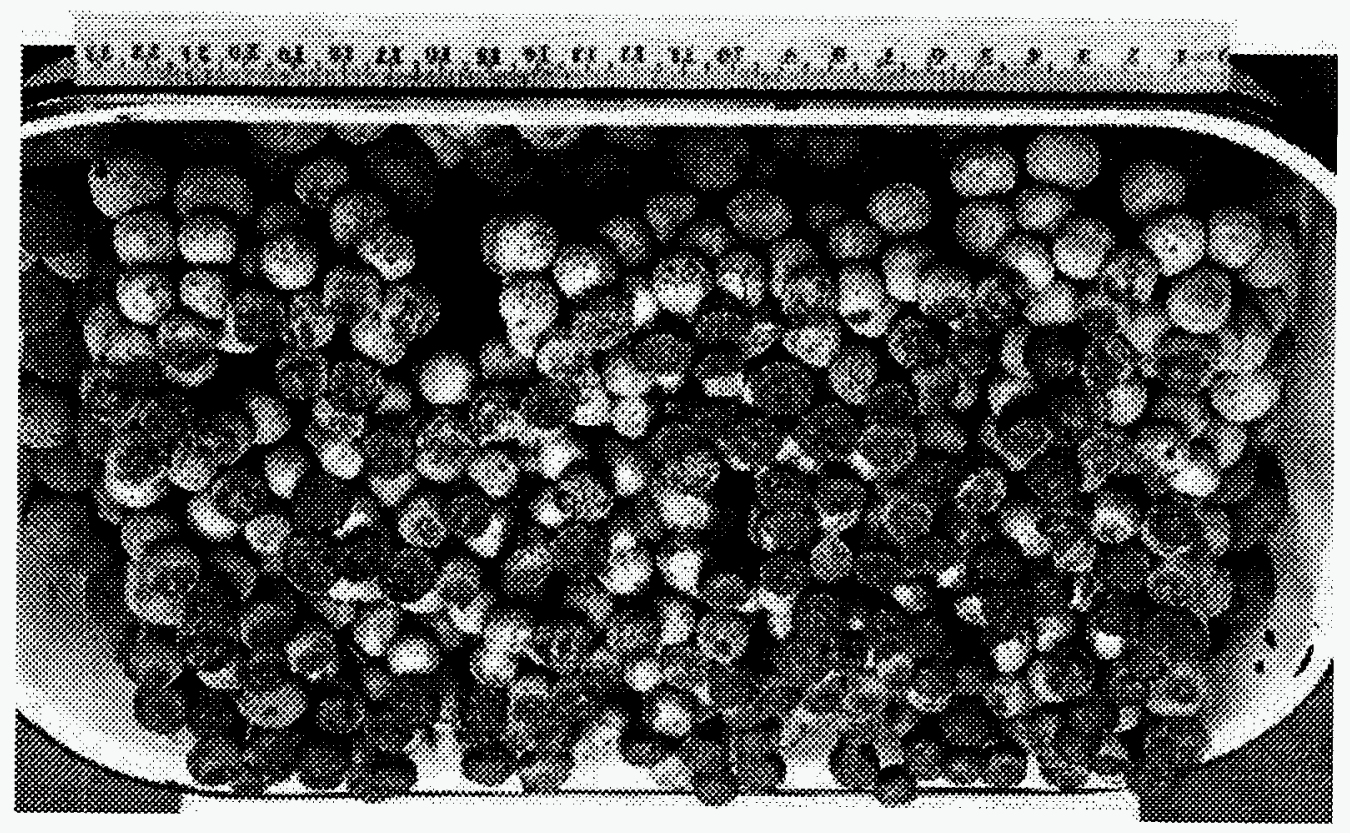


this preliminary stage, one could state that based on this new technology, DRI denser than the steelmaking slag with a degree of metallization over $95 \%$ may be produced consistently.

Table 4-1 Chemical Analysis and Density of DRI of Series A

\begin{tabular}{|c|c|c|c|c|c|c|c|c|c|}
\hline $\begin{array}{l}\text { Exp. } \\
\text { No }\end{array}$ & $\begin{array}{c}\text { Bed } \\
\text { Height } \\
(\mathrm{mm}) \\
\end{array}$ & Coal & $\begin{array}{c}\text { Temp. } \\
\text { /Time } \\
\left({ }^{\circ} \mathrm{C} / \mathrm{min}\right)\end{array}$ & $\begin{array}{l}\text { Location of } \\
\text { sampling* }\end{array}$ & $\begin{array}{c}\mathrm{TFe} \\
\text { (wt.\%) } \\
\end{array}$ & $\begin{array}{c}\mathrm{MFe} \\
\text { (wt.\%) }\end{array}$ & \begin{tabular}{|c|} 
Met. \\
Degree \\
$(\%)$ \\
\end{tabular} & $\begin{array}{c}\text { Residual } \\
\text { Carbon } \\
\text { (wt.\%) }\end{array}$ & $\begin{array}{l}\text { Density } \\
\left(\mathrm{g} / \mathrm{cm}^{3}\right)\end{array}$ \\
\hline \multirow{3}{*}{ A-4 } & \multirow{3}{*}{60} & \multirow{3}{*}{ Pinnacle } & \multirow{3}{*}{$\begin{array}{c}1250 \sim 1500 \\
/ 25\end{array}$} & Top Layer & 85.8 & 77.1 & 89.9 & 0.11 & 4.32 \\
\hline & & & & Middle Body & 85.4 & 81.6 & 95.6 & 1.31 & 3.22 \\
\hline & & & & Bottom Portion & 78.8 & 61.2 & 77.7 & 6.52 & 2.10 \\
\hline \multirow{3}{*}{ A-5 } & \multirow{3}{*}{60} & \multirow{3}{*}{ Coal \#3 } & \multirow{3}{*}{$\begin{array}{c}1250 \sim 1500 \\
/ 25\end{array}$} & Top Layer & 85.4 & 76.8 & 89.9 & 0.03 & 4.20 \\
\hline & & & & Middle Body & 82.5 & 78.7 & 95.4 & 0.66 & 3.73 \\
\hline & & & & Bottom Portion & 73.6 & 58.8 & 79.8 & 6.84 & 1.97 \\
\hline \multirow{3}{*}{ A-1 } & \multirow{3}{*}{60} & \multirow{3}{*}{ Pinnacle } & \multirow{3}{*}{$\begin{array}{c}1250 \sim 1500 \\
/ 30\end{array}$} & Top Layer & 86.9 & 79.4 & 91.4 & 0.07 & 3.77 \\
\hline & & & & Middle Body & 86.3 & 82.6 & 95.7 & 0.29 & 3.46 \\
\hline & & & & Bottom Portion & 81.6 & 72.4 & 88.7 & 3.78 & 2.15 \\
\hline \multirow{3}{*}{ A-6 } & \multirow{3}{*}{60} & \multirow{3}{*}{ Coal \#3 } & \multirow{3}{*}{$\begin{array}{c}1250 \sim 1500 \\
/ 30\end{array}$} & Top Layer & 86.8 & 77.6 & 89.4 & 0.05 & 4.46 \\
\hline & & & & Middle Body & 83.1 & 79.8 & 96.0 & 0.10 & 4.09 \\
\hline & & & & Bottom Portion & 82.7 & 78.3 & 94.7 & 3.36 & 1.98 \\
\hline \multirow{3}{*}{$A-7$} & \multirow{3}{*}{80} & \multirow{3}{*}{ Pinnacle } & \multirow{3}{*}{$\begin{array}{c}1250 \sim 1500 \\
/ 35\end{array}$} & Top Layer & 87.1 & 79.4 & 91.2 & 0.02 & 4.04 \\
\hline & & & & Middle Body & 85.5 & 82.1 & 96.0 & 1.59 & 3.30 \\
\hline & & & & 1 Portion & 71.7 & 53.4 & 74.9 & 8.75 & 1.92 \\
\hline \multirow{3}{*}{ A-8 } & \multirow{3}{*}{80} & \multirow{3}{*}{ Coal \#3 } & \multirow{3}{*}{$\begin{array}{c}1250 \sim 1500 \\
/ 35\end{array}$} & Top Layer & 86.8 & 76.4 & 88.0 & 0.02 & 4.26 \\
\hline & & & & Middle Body & 82.8 & 79.3 & 95.8 & 0.30 & 3.68 \\
\hline & & & & Bottom Portion & 71.8 & 52.7 & 73.5 & 7.99 & 1.97 \\
\hline \multirow{3}{*}{ A-9 } & \multirow{3}{*}{80} & \multirow{3}{*}{$\begin{array}{c}\text { Pinnacle } \\
+ \\
\text { Coal \#3 }\end{array}$} & \multirow{3}{*}{$\begin{array}{c}1250 \sim 1500 \\
/ 35\end{array}$} & Top Layer & 87.1 & 78.4 & 90.0 & 0.08 & 4.52 \\
\hline & & & & Middle Body & 83.8 & 80.6 & 96.2 & 0.74 & 3.32 \\
\hline & & & & Portion & 69.8 & 49.7 & 71.3 & 9.22 & 1.86 \\
\hline \multirow{3}{*}{ A-10 } & & & & Top Layer & 86.4 & 73.2 & 84.7 & 0.02 & 4.53 \\
\hline & 80 & Pinnacle & $50 \sim 1500$ & \begin{tabular}{|l} 
Middle Body \\
\end{tabular} & 86.8 & 83.7 & 96.4 & 0.43 & 3.69 \\
\hline & & & & Bottom Portion & 77.2 & 62.8 & 81.4 & 6.96 & 2.14 \\
\hline & & & & Top La & 88.4 & 77.9 & 88.1 & 0.02 & 5.05 \\
\hline A-2 & 80 & Coal \#3 & $1250 \sim 1500$ & \begin{tabular}{|l|} 
Middle Body \\
\end{tabular} & 84.3 & 80.2 & 95.1 & 0.19 & 4.43 \\
\hline & & & & Bottom Portion & 79.0 & 69.8 & 88.3 & 4.40 & 2.04 \\
\hline & & & & Top Layer & 87.3 & 79.2 & 90.8 & 0.02 & 4.96 \\
\hline 11 & 80 & & $1250 \sim 1500$ & Middle Body & 85.0 & 81.7 & 96.1 & 0.06 & 3.97 \\
\hline & & & & Bottom Portion & 75.0 & 59.4 & 79.2 & 8.04 & 1.81 \\
\hline
\end{tabular}


Table 4-2 Chemical Analysis and Density of DRI of Series B

\begin{tabular}{|c|c|c|c|c|c|c|c|c|c|}
\hline $\begin{array}{l}\text { Exp. } \\
\text { No } \\
\end{array}$ & $\begin{array}{l}\text { Bed } \\
\text { Height } \\
(\mathrm{mm})\end{array}$ & Coal & $\begin{array}{c}\text { Temp. } \\
\text { /Time } \\
\left({ }^{\circ} \mathrm{C} / \mathrm{min}\right)\end{array}$ & $\begin{array}{l}\text { Location of } \\
\text { sampling* }\end{array}$ & $\begin{array}{c}\text { TFe } \\
\text { (wt.\%) }\end{array}$ & $\begin{array}{l}\text { MFe } \\
\text { (wt.\%) }\end{array}$ & $\begin{array}{c}\text { Met. } \\
\text { Degree } \\
(\%)\end{array}$ & $\begin{array}{c}\text { Residual } \\
\text { Carbon } \\
\text { (wt. \%) }\end{array}$ & $\begin{array}{l}\text { Density } \\
\left(\mathrm{g} / \mathrm{cm}^{3}\right)\end{array}$ \\
\hline \multirow{3}{*}{ B-1 } & \multirow{3}{*}{100} & \multirow{3}{*}{ Pinnacle } & \multirow{3}{*}{$\begin{array}{c}1250 \sim 1500 \\
150\end{array}$} & Top La & 89.2 & 83.6 & 85.1 & 0.04 & 4.30 \\
\hline & & & & Middle Body & 87.2 & 83.8 & 98.4 & 0.12 & 3.91 \\
\hline & & & & Bottom Portion & 76.0 & 61.4 & 80.8 & 7.17 & 1.80 \\
\hline \multirow{3}{*}{ B-2 } & \multirow{3}{*}{120} & \multirow{3}{*}{ Pinnacle } & \multirow{3}{*}{$\begin{array}{c}1250 \sim 1500 \\
/ 60\end{array}$} & Top Layer & 89.4 & 76.9 & 86.0 & 0.03 & 4.35 \\
\hline & & & & Middle Body & 86.2 & 83.5 & 96.6 & 0.18 & 4.23 \\
\hline & & & & Bottom Portion & 73.0 & 49.1 & 67.3 & 8.69 & 1.72 \\
\hline \multirow{3}{*}{ B-3 } & \multirow[t]{3}{*}{120} & \multirow{3}{*}{ Coal \#3 } & \multirow{3}{*}{$\begin{array}{c}1350 \sim 1500 \\
/ 50\end{array}$} & Top Layer & 88.8 & 85.6 & 96.4 & 0.04 & 5.28 \\
\hline & & & & Middle Body & 83.6 & 79.4 & 95.0 & 0.59 & 4.01 \\
\hline & & & & Bottom Portion & 76.8 & 69.2 & 90.1 & 8.51 & 1.58 \\
\hline \multirow{3}{*}{ B-4 } & \multirow{3}{*}{120} & \multirow{3}{*}{ Coal \#3 } & \multirow{3}{*}{$\begin{array}{c}1400 \sim 1500 \\
/ 60\end{array}$} & Top Layer & 90.4 & 87.7 & 97.0 & 0.02 & 5.95 \\
\hline & & & & Middle Body & 85.4 & 84.0 & 98.4 & 0.22 & 4.17 \\
\hline & & & & Bottom Portion & 80.9 & 76.2 & 94.2 & 9.05 & 1.57 \\
\hline
\end{tabular}


Table 4-3 Weighted Average of Degree of Metallization, Productivity and Density of DRI of Series A

\begin{tabular}{|c|c|c|c|c|c|c|c|c|c|}
\hline \multirow{2}{*}{$\begin{array}{l}\text { Exp. } \\
\text { No }\end{array}$} & \multirow{2}{*}{$\begin{array}{c}\text { Bed } \\
\text { Height } \\
(\mathrm{mm})\end{array}$} & \multirow[t]{2}{*}{ Coal } & \multirow{2}{*}{$\begin{array}{l}\text { Temp. } \\
\text { /Time } \\
\left({ }^{\circ} \mathrm{C} / \mathrm{min}\right)\end{array}$} & \multirow{2}{*}{$\begin{array}{c}\text { Average } \\
\text { TFe } \\
\left(\mathrm{w} . \mathrm{t}^{\mathrm{o}} \%\right)\end{array}$} & \multirow{2}{*}{$\begin{array}{c}\text { Average } \\
\text { Met. } \\
\text { Degree } \\
(\%)\end{array}$} & \multicolumn{3}{|c|}{$\begin{array}{c}\text { Productivity } \\
\left(\mathrm{kg} / \mathrm{m}^{2} \mathrm{hr}\right)\end{array}$} & \multirow{2}{*}{$\begin{array}{l}\text { Average } \\
\text { Density } \\
\left(\mathrm{g} / \mathrm{cm}^{3}\right)\end{array}$} \\
\hline & & & & & & $\begin{array}{c}\text { Gree } \\
\mathrm{n} \\
\text { Ball } \\
\end{array}$ & DRI & $\begin{array}{c}\mathrm{MF} \\
\mathrm{e}\end{array}$ & \\
\hline$\overline{A-4}$ & 60 & Pinnacle & $\begin{array}{c}1250 \sim 1500 \\
/ 25\end{array}$ & 83.6 & 89.4 & 185 & 123 & 92 & 3.13 \\
\hline$A-5$ & 60 & Coal \#3 & $\begin{array}{c}1250 \sim 1500 \\
/ 25\end{array}$ & 80.8 & 90.4 & 185 & 130 & 95 & 3.37 \\
\hline$\overline{A-1}$ & 60 & Pinnacle & $\begin{array}{c}1250 \sim 1500 \\
130\end{array}$ & 85.0 & 93.7 & 154 & 99 & 79 & 3.32 \\
\hline A-6 & 60 & Coal \#3 & $\begin{array}{c}1250 \sim 1500 \\
/ 30\end{array}$ & 83.8 & 94.4 & 154 & 104 & 81 & 3.85 \\
\hline$A-7$ & 80 & Pinnacle & $\begin{array}{c}1250 \sim 1500 \\
/ 35\end{array}$ & 82.8 & 90.5 & 175 & 119 & 89 & 3.02 \\
\hline A-8 & 80 & Coal \#3 & $\begin{array}{c}1250 \sim 1500 \\
/ 35\end{array}$ & 80.4 & 88.5 & 175 & 124 & 88 & 3.30 \\
\hline$A-9$ & 80 & $\begin{array}{c}\text { Pinnacle } \\
+ \\
\text { Coal \#3 }\end{array}$ & $\begin{array}{c}1250 \sim 1500 \\
/ 35\end{array}$ & 79.9 & 87.3 & 175 & 124 & 86 & 3.05 \\
\hline $\mathrm{A}-10$ & 80 & Pinnacle & $\begin{array}{c}1250 \sim 1500 \\
/ 40\end{array}$ & 84.9 & 91.7 & 154 & 101 & 79 & 3.52 \\
\hline A-2 & 80 & Coal \#3 & $\begin{array}{c}1250 \sim 1500 \\
/ 40\end{array}$ & 84.4 & 93.3 & 154 & 101 & 80 & 4.27 \\
\hline A-11 & 80 & $\begin{array}{c}\text { Pinnacle } \\
+ \\
\text { Coal \#3 } \\
\end{array}$ & $\begin{array}{c}1250 \sim 1500 \\
/ 40\end{array}$ & 83.4 & 92.2 & 154 & 105 & 78 & 3.81 \\
\hline
\end{tabular}

Table 4-4 Weighted Average of Degree of Metallization, Productivity and Density of DRI of Series B

\begin{tabular}{|c|c|c|c|c|c|c|c|c|c|}
\hline \multirow{2}{*}{$\begin{array}{l}\text { Exp. } \\
\text { No }\end{array}$} & \multirow{2}{*}{$\begin{array}{c}\text { Bed } \\
\text { Height } \\
(\mathrm{mm})\end{array}$} & \multirow[t]{2}{*}{ Coal } & \multirow{2}{*}{$\begin{array}{l}\text { Temp. } \\
\text { Time } \\
\left({ }^{\circ} \mathrm{C} / \mathrm{min}\right)\end{array}$} & \multirow{2}{*}{$\begin{array}{c}\text { Average } \\
\text { TFe } \\
\text { (w.t } \% \text { ) }\end{array}$} & \multirow{2}{*}{$\begin{array}{c}\text { Average } \\
\text { Met. } \\
\text { Degree } \\
(\%)\end{array}$} & \multicolumn{3}{|c|}{$\begin{array}{l}\text { Productivity } \\
\left(\mathrm{kg} / \mathrm{m}^{2} \mathrm{hr}\right)\end{array}$} & \multirow{2}{*}{$\begin{array}{l}\text { Average } \\
\text { Density } \\
\left(\mathrm{g} / \mathrm{cm}^{3}\right)\end{array}$} \\
\hline & & & & & & $\begin{array}{c}\text { Gree } \\
\text { n } \\
\text { Ball }\end{array}$ & $\begin{array}{c}\mathrm{DR} \\
\mathrm{I}\end{array}$ & $\begin{array}{c}\mathrm{MF} \\
\mathrm{e}\end{array}$ & \\
\hline B-1 & 100 & Pinnacle & $\begin{array}{c}1250 \sim 1500 \\
/ 50\end{array}$ & 84.1 & 91.4 & 154 & 107 & 82 & 3.32 \\
\hline B-2 & 120 & Pinnacle & $\begin{array}{c}1250 \sim 1500 \\
/ 60\end{array}$ & 82.4 & 86.2 & 154 & 107 & 76 & 3.45 \\
\hline B-3 & 120 & Coal \#3 & $\begin{array}{c}1350 \sim 1500 \\
/ 60\end{array}$ & 82.7 & 94.1 & 154 & 105 & 82 & 3.64 \\
\hline B-4 & 120 & Coal \#3 & $\begin{array}{c}1400 \sim 1500 \\
/ 60\end{array}$ & 85.1 & 97.5 & 154 & 102 & 85 & 3.91 \\
\hline
\end{tabular}




\section{\$4.3 Chemical Compositions of Green Balls}

In Series C experiments, the common features are: bed height $120 \mathrm{~mm}$, total heating time 60 minutes, control of temperature profile: 5 minutes in the range of $1100^{\circ}$ to $1250^{\circ} \mathrm{C}$, then rise to $1500^{\circ} \mathrm{C}$ at the top of the crucible, and the green ball diameter of 16 to $20 \mathrm{~mm}$.

In experiments $\mathrm{C} 1$ to $\mathrm{C} 3$, the variable parameter, $\mathrm{C} / \mathrm{O}$ ratio varied from 0.95 down to 0.80 . For the same value of $\mathrm{C} / \mathrm{O}=0.9$, the volatile matter content in the reductant in Experiment $\mathrm{C} 2$, C4, and C5 was $30.8,27.2$ and to $23.6 \%$, respectively. In experiment C6 and $\mathrm{C} 7$, the iron-bearing materials were mixtures of waste oxides and taconite concentrate instead of taconite concentrate only. In experiment $\mathrm{C} 6$, it was made up of $20 \%$ BOF sludge and 80\% taconite concentrate and Experiment C7, 20\% EAF dust from Dofasco and balance taconite concentrate.

As in $\$ 4.2$, there are two types of data available from these experiments, i.e., characterization of DRI in three layers (Tables 4-1 and 4-2) and performance of the bed as a whole (Table 4-3 and 4-4). These two types of information of Series $\mathrm{C}$ are listed in a composite table, Table 4-5. For Experiment $\mathrm{C} 1$ to $\mathrm{C5}$, in terms of degree of metallization and density of DRI for the whole bed, the results are exc ellent for the ranges of $\mathrm{C} / \mathrm{O}$ ratio and volatile matter content in the reductant investigated. The slight drop in the degree of metallization of the top layer in $\mathrm{C} 3$ and $\mathrm{C} 5$ is the sign of weakening of the protection from re-oxidation by the upward-stream gas flow. It indicates that, for coal of $30.8 \%$ volatile matter, the value of $\mathrm{C} / \mathrm{O}=0.8$ is close to its lower limit; for $\mathrm{C} / \mathrm{O}=0.9$ the lower limit of volatile matter content is about $23.6 \%$.

Other than iron-bearing materials, experimental conditions in Experiments C2, C6 and C7 are comparable. It is clear that the presence of waste oxide has an adverse effect. The lower value of the degree of metallization of the top layer in Experiment C6 is due to slag formation and melting of the top layer; and that in the bottom layer of Experiment $\mathrm{C} 7$ is due to the swelling of pellets during reduction which hinders radiative heat transfer. 


\begin{tabular}{|c|c|c|c|c|c|c|c|c|c|}
\hline $\begin{array}{l}\text { Exp. } \\
\text { No. }\end{array}$ & Conditions & $\begin{array}{l}\mathrm{TFe} \\
(\%)\end{array}$ & $\begin{array}{l}\mathrm{MFe} \\
(\%)\end{array}$ & $\begin{array}{l}\text { M.D } \\
(\%)\end{array}$ & $\begin{array}{l}\mathrm{C} \\
(\%)\end{array}$ & $\begin{array}{c}\text { Dens. } \\
\left(\mathrm{g} / \mathrm{cm}^{3}\right)\end{array}$ & $\begin{array}{r}\begin{array}{r}\text { Weight } \\
\text { Fraction }\end{array} \\
\frac{(\%)}{}\end{array}$ & \multicolumn{2}{|c|}{$\begin{array}{c}\text { Average value } \\
\text { of the whole } \\
\text { bed }\end{array}$} \\
\hline $\mathrm{C} 1-\mathrm{T}$ & \multirow{3}{*}{$\begin{array}{c}\mathrm{C} / \mathrm{O}=0.95, \text { Tac., } \\
\text { Marfork,120/60 } \\
\text { Volatile Matter: } \\
30.8 \%\end{array}$} & 88.80 & 83.39 & 93.91 & 0.019 & 4.51 & 11.97 & $\mathrm{MD}$ & 96.92 \\
\hline $\mathrm{C} 1-\mathrm{M}$ & & 86.09 & 84.39 & 98.02 & 0.06 & 4.13 & 62.46 & $\mathrm{C}$ & 1.5 \\
\hline C1-B & & 80.68 & 77.17 & 95.65 & 5.70 & 1.41 & 25.57 & Dens & 3.48 \\
\hline $\mathrm{C} 2-\mathrm{T}$ & \multirow{3}{*}{$\begin{array}{c}\mathrm{C} / \mathrm{O}=0.90, \text { Tac. } \\
\text { Marfork, } 120 / 60 \\
\text { Volatile Matter: } \\
\mathbf{3 0 . 8 \%}\end{array}$} & 88.70 & 86.39 & 97.40 & 0.025 & 4.55 & 11.90 & $\mathrm{MD}$ & 98.97 \\
\hline $\mathrm{C} 2-\mathrm{M}$ & & 84.49 & 83.79 & 99.17 & 0.179 & 4.14 & 72.56 & $\mathrm{C}$ & 0.77 \\
\hline $\mathrm{C} 2-\mathrm{B}$ & & 80.78 & 80.18 & 99.26 & 4.11 & 1.86 & 15.55 & Dens & 3.83 \\
\hline $\mathrm{C} 3-\mathrm{T}$ & \multirow{3}{*}{$\begin{array}{c}\mathrm{C} / \mathrm{O}=0.80, \text { Tac. } \\
\text { Marfork, } 120 / 60 \\
\text { Volatile Matter: } \\
30.8 \%\end{array}$} & 82.99 & 72.96 & 87.92 & 0.029 & 5.20 & 12.31 & $\mathrm{MD}$ & 95.91 \\
\hline C3-M & & 81.68 & 79.18 & 96.93 & 0.115 & 3.65 & 75.05 & $\mathrm{C}$ & 0.26 \\
\hline C3-B & & 80.88 & 78.98 & 97.65 & 1.37 & 2.50 & 12.63 & Dens & 3.70 \\
\hline $\mathrm{C} 4-\mathrm{T}$ & \multirow{3}{*}{$\begin{array}{c}\mathrm{C} / \mathrm{O}=0.90, \text { Tac. } \\
\text { Marfork/Pinnaci } \\
\text { le } \\
=75 / 25,120 / 60 \\
\text { Volatile Matter: } \\
27.2 \%\end{array}$} & 89.10 & 85.99 & 96.51 & 0.026 & 5.12 & 12.00 & $\mathrm{MD}$ & 98.30 \\
\hline C4-M & & 86.09 & 84.79 & 98.49 & 0.345 & 3.58 & 70.64 & $\mathrm{C}$ & 1.02 \\
\hline C4-B & & 80.88 & 79.88 & 98.76 & 4.43 & 2.13 & 17.36 & Dens & 3.51 \\
\hline $\mathrm{C} 5-\mathrm{T}$ & \multirow{3}{*}{$\begin{array}{c}\mathrm{C} / \mathrm{O}=0.90, \text { Tac., } \\
\text { Marfork/Pinnaci } \\
\text { le } \\
=50 / 50,120 / 60 \\
\text { Volatile Matter: } \\
23.6 \%\end{array}$} & 89.50 & 79.18 & 88.47 & 0.023 & 4.51 & 11.85 & $\mathrm{MD}$ & 95.40 \\
\hline C5-M & & 85.29 & 81.98 & 96.12 & 1.54 & 4.13 & 73.09 & $\mathrm{C}$ & 2.05 \\
\hline C5-B & & 78.88 & 76.77 & 97.33 & 6.11 & 1.41 & 15.06 & Dens & 3.77 \\
\hline $\mathrm{C}-6-\mathrm{T}$ & \multirow{3}{*}{$\begin{array}{c}20 \% \mathrm{BOF} \\
\text { Sludge }+80 \% \\
\text { Taconite, } \\
\text { Marfork, } \\
\mathrm{C} / \mathrm{O}=0.9,120 / 60 \\
\end{array}$} & 88.30 & 72.76 & 82.41 & 0.027 & 4.76 & 11.60 & MD & 94.16 \\
\hline C-6-M & & 81.48 & 78.78 & 96.68 & 0.242 & 4.03 & 72.77 & $\mathrm{C}$ & 0.93 \\
\hline$C-6-B$ & & 79.18 & 72.16 & 91.14 & 4.79 & 2.12 & 15.64 & Dens & 3.82 \\
\hline $\mathrm{C}-7-\mathrm{T}$ & \multirow{3}{*}{$\begin{array}{c}20 \% \mathrm{EAF}+80 \% \mathrm{~T} \\
\text { ac., Marfork, } \\
\mathrm{C} / \mathrm{O}=0.9,120 / 60\end{array}$} & 86.69 & 81.18 & 93.64 & 0.018 & 4.99 & 11.24 & $\mathrm{MD}$ & 91.72 \\
\hline C-7-M & & 79.48 & 73.87 & 92.94 & 0.047 & 4.44 & 62.00 & $\mathrm{C}$ & 1.40 \\
\hline C-7-B & & 70.76 & 62.34 & 88.10 & 5.13 & 2.27 & 26.76 & Dens & 3.92 \\
\hline
\end{tabular}

Table 4.5 Chemical analysis of DRI in the layers and performance of the whole bed 


\section{§4.4 The Processing of Waste Oxides for Recycling}

Waste oxides are being generated at several spots and of different properties within a steel plant. There are two basic approaches in handling waste oxides. When the waste oxides from different production units have different contaminants of different toxicity which require different treatment, therefore, then mixing of waste oxides should be avoided. The other extreme is dumping all the garbage on a big pile and hope that somehow, raw materials for a recycling process can be obtained from that pile.

In the recycling of waste oxides generated in carbon steel plants, Electric Arc Furnace (EAF) dust has the top priority. Unfortunately, the physical and chemical properties of EAF dust make this task very difficult. Physically, it is extremely fine, very much submicron size. Chemically, the gangue phases are of low melting points, particularly, the chlorides. Briquetting could avoid the challenge of pelletization; however, the problem arising from chemical composition remains. In order to solve this problem, one of the ways is by dilution, i.e., mixing EAF dust with coarse and cleaner iron-bearing materials. However, it must be pointed out that iron ores (particularly hematite concentrate) are not among the candidates for this role based on our work on mechanism of iron ore reduction. Experiment $\mathrm{C} 7$ has confirmed this concern.

In the experiments of Series D, three types of waste oxides of significant amount were investigated, i.e., EAF dust, BOF (Blast Oxygen Furnace) sludge and mill scale (for chemical compositions, see Table 2.3 to 2.5 ).

The results of 10 experiments in Series D are listed in Table 4.6. The size of green balls used in these experiments were in the range of 16 to $20 \mathrm{~mm}$ in diameter. Experimental conditions including the composition of green balls, bed height and total heating time are listed in the second column of Table 4.6.

In Experiments D8 and D9, BOF sludge was the only iron-bearing material in the green balls. In comparison with similar cases with taconite concentrate, higher $\mathrm{C} / \mathrm{O}$ ratio is required $(\mathrm{C} / \mathrm{O}=1.0$ instead of $\mathrm{C} / \mathrm{O}=0.9)$ because of the presence of more ferrous oxide (which is more difficult to reduce than ferric oxide). The bottom layer of this $120 \mathrm{~mm}$ bed was very good in terms of degree of metallization (94.6\% and $98.95 \%$ ) (after the relining of furnace). The binary mixtures of mill scale and BOF sludge were investigated in Experiments D1 and D2. In comparison with the case with taconite concentrate, the same experimental conditions result in comparable results.

Based on one of the mechanisms of swelling during reduction, we anticipated problems with pellets containing a mixture of EAF dust and mill scale (see Experiment D3 in Table 4.6). The bottom portion of DRI bed in Experiment D3 is large in quantity and low in the degree of metallization, same as Experiment $\mathrm{C} 7$. The swelling of partially reduced pellets hinders the heat transfer further down in the pellet bed. 
Our knowledge of the effect of calcia on the diffusion and nucleation steps of the metallization of wustite suggests that BOF sludge should be the best waste oxide to be mixed with EAF dust for improvement in reduction. Five experiments, D4 to D7r, were designed for this purpose. In comparison with the reduction of BOF sludge, mill scale and taconite concentrate, the processing temperature (in step 2 for D4 to D7r) was lower by $50^{\circ} \mathrm{C}$ from $1500^{\circ} \mathrm{C}$ to $1450^{\circ} \mathrm{C}$ and the $\mathrm{C} / \mathrm{O}$ ratio was slightly increased (from 0.9 to 1.0). In order to gasify and to remove zinc and lead in the bottom layer, the processing rate was also lowered from $100 \mathrm{~mm} / 50 \mathrm{~min}$ to $100 \mathrm{~mm} / 60 \mathrm{~min}$., and form $120 \mathrm{~mm} / 60 \mathrm{~min}$ to $120 \mathrm{~mm} / 65 \mathrm{~min}$. In all these five experiments in which EAF dust is about $1 / 3$ to $1 / 2$ of iron bearing materials, the degree of metallization of iron oxide is excellent, the removal ratio of zinc (based on mass balance) is from $85 \%$ to $99 \%$ and for lead, it is essentially complete. 
Table 4.6 Chemical analysis of DRI in the three layers and the performance of the whole bed

\begin{tabular}{|c|c|c|c|c|c|c|c|c|c|c|c|c|c|c|}
\hline \multirow[t]{2}{*}{ Exp. No. } & \multirow[t]{2}{*}{ Conditions } & \multirow{2}{*}{$\begin{array}{l}\mathrm{TFe} \\
(\%)\end{array}$} & \multirow{2}{*}{$\begin{array}{c}\mathrm{MFe} \\
(\%)\end{array}$} & \multirow{2}{*}{$\begin{array}{l}\text { M.D } \\
(\%)\end{array}$} & \multirow{2}{*}{$\begin{array}{c}\mathrm{C} \\
(\%)\end{array}$} & \multirow{2}{*}{$\begin{array}{l}\text { Dens. } \\
\left(\mathrm{g} / \mathrm{cm}^{3}\right. \\
\quad)\end{array}$} & \multirow{2}{*}{$\begin{array}{l}\text { Weight } \\
\text { Eraction } \\
(\%)\end{array}$} & \multirow{2}{*}{$\begin{array}{r}\mathrm{Zn} \\
\text { (wt. } \\
\% \text { ) }\end{array}$} & \multirow{2}{*}{$\begin{array}{c}\mathrm{Pb} \\
\text { (wt.\%) }\end{array}$} & \multirow{2}{*}{\begin{tabular}{|c|} 
Rate of \\
Zinc \\
Remova \\
1 \\
$(\%)$ \\
\end{tabular}} & \multicolumn{4}{|c|}{ Average of whole bed } \\
\hline & & & & & & & & & & & MD & $\mathrm{C}$ & $\begin{array}{l}\mathrm{Zn} \\
\mathrm{RM}\end{array}$ & $\begin{array}{c}\text { Den } \\
\text { s }\end{array}$ \\
\hline $\mathrm{D} 1-\mathrm{T}$ & \multirow{3}{*}{$\begin{array}{c}20 \% \text { BOF } \\
\text { Sludge }+80 \% \text { Mil } \\
1 \text { Scale, Marfork, } \\
\text { C/O }=0.9,120 / 60\end{array}$} & 89.90 & 82.08 & 91.30 & 2.021 & 4.70 & 12.09 & & & & 96.8 & 0.91 & & 3.82 \\
\hline D1-M & & 88.70 & 85.19 & 96.05 & 0.098 & 3.98 & 75.31 & & & & & & & \\
\hline D1-B & & 82.28 & 71.76 & 87.21 & 4.69 & 2.04 & 12.60 & & & & & & & \\
\hline $\mathrm{D} 2-\mathrm{T}$ & \multirow{3}{*}{$\begin{array}{c}50 \% \mathrm{BOF} \\
\text { Sludge+50\%Mil } \\
1 \text { Scale, Marfork, } \\
\mathrm{C} / \mathrm{O}=0.9,120 / 60\end{array}$} & 89.60 & 82.59 & 92.17 & 0.032 & 5.01 & 11.24 & & & & 96.3 & 0.28 & & 3.93 \\
\hline $\mathrm{D} 2-\mathrm{M}$ & & 86.29 & 84.59 & 98.03 & 0.045 & 4.44 & 62.00 & & & & & & & \\
\hline D2-B & & 85.99 & 80.58 & 93.71 & 0.94 & 2.31 & 26.76 & & & & & & & \\
\hline D3-T & \multirow{3}{*}{\begin{tabular}{|c|}
$20 \% \mathrm{EAF}+80 \%$ \\
Mill Scale., \\
Marfork, \\
$\mathrm{C} / \mathrm{O}=0.9,120 / 60$
\end{tabular}} & 89.50 & 85.89 & 95.97 & 0.021 & 4.99 & 11.00 & & & & 72.4 & 2.50 & & 3.93 \\
\hline D3-M & & 83.99 & 78.38 & 93.32 & 0.037 & 4.44 & 62.63 & & & & & & & \\
\hline D3-B & & 61.74 & 8.02 & 12.99 & 9.40 & 2.27 & 26.37 & & & & & & & \\
\hline $\mathrm{D} 4-\mathrm{T}$ & \multirow{3}{*}{\begin{tabular}{|c}
$50 \%$ BOF Sludge \\
$+50 \% \mathrm{EAF}$ \\
Marfork \\
$\mathrm{C} / \mathrm{O}=1.0,100 / 60$ \\
$1250 \sim 1450^{\circ} \mathrm{C}$
\end{tabular}} & 70.36 & 60.64 & 86.18 & 0.052 & 3.95 & 12.61 & 0.08 & $<0.1$ & 99.5 & 97.0 & 0.27 & 99.2 & 3.55 \\
\hline D4-M & & 71.36 & 70.36 & 98.60 & 0.238 & 3.64 & 74.63 & 0.14 & $<0.1$ & 99.2 & & & & \\
\hline D4-B & & 69.56 & 68.65 & 98.70 & 0.711 & 2.62 & 12.76 & 0.16 & $<0.1$ & 99.0 & & & & \\
\hline D5-T & \multirow{3}{*}{\begin{tabular}{|c|}
$66 \%$ BOF Sludge \\
$+34 \%$ EAF, \\
Marfork, \\
$\mathrm{C} / \mathrm{O}=1.0,100 / 60$ \\
$1250 \sim 1450^{\circ} \mathrm{C}$
\end{tabular}} & 77.87 & 73.36 & 94.21 & 0.033 & 4.66 & 12.33 & 0.01 & $<0.1$ & 99.9 & 96.5 & 0.12 & 98.16 & 3.65 \\
\hline D5-M & & 76.97 & 74.57 & 96.88 & 0.083 & 3.73 & 74.86 & 0.17 & $<0.1$ & 98.6 & & & & \\
\hline D5-B & & 74.97 & 72.36 & 96.52 & 0.386 & 2.22 & 12.81 & 0.72 & $<0.1$ & 93.9 & & & & \\
\hline
\end{tabular}




\begin{tabular}{|c|c|c|c|c|c|c|c|c|c|c|c|c|c|}
\hline D6-T & $50 \%$ BOF Sludge & 72.76 & 63.14 & 86.78 & 0.052 & 3.84 & 12.17 & 0.32 & $<0.1$ & 98. & 94.4 & 0.64 & 89.31 \\
\hline D6-M & Marfork, & 72.56 & 70.06 & 96.55 & 0.249 & 2.86 & 73.21 & 0.44 & $<0.1$ & 97. & & & \\
\hline D6-B & $\begin{array}{c}\mathrm{C} / \mathrm{O}=1.0,120 / 65 \\
1250 \sim 1450^{\circ} \mathrm{C}\end{array}$ & 60.54 & 54.32 & 89.74 & 3.10 & 1.51 & 14.63 & 8.50 & $<0.1$ & 41. & & & \\
\hline
\end{tabular}

Table 4.6 (continued)

\begin{tabular}{|c|c|c|c|c|c|c|c|c|c|c|c|c|c|c|}
\hline \multirow[t]{2}{*}{ Exp. No. } & \multirow[t]{2}{*}{ Conditions } & \multirow[t]{2}{*}{$\begin{array}{l}\mathrm{TFe} \\
(\%)\end{array}$} & \multirow[t]{2}{*}{$\begin{array}{c}\mathrm{MFe} \\
(\%)\end{array}$} & \multirow[t]{2}{*}{$\begin{array}{l}\text { M.D } \\
(\%)\end{array}$} & \multirow[t]{2}{*}{$\begin{array}{c}\mathrm{C} \\
(\%)\end{array}$} & \multirow{2}{*}{$\begin{array}{l}\text { Dens. } \\
\left(\mathrm{g} / \mathrm{cm}^{3}\right. \\
\quad)\end{array}$} & \multirow[t]{2}{*}{$\begin{array}{l}\text { Weight } \\
\text { Fraction } \\
(\%)\end{array}$} & \multirow{2}{*}{$\begin{array}{l}\mathrm{Zn} \\
\text { (wt. } \\
\% \text { ) }\end{array}$} & \multirow[t]{2}{*}{$\begin{array}{c}\mathrm{Pb} \\
(\mathrm{wt} . \%)\end{array}$} & \multirow{2}{*}{\begin{tabular}{|c} 
Rate of \\
Zinc \\
Remova \\
1 \\
$(\%)$ \\
\end{tabular}} & \multicolumn{4}{|c|}{$\begin{array}{c}\text { Average value of whole } \\
\text { bed }\end{array}$} \\
\hline & & & & & & & & & & & $\mathrm{MD}$ & $\mathrm{C}$ & $\begin{array}{l}\mathrm{Zn} \\
\mathrm{Rm}\end{array}$ & \\
\hline$-\mathrm{T}$ & $\begin{array}{r}6 \\
\text { Sluds }\end{array}$ & .28 & 1.16 & 0.91 & 0.06 & 4.19 & 11.86 & 0.11 & $<0.1$ & 99.1 & 96.1 & 0.92 & 85.34 & \\
\hline D7-M & & 76.57 & 73.77 & 6.34 & 0.15 & .61 & 72.75 & 0.28 & $<0.1$ & 97.7 & & & & \\
\hline D7-B & $1250-$ & 61.54 & 60.34 & 8.05 & 5.25 & 46 & 5.39 & 8.1 & $<0.1$ & 16.4 & & & & \\
\hline D7r-T & & 76.17 & 7 & 4 & 0.30 & 4.52 & 4 & 15 & $<0.1$ & 8 & 99.2 & 0.71 & 87.09 & \\
\hline D7r-M & & 76.37 & 75.77 & 99.21 & 0.07 & 3.58 & 72.39 & 0.37 & $<0.1$ & 96.9 & & & & \\
\hline $\mathrm{D} 7 \mathrm{r}-\mathrm{B}$ & $\begin{array}{r}\quad R_{e} \\
\text { after furr }\end{array}$ & 63.54 & 62.74 & .74 & 8 & 45 & 15.27 & 6.9 & $<0.1$ & 31.1 & & & & \\
\hline D8-T & BOF Sludge, & 84.59 & 70.96 & 83.89 & 0.026 & 4.73 & 12.59 & 0.03 & $<0.1$ & 98.7 & 94.5 & 0.07 & 96.84 & 3.6 \\
\hline D8-M & & 84.99 & 81.78 & 96.23 & 0.071 & 3.65 & 75.20 & 0.06 & $<0.1$ & 97.4 & & & & \\
\hline D8-B & $\begin{array}{r}12 \\
1250- \\
\end{array}$ & 87.30 & 82.59 & 94.60 & 0.123 & 2.34 & 12.20 & 0.20 & $<0.1$ & 91.6 & & & & \\
\hline D9-T & $\begin{array}{l}\text { BOF Sludge, } \\
\text { Marfork. }\end{array}$ & 84.79 & 81.38 & 95.98 & 0.02 & 5.05 & 12.65 & 0.05 & $<0.1$ & 97.8 & {$[98.4$} & 0.03 & 16. & .4 \\
\hline
\end{tabular}




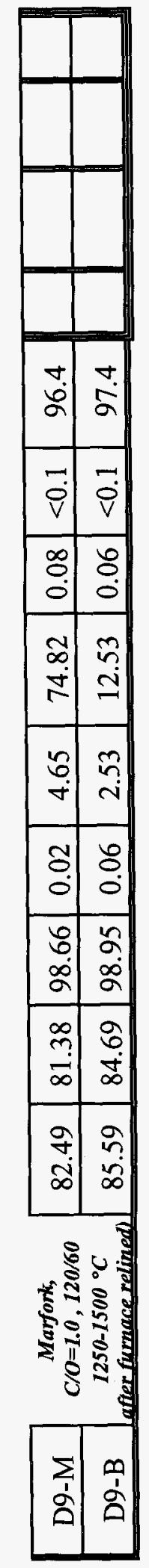

n 


\section{\$4.5 Summary}

In a laboratory natural gas-fired furnace, ore/coal pellets in a bed of $120 \mathrm{~mm}$ height and a heat size of 6 to $7 \mathrm{~kg}$ of green balls can be processed under a fully oxidized flame of $1600^{\circ}$ to $1650^{\circ} \mathrm{C}$ to produce DRI of very high quality (particularly in metallization and apparent density) in 60 minutes. BOF sludge, mill scale and mixture thereof can be processed as well as taconite concentrate. The risk of re-oxidation of sponge iron under these conditions has been practically eliminated. The process gives very good results with a wide range in the amount of coal addition and in coal properties so that the operation appears to be stable and tolerant.

EAF dust in the form of a mixture with BOF sludge may be processed by this technology successfully in both pelletization and reduction. Experimental conditions, in comparison with iron ore reduction, are slightly gentler in slower processing rate and lower processing temperature by $50^{\circ} \mathrm{C}\left(1450^{\circ} \mathrm{C}\right.$ instead of $\left.1500^{\circ} \mathrm{C}\right)$ which is compensated by slightly longer heating time. Under the experimental conditions investigated, the removal of zinc and lead from the green balls are essentially complete when the processing rate is lower, i.e. $100 \mathrm{~mm} / 60 \mathrm{~min}$. The DRIs are also of very good qualities. 


\section{§5. PILOT PLANT TRIALS AT CSM, GENOA, ITALY}

$\$ 5.1$ The Need of a Pilot Plant Trial 58

$\$ 5.2$ The Selection of a Pilot Plant $\quad 59$

$\$ 5.3$ Pilot Plant Equipment $\quad 59$

$\S 5.4$ Operational Problem of the Gas-Fired Furnace 65

$\$ 5.5$ Experimental Conditions and Procedures $\quad 67$

$\S 5.6$ Experimental Results $\quad 71$

$\$ 5.7$ Chemical Analysis of DRI $\quad 84$

$\begin{array}{lll}\S 5.8 & \text { Summary } & 90\end{array}$ 


\section{§5. PILOT PLANT TRIALS AT CSM, GENOA, ITALY}

This project started officially on April 22, 1999 to complete all proposed work. over a period of 24 months. As a result of two very important developments, pilot plant trials became a part of the agenda for meetings attended by representatives of industrial sponsors, managers of AISI Technology Roadmap Program (TRP) office and personnel of this project at McMaster University, in the period between December, 1999 and March, 2000. The International Metals Reclamation Company, Inc (INMETCO) of Elmwood City, PA, joined the consortium under AISI in supporting this project and expressed their willingness to host a pilot plant on its site. INMETCO is the first company in the world and remains to be the most successful one in commercialization of rotary hearth furnace for the recycling of waste oxides. The second development was that most of the data reported in $\S 4$ have been examined at meetings and demonstration experiments had been observed by representatives of industrial sponsors. It was generally accepted that we at McMaster University must have the luck and competence in physical chemistry and transport phenomena to come up with these successes in laboratory in a very short time. By applying the thermochemical knowledge we have, the development of a hearth furnace process of low coal rate and high furnace productivity is within our reach.

\section{\$5.1 The Need of a Pilot Plant Trial}

To build and to operate a pilot plant is clearly outside of the scope of this project; however, it should be the logical consequence. A leapfrog approach was accepted in these meetings. If we could find a pilot plant which yields data under conditions closer to the real world in industry (instead of a university campus), the commercialization of this new technology would be accelerated.

Needs of a pilot plant trial, which should be carried out soon, were established:

1. Larger heat sizes to be carried out in an industrial setting, and

2. Waste oxides recycling.

The necessity of conducting experiments in an industrial setting was perceived as the following: On campus, experiments were carried out by $\mathrm{Ph} . \mathrm{Ds}$ with modern instruments and computers. The valid question is "Can the workers at an ordinary steel plant perform the same tasks?"

The second concern is that in our laboratory at McMaster University there is no gas cleaning system. Very limited experiments with waste oxides containing very limited amount of lead were conducted on holidays. On an industrial site, meaningful tests for waste oxide recycling may be carried out. 


\section{§5.2 The Selection of a Pilot Plant}

For various reasons and after a thorough search, a decision was made collectively at a meeting with industrial representatives and AISI TRP officials that there was no pilot plant in North America which would meet our needs. We were told that the contractor in Genoa, Italy that SMS Demag used for tests of raw materials for rotary hearth furnace, has a furnace with a hearth of one half meter square. W-K. Lu made a trip to visit the Combustion Laboratory of Centro Sviluppo Materili S.P.S. (CSM), Genoa, Italy. The furnace used for tests for SMS Demag was for a heat size of a few hundred grams of pellets in the form of a shallow bed under a flame of $1300^{\circ} \mathrm{C}$ maximum. It could not be modified to suite our needs. However, the director of the pilot plant offered any furnace in the plant to us - there were many huge furnaces. A verbal agreement was reached about the use of a high temperature furnace $\left(1650^{\circ} \mathrm{C}\right)$ with a rectangular chamber fired by a natural gas burner. They would make modifications on the furnace floor for placing crucibles and raise the ceiling for proper expansion of the flame.

The setting of the pilot plant is certainly industrial and relevant. It is inside a very old steel works. CSM and the steel company were separated during privatization. The pilot plant was scheduled to move to another city in the summer and the shut-down would start with a holiday period at the end of July. A contract was signed between AISI and SMS Demag for the pilot plant services which included the preparation of raw materials, pelletization, reduction, sampling of DRI, chemical analysis, density measurement of DRI and of course, the modifications of the furnace. AISI TRP office had the budget increased including the portion at McMaster University for 3 months extension and costs for shipping of raw materials and travelling.

\section{\$5.3 Pilot plant Equipment}

As mentioned in $\S 5.2$, the pilot plant of CSM in Genoa is a contractor for SMS Demag to test the raw materials for rotary hearth furnace. This pilot plant, therefore, has the necessary auxiliary equipments for raw material mixing, pelletizing of green balls, and drying of green ball.

\section{\$5.3.1 The natural gas-fired furnace at the pilot plant}

The high temperature furnace chosen for the reduction experiments has been used to test the combustion and performance of high temperature natural gas burners. The combustion chamber of the furnace is long enough for the expansion of flame. However, vertically there were changes to be made. When crucibles were placed on the floor of the furnace the centerline of the burner was right on the top of the crucible. In industry and on campus, there is a distance between the centerline of the burner and the top of the pellet bed. Ideally, the ceiling of the chosen furnace and the position of the burner should 
move up and the floor go down. There were no metallurgists working in the pilot plant so that they were not sympathetic to our needs. When they were informed in the early part of June of 2000 that there was no point for us to do any experiments at all, they promised necessary actions would be taken.

Unfortunately, we were very surprised and disappointed after seeing that, the support for the crucibles was not designed/constructed properly. The support of the crucibles was based on a frame which consisted of four big square pipes ( $40 \mathrm{~mm}$ by $40 \mathrm{~mm}$ ) with strong water cooling which were very close to the bottom of the crucible (see Figure 5-1). The negative effect of this strong water cooling on the reduction of the bottom layer of ore/coal pellets will be shown in the following sections.

The appearance of the modified high temperature furnace is shown in Figure 5-2 and its specifics are listed in Table 5-1.

Table 5-1. Specifics of the Natural Gas-fired Furnace used for reduction experiments

\begin{tabular}{|l|c|}
\hline Full power (Burner) & $300 \mathrm{kw}$ \\
\hline Insulating materials & $\left(30 \mathrm{Nm}^{3}\right.$-natural gas/hour $)$ \\
\hline Highest service temperature & Alumina Insulating Boards and Fiber \\
\hline Heating-Up Rate & $1650^{\circ} \mathrm{C}$ \\
\hline Furnace atmosphere & 1200 to $1500^{\circ} \mathrm{C}$ in 20 to 25 minutes \\
\hline Heat-Size (depending on the density) & Full combustion \\
\hline Highest pellet bed & 13 to $15 \mathrm{~kg}$ green balls, \\
\hline Dimensions of pellet bed & $120 \mathrm{~mm}$ \\
\hline
\end{tabular}




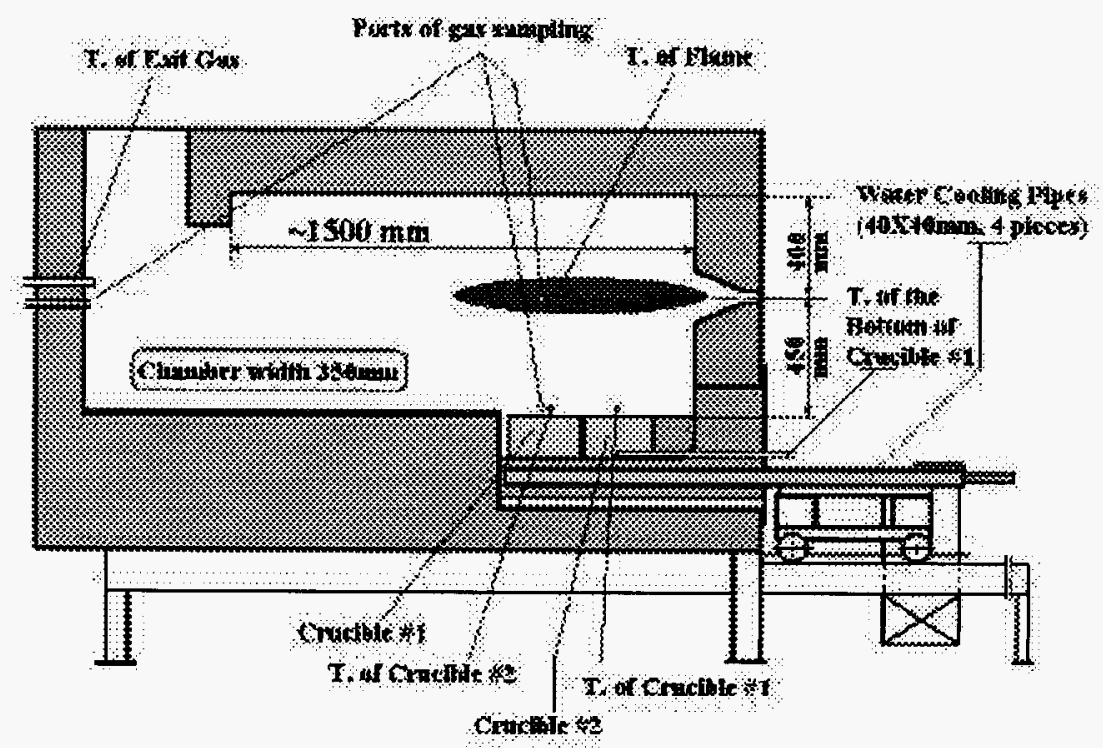

Figure 5-1 The configuration of the natural gas fired furnace used for reduction experiments

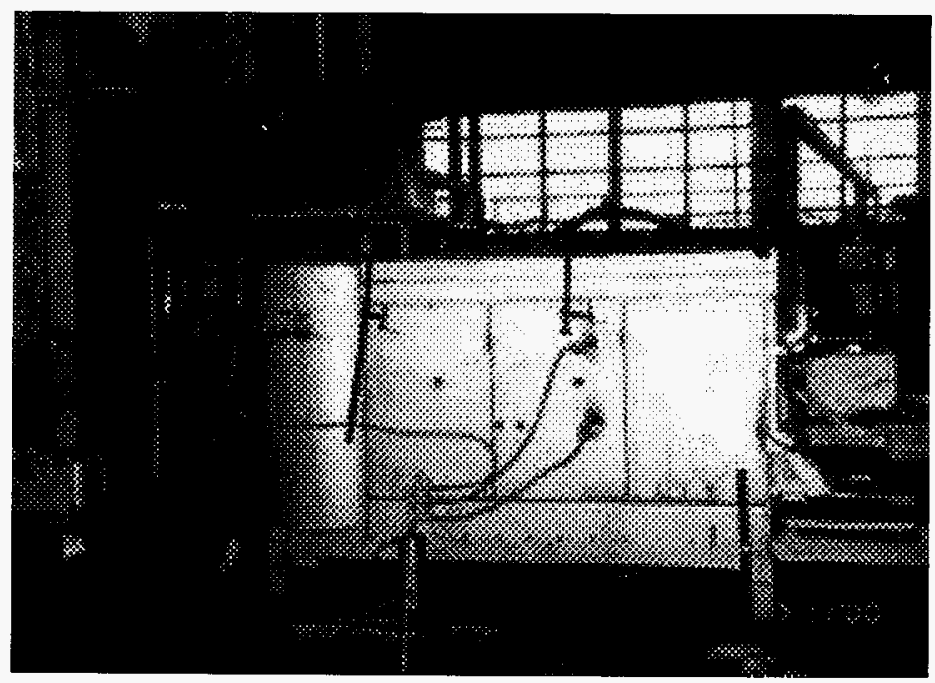

Figure 5-2 The appearance of the natural gas fired furnace used for reduction experiments

\section{§5.3.2 The temperature control and gas sampling}

As shown in Figure 5-1, there are 5 thermocouples installed for the measurement of the temperature at the top of crucible \#2 (T. of Crucible \#2), the temperature at the top of crucible \#1 (T. of Crucible \#1), the temperature of flame, the temperature of exit gas, and the temperature at the bottom of crucible \#1. The processing temperature is defined by the temperature at the top of crucible $\# 2$, similar to that defined in our laboratory. 
There are three ports for gas sampling inside the furnace, at the top of the pellet bed, in the core of the combusting flame and at the exit.

Unfortunately, there was no gas analyzer in the pilot plant which was designed for the composition range in our experiment. The reported (by the pilot plant) compositions of gas should be accepted with reservation particularly $\mathrm{CO}$, because the gas was analyzed by using a Combustion Analyzer which was designed for CO concentration lower than 1000 ppm. In order to meet concentration limits of the Combustion Analyzer, the pilot plant staff diluted the gas sampled from the furnace by air before it was sent to the Combustion Analyzer. Errors might have happened because the dilution was carried out manually and to certain extent secondary oxidation might have happened during dilution.

\section{§5.3.3 The operation of the burner}

The operation of the burner is essentially the same as in our laboratory on campus. There is no need of oxygen enrichment nor pre-heating of the air for the flame to reach $1650^{\circ} \mathrm{C}$.

- Fixed the ratio of air to natural gas at 10 to 1

- Control of the temperature of processing temperature and heat-up rate was achieved by adjusting the input rate of natural gas flow (that is rate of the energy supply).

The advantage of the combustion control system is that the flow rates of air and natural gas supplied to the burner are recordable because the special flow meters were used (The pilot plant is a professional combustion laboratory). The typical record of the flow rates of air and natural gas, and the ratio of air to gas are shown in Figure 5-3. 


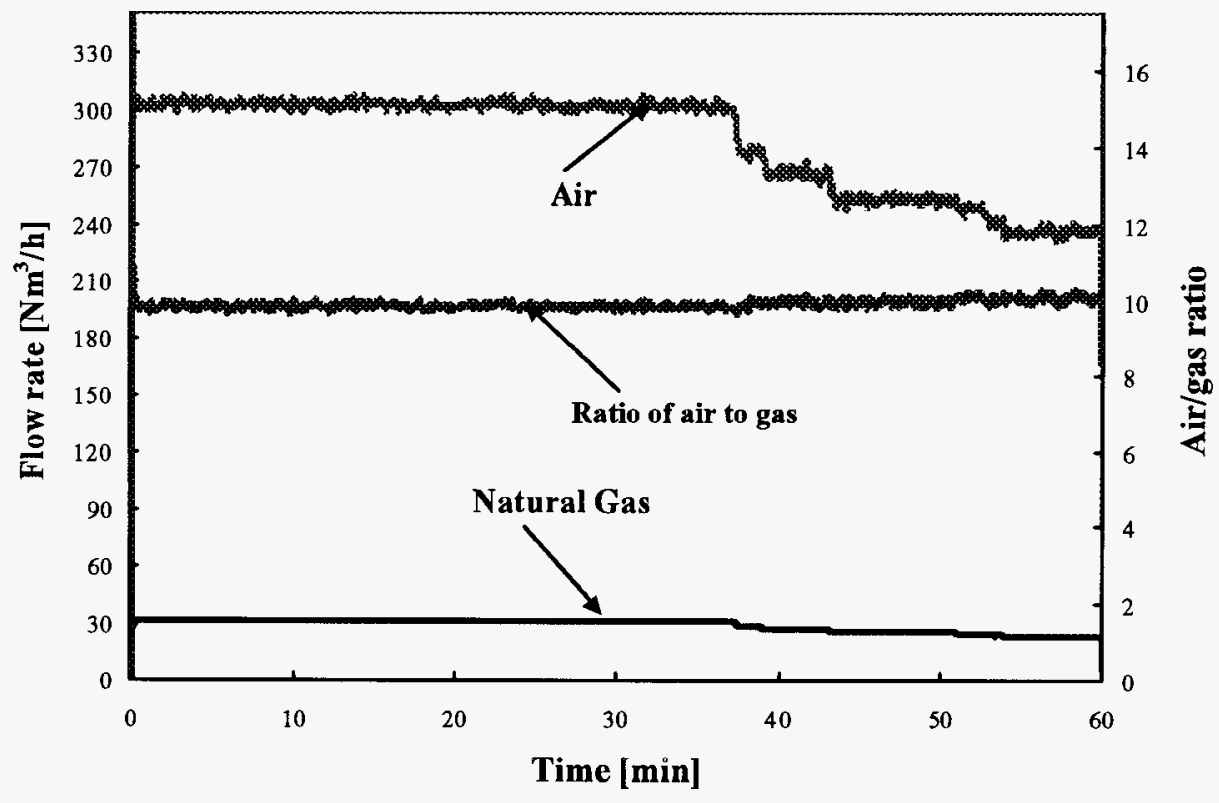

Figure 5-3. A record of the air and gas flow rate during an experiment at the pilot plant

\section{§5.3.4 The pelletizing disk at CSM}

At the pilot plant, there is a pelletizing disk (see Figure 5-4) which is similar to that at our laboratory (Figure 2-8), but bigger in size (about $900 \mathrm{~mm}$ in diameter) and of course larger capacity.

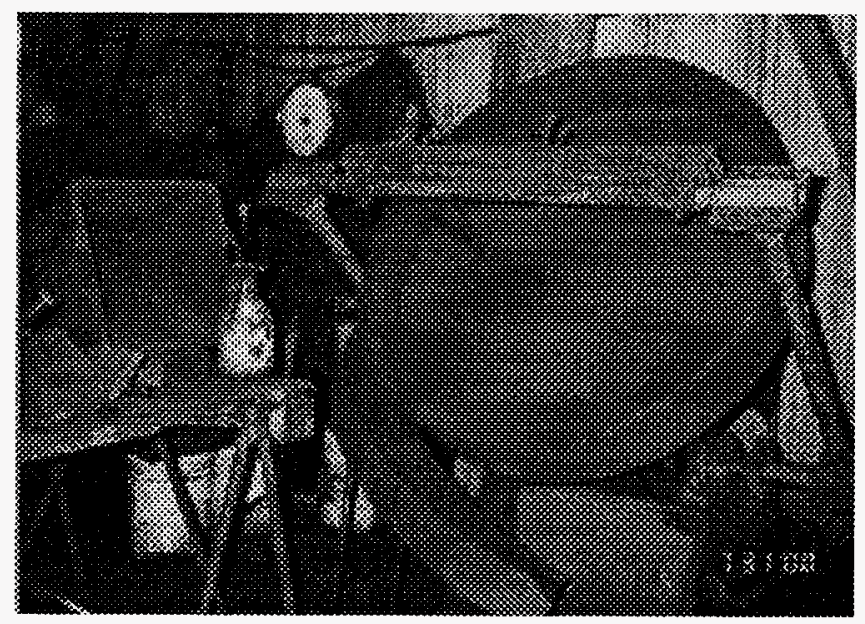

Figure 5-4. Appearance of the pelletizing disk at the pilot plant 


\section{§5.3.5 The crucibles}

The crucibles which were provided by the pilot plant are rectangular boxes made of castable refractory materials. They are $230 \mathrm{~mm}$ in length, $190 \mathrm{~mm}$ in width and $120 \mathrm{~mm}$ in depth. The thickness of the four walls of the crucible is $10 \mathrm{~mm}$ and the bottom is 15 to $20 \mathrm{~mm}$. Because the maker of the crucibles prefers the type of refractory material for the quality of green ware, not necessarily for its high temperature properties, the crucible deformed and cracked just after one heating (see Figure 5-5). Meanwhile, pilot plant staff did not prepare enough crucibles before starting the trials and led us some days to sit and wait for the crucibles to come.

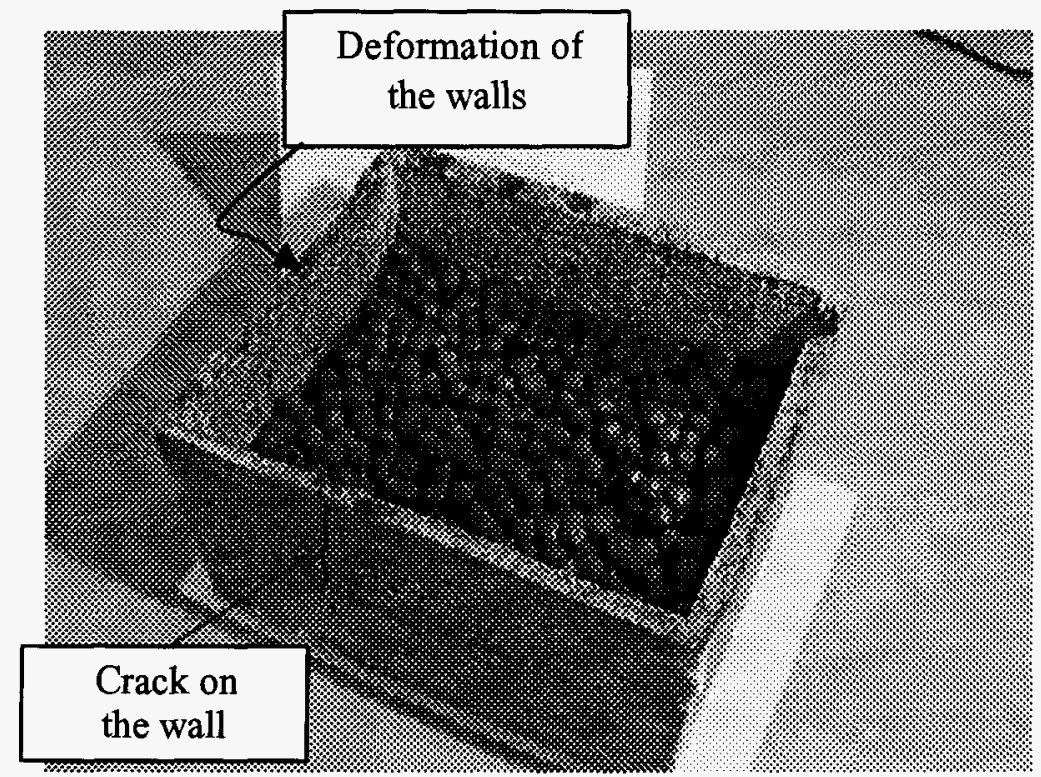

Figure 5-5. Appearance of the crucible made in the pilot plant after one experiment

\section{\$5.3.6 The charger}

The charger was a steel box with a sliding bottom, the box being divided into 6 parts (see Figure 5-6) with the goal to charge the green balls into the two crucibles underneath in a single charging operation. Unfortunately, the sliding bottom of this charger was often jammed by the green balls, some of which broke in the process. It worked a little bit better after several modifications. 


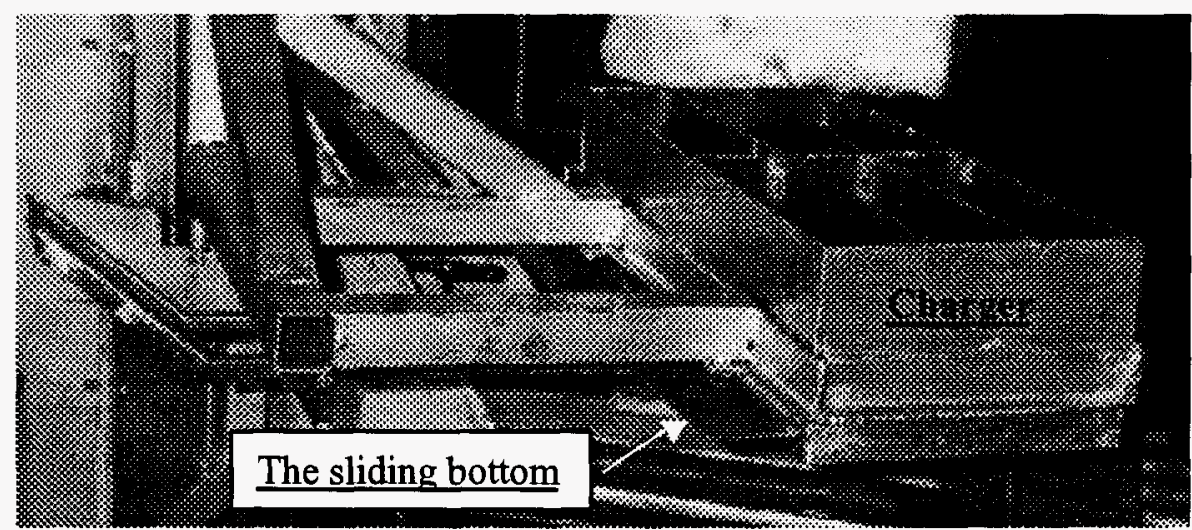

Figure 5-6. The charger at CSM for the trials

\section{§5.3.7 Discharging of DRI}

At the end of each experiment, the crucibles containing DRI were withdrawn from the furnace together with the support on the carriage. A hood with flowing nitrogen for cooling was placed to cover both crucibles.

\section{\$5.4 Operational Problems of the Gas-Fired Furnace}

Beside the support/carrier of the crucibles was not designed properly (see §5.3.1), the gas-fired furnace at CSM for carrying out our trials in Italy also had the following problems:

\section{(1). Air Leaking through the door}

Before charging, the burner was adjusted to air/naturalgas $=10$ in volumetric flow rates and kept constant throughout every experiment. The pressure inside the furnace partly depends on the rate of gas generation from pellet bed, from positive in relation to ambient atmosphere due to intensive de-volatilization in the early stage, to increasingly negative for the remaining time of the experiment. The leaks between the door and the shell of the furnace were very visible by the leaked black smoke in the first few minutes of experiments. Through the same gaps, air leaked in with increasing rate and reached maximum value (but unknown) at the end of the experiment. The leaked-in air burned off the soot which were closer to the door of the furnace (see Figure 5-7) and might oxidized the DRI too. The area A and B should be black without the leaking of air through gaps around the door in the later period of the reduction process because soot was deposited in the earlier period of reduction process. No repair was attempted because of the magnitude of the job required and available time. 


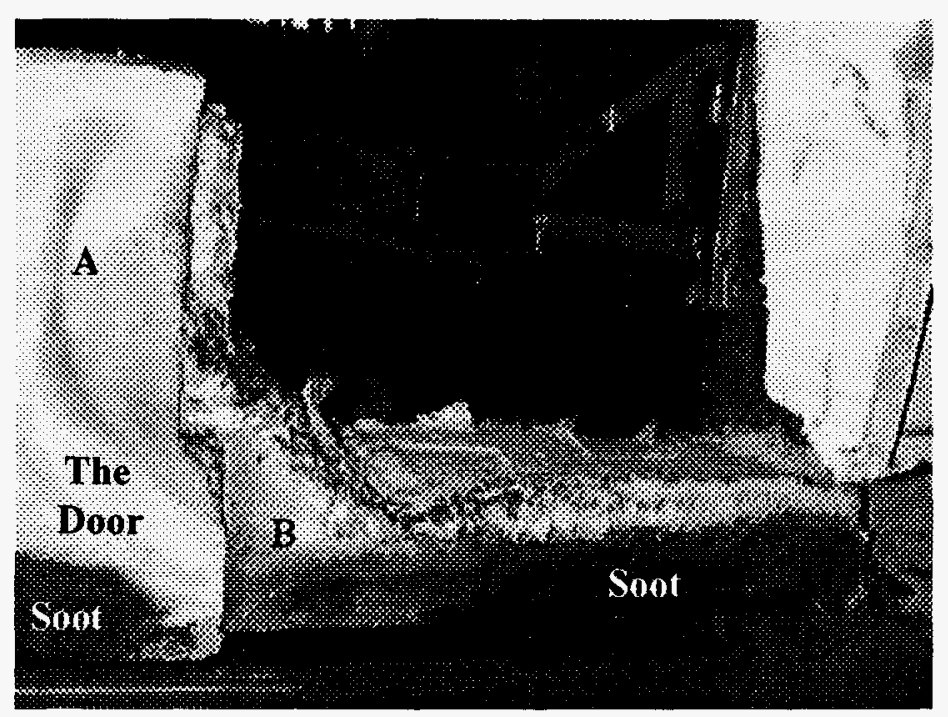

Figure 5-7. The carbon soot was burned off by the leaked-in air through the door

(2). Leak at the Hole for Thermocouple

All the thermocouples were just simply inserted through the related holes into the furnace. There were no sealing applied to the gaps between the sheath of thermocouple and the steel shell of the furnace. The amount of air leaking through these gaps might be very limited. But the effect of the air leaking in through the hole on the door for the thermocouple to detect the temperature at the bottom of the crucible \#1 may not be insignificant, because the sheath of this thermocouple was often stuck on the bottom of the crucible \#1 by the solidified FeO slag.

\section{(3). Temperature Distribution and Heating up Rate}

There was a systematic temperature variation at the top level of the pellet bed with the value at the center above Crucible $\# 2$ to be about $20 \sim 40^{\circ} \mathrm{C}$ higher than the corresponding value of Crucible \#1, because the support/carrier of the crucible was too short to place both crucibles into the "hot zone" of the furnace.

\section{(4). Turning Off the Burner}

It is the general practice at this combustion laboratory that at the termination of an experiment the natural gas flow is cut off, but not the air flow. Frank Huang discovered this practice when he tried to find the cause of re-oxidation of DRI in Crucible \#2. There was up to about one minute exposure to air flow at full speed for DRI in both crucibles. For DRI in Crucible \#1 the cause of re-oxidation may be attributed also to leaks at the door and around the thermocouple sheath. About halfway through the trial program in Genoa, a valve was installed to reduce the air flow rate (after cut-off of natural gas) from 
200 to $65 \mathrm{~m}^{3} / \mathrm{hr}$. The extent of DRI re-oxidation in Experiments \#5 - \#9 appear to be significantly less than that in earlier experiments.

\section{\$5.5 Experimental Conditions and Procedures}

The pilot plant trials used two types of iron ores, American and Brazilian and three kinds of waste oxides, see Table 2.1, 2.2, 2.3, 2.4 and 2.6 for chemical compositions. Most experiments conducted on campus were based on taconite concentrate. In order to assess the similarity or difference in the art of ironmaking on campus and in an old steel works, taconite concentrates were reduced under supposedly similar conditions. Including Brazilian ore in the program was suggested by SMS Demag. Three typical kinds of waste oxides were used in these trials. The chosen ratio between EAF dust and BOF sludge was due to the fact that they are of relevance to Dofasco's interest.

\section{$\S 5.5 .1$ Procedures}

The experimental procedures were provided to the staff of the pilot plant and watched by Frank Huang who played the role of the quality control person. The general procedure consists of the following steps:

- Make the green balls of pre-determined compositions, with the size of 16 to $19 \mathrm{~mm}$.

- Dry the green balls at the temperature between 100 and $200^{\circ} \mathrm{C}$,

- Preheat the gas-fired furnace (with two empty crucibles inside the furnace) until the temperature at the top of crucible $\# 2$ reaches $1500^{\circ} \mathrm{C}$ and cool it down to $1250^{\circ} \mathrm{C}$ and keep at the temperature for 30 minutes,

- Weigh out the pre-determined amount of green balls and place them into the charger.

- Open the furnace door, and withdraw both crucibles on the carriage from the furnace for loading the green balls,

- Aim the bottom of the charger onto the crucibles and open the sliding bottom of the charger, deliver the green balls into the crucibles.

- Push the carriage with the loaded crucibles back into the furnace,

- Increase the supply rate of natural gas to the burner to heat up the furnace and the pelle ts until the temperature at the top of the crucible \#2 reaches the per-determined temperatures, then keep the furnace at the temperature,

- When the pre-determined total heating time lapsed, shut off the burner, open the door of the furnace to withdraw the carriage and the crucibles and cool DRI under the flowing nitrogen. [Unfortunately, when the burner was shut off, it did not mean the air flow stopped, see §5.4-(4)].

\section{§5.5.2 Experimental conditions}

In terms of the floor area for the pellet bed, the furnace at the pilot plant was twice that on campus. At one the meetings with representative of sponsoring companies, it was agreed that. 
- There is no need to have a very long bed to prove that experimental results obtained on campus was not perturbed by the edge effect. It was well established.

- Larger crucible would have shorter service life

- The pilot plant has half-size crucibles, which are similar to that used on campus, in stock

- In each experiment, different green balls may be charged into different crucibles; therefore, one trial has two tests.

The following conditions are common to all experiments conducted at the pilot plant in Genoa:

- Height of pellet bed, $120 \mathrm{~mm}$

- Furnace temperature, $1250^{\circ} \sim 1500^{\circ} \mathrm{C}$ for pellets of ore/coal and mill-scale/coal and $1250^{\circ} \sim 1475^{\circ} \mathrm{C}$ for the pellets of the other waste-oxide and coal.

- Size of pellets, $16 \sim 19 \mathrm{~mm}$

- Atmosphere, flame of complete combustion (volumetric ratio of air to natural gas for the burner was maintained at 10 to 1 )

The compositions of green balls are listed in table 5-2 and their compression strength in Table 5-3. The planned temperature profile, types of green balls in each crucible and total time of heating are listed in Table 5-4. Since the DRI in the crucible \#1 of trial \#8 was mixed up before sampling, no samples were taken for chemical analysis.

Table 5-2. Compositions of Green Balls, wt.\% (dry basis). All Green Balls Contain 1\% Bentonite, the Diameter is in a Range of $16 \sim 19 \mathrm{~mm}$.

\begin{tabular}{|c|c|c|c|c|c|c|c|c|c|}
\hline & No. & Taconite & Carajas & $\begin{array}{l}\text { Carajas } \\
\text { (Fine } \\
\text { Ground) }\end{array}$ & $\begin{array}{c}\text { Mill } \\
\text { Scale }\end{array}$ & $\begin{array}{c}\text { BOF } \\
\text { Sludge }\end{array}$ & $\begin{array}{l}\text { EAF } \\
\text { Dust }\end{array}$ & Pinnacle & Marfork \\
\hline \multirow{6}{*}{ 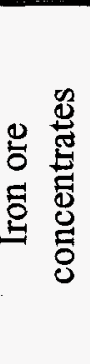 } & 1 & 82.24 & & & & & & 4.44 & 13.32 \\
\hline & 2 & & 80.61 & & & & & 4.85 & 14.54 \\
\hline & 3 & & 82.42 & & & & & 4.39 & 13.19 \\
\hline & $3 \mathrm{~A}$ & & & 82.42 & & & & 4.39 & 13.19 \\
\hline & 4 & 83.89 & & & & & & 4.03 & 12.08 \\
\hline & 5 & & 81.52 & & & & & 4.62 & 13.86 \\
\hline \multirow{6}{*}{ 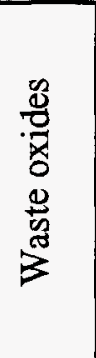 } & 6 & & & & & 84.50 & & 3.88 & 11.62 \\
\hline & 7 & & & & & 83.85 & & 4.04 & 12.11 \\
\hline & 9 & & & & & 59.78 & 25.62 & 3.65 & 10.95 \\
\hline & $10 / 10 \mathrm{~A}$ & & & & & 59.36 & 25.44 & 3.80 & 11.40 \\
\hline & 11 & & & & 81.7 & & & 4.58 & 13.72 \\
\hline & 12 & & & & & 42.7 & 42.7 & 3.65 & 10.95 \\
\hline
\end{tabular}


Table 5-3. Compression strength of dried green balls $(\mathrm{kg} / \mathrm{pellet})$

\begin{tabular}{|c|c|c|c|c|c|c|c|c|c|c|c|c|}
\hline & \multirow{2}{*}{$\begin{array}{c}\text { Green } \\
\text { ball No. }\end{array}$} & \multicolumn{10}{|c|}{ Sample } & \multirow{2}{*}{ Average } \\
\hline & & 1 & 2 & 3 & 4 & 5 & 6 & 7 & 8 & 9 & 10 & \\
\hline \multirow{5}{*}{ 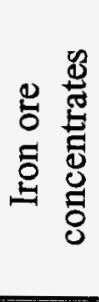 } & 1 & 5 & 2 & 3 & 2 & 2 & 2 & 3 & 3 & 3 & 2 & 2.7 \\
\hline & 3 & 4 & 4.5 & 5 & 7 & 6 & 4 & 4.5 & 5.5 & 5 & 6 & 5.2 \\
\hline & $3 \mathrm{~A}$ & 6 & 12 & 15 & 11 & 13 & 13 & 9 & 6 & 22 & 10 & 11.7 \\
\hline & 4 & 5 & 3 & 3 & 3 & 4 & 3 & 2 & 4 & 5 & 3 & 3.5 \\
\hline & 5 & 6 & 7 & 5 & 7 & 9 & 6 & 5 & 3 & 4 & 4 & 5.6 \\
\hline \multirow{6}{*}{ 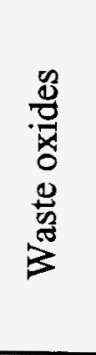 } & 7 & 22 & 15 & 18 & 15 & 17 & 14 & 15 & 23 & 15 & 12 & 16.6 \\
\hline & 9 & 38 & 48 & 43 & 46 & 45 & 49 & 25 & 38 & 39 & 43 & 41.4 \\
\hline & 10 & 30 & 28 & 30 & 23 & 28 & 26 & 29 & 29 & 23 & 20 & 26.6 \\
\hline & $10 \mathrm{~A}$ & 20 & 24 & 23 & 10 & 24 & 17 & 20 & 23 & 21 & 23 & 20.5 \\
\hline & 11 & 12 & 11 & 7 & 9 & 6 & 12 & 6 & 12 & 9 & 5 & 8.9 \\
\hline & 12 & 26 & 25 & 23 & 32 & 23 & 27 & 23 & 28 & 22 & 29 & 25.8 \\
\hline
\end{tabular}




\section{Table 5-4. Reduction Conditions}

- Burner has been kept at air/gas ratio of $10 / 1$, by volume.

- Pellet bed height has been kept at $120 \mathrm{~mm}$

- Crucible size, mm (inner dimension): 230(L)x190(W)x120(H)

- Door open at furnace temperature (measured by the thermocouple at the top of crucible \#2) of $1300^{\circ} \mathrm{C}$ for charging (under this situation, the temperature of the furnace and the bottom of the crucible dropped down to $1200^{\circ} \mathrm{C}$ or lower as soon as the door was opened)

- DRI was cooled under a cover with flowing nitrogen.

\begin{tabular}{|c|c|c|c|c|c|c|c|}
\hline $\begin{array}{c}\text { Trial } \\
\text { No. }\end{array}$ & \multicolumn{2}{|c|}{\begin{tabular}{c} 
Green ball \\
\cline { 2 - 6 } \\
$\# 1$
\end{tabular}} & $\begin{array}{c}\text { Cruciblemperature } \\
\# 2\end{array}$ & $\begin{array}{c}\text { Time } \\
\left({ }^{\circ} \mathrm{C}\right)\end{array}$ & $\begin{array}{c}\text { Peak of } \\
\text { temp. } \\
\left({ }^{\circ} \mathrm{C}\right)\end{array}$ & $\begin{array}{c}\text { Air/Gas } \\
\text { Flow for } \\
\text { heating-up } \\
\left(\mathrm{m}^{3} / \text { hour }\right)\end{array}$ & $\begin{array}{c}\text { Time taken } \\
\text { to heat-up to } \\
\text { the Tb (min.) }\end{array}$ \\
\hline 1 & $\# 4$ & $\# 1$ & $1250(\mathrm{Ta}) \sim 1500(\mathrm{~Tb})$ & 60 & 1520 & $150 / 15$ & 46.0 \\
\hline 2 & $\# 4$ & $\# 1$ & $1250(\mathrm{Ta}) \sim 1500(\mathrm{~Tb})$ & 60 & 1520 & $300 / 30$ & 13.0 \\
\hline 3 & $\# 1$ & $\# 5$ & $1250(\mathrm{Ta}) \sim 1500(\mathrm{~Tb})$ & 60 & 1520 & $300 / 30$ & 18.5 \\
\hline 4 & $\# 3$ & $\# 4$ & $1250(\mathrm{Ta}) \sim 1500(\mathrm{~Tb})$ & 60 & 1520 & $300 / 30$ & 20.0 \\
\hline 5 & $\# 6$ & $\# 7$ & $1250(\mathrm{Ta}) \sim 1475(\mathrm{~Tb})$ & 60 & 1500 & $300 / 30$ & 21.0 \\
\hline 6 & $\# 7$ & $\# 6$ & $1250(\mathrm{Ta}) \sim 1475(\mathrm{~Tb})$ & 60 & 1500 & $300 / 30$ & 23.0 \\
\hline 7 & $\# 10$ & $\# 9$ & $1250(\mathrm{Ta}) \sim 1450(\mathrm{~Tb})$ & 65 & 1490 & $300 / 30$ & 14.0 \\
\hline 8 & $\# 12$ & $\# 10$ & $1250(\mathrm{Ta}) \sim 1450(\mathrm{~Tb})$ & 65 & 1480 & $300 / 30$ & 16.5 \\
\hline 9 & $\# 3 \mathrm{~A}$ & $\# 11$ & $1250(\mathrm{Ta}) \sim 1500(\mathrm{~Tb})$ & 60 & 1520 & $300 / 30$ & 17.5 \\
\hline $10(4 \mathrm{R})$ & $\# 4$ & $\# 3$ & $1250(\mathrm{Ta}) \sim 1500(\mathrm{~Tb})$ & 60 & 1520 & $300 / 30$ & 15.5 \\
\hline
\end{tabular}




\section{$\$ 5.6$ Experimental Results}

During each experiment, five temperature readings and the concentration of carbon monoxide above the pellet bed of the crucible $\# 2$ were recorded. As examples, three cases are shown in Figures 5-8, 5-9 and 5-10. It should be noted that there are signs which indicated the closeness to the completion of reduction, i.e., the rise of temperature at the bottom of crucible and the drop of $\mathrm{CO}$ concentration above the bed. Acomparing of Figure 5-8 and Figure 5-9 shows that, the progress of reduction of BOF sludge was faster than that of taconite concentrate. Furthermore, In Figure 5-10, four temperature readings are shown where the EAF dust was part of iron bearing material.

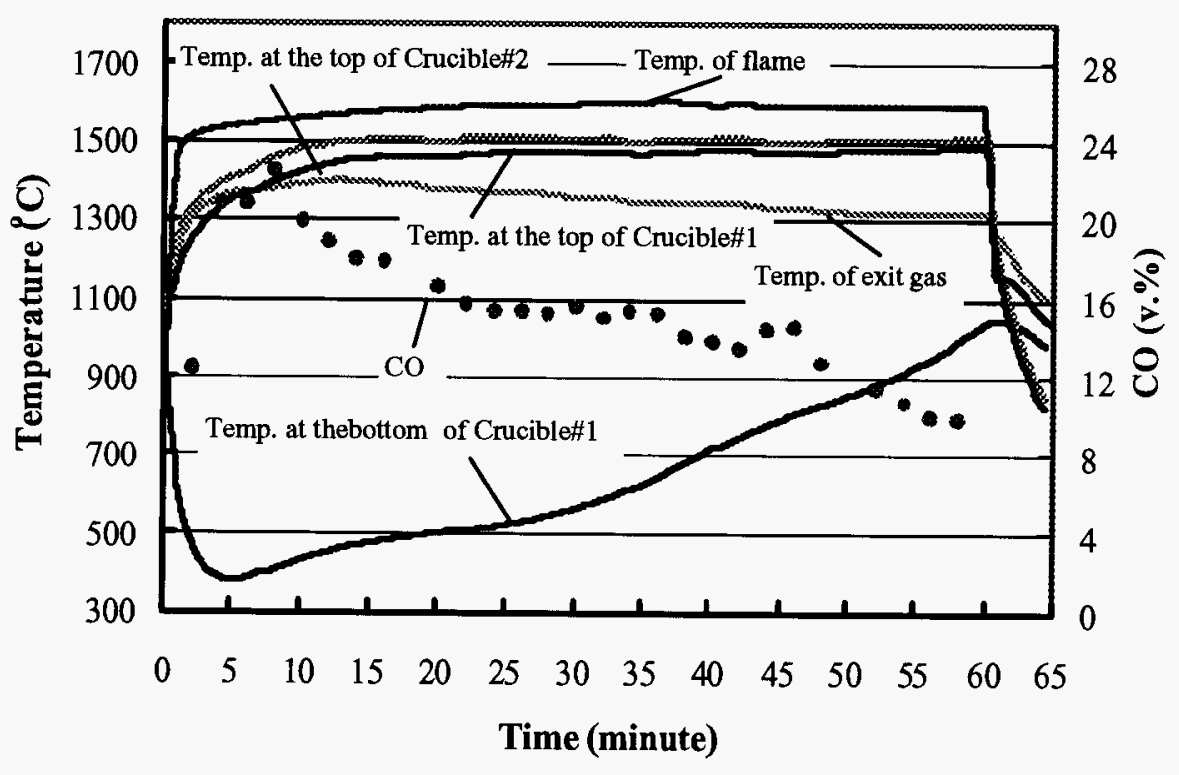

Figure 5-8. Temperature profiles and CO concentration of Trial \#2 (Taconite) 


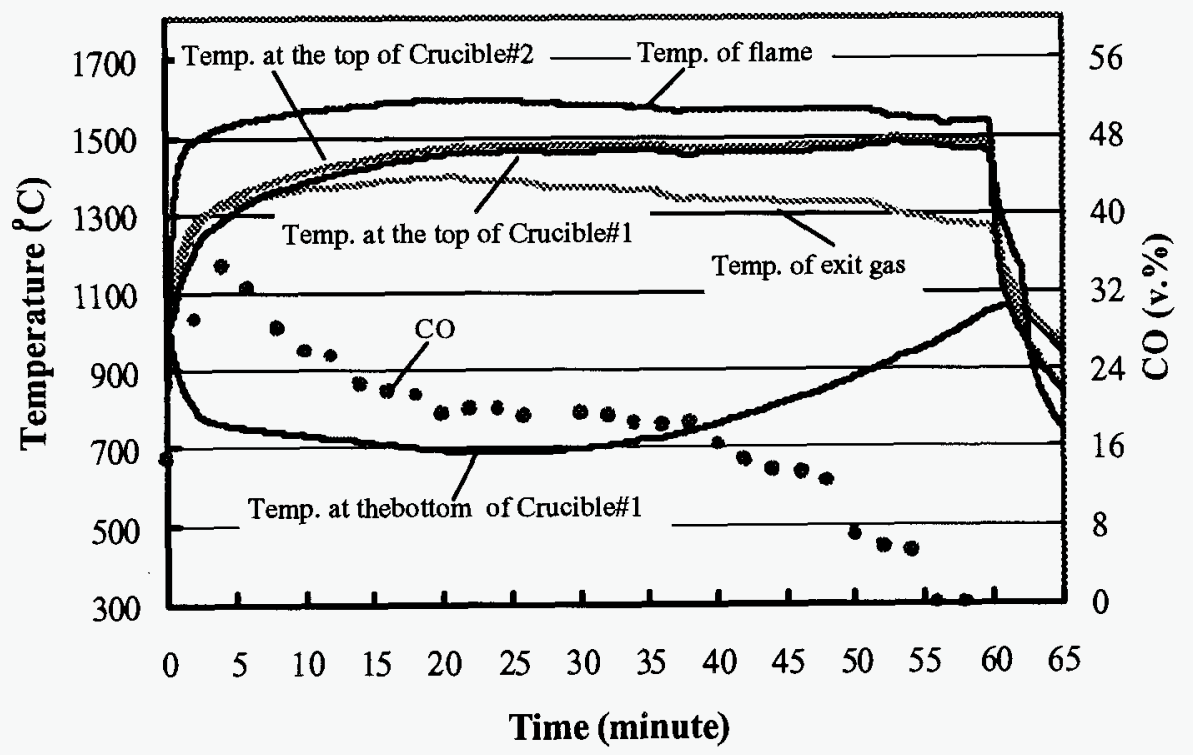

Figure 5-9. Temperature profiles and CO concentration of Trial \#6 (BOF Sludge) 


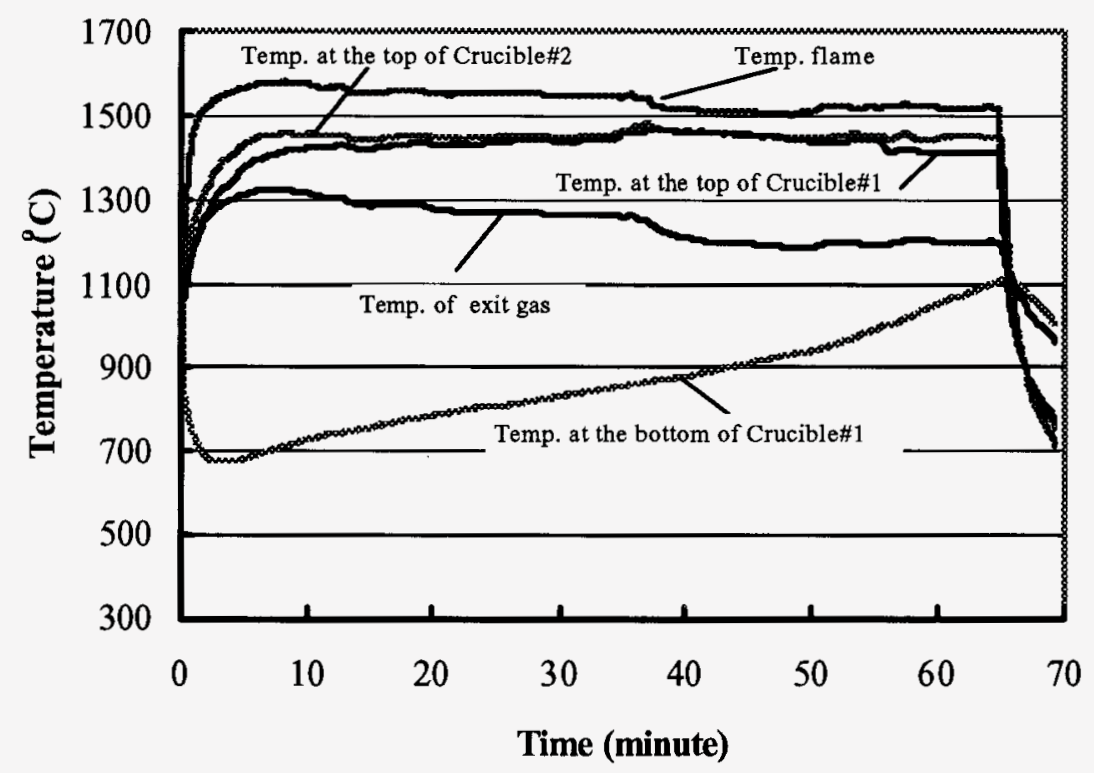

Figure 5-10. Temperature profiles and $\mathrm{CO}$ concentration of Trial \#8 (70\%BOF sludge + $30 \% \mathrm{EAF}$ dust, the gas from the top of pellet bed was not sampled properly, so no $\mathrm{CO}$ concentration could be reported.)

The appearance of five DRI cakes, as examples, are shown in Figures 5-11 to 5-15. Pellet properties and heating conditions are shown with each photograph. After taking the picture, sample representing three portions of the DRI bed, i.e., the top layer, main body and the bottom portion were taken according to the procedure outline in \$4.1. More pictures of DRI are shown in Appendix A.

\section{§5.6.1 Visual Observation}

The major difference with respect to flame expansion of these two furnaces used for reduction experiments may be described in terms of the situation at the top of the pellet bed. As mentioned in \$5.3.1, the combustion chamber of the gas-fired furnace at the pilot plant is long enough for the flame to expand completely. The turbulence of the flue gas on the top of the pellet bed in the gas-fired furnace of the pilot plant is much weaker than that in the gas-fired furnace on campus because the shorter combustion chamber. The evidences are: 
Green Ball : Taconite: $\quad 83.89 \%$,

Coal: $\quad 16.11 \%$,

Bentonite: $\quad 1 \%$

Pellet Size: $\quad 16 \sim 19 \mathrm{~mm}$

Bed Height: $\quad 120 \mathrm{~mm}$

Temperature: $1200^{\circ} \sim 1500^{\circ} \mathrm{C}$

Time: $\quad 60$ minutes

Appearance of DRI cake $(230 \mathrm{~mm} \times 190 \mathrm{~mm} \times 70 \mathrm{~mm})$

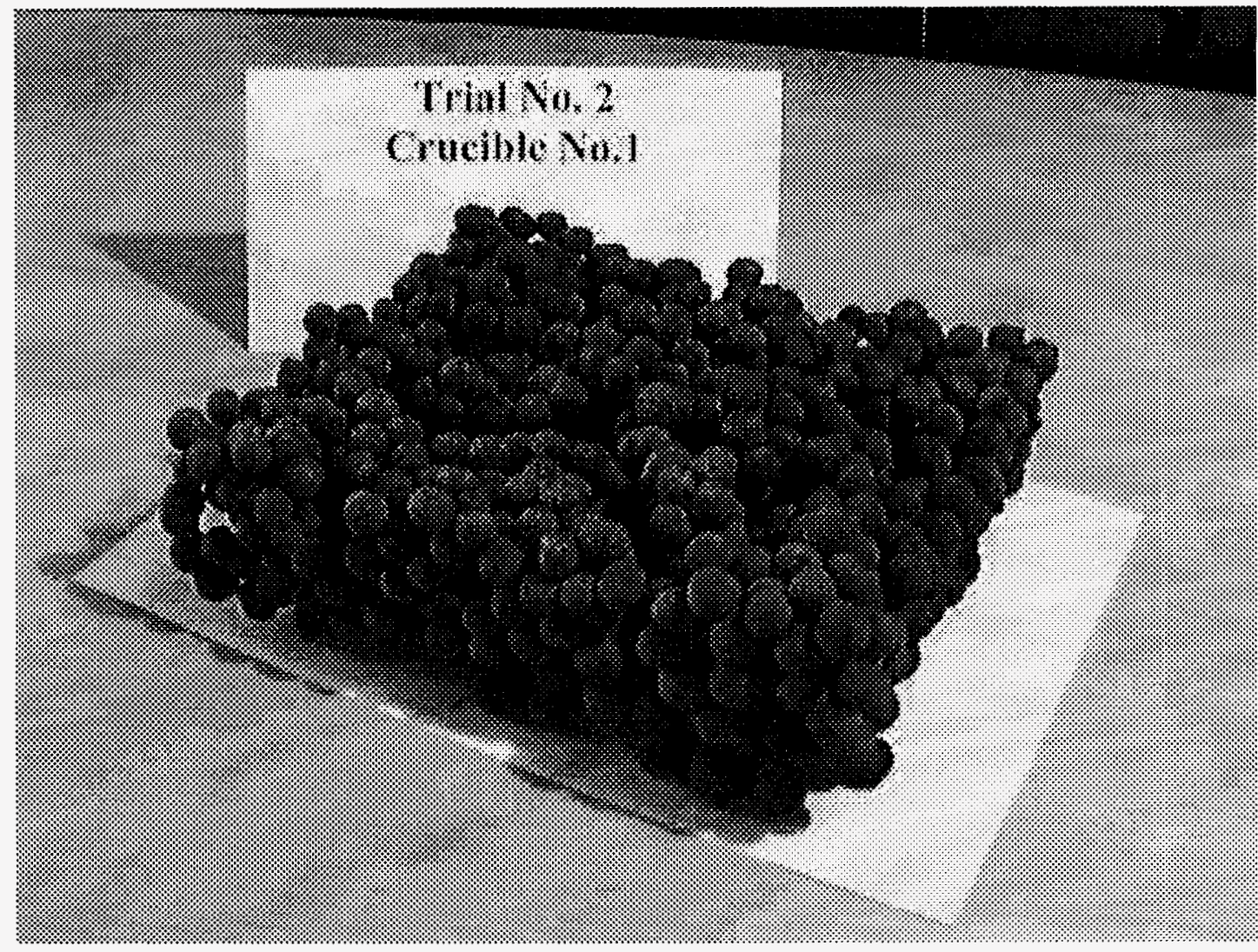

Figure 5-11. DRI cake made from Taconite Concentrate 


$$
\begin{array}{lll}
\text { Green Ball : } & \text { Carajas: } & \multicolumn{1}{c}{82.42 \%,} \\
& \text { Coal: } & 17.58 \%, \\
& \text { Bentonite: } & 1 \% \\
& \text { Pellet Size: } & 16 \sim 19 \mathrm{~mm} \\
\text { Bed Height: } & 120 \mathrm{~mm} &
\end{array}
$$

Temperature: $1200 \sim 1500^{\circ} \mathrm{C}$

Time: $\quad 60$ minutes

Appearance of DRI cake $(230 \mathrm{~mm} \times 190 \mathrm{~mm} \times 70 \mathrm{~mm})$

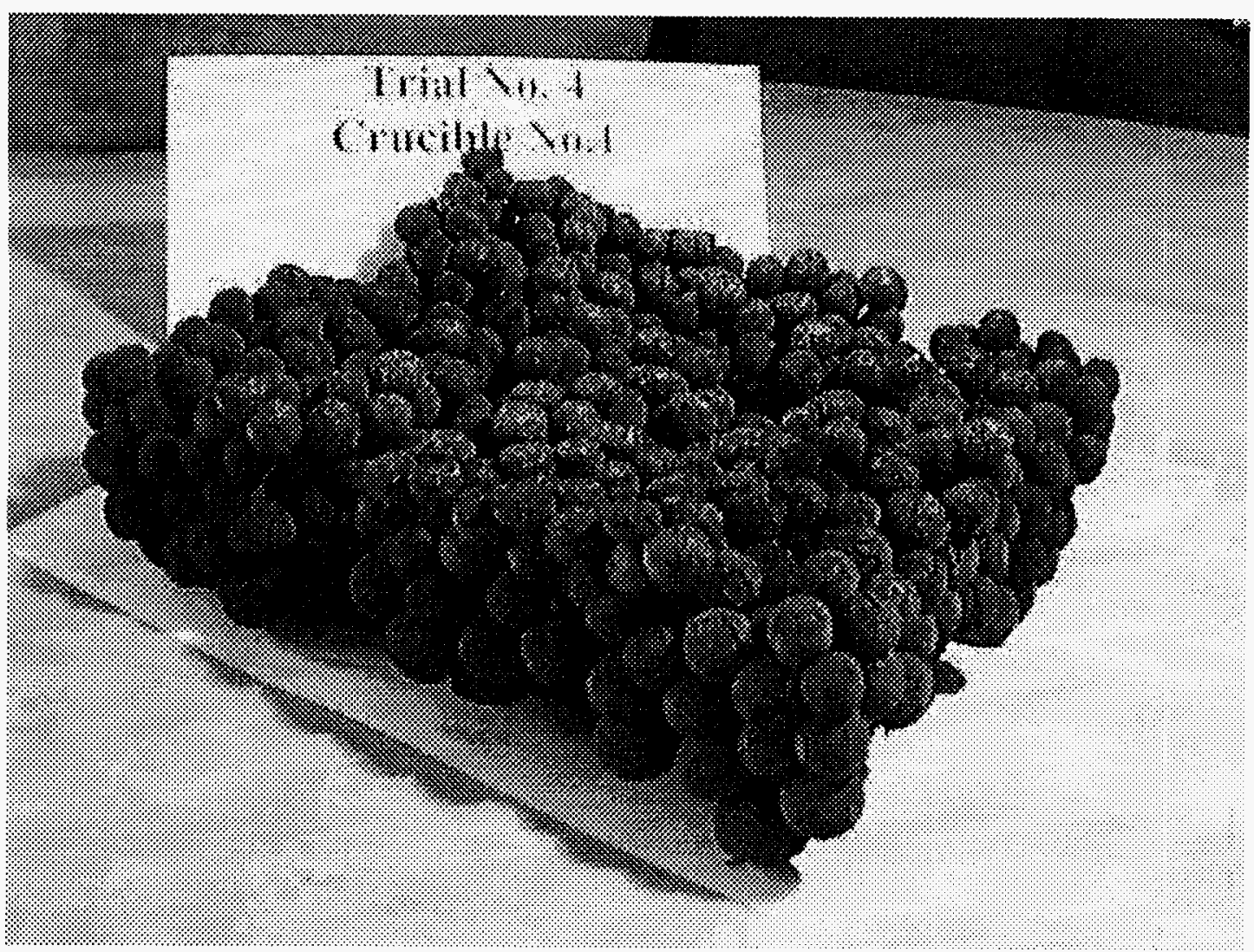

Figure 5-12. DRI cake made from Brazilian hematite concentrate (Carajas) 
Green Ball : Mill Scale: $\quad 81.7 \%$,

Coal: $\quad 18.3 \%$,

Bentonite: $\quad 1 \%$

Pellet Size: $\quad 16 \sim 19 \mathrm{~mm}$

Bed Height: $\quad 120 \mathrm{~mm}$

Temperature: $1200 \sim 1500^{\circ} \mathrm{C}$

Time: $\quad 60$ minutes

Appearance of DRI cake $(230 \mathrm{~mm} \times 190 \mathrm{~mm} \times 60 \mathrm{~mm})$

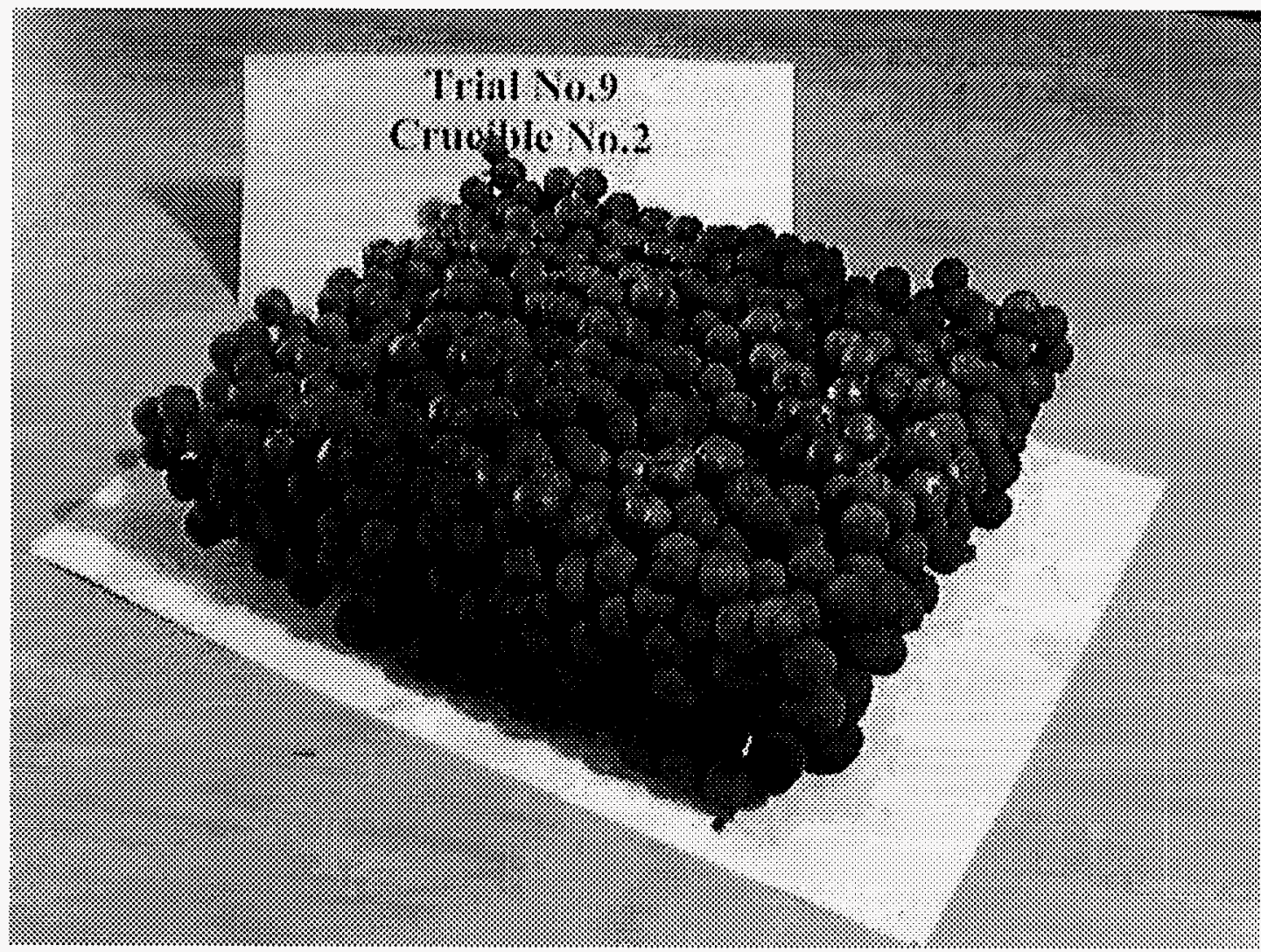

Figure 5-13. DRI cake made from mill scale 

Green Ball : BOF Sludge: $83.85 \%$, Coal: $\quad 16.15 \%$,
Bentonite: $\quad 1 \%$
Pellet Size: $\quad 16 \sim 19 \mathrm{~mm}$

Bed Height: $\quad 120 \mathrm{~mm}$

Temperature: $1200 \sim 1500^{\circ} \mathrm{C}$

Time: $\quad 60$ minutes

Appearance of DRI cake $(230 \mathrm{~mm} \times 190 \mathrm{~mm} \times 55 \mathrm{~mm})$

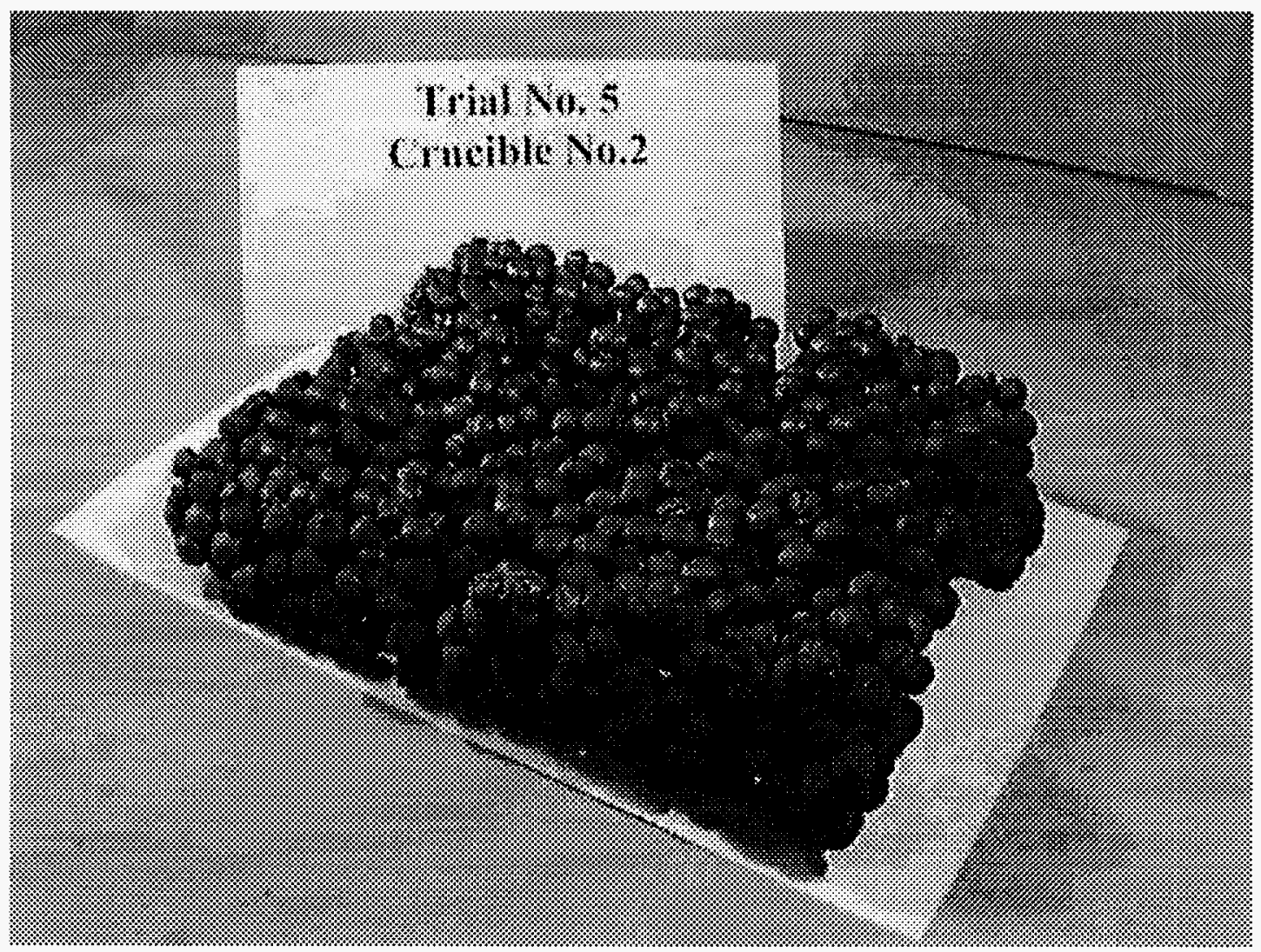

Figure 5-14. DRI cake made from BOF sludge 


$\begin{array}{lll}\text { Green Ball : } & \text { BOF Sludge: } & 59.35 \% \\ & \text { EAF Dust: } & 25.44 \% \\ & \text { Coal: } & 15.20 \%, \\ & \text { Bentonite: } & 1 \% \\ & \text { Pellet Size: } & 16 \sim 19 \mathrm{~mm}\end{array}$

Bed Height: $\quad 120 \mathrm{~mm}$

Temperature: $1200 \sim 1500^{\circ} \mathrm{C}$

Time: $\quad 60$ minutes

Appearance of DRI cake $(230 \mathrm{~mm} \times 190 \mathrm{~mm} \times 64 \mathrm{~mm})$

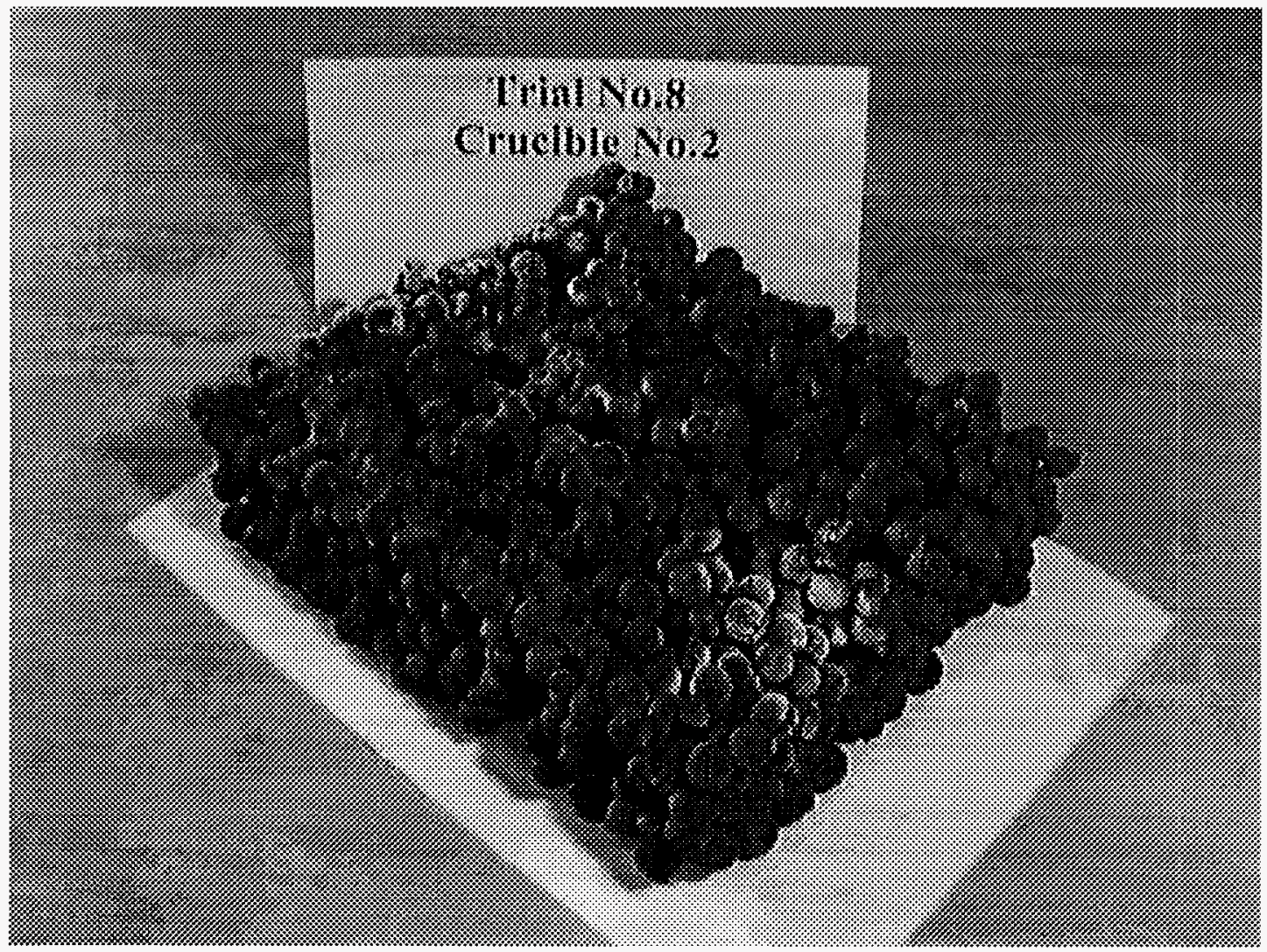

Figure 5-15. DRI cake made from BOF sludge and EAF dust 
- The CO concentration at the top of the crucible in the gas-fired furnace of the pilot plant is higher than that in the gas-fired furnace of our laboratory (comparing Figure 5-8 and Figure 4-1), and

- Under the similar experimental conditions, the top layer of the DRI produced in the pilot plant consists of spheres and appear metallic without melting, and some of the DRI at the top layer of the DRI cake produced on campus showed that upper half of the spheres have melted (see Figure 5-16).

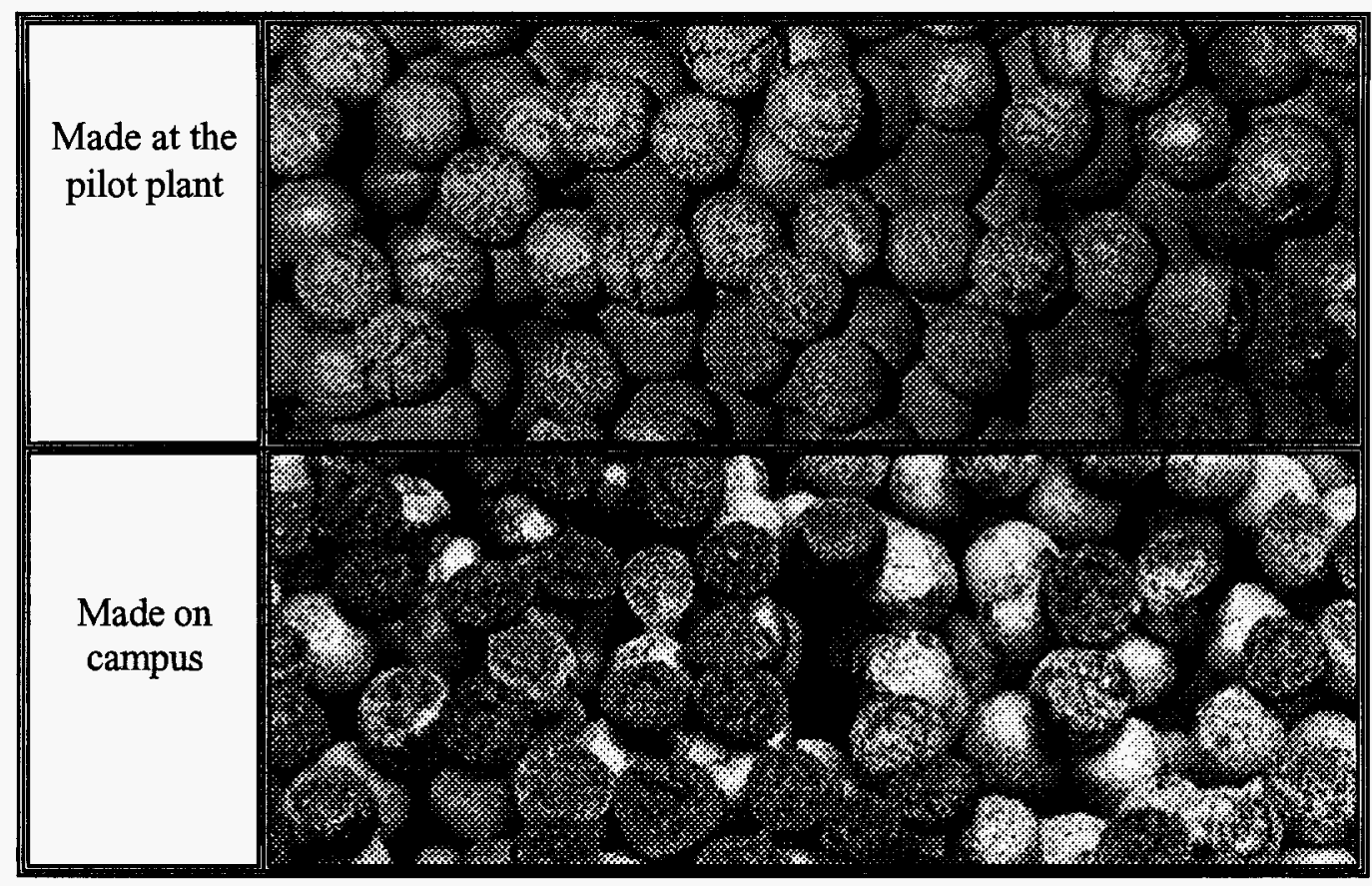

Figure 5-16. The Effects of the turbulence of the flue gas on the top of the pellet bed.

The main body of the DRI cake produced at pilot plant, which is more than $85 \%$ of the total product, is very similar to that produced at McMaster, except for the color and luster. They are dull and dark, not like the silvery and shiny DRI produced at McMaster. There was certainly re-oxidation when DRI were exposed to air flow and cooled by industrial grade nitrogen.

Some of the loose pellets of the bottom layer are large, black and weak in mechanical strength, suggesting that the reduction conditions were rather unfavorable. The unfavorable conditions with respect to thermal state are very low amount of heat stored in the hearth, and strong heat leakage through the hearth due to water-cooling tubes below. The additional unfavorable condition with respect to chemical reactions, particularly in Crucible \#1, is the leak of air to the bottom of the pellet bed around the thermocouple sheath, lowering the reducing power of the local gaseous phase. 


\section{§5.6.2 Metallographic Examination}

Polished specimens of DRI located at the top and loose pellets of the bottom layer, plus those representing the main body of the bed, were examined under a microscope. In Figures 5-17 to 5-19, in all these cases, the degree of metallization, even in the bottom, is high. But the shrinkage and the difference in appearance are due to the size and connectness of iron grains. Residual carbon is visible as black spots in the bottom layer of DRI. Some general comments are given below:

(a) Other than that at the bottom layer, metallization at the center of the pellet was near completion.

(b) Re-oxidation of DRI in Trial \#1 to \#4 was significant, as shown by the presence of an oxide rim near the surface of the DRI at low magnification and the rim around the iron particles at higher magnification.

(c) Metallic iron grains originated from iron ores are massive and dense and those from waste oxides are large and porous.

(d) After grinding in a shatter box to prepare the sample for chemical analysis, the larger particles and the fine portion were examined metallographically. In larger particles (above $160 \mathrm{mesh}$ ), the compressive force of grinding has deformed both metallic and slag phases to wrap around each other and to result in densification.

(e) The average degree of metallization (M\%) of DRI for the whole crucible has been estimated based on the measured values of weight fractions of the top layer and the loose pellets in the bottom layer and the main body; and using well-characterized DRI made at McMaster as the reference. The results are shown in the following table. 


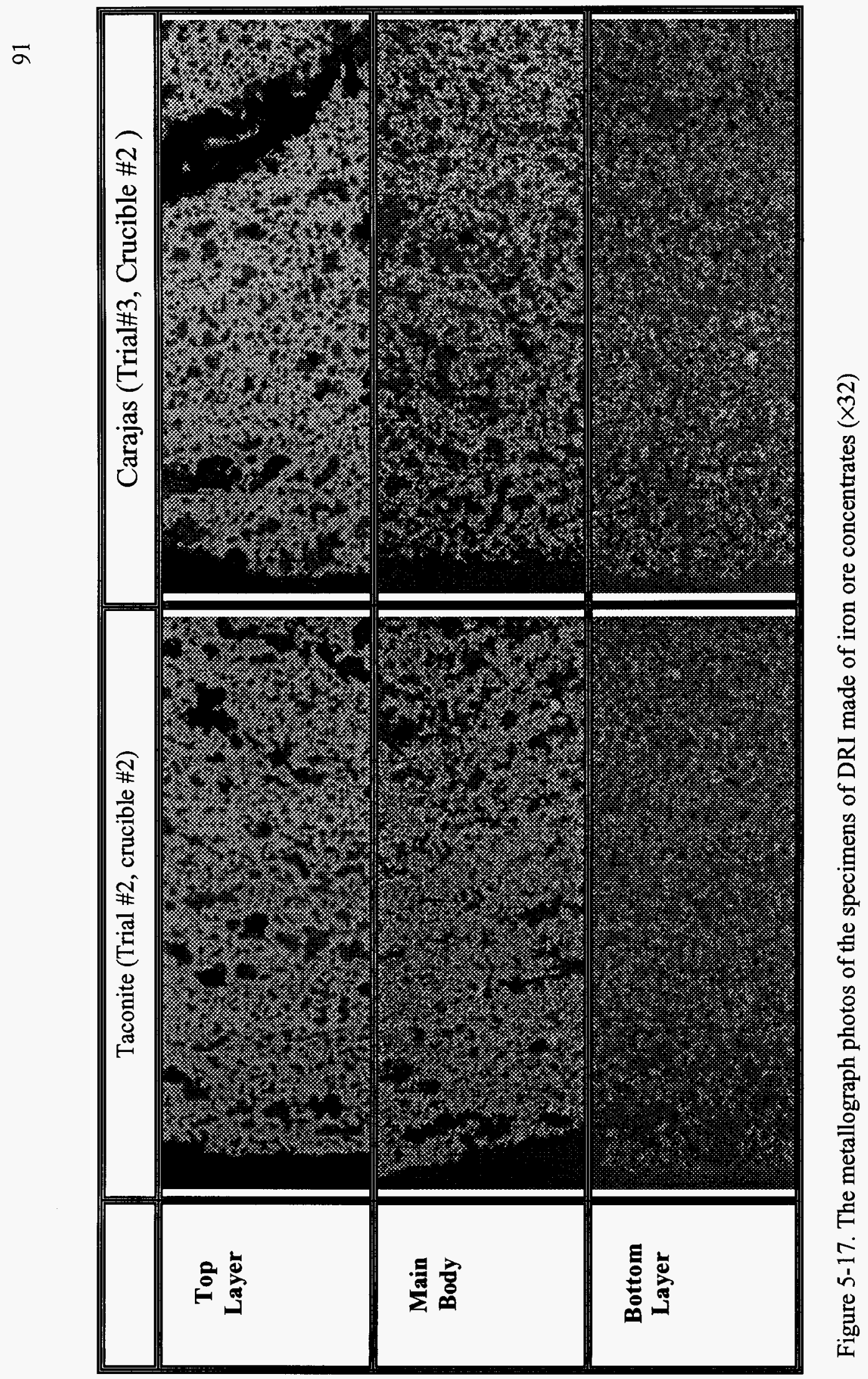




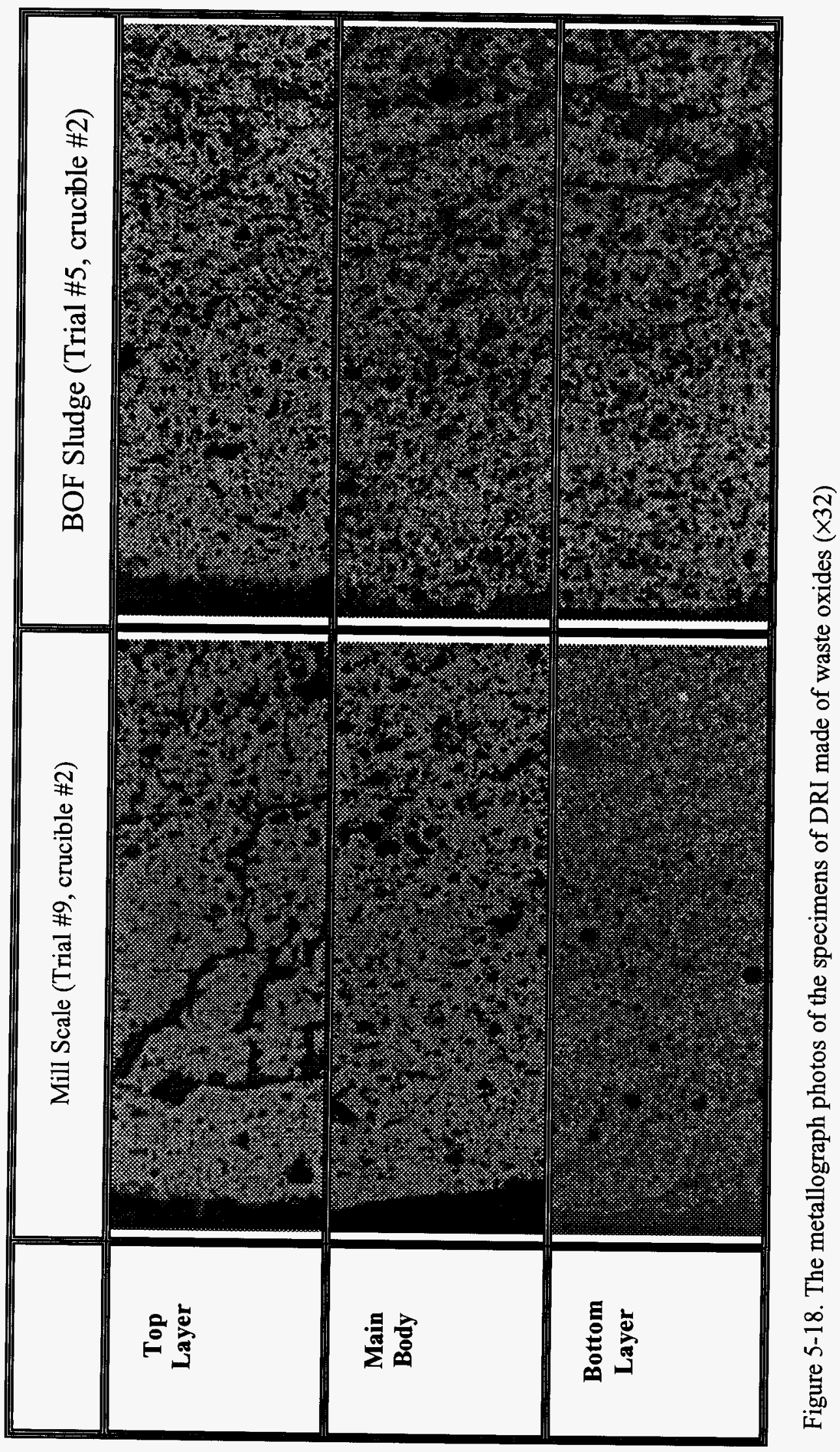




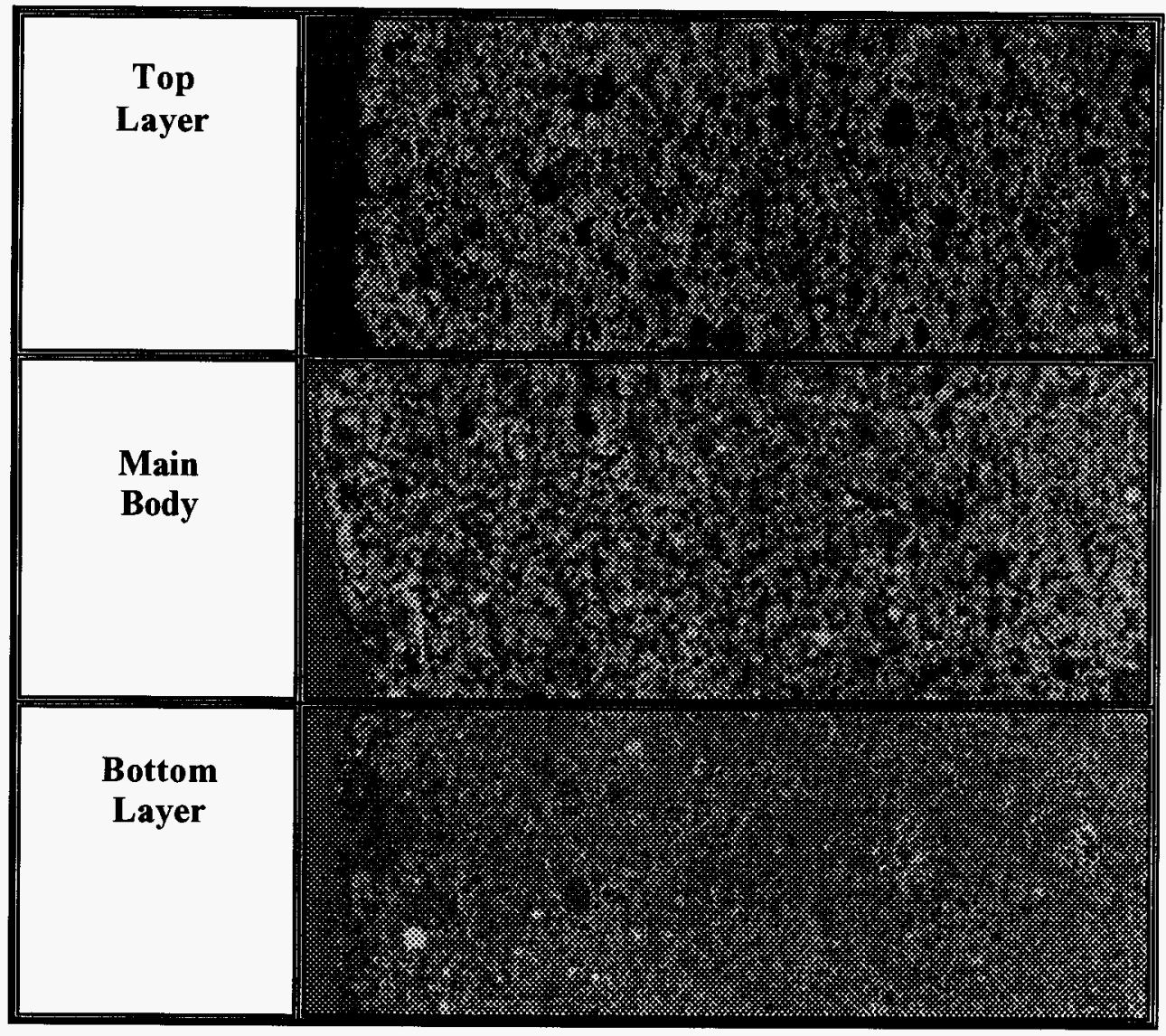

Figure 5-19. The metallograph photos of the specimens of DRI made of BOF sludge and EAF dust $(\times 32)$

Table 5-5. Metallographic Examination

\begin{tabular}{|c|c|c|c|c|c|}
\hline \multicolumn{2}{|c|}{ Material } & $\begin{array}{c}\text { Trial } \\
\text { Number }\end{array}$ & $\frac{\text { Crucible }}{\text { Number }}$ & $\begin{array}{l}\text { M\% Estimated } \\
\text { Overall Value }\end{array}$ & $\begin{array}{c}\text { M\% Corrected } \\
\text { for Re- } \\
\text { Oxidation }\end{array}$ \\
\hline \multirow{5}{*}{$\begin{array}{l}Z \\
\cong\end{array}$} & Taconite, $\quad 17.8 \%$ coal & 2 & 2 & 90 & $>92$ \\
\hline & Taconite, $\quad 16.1 \%$ coal & 2 & 1 & 87 & $>89$ \\
\hline & Carajas, $\quad 18.5 \%$ coal & 3 & 2 & 91 & $>93$ \\
\hline & $17.6 \% \mathrm{coal}$ & 4 & 1 & 87 & $>89$ \\
\hline & Carajas (Fine), $17.6 \%$ coal & 9 & 1 & 91 & $>92$ \\
\hline \multirow{4}{*}{ 毛 } & BOF Sludge & 5 & 2 & 94 & $>94$ \\
\hline & Mill Scale & 9 & 2 & 94 & $>94$ \\
\hline & BOF Sludge(70\%) & \multirow[t]{2}{*}{8} & \multirow{2}{*}{2} & \multirow{2}{*}{91} & \multirow{2}{*}{$>94$} \\
\hline & + EAF Dust (30\%) & & & & \\
\hline
\end{tabular}




\section{§5.7 Chemical Analysis of DRI}

\section{\$5.7.1 Degree of Metallization of DRI}

DRIs made on campus have been analyzed by Frank Huang, using generally accepted methods without any problem. In order to determine the degree of metallization of DRI, total iron and metallic iron were determined by titration. The copper sulfate method has been used for the determination of metallic iron. This method (see appendix B) was provided by a colleague on campus who is a chemist formerly employed by one of the local steel companies.

Two sets of samples for chemical analysis were prepared from each DRI cake (except the DRI cake from Crucible \#1 of Trial \#8 which was broken and mixed up before sampling) produced in the pilot plant to be analyzed by two commercial chemical laboratories, namely, COREM of Quebec City, Canada and the chemical laboratory of CSM, ROME, Italy. The COREM report came first and contained many abnormalities. The best DRI based on visual and metallographic examination were determined to be of very low degree of metallization. The other situation was that the bottom layer had a higher degree of metallization than the main body and the top layer. These abnormalities appeared in similar ways in the report from the chemical laboratory in Rome. Through an effort over a period of several months, we found that: (1) the systematic errors in the results reported by commercial chemical laboratories were caused by incomplete extraction of metallic iron in the method which was designed for low temperature DRI, and. (2) The reliability of the copper sulfate method was confirmed for the analysis of high temperature DRI. The details are given in Appendix C.

Ground samples were returned by COREM and analyzed by Frank Huang using the copper sulfate method. These results are listed in Table 5-6 and Figure 5-20 for DRI made from iron ores and in Tables 5-7 and Figure 5-21 for those from waste oxides. The apparent densities of DRI, an average value of 10 pieces, are also given in Table 5.6 and 5.7 which were measured on campus.

DRIs in the top layer and the main body, in general, have very high degrees of metallization (see Figures 5-20 and 5-21). For the reduction of iron ore, the degrees of metallization of the DRI in the top layer and the main body are between 95 and $99 \%$, except one specimen (Crucible \#2 of Trial \#2). The specimen was not handled properly during discharging and cooling (one side of the crucible wall was broken). These results mean that the mechanism of prevention of reoxidation of sponge iron (see Figure 1-1) which is the basis of the McMaster Process is functioning. Furthermore, in comparison with the results obtained on campus, the top layer DRI produced in the pilot plant is better (because of better flame expansion in the longer combustion chamber and less turbulence). On the other hand, the bottom layer is much worse because the excessive cooling below due to inadequate insulation. The very large scattering of the data including high values of the degree of metallization for the bottom layer (see Figure 5-20), indicates that improved operation is within our reach. In term of the average value for the whole bed, in view of the design flaws and operational difficulties, these DRIs are excellent, both in chemical and physical properties. 
Figure 5-20. The degree of metallization of three portions of every DRI cake made from iron ores. The average values of DRI cakes are also included
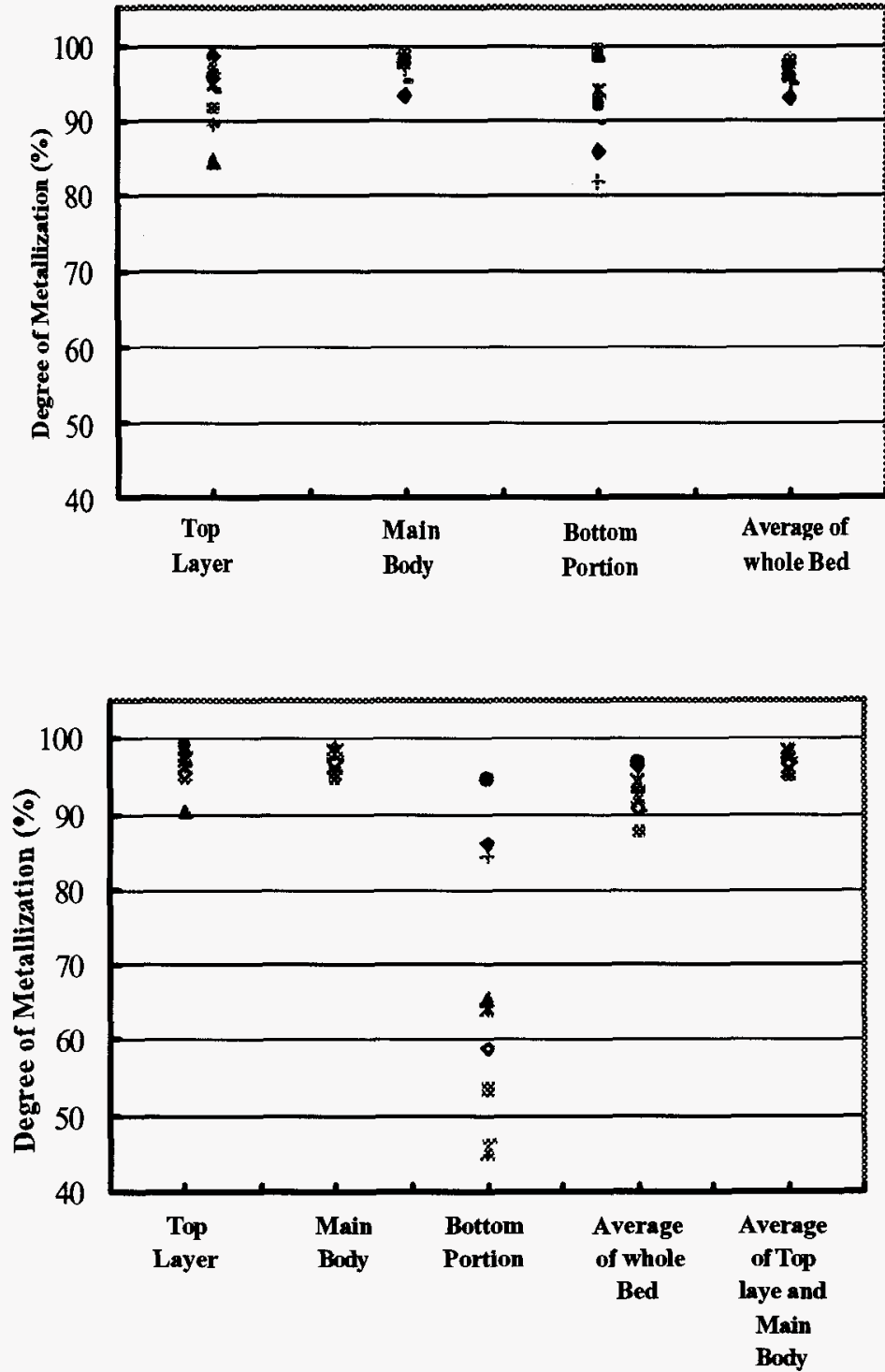

Figure 5-21. The degree of metallization of three portions of every DRI cake made from waste oxides. The average values of DRI cakes are also included.

For the case of waste oxides reduction, the degrees of metallization of DRI of top layers are between 85 and $99 \%$, those of main bodies are between 93 and $99 \%$, and those of bottom portion are between 82 to $99 \%$. For the average value, the degree of metallization of the whole DRI bed is between 93 and $98 \%$. In this case, the degree of metallization of DRI of the bottom portion is much higher than that for the reduction of iron ores. The reason is that the total amount 
of iron oxides in waste oxides in the pellet bed is less than that in the case for iron ore, so that endothermic reactions require less total heat. Within the comparable total heating time, there was enough heat transferred down to the bottom of the pellet bed for the reduction (please compare the temperatures at the bottom of crucible \#1 in Figures 5-8 to 5-10)

\section{§5.7.2 The Removal of Zinc and Lead}

For three tests involving EAF dust, the analytical results are shown in table 5-8. The excessive cooling by running water led to unacceptably low removal rate for the bottom portion. For the top layer and the main body, the results are excellent. The weighted average values for the whole bed are listed in the fourth row for each crucible. The removal rate of zinc is between $94 \%$ and $99 \%$, and removal of lead is almost complete. The density values of DRI are also listed.

Table 5-6 The chemical analyses of DRI made of iron ores in the pilot plant

\begin{tabular}{|c|c|c|c|c|c|c|c|c|c|c|}
\hline \multirow[t]{2}{*}{ No } & \multirow[t]{2}{*}{$\begin{array}{c}\text { Crucible } \\
\text { No. }\end{array}$} & \multirow{2}{*}{ 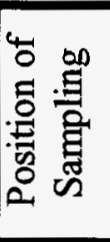 } & \multirow{2}{*}{$\begin{array}{l}\text { Weight } \\
\text { Fraction } \\
(\%)\end{array}$} & \multirow{2}{*}{ 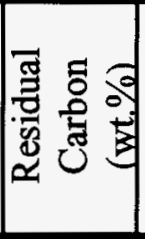 } & \multirow{2}{*}{$\begin{array}{l}\text { Density } \\
\left(\mathrm{g} / \mathrm{cm}^{3}\right)\end{array}$} & \multicolumn{3}{|c|}{$\begin{array}{c}\text { Analyzed } \\
\text { at McMaster Univ. * }\end{array}$} & \multicolumn{2}{|c|}{ Average } \\
\hline & & & & & & $\begin{array}{c}\mathrm{TFe} \\
(\mathrm{wt} \%)\end{array}$ & $\begin{array}{c}\mathrm{MFe} \\
(\mathrm{wt} \% \text { ) }\end{array}$ & $\begin{array}{l}\text { M.D. } \\
(\%)\end{array}$ & & \\
\hline \multirow{6}{*}{1} & \multirow{3}{*}{$\begin{array}{l}\text { 1: } \quad \text { Taconite, } \\
\mathrm{C} / \mathrm{O}=0.8 \\
120 \mathrm{~mm} / 60 \mathrm{~min} \text {, } \\
1250 \\
1500^{\circ} \mathrm{C}\end{array}$} & Top & 11.86 & 0.04 & 4.12 & 90.4 & 88.5 & 97.9 & M.D & 96.3 \\
\hline & & M.B. & 74.44 & 0.07 & 4.05 & 86.6 & 84.8 & 97.9 & $\mathrm{C}$ & 0.63 \\
\hline & & $\mathrm{Bttm}$ & 13.71 & 4.19 & 2.13 & 77.2 & 66.5 & 86.1 & Dens & 3.80 \\
\hline & \multirow[b]{3}{*}{$\begin{array}{l}120 \mathrm{~mm} / 60 \\
\mathrm{~min}, 1250 \\
\text { to } 1500^{\circ} \mathrm{C}\end{array}$} & Top & 11.53 & 0.04 & 4.12 & 89.8 & 86.9 & 96.8 & M.D & 87.5 \\
\hline & & M.B. & 70.39 & 0.17 & 4.05 & 85.1 & 80.6 & 94.7 & $\mathrm{C}$ & 1.51 \\
\hline & & $\mathrm{Bttm}$ & 18.09 & 7.63 & 2.13 & 69.4 & 37.1 & 53.5 & Dens & 3.71 \\
\hline \multirow{6}{*}{2} & \multirow[t]{3}{*}{ 1: } & Top & 11.75 & 0.04 & 4.36 & 91.0 & 88.6 & 97.4 & M.D & 92.1 \\
\hline & & M B. & 76.40 & 0.30 & 3.89 & 87.2 & 86.0 & 98.6 & $\mathrm{C}$ & 1.18 \\
\hline & & $\mathrm{Bttm}$ & 11.86 & 8.02 & 2.29 & 69.3 & 31.3 & 45.2 & Dens & 3.76 \\
\hline & \multirow{3}{*}{ Toronite } & Top & 11.86 & 0.06 & 4.19 & 91.8 & 82.8 & 90.2 & M.D & 93.7 \\
\hline & & \begin{tabular}{|l|} 
M.B. \\
\end{tabular} & 82.48 & 0.07 & 3.84 & 87.5 & 84.2 & 96.2 & $\mathrm{C}$ & 0.45 \\
\hline & & Bttm & 5.65 & 6.84 & 2.12 & 72.0 & 47.1 & 65.4 & Dens & 3.78 \\
\hline & \multirow{2}{*}{$\begin{array}{l}\text { Taconite, } \\
\mathrm{C} / \mathrm{O}=0.9\end{array}$} & Top & 11.80 & 0.04 & 4.89 & 91.3 & 88.8 & 97.3 & M.D & 94.2 \\
\hline & & M.B. & 77.13 & 0.07 & 4.00 & 87.5 & 85.8 & 98.1 & $\mathrm{C}$ & 0.89 \\
\hline
\end{tabular}




\begin{tabular}{|c|c|c|c|c|c|c|c|c|c|c|}
\hline \multirow[t]{4}{*}{3} & $\begin{array}{l}120 \mathrm{~mm} / 60 \\
\mathrm{~min}, 1250 \\
\text { to } 1500^{\circ} \mathrm{C}\end{array}$ & $\mathrm{Bttm}$ & 11.07 & 7.46 & 2.09 & 71.3 & 45.7 & 64.1 & Dens & 3.89 \\
\hline & \multirow{3}{*}{$\begin{array}{l}\text { Carajas, } \\
\text { C/0 }=0.85 \\
120 \mathrm{~mm} / 60 \\
\min , 1250 \\
\text { to } 1500^{\circ} \mathrm{C}\end{array}$} & Top & 12.28 & 0.04 & 5.21 & 89.4 & 88.4 & 98.9 & M.D & 96.7 \\
\hline & & M.B. & 73.76 & 0.16 & 4.17 & 89.3 & 86.4 & 96.8 & C & 0.96 \\
\hline & & $\mathrm{Bttm}$ & 13.97 & 6.03 & 1.84 & 78.6 & 74.2 & 94.4 & Dens & 3.97 \\
\hline \multirow{6}{*}{4} & \multirow{3}{*}{$\begin{array}{l}\text { Carajas, } \\
\mathrm{C} / 0=0.8 \\
120 \mathrm{~mm} / 60 \\
\mathrm{~min}, 1250 \\
\text { to } 1500^{\circ} \mathrm{C}\end{array}$} & Top & 11.83 & 0.04 & 3.38 & 90.4 & 86.5 & 95.7 & M.D & 93.6 \\
\hline & & M.B. & 72.17 & 0.14 & 3.27 & 86.7 & 82.6 & 95.3 & C & 1.05 \\
\hline & & $\mathrm{Bttm}$ & 16.01 & 5.92 & 1.63 & 76.6 & 64.7 & 84.5 & Dens & 3.02 \\
\hline & \multirow{3}{*}{$101500^{\circ}$} & Top & 11.53 & 0.03 & 4.40 & 91.1 & 88.0 & 96.6 & M.D & 90.2 \\
\hline & & M.B. & 76.91 & 0.31 & 4.07 & 85.4 & 82.8 & 97.0 & C & 1.16 \\
\hline & & $\mathrm{Bttm}$ & 11.55 & 7.99 & 2.10 & 68.1 & 26.1 & 38.3 & Dens & 3.88 \\
\hline \multirow{3}{*}{9} & \multirow{3}{*}{$\begin{array}{l}\text { 1: Carajas, } \\
\mathrm{C} / 0=0.8 \\
120 \mathrm{~mm} / 60 \mathrm{~min} \text {, } \\
1250 \\
1500^{\circ} \mathrm{C}\end{array}$} & Top & 12.09 & 0.04 & 5.13 & 89.4 & 84.2 & 94.2 & M.D & 90.2 \\
\hline & & M.B. & 74.04 & 0.37 & 3.42 & 89.5 & 87.4 & 97.7 & C & 1.76 \\
\hline & & $\mathrm{Bttm}$ & 13.87 & 10.72 & 1.84 & 67.7 & 31.5 & 46.5 & Dens & 3.41 \\
\hline \multirow{3}{*}{$\begin{array}{l}\stackrel{\widehat{\alpha}}{5} \\
\stackrel{0}{0}\end{array}$} & \multirow{3}{*}{$\begin{array}{l}\text { 1: Taconite, } \\
\mathrm{C} / \mathrm{O}=0.8 \\
120 \mathrm{~mm} / 60 \mathrm{~min}, \\
1250 \quad \text { to } \\
1500^{\circ} \mathrm{C}\end{array}$} & Top & 11.64 & 0.04 & 5.27 & 88.7 & 84.4 & 95.2 & M.D & 90.7 \\
\hline & & M.B. & 72.91 & 0.04 & 4.14 & 84.2 & 81.4 & 96.7 & $\mathrm{C}$ & 1.07 \\
\hline & & $\mathrm{Bttm}$ & 15.45 & 6.73 & 2.07 & 70.6 & 41.5 & 58.8 & Dens & 3.95 \\
\hline
\end{tabular}


Table 5-7 The chemical analyses of DRI made of waste oxides in the pilot plant

\begin{tabular}{|c|c|c|c|c|c|c|c|c|c|c|}
\hline \multirow[t]{2}{*}{ No } & \multirow[t]{2}{*}{$\begin{array}{c}\text { Crucible } \\
\text { No. }\end{array}$} & \multirow{2}{*}{ 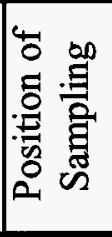 } & \multirow{2}{*}{$\begin{array}{l}\text { Weight } \\
\text { Fraction } \\
(\%)\end{array}$} & \multirow{2}{*}{ 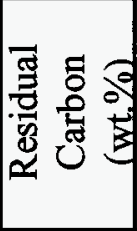 } & \multirow{2}{*}{$\begin{array}{l}\text { Density } \\
\left(\mathrm{g} / \mathrm{cm}^{3}\right)\end{array}$} & \multicolumn{3}{|c|}{$\begin{array}{c}\text { Analyzed } \\
\text { at McMaster Univ. * }\end{array}$} & \multicolumn{2}{|c|}{ Average } \\
\hline & & & & & & $\begin{array}{c}\mathrm{TFe} \\
\text { (wt.\%) }\end{array}$ & $\begin{array}{l}\text { MFe } \\
(w t . \%)\end{array}$ & $\begin{array}{r}\text { M.D. } \\
(\%)\end{array}$ & & \\
\hline \multirow{6}{*}{5} & \multirow{3}{*}{$\begin{array}{l}\text { 1: BOF Sludge, } \\
\mathrm{C} / \mathrm{O}=1.0 \\
120 \mathrm{~mm} / 60 \mathrm{~min} . \\
1250 \sim 1475^{\circ} \mathrm{C}\end{array}$} & Top & 12.48 & 0.078 & 5.08 & 80.4 & 79.2 & 98.5 & M.D & 93.0 \\
\hline & & M B. & 75.07 & 0.078 & 4.95 & 80.7 & 75.2 & 93.2 & $\mathrm{C}$ & 0.08 \\
\hline & & Bttm & 12.45 & 0.085 & 4.54 & 77.8 & 67.0 & 86.1 & Dens & 4.92 \\
\hline & \multirow{3}{*}{$\begin{array}{l}\text { 2: BOF Sludge, } \\
\mathrm{C} / \mathrm{O}=1.05 \\
120 \mathrm{~mm} / 60 \mathrm{~min} . \\
1250 \sim 1475^{\circ} \mathrm{C}\end{array}$} & Top & 12.62 & 0.120 & 5.27 & 81.8 & 75.2 & 91.9 & M.D & 98.0 \\
\hline & & M.B. & 81.25 & 0.122 & 4.05 & 83.8 & 82.8 & 98.8 & $\mathrm{C}$ & 0.13 \\
\hline & & $\mathrm{Bttm}$ & 6.12 & 0.309 & 3.64 & 84.0 & 83.6 & 99.5 & Dens & 4.18 \\
\hline \multirow{6}{*}{6} & \multirow{3}{*}{$\begin{array}{l}\text { 1: BOF Sludge, } \\
\mathrm{C} / \mathrm{O}=1.05 \\
120 \mathrm{~mm} / 60 \mathrm{~min} . \\
1250 \sim 1475^{\circ} \mathrm{C}\end{array}$} & Top & 12.39 & 0.080 & 5.11 & 83.0 & 80.8 & 97.3 & M.D & 98.0 \\
\hline & & M.B. & 77.93 & 0.176 & 3.54 & 83.4 & 82.2 & 98.6 & $\mathrm{C}$ & 0.67 \\
\hline & & $\mathrm{Bttm}$ & 9.69 & 5.411 & 2.19 & 72.0 & 67.6 & 93.9 & Dens & 3.60 \\
\hline & \multirow{3}{*}{$\begin{array}{l}\text { 2: BOF Sludge, } \\
\mathrm{C} / \mathrm{O}=1.0 \\
120 \mathrm{~mm} / 60 \mathrm{~min} . \\
1250 \sim 1475^{\circ} \mathrm{C}\end{array}$} & Top & 12.06 & 0.080 & 5.35 & 84.1 & 71.2 & 84.7 & M.D & 96.4 \\
\hline & & M.B. & 82.34 & 0.128 & 5.01 & 80.8 & 79.1 & 97.9 & $\mathrm{C}$ & 0.14 \\
\hline & & Bttm & 5.60 & 0.488 & 4.27 & 80.2 & 79.2 & 98.8 & Dens & 5.01 \\
\hline \multirow{3}{*}{9} & \multirow{3}{*}{$\begin{array}{l}\text { 2: Mill Scale, } \\
\mathrm{C} / \mathrm{O}=1.0 \\
120 \mathrm{~mm} / 60 \mathrm{~min} . \\
1250 \sim 1500^{\circ} \mathrm{C}\end{array}$} & Top & 12.48 & 0.067 & 4.63 & 90.6 & 86.0 & 94.9 & M.D & 97.1 \\
\hline & & M.B. & 75.23 & 2.108 & 4.19 & 90.7 & 88.8 & 97.9 & $\mathrm{C}$ & 2.02 \\
\hline & & Bttm & 12.29 & 3.460 & 2.91 & 88.9 & 83.8 & 94.3 & Dens & 4.09 \\
\hline
\end{tabular}


Table 5-8 The chemical analyses of DRI made of iron ores in the pilot plant

\begin{tabular}{|c|c|c|c|c|c|c|c|c|c|c|c|}
\hline \multirow[t]{2}{*}{ No } & \multirow[t]{2}{*}{$\begin{array}{c}\text { Crucible } \\
\text { No. }\end{array}$} & \multirow{2}{*}{ 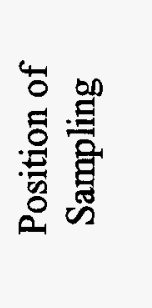 } & \multirow{2}{*}{ 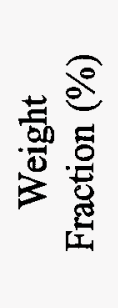 } & \multirow{2}{*}{ 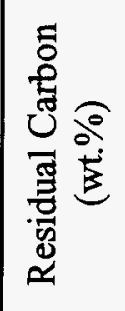 } & \multirow{2}{*}{ 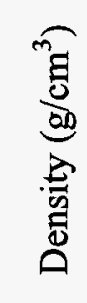 } & \multicolumn{3}{|c|}{$\begin{array}{l}\text { Analyzed at McMaster } \\
\text { Using Copper sulfate } \\
\text { Method }\end{array}$} & \multirow{2}{*}{$\begin{array}{c}\mathrm{Zn} \\
\text { (wt.\%) }\end{array}$} & \multirow{2}{*}{ 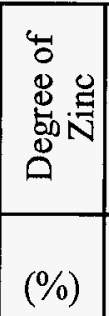 } & \multirow{2}{*}{$\begin{array}{r}\mathrm{Pb} \\
\text { (ppn }\end{array}$} \\
\hline & & & & & & $\begin{array}{c}\mathrm{TFe} \\
\text { (wt.\%) }\end{array}$ & $\begin{array}{c}\mathrm{MFe} \\
\text { (wt.\%) }\end{array}$ & $\begin{array}{l}\text { M.D. } \\
(\%)\end{array}$ & & & \\
\hline \multirow{8}{*}{7} & \multirow{4}{*}{$\begin{array}{l}\quad \begin{array}{l}\quad(70 \% \mathrm{BO} \\
\text { F Sludge }\end{array} \\
+30 \% \mathrm{EAF} \\
\text { Dust }) \\
\quad \mathrm{C} / \mathrm{O}=1.05 \\
120 \mathrm{~mm} / 65 \mathrm{~min} \\
1250 \sim 1450^{\circ} \mathrm{C}\end{array}$} & Top & 12.45 & 0.126 & 4.25 & 70.7 & 67.8 & 95.9 & $\overline{0.10}$ & \begin{tabular}{|l|}
98.9 \\
\end{tabular} & $\overline{<1}$ \\
\hline & & M. B. & 83.87 & 0.181 & 3.62 & 70.9 & 69.2 & 97.6 & 0.14 & \begin{tabular}{|l|}
98.4 \\
\end{tabular} & $\overline{33}$ \\
\hline & & Bttm. & 3.68 & 5.221 & 2.15 & 57.9 & 53.4 & 92.2 & 4.25 & 41.0 & $\overline{290}$ \\
\hline & & Average & & 0.36 & 3.64 & & & 97.2 & 0.28 & 96.7 & $13 ;$ \\
\hline & \multirow{4}{*}{$\begin{array}{l}2: \quad(70 \% \mathrm{BO} \\
\text { F Sludge } \\
+30 \% \mathrm{EAF} \\
\text { Dust }) \\
\mathrm{C} / \mathrm{O}=1.0, \\
120 \mathrm{~mm} / 65 \mathrm{~min} \\
, \quad 1250 \sim 1450^{\circ} \mathrm{C}\end{array}$} & Top & 12.40 & 0.136 & 4.25 & 71.8 & 64.2 & 89.4 & 0.13 & 98.6 & $<1$ \\
\hline & & M. B. & 81.57 & 0.214 & 3.31 & 72.2 & 70.1 & 97.1 & 0.29 & 96.8 & $\overline{36}$ \\
\hline & & Bttm. & 6.03 & 5.960 & 1.64 & 56.7 & 46.5 & 82.0 & 4.98 & 30.0 & $\overline{300}$ \\
\hline & & Average & & 0.55 & 3.33 & & & & 0.54 & 93.5 & 20 \\
\hline \multirow{4}{*}{8} & \multirow{3}{*}{$\begin{array}{l}\quad \text { 2: } \quad(70 \% \mathrm{BO} \\
\text { F Sludge } \\
+30 \% \mathrm{EAF} \\
\text { Dust })\end{array}$} & Top & 12.42 & 0.118 & 3.72 & 71.7 & 67.5 & 94.1 & 0.075 & 99.2 & $\overline{<1}$ \\
\hline & & M. B. & 83.77 & 0.547 & 3.26 & 71.4 & 68.1 & 95.4 & 0.081 & \begin{tabular}{|l|}
99.1 \\
\end{tabular} & 5 \\
\hline & & Bttm. & 3.81 & 2.295 & 1.59 & 66.6 & 59.9 & 89.9 & 1.39 & 83.5 & 120 \\
\hline & $\begin{array}{l}\text { Dust) } \\
\mathrm{C} / \mathrm{O}=1.05 \\
120 \mathrm{~mm} / 65 \mathrm{~min} \\
1250 \sim 1450^{\circ} \mathrm{C}\end{array}$ & Average & & 0.56 & 3.25 & & & 95.0 & 0.13 & 98.5 & 46 \\
\hline
\end{tabular}




\section{$\$ 5.8$ Summary}

Pilot plant trials were conducted in an industrial setting, in terms of facilities and personnel, with little time for planning and preparation. The furnace used for reduction experiments had large enough chamber for flame expansion, closer to commercial practice, and less turbulence for the pellet bed. There was a very serious design flaw - the bottom of the crucible was insufficiently insulated from the bank of pipes containing running water. The operational problem, viz., the inability to shut off the air flow with natural gas, had an significant impact on the results. There was about one minute duration, after turning off natural gas, and before discharging, during which the DRI bed was exposed to an air flow above and as a result, re-oxidation took place.

1. All five types of iron-bearing raw material used can be processed successfully. BOF sludge and millscale have the best reducibility and shrinkage to the extent that the adverse effect of bottom cooling is not pronounced.

2. The main body of all DRI cakes produced, representing $70 \%$ to $84 \%$ of the whole bed, has a degree of metallization of iron oxide in the range of $95 \%$ to $98 \%$ with an apparent density around $4 \mathrm{~g} / \mathrm{cm}^{3}$, significantly heavier than the steelmaking slag.

3. For the top layer, the apparent density of DRI is always higher than that of the main body. In general, the degree of metallization of the top la yer is also higher than that of the main body, except in a few cases where re-oxidation of metallic iron was evident.

4. For the bottom layer, representing $5 \%$ to $18 \%$ of the DRI bed, the reduction of metal oxides were hindered and delayed due to heat loss to the supporting structure. The adverse effect is most clearly shown in Trials \#7 and \#8. The bottom fraction, which is about $4 \%$ to $6 \%$ of DRI produced, contains most of the residual zinc and lead in the bed.

5. If we were able to go back to the pilot plant and repeat these experiments, the following two changes on the equipment would have been implemented:

- Put another insulation brick between the bottom of the crucible and the bank of pipes of cooling water.

- Turn off the air flow in few second, after cutting off natural gas, to shut down the burner. 
Leaving all other imperfections as they were, it would be very reasonable to anticipate that the produced DRI would be dense and shining spheres with essentially complete metallization of iron oxide and complete removal of zinc and lead. 
§6 Systematic Experimentation and Mathematical Analysis for Technology Transfer

§6.1 DESIGN OF EXPERIMENTS 93

\$6.2 RESULTS OF EXPERIMENTS AND MATHEMATICAL ANALYSIS 94 


\section{§6 Systematic Experimentation and Mathematical Analysis for Technology Transfer}

\section{§6.1 Design of Experiment}

This series of 15 experiments were designed to characterize the performance of the process (e.g. productivity, properties of DRI, etc.) as functions of major process parameters (composition of green balls, properties of coal, and processing rate). These experiments were carried out at McMaster University by using the natural gas fired furnace. Several important process variables were maintained constant in all these 15 experiments.

- Taconite ore concentrate and American coals

- Green balls were in the size range $16 \mathrm{~mm}$ to $19 \mathrm{~mm}$ and a bed height of $120 \mathrm{~mm}$

- Flame temperature was controlled to rise to $1600^{\circ}$ to $1650^{\circ} \mathrm{C}$ and fully oxidized,

- The heating rate was controlled by keeping the temperature right on the top of the crucible aimed at $1250^{\circ} \mathrm{C}$ for 5 minutes, then raised to $1500^{\circ} \mathrm{C}$

- The charging and discharging methods were the same as described in $\$ 2.3 .6$ and $\S 2.3 .7$.

The statistical design for systematic experimentation of reduction of taconite is based on the "Central Composite Design", 5$]$. The table of central composite design for 3 factors is listed in table 6-1, the value of $\alpha$ is 1.215 for 3 factors:

The three variables of the study are listed bellows:

- The carbon (in coal) addition is denoted as $\mathrm{C} / \mathrm{O}$ which stands for the gram-atomic ratio of total carbon of coal to the combined oxygen in iron oxides.

- Volatile matter of coal is denoted as VM which stands for the volatile matter content (wt.\%) of coal or coal mixture in the green balls.

- Processing rate denoted as PR which stands for the ratio of the height of pellet bed in $\mathrm{mm}$ to the total heating time.

In order to study these factors in the range as necessary, we choose the level of each factor as follows:

- The coal addition, $\mathrm{C} / \mathrm{O}$, is centered at 1.0 and take 0.1 as 1 level.

- The volatile matter, VM, is centered at 28.0 and take 4.0 as 1 level.

- The processing rate, PR, is centered at 2.0 and take 0.2 as 1 level. 
Table 6-1 The Central Composite Design for 3 Factors

\begin{tabular}{|c|c|c|c|}
\hline No. & Factor-1 & Factor-2 & Factor-3 \\
\hline 1 & 1 & 1 & -1 \\
\hline 2 & 1 & 1 & 1 \\
\hline 3 & 1 & -1 & -1 \\
\hline 4 & 1 & -1 & 1 \\
\hline 5 & -1 & 1 & -1 \\
\hline 6 & -1 & 1 & 1 \\
\hline 7 & -1 & -1 & -1 \\
\hline 8 & -1 & -1 & 0 \\
\hline 9 & $\alpha$ & 0 & 0 \\
\hline 10 & $-\alpha$ & 0 & 0 \\
\hline 11 & 0 & $\alpha$ & 0 \\
\hline 12 & 0 & $-\alpha$ & $\alpha$ \\
\hline 13 & 0 & 0 & $-\alpha$ \\
\hline 14 & 0 & 0 & 0 \\
\hline 15 & 0 & 0 & \\
\hline
\end{tabular}

Based on the values of central points and the levels, the actual arrangements are designed as shown in Table 6-2.

\section{\$6.2 Results of Experiments and Mathematical Analysis}

Experimental results were expressed by quadratic models as follows:

$$
\mathrm{U}_{\mathrm{i}}=\mathrm{B}_{0}+\mathrm{B}_{1} \mathrm{X}+\mathrm{B}_{2} \mathrm{Y}+\mathrm{B}_{3} \mathrm{Z}+\mathrm{B}_{4} \mathrm{XY}+\mathrm{B}_{5} \mathrm{XZ}+\mathrm{B}_{6} \mathrm{YZ}+\mathrm{B}_{7} \mathrm{X}^{2}+\mathrm{B}_{8} \mathrm{Y}^{2}+\mathrm{B}_{9} Z^{2}
$$

where:

$\mathrm{X}=\mathrm{C} / \mathrm{O}, \mathrm{C}=$ Total Carbon of Coal (g-atom), $\mathrm{O}=$ The Oxygen combined with iron (g-atom)

$\mathrm{Y}=$ volatile matter of coal, (wt.\%)

$\mathrm{Z}=\quad$ processing rate $(\mathrm{PR}), \mathrm{mm} / \mathrm{min}$. for a give height of pellet bed $(\mathrm{H}, \mathrm{mm})$, Processing time $(\mathrm{t}, \mathrm{min}$.), $\mathrm{PR}=\mathrm{H} / \mathrm{t}$

$\mathrm{U}_{1}=\quad$ degree of metallization of iron oxide (\%) 


$$
\begin{aligned}
& \mathrm{U}_{2}=\text { residual carbon }(\mathrm{wt} . \%) \\
& \left.\mathrm{U}_{3}=\text { density of DRI (gram/ } \mathrm{cm}^{3}\right) \\
& \mathrm{U}_{4}=\Delta \mathrm{O} / \Delta \mathrm{C} \text { (gram-atom/gram-atom) (see } \$ 3.4 \text { for the definition) }
\end{aligned}
$$

Table 6-2. The Arrangement of the systematic experimentation

\begin{tabular}{|c|c|c|c|c|}
\hline Exp. No. & C/O & VM & PR(mm/min) & Time(min) \\
\hline 1 & 1 & 34 & 2.2 & 54.5 \\
\hline 2 & 1 & 34 & 1.8 & 66.7 \\
\hline 3 & 1 & 22 & 2.2 & 54.5 \\
\hline 4 & 1 & 22 & 1.8 & 66.7 \\
\hline 5 & 0.8 & 34 & 2.2 & 54.5 \\
\hline 6 & 0.8 & 34 & 1.8 & 66.7 \\
\hline 7 & 0.8 & 22 & 2.2 & 54.5 \\
\hline 8 & 0.8 & 22 & 1.8 & 66.7 \\
\hline 9 & 1.0215 & 28 & 2 & 60 \\
\hline 10 & 0.7785 & 28 & 2 & 60 \\
\hline 11 & 0.9 & 35.29 & 2 & 60 \\
\hline 12 & 0.9 & 20.71 & 2 & 60 \\
\hline 13 & 0.9 & 28 & 2.243 & 53.5 \\
\hline 14 & 0.9 & 28 & 1.757 & 68.3 \\
\hline 15 & 0.9 & 28 & 2 & 60 \\
\hline
\end{tabular}

After each reduction experiment, DRIs were separated into three portions (top layer, main body and bottom layer) and weighted. Samples from each portion were taken and chemically analyzed for the degree of metallization of iron oxide, residual carbon, and the determination of apparent density of DRI. For each portion, the performance parameters can be determined.

There are two important categories computed performance parameters, the first being the average value of $U_{1}, U_{2}$, and $U_{3}$ for the whole bed, with weighting factor of mass fractions of DRI in each portion, and the second being the changes of residual carbon and combined oxygen as functions of processing time. The ratio, $\Delta \mathrm{O} / \Delta \mathrm{C}$, represents the efficiency of the utilization of reductant. 
As an example, the results from data logging, chemical analysis and density measurement of DRI of experimental No. 1 are given in Fig. 6-1 and Table 6-3. The increase in the concentration of both $\mathrm{CO}$ and $\mathrm{CO}_{2}$, sampled at the top of the crucible after about 30 minutes of reduction, is due to the decrease of natural gas flow rate because the rate of consumption of heat by the pellet bed has lowered.

The most valuable output in term of laboratory data are the detailed expressions of these quadratic models. As an example of the usage of these quadratic relationships of productivity of furnace vs. degree of metallization is shown in Fig. 6-2. The productivity is expressed both in terms of weight of DRI and metallic iron.

It is obvious that the productivity of DRI may be increased by lowering the quality of the product through shortening process time and including the residual oxygen as part of the product. However, the productivity in term of metallic iron produced, as it should be for an ironmaking process, varies within a limited range in the domain of this design. The effect of volatile matter is clearly shown in Fig. 6-2. The dependence of productivity on $\mathrm{C} / \mathrm{O}$ ratio in green balls has been computed and found to be relatively insignificant, and therefore, not shown here.

From modeling, we recommend two cases to our colleagues in industry. Process parameters and expected performance are listed in table 6-4 and table 6-5. In both cases, the productivity in terms of metallic iron is lower than the maximum value and on the high side of the degree of metallization by having relatively longer residence time. We trade off a little of productivity for lower energy requirement and high rate in melting steps as well as much lower fines and dust generation in DRI plant and during shipping.

Table 6-3 Chemical Analysis and Density Measurement of DRI in Experiment No. 1

\begin{tabular}{|c|c|c|c|c|c|}
\hline Location in Bed & $\begin{array}{c}\text { Wt. Fraction } \\
(\%)\end{array}$ & M.D. & $\begin{array}{c}\text { Residual C. } \\
(\mathrm{wt} \%)\end{array}$ & $\begin{array}{c}\text { Density } \\
\left(\mathrm{g} / \mathrm{cm}^{3}\right)\end{array}$ & $\Delta \mathrm{O} / \Delta \mathrm{C}$ \\
\hline Top Layer & 12.03 & 98.62 & 0.037 & 5.03 & 0.991 \\
\hline Main Body & 66.67 & 99.76 & 1.177 & 3.04 & 1.049 \\
\hline $\begin{array}{c}\text { Bottom Layer } \\
\text { (or portion) }\end{array}$ & 21.30 & 81.87 & 8.425 & 1.81 & 1.449 \\
\hline Whole Bed & 100.00 & 95.81 & 2.58 & 3.02 & 1.128 \\
\hline
\end{tabular}




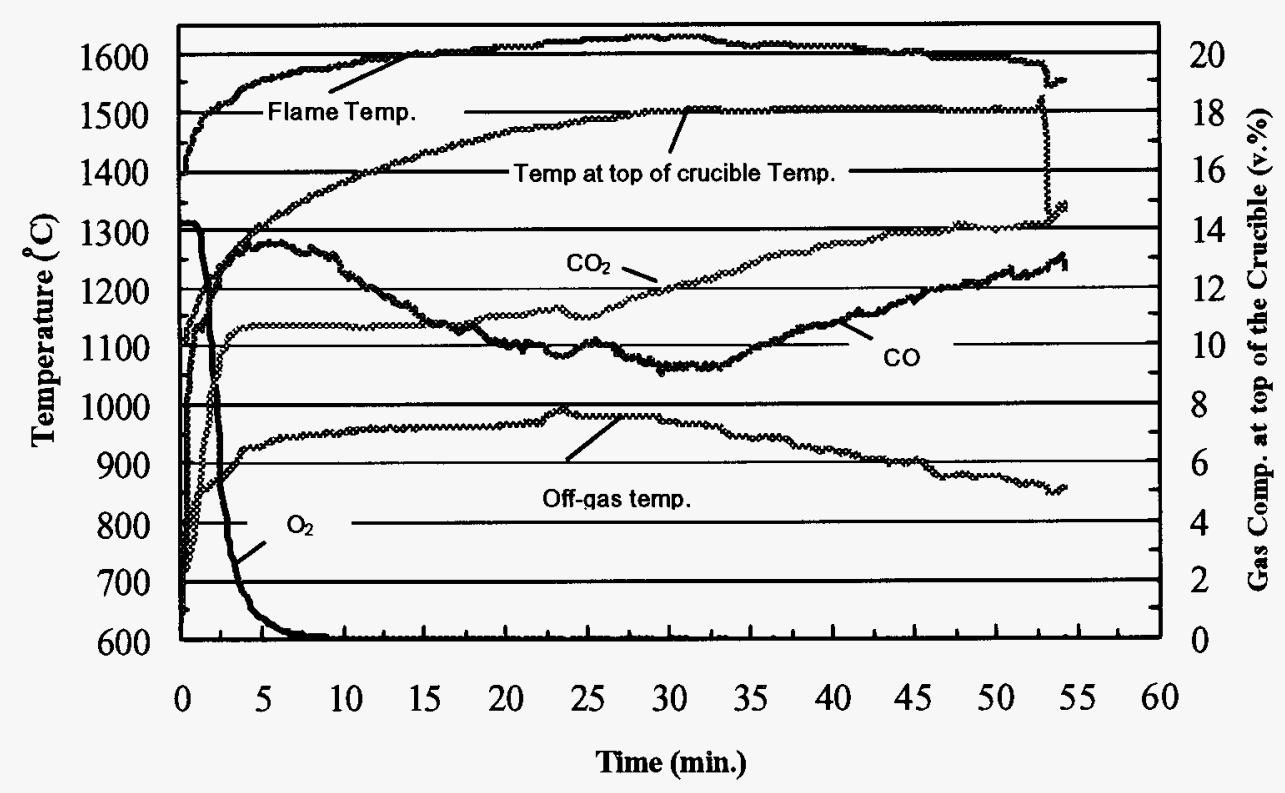

Figure 6-1. The furnace temperatures and gas composition at the top of crucible in Experiment No.1

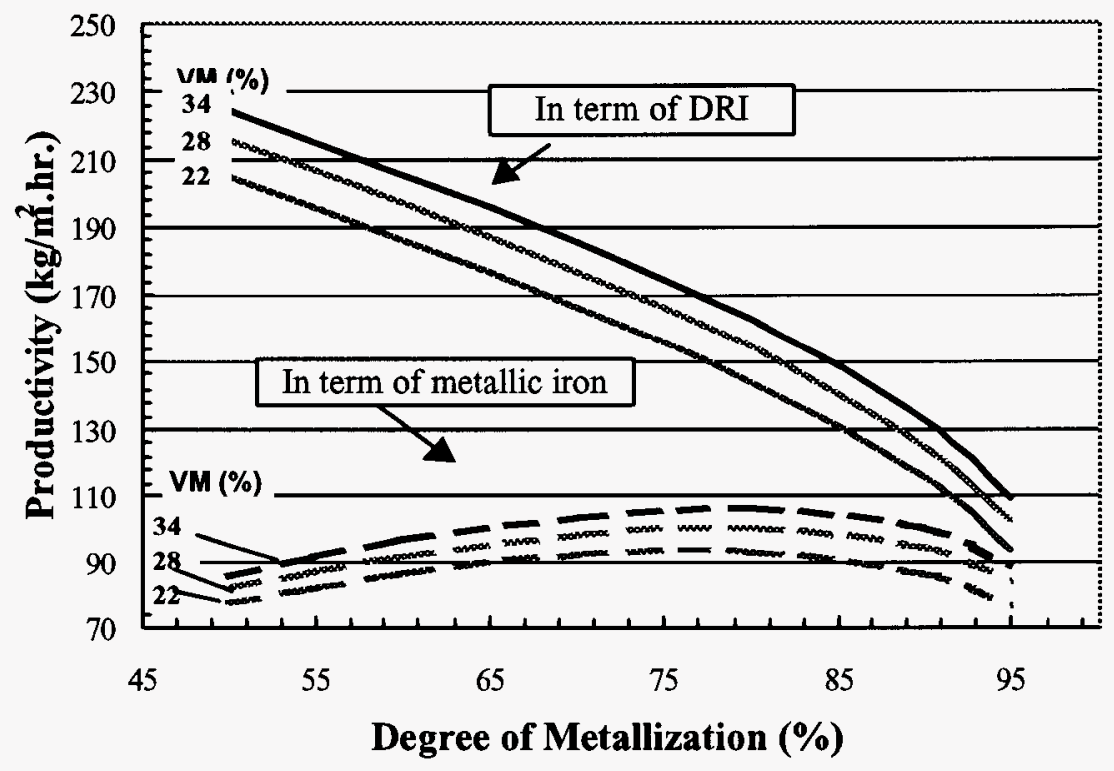

Figure 6-2. Productivity vs. Degree of Metallization $(\mathrm{C} / \mathrm{O}=0.9)$ 
Table 6-4 Recommended Conditions for Producing DRI of high Metallization Degree at High Productivity

\begin{tabular}{|c|c|c|c|c|}
\hline \multicolumn{5}{|l|}{ Recommended Conditions: } \\
\hline $\mathrm{C} / \mathrm{O}$ & 0.8 & \multicolumn{3}{|l|}{ Time } \\
\hline Volatile Matter & $34 \%$ & \multicolumn{3}{|c|}{ Temperature, above the pellet bed } \\
\hline Bed Height & $120 \mathrm{~mm}$ & \multicolumn{3}{|l|}{ Flame temperature } \\
\hline Size of Green Balls & $16-20 \mathrm{~mm}$ & & & \\
\hline Projected Results & Whole Bed & Top layer & \multicolumn{2}{|c|}{ Main Body } \\
\hline Degree of Metallization (\%) & 95 & 91 & \multicolumn{2}{|l|}{97} \\
\hline Density $\left(\mathrm{g} / \mathrm{cm}^{3}\right)$ & 3.1 & 4.9 & \multicolumn{2}{|l|}{3.0} \\
\hline Residual Carbon (\%) & 1.4 & 0 & \multicolumn{2}{|l|}{0.7} \\
\hline Weight Fraction (\%) & 100.0 & 11.7 & \multicolumn{2}{|c|}{75.5} \\
\hline Productivity $\mathrm{kg} / \mathrm{m}^{2} . \mathrm{h}$ & \multicolumn{4}{|c|}{125 in terms of DRI, 99 in terms of metallic iro } \\
\hline
\end{tabular}

Table 6-5 Recommended Conditions for Producing DRI of High Quality

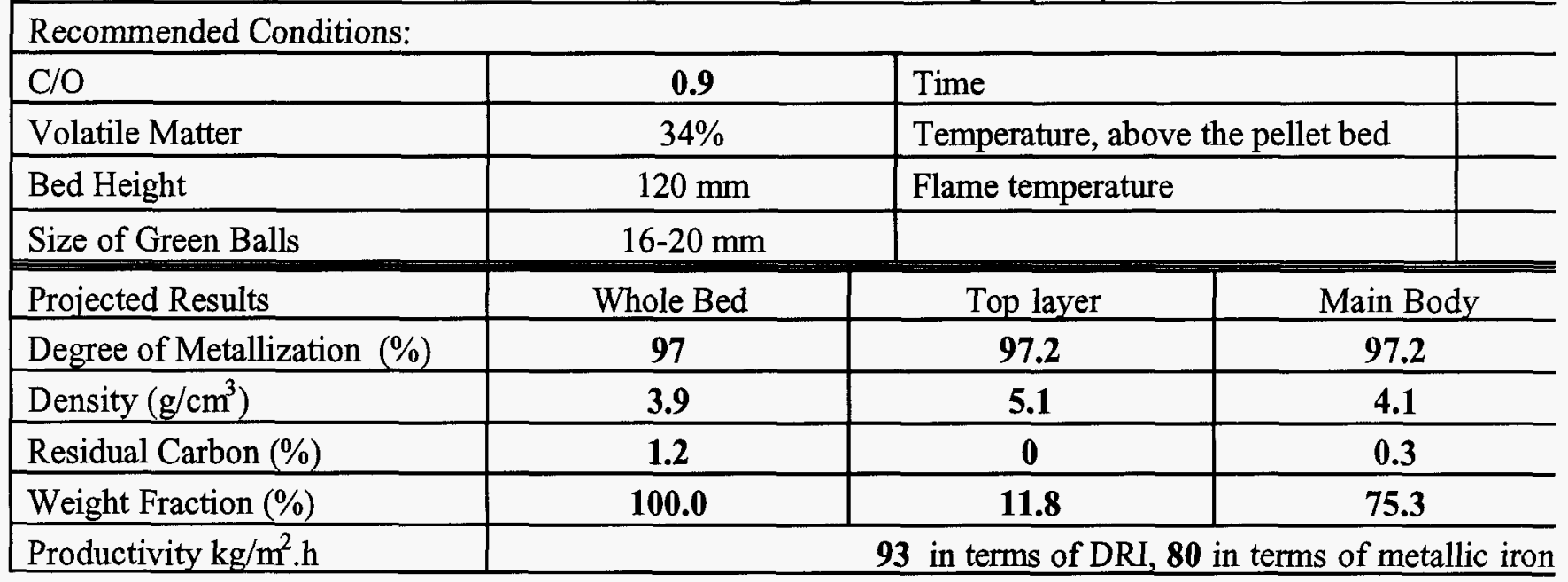




\section{$\S 7$ ENERGY CONSUMPTION AND ENVIRONMENT PROTECTION}

§7.1 In Comparison with Current RHF Practice 100

§7.2 In Comparison with blast Furnace for hot metal production 107

$\begin{array}{lll}\$ 7.3 \text { Summary } & 114\end{array}$ 


\section{§7 ENERGY CONSUMPTION AND ENVIRONMENT PROTECTION}

In this section of the report, this new technology will be compared with the current rotary hearth furnace practice, with respect to energy consumption and environmental protection considerations. The case with the blast furnace will be presented for hot metal production.

\section{\$7.1 In Comparison with Current RHF Practice}

In a RHF plant, there are two major sources of thermal energy for the process, namely, coal or carbon in the mixture (to serve as reductants first and then, gaseous reaction products as fuel in the freeboard) and the fuel (coal or natural gas) introduced through the burner. D. H. Wakelin and R. Furehan ${ }^{[6]}$ reported the typical energy input for ironmaking in a RHF as follows:

Table 7-1 Typical RHF Processes Input ${ }^{[6]}$

\begin{tabular}{|c|c|}
\hline Item of input per tonne of DRI & \\
\hline Iron Oxide Feed (68\%Fe) & $1300 \mathrm{~kg}$ \\
\hline Reduction Coal (75\% Fixed Carbon) & $380 \mathrm{~kg}(11.4 \mathrm{GJ})$ \\
\hline Burner Coal or Coal Equivalent (75\% Fixed Carbon) & $120 \mathrm{~kg}(5.36 \mathrm{GJ})$ \\
\hline Total Fuel Consumption & $500 \mathrm{~kg}(16.8 \mathrm{GJ})$ \\
\hline
\end{tabular}

For comparison, based on experimental results we have in our laboratory and in the pilot plant, the calculation of heat and mass balances are given below:

In Table 7-2, the typical chemical compositions of raw materials (coal and ore) and products (DRI and exit gas) are listed.

Table 7-2 Chemical Compositions

- Taconite Concentrate (wt.\%)

\begin{tabular}{|c|c|c|c|c|c|c|c|}
\hline $\mathrm{TFe}$ & $\mathrm{FeO}$ & $\mathrm{SiO}_{2}$ & $\mathrm{CaO}$ & $\mathrm{Al}_{2} \mathrm{O}_{3}$ & $\mathrm{MgO}$ & $\mathrm{S}$ & $\mathrm{P}$ \\
\hline 67.84 & 31.1 & 4.2 & 0.277 & 1.14 & 0.637 & 0.21 & 0.21 \\
\hline
\end{tabular}


- Coal Composition (wt.\%)

\begin{tabular}{|c|c|c|c|c|}
\hline C total & C fixed & Volatile Mater & Ash & S \\
\hline 82.00 & 60.81 & 34.36 & 5.08 & 0.60 \\
\hline
\end{tabular}

- DRI Composition (wt.\%)

\begin{tabular}{|c|c|c|c|c|c|c|c|c|c|c|}
\hline $\mathrm{TFe}$ & $\begin{array}{c}\mathrm{MF} \\
\mathrm{e}\end{array}$ & $\mathrm{FeO}$ & $\mathrm{S}$ & $\mathrm{C}$ & $\mathrm{SiO}_{2}$ & $\mathrm{Ab}_{2} \mathrm{O}_{3}$ & $\mathrm{CaO}$ & $\mathrm{MgO}$ & $\begin{array}{c}\text { Other } \\
\text { Oxides }\end{array}$ & $\begin{array}{c}\text { Degree of } \\
\text { Metallization( } \\
\% \text { ) }\end{array}$ \\
\hline 86.71 & 82.38 & 5.570 & 0.173 & 2.5 & 6.00 & 1.78 & 0.37 & 0.81 & 0.077 & 95 \\
\hline
\end{tabular}

- Exit Gas Composition (v.\%)

\begin{tabular}{|c|c|c|c|}
\hline $\mathrm{CO}_{2}$ & $\mathrm{H}_{2} \mathrm{O}$ & $\mathrm{N}_{2}$ & $\{\mathrm{~S}\}$ \\
\hline 21.1 & 14.64 & 64.24 & 0.01 \\
\hline
\end{tabular}

Natural gas is assumed to be $100 \% \mathrm{CH}_{4}$

For heat balance, the raw materials are assumed to be at the reference temperature $\left(25^{\circ} \mathrm{C}\right)$ and the DRI has an average temperature of $1400^{\circ} \mathrm{C}$. It is common to all ironmaking process that the gaseous reactants and products have very large mass and dominant impact on the overall thermal efficiency of the process. Results shown in Table 7-3 were calculated with the following assumptions:

- The combustion air is preheated to $850^{\circ} \mathrm{C}$, which could be attained with the use of a metal heat exchanger.

- The temperature of exit gas is assumed to be $1300^{\circ} \mathrm{C}$ which is unusually high, in order to suggest a sort of upper bound of energy consumption

- Natural gas is used at burners. 
Table 7-3 Mass and Heat Balance with Natural Gas Burners

Mass Balance
\begin{tabular}{|c|c|c|c|}
\hline \multicolumn{2}{|c|}{ Input } & \multicolumn{2}{c|}{ Output } \\
\hline & $\mathrm{kg}$ & $\mathrm{Kg}$ \\
\hline Taconite & 1276.3 & DRI & 1000.0 \\
\hline Reductant Coal & 268.9 & & 2706.7 \\
\hline Natural gas & 44.6 & \multirow{3}{*}{ Off Gas } & \\
\cline { 4 - 4 } & $62.4\left(\mathrm{~m}^{3}\right)$ & & $2026.7\left(\mathrm{Nm}^{3}\right)$ \\
\hline Preheated Air & 2116.0 & & 3706.7 \\
\cline { 2 - 4 } & $1643.5\left(\mathrm{Nm}^{3}\right)$ & Total & \\
\hline Total & 3706.7 & & \\
\hline
\end{tabular}

Heat Balance

\begin{tabular}{||l|r|r|l|r|r||}
\hline \multicolumn{1}{|c|}{ Input } & \multicolumn{1}{c|}{ MJ } & \multicolumn{1}{c|}{$\%$} & \multicolumn{1}{c|}{ Output } & MJ & $\%$ \\
\hline $\mathrm{C}+1 / 2 \mathrm{O}_{2} \rightarrow \mathrm{CO}$ & 0 & 0 & $\begin{array}{l}\text { Endothermic Direct } \\
\text { Reductions }\end{array}$ & 3082.9 & 29.47 \\
\hline $\mathrm{CO}+1 / 2 \mathrm{O}_{2} \rightarrow \mathrm{CO}_{2}$ & 5358.1 & 51.21 & $\begin{array}{l}\text { Decomposition of Coal } \\
\text { \& natural gas }\end{array}$ & 479.1 & 4.58 \\
\hline $\mathrm{H}_{2}+1 / 2 \mathrm{O}_{2} \rightarrow \mathrm{H}_{2} \mathrm{O}$ & 3205.9 & 30.64 & Sensible Heat of DRI & 1093.5 & 10.45 \\
\hline Preheated Air at $850^{\circ} \mathrm{C}$ & 1898.8 & 18.15 & Sensible Heat of Gas & 4274.0 & 40.85 \\
\hline & & & Heat Loss & 1533.1 & 14.65 \\
\hline Total & 10463 & 100.00 & Total & 10463 & 100.00 \\
\hline
\end{tabular}

When coal (same composition as shown in Table 7-2) is used at burners, instead of natural gas, with air preheating temperature of $850^{\circ} \mathrm{C}$ and exit temperature of $1300^{\circ} \mathrm{C}$, the computed results are shown in Table 7-4 and Table 7-5

Table 7-4 Chemical Composition of Products

- DRI Composition (wt.\%)

\begin{tabular}{|c|c|c|c|c|c|c|c|c|c|c|}
\hline $\mathrm{TFe}$ & $\mathrm{MFe}$ & $\mathrm{FeO}$ & $\mathrm{S}$ & $\mathrm{C}$ & $\mathrm{SiO}_{2}$ & $\mathrm{Ab}_{2} \mathrm{O}_{3}$ & $\mathrm{CaO}$ & $\mathrm{MgO}$ & $\begin{array}{c}\text { Other } \\
\text { Oxides }\end{array}$ & $\begin{array}{c}\text { Degree of } \\
\text { Metallization } \\
(\%)\end{array}$ \\
\hline 86.42 & 82.14 & 5.55 & 0.207 & 2.5 & 6.13 & 1.85 & 0.368 & 0.81 & 0.10 & 95 \\
\hline
\end{tabular}

- Exit Gas Composition (v.\%)

\begin{tabular}{|c|c|c|c|}
\hline $\mathrm{CO}_{2}$ & $\mathrm{H}_{2} \mathrm{O}$ & $\mathrm{N}_{2}$ & $\{\mathrm{~S}\}$ \\
\hline 23.85 & 10.94 & 65.21 & 0.01 \\
\hline
\end{tabular}


Table 7-5 Mass and Heat Balance with Coal Burners

\begin{tabular}{|c|c|c|c|}
\hline \multicolumn{2}{|c|}{ Input } & \multicolumn{2}{|c|}{ Output } \\
\hline Item & $\mathrm{kg}$ & & $\mathrm{kg}$ \\
\hline Taconite & 1273.2 & DRI & 1000.0 \\
\hline Reductant Coal & 268.4 & \multirow[t]{3}{*}{ Off Gas } & \multirow[t]{2}{*}{3654.5} \\
\hline Burner Coal & 63.1 & & \\
\hline \multirow[t]{2}{*}{ Preheated Air } & 2049.7 & & $1935.4\left(\mathrm{Nm}^{3}\right)$ \\
\hline & $1592.0\left(\mathrm{Nm}^{3}\right)$ & \multirow[b]{2}{*}{ Total } & \multirow[b]{2}{*}{3654.5} \\
\hline Total & 3654.5 & & \\
\hline
\end{tabular}

Heat Balance

\begin{tabular}{|l|c|c|l|c|c|}
\hline \multicolumn{1}{|c|}{ Input } & MJ & $\%$ & \multicolumn{1}{|c|}{ Output } & \multicolumn{1}{c|}{ MJ } & \multicolumn{1}{c|}{$\%$} \\
\hline $\mathrm{C}+1 / 2 \mathrm{O}_{2} \rightarrow \mathrm{CO}$ & 116.4 & 1.15 & $\begin{array}{l}\text { Endothermic Direct } \\
\text { Reductions }\end{array}$ & 3076.6 & 30.44 \\
\hline $\mathrm{CO}+1 / 2 \mathrm{O}_{2} \rightarrow \mathrm{CO}_{2}$ & 5847.9 & 57.77 & Decomposition of Coal & 333.1 & 3.3 \\
\hline $\mathrm{H}_{2}+1 / 2 \mathrm{O}_{2} \rightarrow \mathrm{H}_{2} \mathrm{O}$ & 2288.0 & 22.64 & Sensible Heat of DRI & 1094.5 & 10.83 \\
\hline Preheated Air at $850^{\circ} \mathrm{C}$ & 1855.5 & 18.36 & Sensible Heat of Gas & 4113.8 & 40.70 \\
\hline & & & Heat Loss & 1489.7 & 14.74 \\
\hline Total & 10108 & 100.00 & Total & 10108 & 100.00 \\
\hline
\end{tabular}

It is very interesting to compare coal requirements in the current practice ( as reported in Table 7-1) and that in an operation of tall bed, high flame temperature and high volatile matter coal (Table 7-4). The McMaster process uses 30\% less reductant coal and 50\% less burner coal. A saving of $110 \mathrm{~kg}$ reductant coal per tonne of DRI is expected. This benefit should not be influenced by the scale-up of the size of the furnace. The amount of reductant to be used in green balls, in our case is expressed using total carbon of coal. In the current practice in industry, the amount is expressed using fixed carbon. The explanation of the saving of reductant coal by 110 kgs per tonne of DRI is rather simple and straight forward. The rising gas flow from tall bed as shown in $\S 1.3$ is protective; therefore, the sacrificial carbon in DRI which is necessary in shallow bed to protect the nascent sponge iron from re-oxidation is no longer needed. The reaction products $\mathrm{CO}$ and $\mathrm{H}$ inside the tall bed, have longer residence time and little disturbance by flame so that a part of those gases in a reducing atmosphere removes more oxygen from the ore to become $\mathrm{CO}_{2}$ and $\mathrm{H}_{2} \mathrm{O}$. 
The saving in burner coal by $60 \mathrm{~kg}$ per tonne of DRI requires more detail discussions. These numbers can not be directly compared because heat to be delivered by burner fuel depends on operating conditions.

The explanation of the saving in burner coal by $60 \mathrm{~kg}$ per tonne of DRI requires more detail discussions. These numbers can not be directly compared because the heat efficiency of burner fuel depends on operating conditions, for example, productivity, the temperature of the exit gas and degree of metallization of DRI, etc.

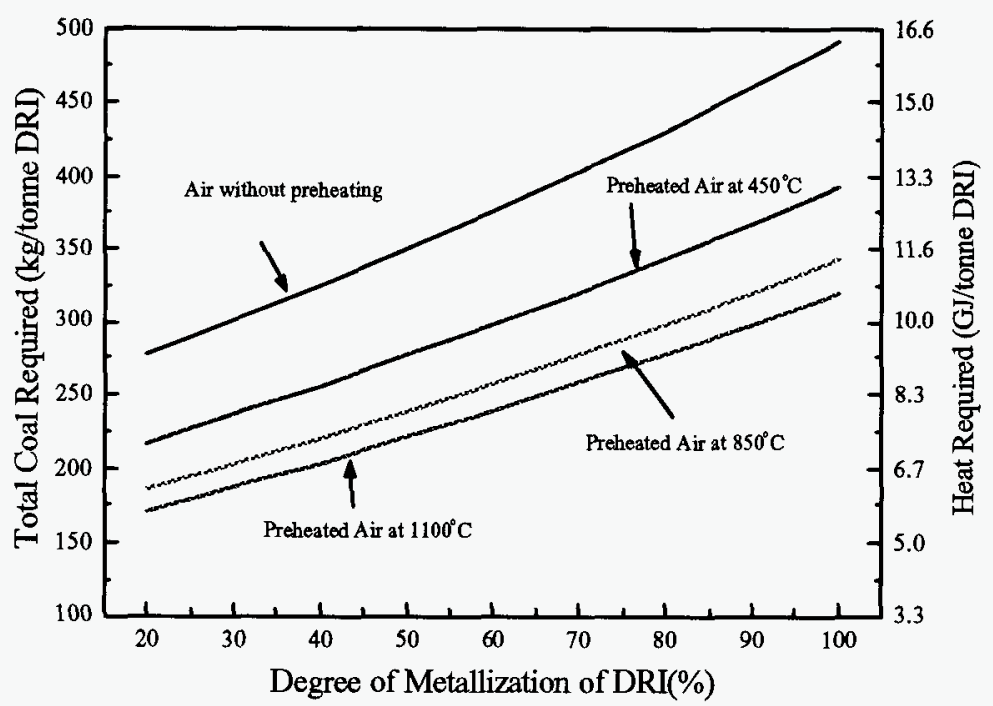

Fig 7-1 Coal rate for the reduction of taconite concentrate based on heat and mass balance 


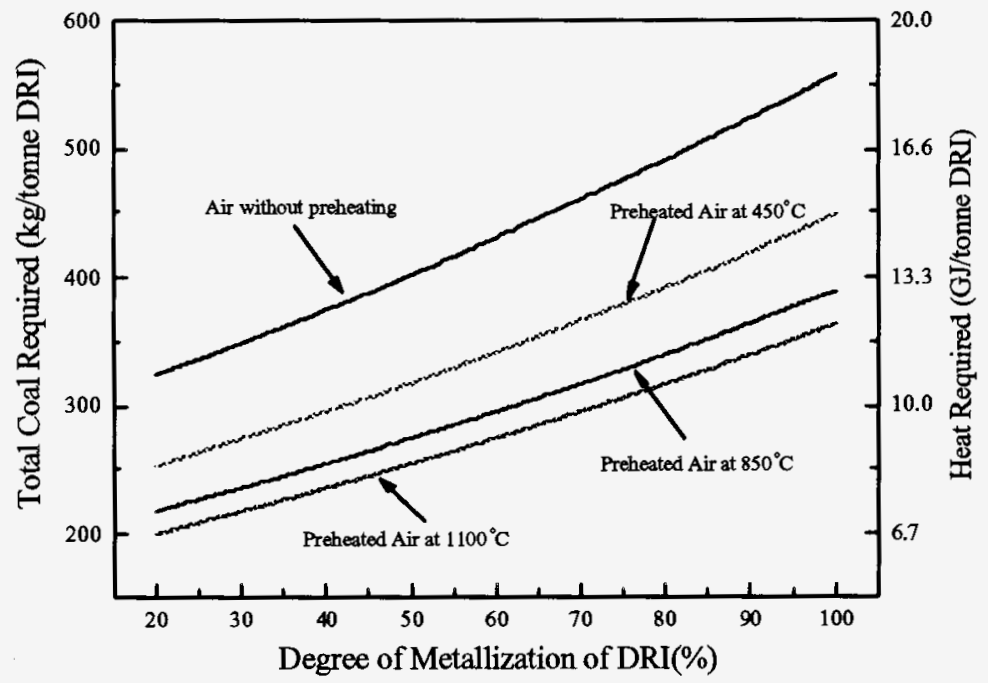

Fig 7-2 Coal rate for the reduction of hematite concentrate based on heat and mass balance

The typical operating conditions to yield data shown in Table 7-1 are not completely clear to us. To the best of our knowledge, it is the only source of burner fuel consumption reported in the open literature. There are two important factors which determine the efficiency of burner fuel, i.e., due to heat balance and heat transfer.

\section{\$7.1.1 Heat balance}

Fig. 7-1 for taconite concentrate and Fig. 7-2 for hematite concentrate (of the composition as the ore used in Genoa pilot plant) show the total coal requirement as functions of preheating temperature of air and degree of metallization. When pure oxygen at reference temperature is used, instead of air, the curve is essentially the same as the one for air at $1100^{\circ} \mathrm{C}$. In Table $7-6$, some data points in Fig. 7-1 are listed for easy comparison. Table 7-7 shows that, for the case shown in Table 7-5, if the exit gas temperature is lowered by $100^{\circ} \mathrm{C}$, the coal rate will decrease by about 15 kilogram per tonne of DRI. The impact of the degree of metallization and preheating of air are clearly shown to be very important. The influence of productivity on heat loss to the surroundings should be very significant. 
Table 7-6. The coal rate under different operations for taconite concentrate reduction, from Fig. 7-1.

\begin{tabular}{|c|c|c|c|c|c|}
\hline Temp. $\left({ }^{\circ} \mathrm{C}\right)$ & $\begin{array}{c}\text { Without Pre- } \\
\text { heat }\end{array}$ & 450 & 850 & 1100 & $\begin{array}{c}\text { Using } \\
\text { Oxygen }\end{array}$ \\
\hline 100 & 491 & 394 & 344 & 320 & 316 \\
\hline 95 & 476 & 381 & 332 & 309 & 305 \\
\hline 90 & 461 & 368 & 320 & 299 & 294 \\
\hline 85 & 444 & 355 & 309 & 287 & 284 \\
\hline 80 & 404 & 342 & 298 & 277 & 273 \\
\hline 70 & 381 & 319 & 277 & 257 & 253 \\
\hline 60 & 349 & 276 & 257 & 238 & 235 \\
\hline
\end{tabular}

Table 7-7. The computation of the cases shown in Table 7-3 and Table 7-5 with lower temperature of exit gas

\begin{tabular}{|c|c|c|c|}
\hline Off Gas Temp. ${ }^{\circ} \mathrm{C}$ & $\begin{array}{c}\text { Coal Rate kg/t-DRI } \\
(\text { Coal NOLY) }\end{array}$ & \multicolumn{2}{|c|}{ Coal +Natural Gas } \\
\cline { 3 - 4 } & & Coal & Natural Gas \\
\hline 1100 & $301.8(268.9+32.9)$ & 268.9 & $22.9 \mathrm{~kg}\left(32.1 \mathrm{~m}^{3}\right)$ \\
\hline 1200 & $315.6(268.9+46.7)$ & 268.9 & $32.8 \mathrm{~kg}\left(45.9 \mathrm{~m}^{3}\right)$ \\
\hline 1300 & $331.5(268.9+62.6)$ & 268.9 & $44.6 \mathrm{~kg}\left(62.4 \mathrm{~m}^{3}\right)$ \\
\hline
\end{tabular}




\section{\$7.1.2 Heat transfer}

It would be relevant to review the well-known problem of post-combustion in the freeboard of a BOF or a smelting reduction vessel. The efficiency in terms of heat received by the process (i.e. slag and metal) from the heat released by combustion in freeboard decreases rapidly with the increase of degree of combustion as limited by the rate of heat transfer. In shallow bed practices, for the moderation of the rate of re-oxidation of nascent sponge iron, the gas composition in freeboard is limited to $\mathrm{CO} / \mathrm{CO}_{2}=2.0$. Therefore, the heat liberated in the flame in reduction zone, where heat is consumed by the process, only represents about $50 \%$ of heat available in the fuel. Furthermore, the heat actually transfered to the reacting pellets would be even less. For environment protection, the exit gas must be fully oxidized outside of the reduction zone, i.e., the preheating and pre-reduction zone of an RHF or even later. This will lead to a high heat loss term and high exit gas temperature, thus, to less efficient use of heat in the process.

In this new technology, burner fuel and gases ( $\mathrm{CO}$ and $\left.\mathrm{H}_{2}\right)$ rising from the tall bed are fully oxidized; and heat is released in the reduction zone where heat is mostly needed. In this region, a substantial portion of the heat input is driven downwards, by radiation, with large driving force (flame temperature of $1600^{\circ}$ to $1650^{\circ} \mathrm{C}$ ) to the interior of the bed and the core of partially metallized DRI. When the gas flow in the freeboard reaches the pre-reduction and preheating zone, the remaining portion of the input heat in the form of sensible heat of gases will be partly absorbed by the incoming pellets which move counter-currently. All hearth-type furnace ironmaking processes, by heating chemically self-sufficient agglomerates, are heat transferlimited operations. Therefore, one can not over emphasize the importance of enhanced heat transfer, as in this new technology, in the increase of productivity and burner fuel efficiency.

\section{\$7.1.3 Environment protection}

In comparison with current RHF practices, the advantage of this new technology is directly in less $\mathrm{CO}_{2}$ generation, and indirectly in less flue gas, which contains less entrained dust, and possibly hydrocarbons, in case coal is used as the burner fuel. For certain, $\mathrm{CO}_{2}$ generation is lowered by $330 \mathrm{~kg}$ per tonne of DRI due to savings of $110 \mathrm{~kg}$ of reductant coal alone. Further savings in burner fuel would lead to even lower linear velocity of gas streams with beneficial effect of more complete heat transfer and less entrained dust to improve the quality of by-product of $\mathrm{ZnO}$ and $\mathrm{PbO}$ in the recycling of waste oxides.

\section{\$7.2 In Comparison with blast Furnace for hot metal production}

\section{\$7.2.1 The total coal rate per tonne of H.M.}

The total coal requirement in the production of liquid iron of $4 \%$ carbon by two routes, i.e., the blast furnace and DRI/melting, will be compared here. With pellet feeds, it has been estimated that the very good BF practice in North America in the next decade will result in about $320 \mathrm{~kg}$ coke and $150 \mathrm{~kg}$ coal (for injection through tuyeres) consumption per THM. The yield in cokemaking is assumed to be $75 \%$. Therefore the total requirement, including $50 \mathrm{~kg}$ coal for high temperature iron ore agglomeration, is 
The melting operation of DRI at $1400^{\circ} \mathrm{C}$ to produce hot metal, slag and exit gas all at $1600^{\circ} \mathrm{C}$ by an oxy-coal burner is considered here. A schematic diagram is shown in Fig. 7-3. Chemical compositions of incoming and outgoing streams are given in Table 7-8 and mass and heat balance in Table 7-9. The heat and mass balances of the melter are shown in Table 7-10.

Table 7-8 Chemical Compositions (case of oxygen melter)

- DRI Composition (wt.\%)

\begin{tabular}{|c|c|c|c|c|c|c|c|c|c|c|}
\hline $\mathrm{TFe}$ & $\mathrm{MFe}$ & $\mathrm{FeO}$ & $\mathrm{S}$ & $\mathrm{C}$ & $\mathrm{SiO}_{2}$ & $\mathrm{Al}_{2} \mathrm{O}_{3}$ & $\mathrm{CaO}$ & $\mathrm{MgO}$ & $\begin{array}{c}\text { Other } \\
\text { Oxides }\end{array}$ & $\begin{array}{c}\text { Degree of } \\
\text { Metallization } \\
(\%)\end{array}$ \\
\hline 86.71 & 82.38 & 5.57 & 0.176 & 2.5 & 6.00 & 1.78 & 0.37 & 0.81 & 0.08 & 95 \\
\hline
\end{tabular}

- Coal Composition (wt.\%)

\begin{tabular}{|c|c|c|c|c|}
\hline C total & C fixed & Volatile Mater & Ash & S \\
\hline 87.83 & 80.66 & 12.70 & 6.14 & 0.5 \\
\hline
\end{tabular}


- The exit gas from melter is used to replace burner fuel in the hearth furnace

\begin{tabular}{|c|c|c|c|c|c|}
\hline $\mathrm{CO}$ & $\mathrm{CO}_{2}$ & $\mathrm{H}_{2}$ & $\mathrm{H}_{2} \mathrm{O}$ & $\mathrm{N}_{2}$ & $\{\mathrm{~S}\}$ \\
\hline 59.96 & 25.70 & 9.80 & 4.20 & 0.29 & 0.05 \\
\hline
\end{tabular}

- Hot Metal Composition (wt.\%)

\begin{tabular}{|c|c|c|c|}
\hline $\mathrm{Fe}$ & $\mathrm{C}$ & $\mathrm{S}$ & $\mathrm{P}$ \\
\hline 95.93 & 4.00 & 0.037 & 0.033 \\
\hline
\end{tabular}

- Slag Composition (wt.\%)

\begin{tabular}{|c|c|c|c|c|c|c|}
\hline $\mathrm{FeO}$ & $\mathrm{SiO}_{2}$ & $\mathrm{Al}_{2} \mathrm{O}_{3}$ & $\mathrm{CaO}$ & $\mathrm{MgO}$ & $(\mathrm{S})$ & $\mathrm{CaO} / \mathrm{SiO}_{2}$ \\
\hline 0.30 & 33.85 & 10.63 & 47.40 & 5.31 & 0.96 & 1.40 \\
\hline
\end{tabular}

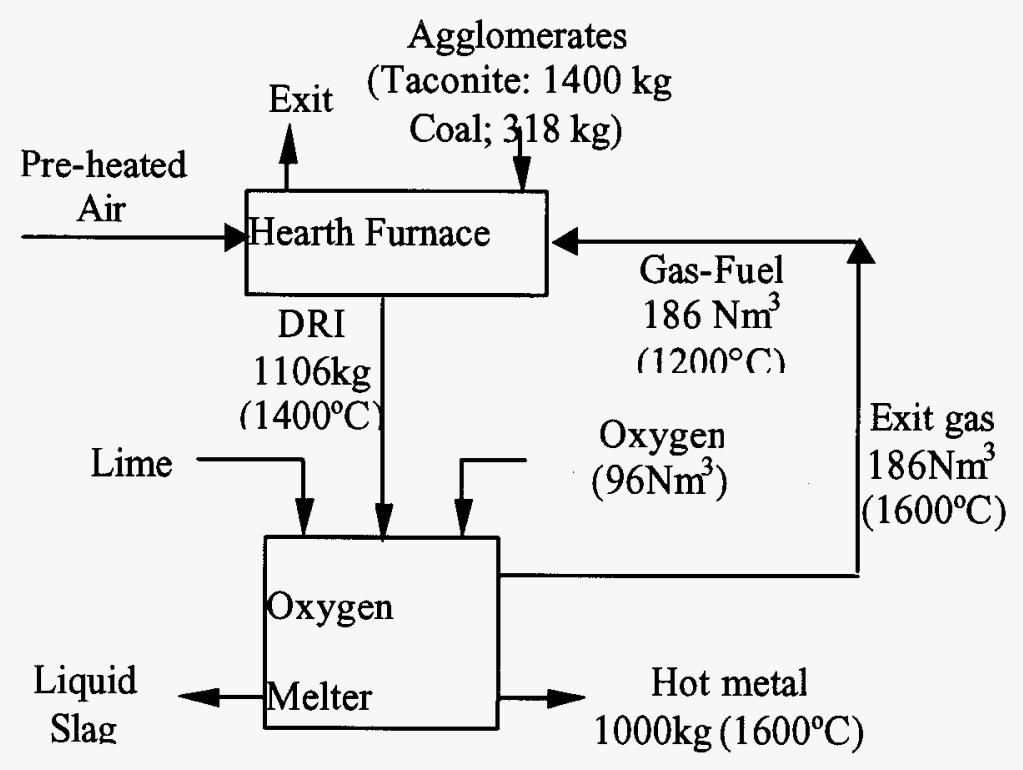

Fig. 7-3 A schematic diagram of a melting operation 
Table 7-9. Heat and Mass Balance for the Hearth Furnace

Mass Balance

\begin{tabular}{||c|c||c|c||}
\hline \multicolumn{2}{|c|}{ Input } & \multicolumn{2}{c|}{ Output } \\
\hline & $\mathrm{kg}$ & & $\mathrm{kg}$ \\
\hline Taconite & 1275.9 & DRI & 1000.0 \\
\hline Reductant Coal & 288.0 & & 2670.4 \\
& & \multirow{2}{*}{ Off Gas } & $1906.9\left(\mathrm{Nm}^{3}\right)$ \\
\cline { 1 - 2 } $\begin{array}{c}\text { Gas from Melting } \\
\text { Unit }\end{array}$ & 242.0 & & \\
\hline \begin{tabular}{c} 
Preheated Air \\
\cline { 2 - 2 }
\end{tabular} & $186.0\left(\mathrm{~m}^{3}\right)$ & & \\
\hline Total & 1900.9 & Total & 3670.4 \\
\hline
\end{tabular}

Heat Balance

\begin{tabular}{||l|r|r|l|r|r||}
\hline \multicolumn{1}{|c|}{ Input } & \multicolumn{1}{c|}{ MJ } & \multicolumn{1}{c|}{$\%$} & \multicolumn{1}{c|}{ Output } & \multicolumn{1}{c|}{ MJ } & \multicolumn{1}{c|}{$\%$} \\
\hline $\mathrm{C}+1 / 2 \mathrm{O}_{2} \rightarrow \mathrm{CO}$ & 0 & 0 & $\begin{array}{l}\text { Endothermic Direct } \\
\text { Reductions }\end{array}$ & 3081.6 & 30.27 \\
\hline $\mathrm{CO}+1 / 2 \mathrm{O}_{2} \rightarrow \mathrm{CO}_{2}$ & 6003.3 & 58.98 & Decomposition of Coal & 361.9 & 3.56 \\
\hline $\mathrm{H}_{2}+1 / 2 \mathrm{O}_{2} \rightarrow \mathrm{H}_{2} \mathrm{O}$ & 2228.6 & 21.89 & Sensibl Heat of DRI & 1093.8 & 10.75 \\
\hline $\begin{array}{l}\mathrm{Hot} \text { gas } \\
\text { from melting Unit }\end{array}$ & 296.3 & 2.91 & Sensible Heat of Gas & 4143.4 & 40.70 \\
\hline Preheated Air at $850^{\circ} \mathrm{C}$ & 1651.3 & 16.22 & Heat Loss & 1498.9 & 14.72 \\
\hline Total & 10179.5 & 100.00 & Total & 10179.5 & 100.00 \\
\hline
\end{tabular}

Table 7-10 Heat and Mass Balance of the Melter

Mass Balance

\begin{tabular}{||c|c|c|c||}
\hline \multicolumn{2}{|c|}{ Input } & \multicolumn{2}{c||}{ Output } \\
\hline DRI & $\mathrm{kg}$ & & $\mathrm{Kg}$ \\
\hline Lime & 1106.4 & Hot Metal & 1000.0 \\
\hline Coal & 97.2 & Slag & 208.4 \\
\hline \multirow{2}{*}{ Oxygen } & 110.3 & \multirow{2}{*}{ Off Gas } & 242.0 \\
\cline { 2 - 2 } & 136.5 & & $186.0\left(\mathrm{Nm}^{3}\right)$ \\
\hline Total & $95.6\left(\mathrm{Nm}^{3}\right)$ & & 1450.4 \\
\hline
\end{tabular}


Heat Balance

\begin{tabular}{|c|c|c|c|c|c|}
\hline Input & $\mathrm{MJ}$ & $\%$ & Output & MJ & $\%$ \\
\hline $\mathrm{C}+1 / 2 \mathrm{O}_{2} \rightarrow \mathrm{CO}$ & 736.5 & 28.02 & $\begin{array}{l}\text { Endothermic Direct } \\
\text { Reductions }\end{array}$ & 162.5 & 6.18 \\
\hline $\mathrm{CO}+1 / 2 \mathrm{O}_{2} \rightarrow \mathrm{CO}_{2}$ & 604.6 & 23.01 & Decomposition of Coal & 110.9 & 4.22 \\
\hline $\mathrm{H}_{2}+1 / 2 \mathrm{O}_{2} \rightarrow \mathrm{H}_{2} \mathrm{O}$ & 84.4 & 3.21 & Sensible Heat of HM & 1162.1 & 44.22 \\
\hline \multirow{3}{*}{$\begin{array}{c}\text { Sensible Heat of DRI } \\
\text { (at } 1400^{\circ} \mathrm{C} \text { ) }\end{array}$} & \multirow{3}{*}{1202.7} & \multirow{3}{*}{45.76} & Sensible Heat of Slag & 364.5 & 13.87 \\
\hline & & & Sensible Heat of Gas & 501.0 & 19.06 \\
\hline & & & Heat Loss & 327.3 & 12.45 \\
\hline Total & 2618.3 & 100.00 & Total & 2628.3 & 100.00 \\
\hline
\end{tabular}

The total coal rate of making hot metal will include the coal for making DRI (288 kgs) and that for melting and partial desulfurization $(110.3 \mathrm{kgs}), 428.8 \mathrm{~kg}$ coal $/$ tonne hot metal.

When the hearth furnace is a unit of the system for making hot metal as shown in Fig. 7-3, the heat and mass balance of the melter are given in Table 7-10. It should be noted that there is plenty of heat carried by the gas from the melter to the hearth furnace. It could be an all coal operation, free from natural gas, making hot metal with relaxed requirements on qualities of raw materials (preferably magnetic concentrate and high volatile matter coal). From same types of ore and coal to make hot metal of comparable compositions (much less silicon by DRI route), there is a difference of coal requirement, about $200 \mathrm{~kg}$ per tonne of hot metal, i.e. $626 \mathrm{~kg}$ for blast furnace and 428 by DRI route. It should be noted that the exit gas of the hearth furnace has enough sensible heat to preheat air to these temperatures used in our calculations. On the other hand, there is a large amount of top gas from a blast furnace; this gas and the coke oven gas need to be used for other purposes, in addition to firing the stoves for hot blast.

\section{\$7.2.2 Environment Protection}

In North America, a typical integrated plant consists of coke ovens and blast furnaces with pellet feeds. Concerns about environmental protection issues are mainly in the operations of coke ovens, i.e. emission of hydrocarbons to atmosphere and the contamination of the water which has been used to clean coke oven gas. The blast furnace top gas must be cleaned before re-use such as firing stoves for the hot blast. The blast furnace top gas is very dirty because of physical entrapment of dust and condensation of alkalis compounds and hydrocarbons (particularly with high level of coal injection), etc. The treatment of water used for the cleaning the top gas is an important task. In terms of the rate of carbon dioxide generation, significant improvement is not expected because blast furnace ironmaking is a mature process which operates rather close to its theoretical limit. For smelting reduction processes to produce hot metal, the coal rate is expected to be about $1000 \mathrm{~kg}, 400 \mathrm{~kg}$ more than the blast furnace/coke oven.route The exit gas from the smelting reduction process has to be cleaned before it can be used for certain pre-reduction of iron ore and export outside of ironmaking operations.

Significant advantages of this new technology, an all coal process for hot metal production as shown in Fig 7-3, are outlined below. The melter is a closed system powered by an Oxy-coal 
lance and operated continuously under positive pressure. The hearth furnace, as in current RHF, is under negative pressure. In both reactors, the main gas stream moves in freeboard at relatively low velocity, and thus, the amount of entrained dust will be low. No wet scrubber is used in any of the existing RHF plants.

In the case of using an electric melter for smelting, the heat and mass balances of the whole process are listed in Tables 7-11, 7-12 and 7-13, and Figure 7-4.

Table 7-11 Chemical Compositions (case of electric melter)

- The exit gas from melter is used to replace burner fuel in the hearth furnace (v\%)

\begin{tabular}{|c|c|c|c|}
\hline $\mathrm{CO}$ & $\mathrm{H}_{2}$ & $\mathrm{~N}_{2}$ & $\{\mathrm{~S}\}$ \\
\hline 77.34 & 22.13 & 0.38 & 0.15 \\
\hline
\end{tabular}

- Hot Metal Composition (wt.\%)

\begin{tabular}{|c|c|c|c|}
\hline $\mathrm{Fe}$ & $\mathrm{C}$ & $\mathrm{S}$ & $\mathrm{P}$ \\
\hline 95.93 & 4.00 & 0.037 & 0.033 \\
\hline
\end{tabular}

- Slag Composition (wt.\%)

\begin{tabular}{|c|c|c|c|c|c|c|}
\hline $\mathrm{FeO}$ & $\mathrm{SiO}_{2}$ & $\mathrm{Al}_{2} \mathrm{O}_{3}$ & $\mathrm{CaO}$ & $\mathrm{MgO}$ & $(\mathrm{S})$ & $\mathrm{CaO} / \mathrm{SiO}_{2}$ \\
\hline 0.30 & 33.85 & 10.63 & 47.40 & 5.31 & 0.96 & 1.40 \\
\hline
\end{tabular}

Agglomerates

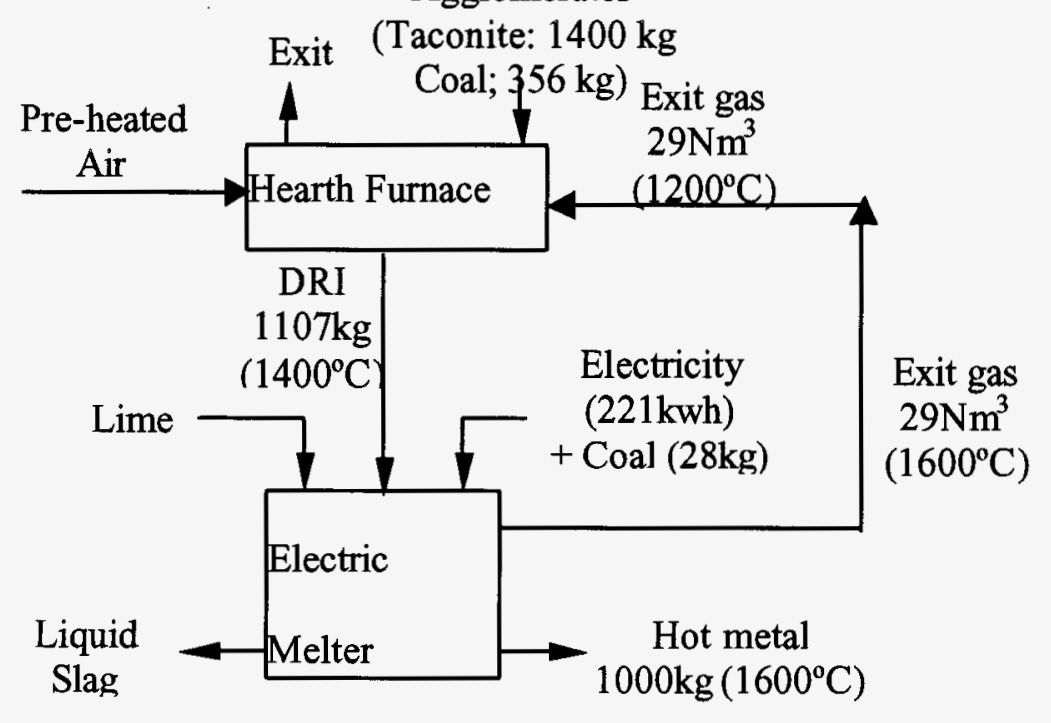

Fig. 7-4 A schematic diagram of a melting operation(electric) 
Table 7-12. Heat and mass balance for the hearth furnace (case of electric melter) Mass Balance

\begin{tabular}{||c|c|c|c|}
\hline \multicolumn{2}{|c|}{ Input } & \multicolumn{2}{c|}{ Output } \\
\hline & $\mathrm{Kg}$ & & $\mathrm{Kg}$ \\
\hline Taconite & 1273.9 & DRI & 1000.0 \\
\hline Reductant Coal & 268.4 & & 2629.6 \\
\hline Burner Coal & 34.9 & \multirow{2}{*}{ Off Gas } & $1913.2\left(\mathrm{Nm}^{3}\right)$ \\
\cline { 1 - 1 } $\begin{array}{c}\text { Gas from Melting } \\
\text { Unit }\end{array}$ & 28.7 & & \\
\hline \begin{tabular}{c} 
Preheated Air \\
\cline { 2 - 2 }
\end{tabular} & $28.9\left(\mathrm{~m}^{3}\right)$ & & \\
\hline Total & 2010.1 & Total & 3629.6 \\
\hline
\end{tabular}

Heat Balance
\begin{tabular}{|l|r|r|l|r|r||}
\hline \multicolumn{1}{|c|}{ Input } & \multicolumn{1}{|c|}{ MJ } & $\%$ & \multicolumn{1}{c|}{ Output } & \multicolumn{1}{c|}{ MJ } & \multicolumn{1}{c|}{$\%$} \\
\hline $\mathrm{C}+1 / 2 \mathrm{O}_{2} \rightarrow \mathrm{CO}$ & 38.4 & 0.38 & $\begin{array}{l}\text { Endothermic Direct } \\
\text { Reductions }\end{array}$ & 3077.8 & 30.61 \\
\hline $\mathrm{CO}+1 / 2 \mathrm{O}_{2} \rightarrow \mathrm{CO}_{2}$ & 5889.9 & 58.57 & Decomposition of Coal & 322.8 & 3.21 \\
\hline $\mathrm{H}_{2}+1 / 2 \mathrm{O}_{2} \rightarrow \mathrm{H}_{2} \mathrm{O}$ & 2276.0 & 22.63 & Sensible Heat of DRI & 1094.3 & 10.88 \\
\hline $\begin{array}{l}\mathrm{Hot} \text { gas } \\
\text { from melting Unit }\end{array}$ & 40.9 & 0.41 & Sensible Heat of Gas & 4077.6 & 40.55 \\
\hline Preheated Air at $850^{\circ} \mathrm{C}$ & 1811.0 & 18.01 & Heat Loss & 1483.6 & 14.75 \\
\hline Total & 10056.2 & 100.00 & Total & 10056.2 & 100.00 \\
\hline
\end{tabular}

Table 7-13 Heat and mass balance of the electric melter Mass Balance

\begin{tabular}{||c|c|c|c|}
\hline \multicolumn{2}{|c|}{ Input $(\mathrm{kg})$} & \multicolumn{2}{c|}{ Output $(\mathrm{kg})$} \\
\hline DRI & 1106.8 & Hot Metal & 1000.0 \\
\hline Lime & 92.9 & Slag & 198.9 \\
\hline Coal & 27.9 & \multirow{2}{*}{ Off Gas } & 28.7 \\
\hline Total & 1227.6 & Total & $28.90\left(\mathrm{Nm}^{3}\right)$ \\
\hline
\end{tabular}

\begin{tabular}{|c|c|c|c|c|c|}
\hline Input & MJ & $\%$ & Output & MJ & $\%$ \\
\hline $\begin{array}{c}\text { Sensible Heat of } \\
\text { DRI } \\
\text { (at } 1400^{\circ} \mathrm{C} \text { ) }\end{array}$ & 1202.7 & 57.89 & $\begin{array}{l}\text { Endothermic Direct } \\
\text { Reductions }\end{array}$ & 159.1 & 7.96 \\
\hline \multirow{5}{*}{ Electricity } & 796.9 & \multirow{5}{*}{42.11} & Decomposition of Coal & 28.00 & 1.40 \\
\hline & \multirow{4}{*}{221.4 (kwh) } & & Sensible Heat of HM & 1162.1 & 58.12 \\
\hline & & & Sensible Heat of Slag & 348.7 & 17.43 \\
\hline & & & Sensible Heat of Gas & 61.71 & 3.09 \\
\hline & & & Heat Loss & 240.0 & 12.00 \\
\hline Total & 1999.6 & 100.00 & Total & 1999.6 & 100.00 \\
\hline
\end{tabular}




\section{$\$ 7.3 \quad$ Summary}

The new ironmaking technology proposed in the present work, based on a hearth furnace and all coal operation, the advantages in energy consumption and in environment protection are listed below:

1. The exit gas is low in dust and free of hydrocarbons and may be cleaned dry. No wet scrubber is used (no water contamination) in the existing RHF plants.

2. No environmental problems associated with the operation of coke ovens.

3. Low total carbon rate (Table 7-6, and hence, low $\mathrm{CO}_{2}$ emission) in comparison with reported value (Table 7-1) for the existing RHF operations:

$320 \mathrm{~kg}$ coal of $61 \%$ fixed carbon vs. $500 \mathrm{~kg}$ of $75 \%$ fixed carbon per tonne of DRI.

4. Low total carbon rate (and hence, low $\mathrm{CO}_{2}$ emission) in comparison with a good blast furnace operation:

428 vs. $626 \mathrm{~kg}$ coal per tonne of hot metal 


\section{$\S 8$ THE NEW HEARTH FURNACE FOR THE NEW TECHNOLOGY}

$\S 8.1$ The Use of a Screw Discharger 116

$\S 8.2$ The Retaining Wall of Pellet Bed 116

$\S 8.3$ The Paired Straight Hearth (PSH) Furnace 118

$\$ 8.4$ Solicitation of Advice from Engineering Companies 120 


\section{§8. THE NEW HEARTH FURNACE FOR THE NEW TECHNOLOGY}

The most important difference between this new technology and the existing RHFs is the height of the fixed bed of green balls or briquettes. The tall bed (e.g. $120 \mathrm{~mm}$ ) is the fundamental feature which provides operational stability, high productivity and high energy efficiency. The steady flow of protective gas originated from the bed and long residence time at higher temperature allow DRI to be of high quality, consistently.

The features of existing RHFs, which are of concern for this discussion, are the shallow bed (20$25 \mathrm{~mm}$ ) and the metallic screw discharger. If a screw discharger were used to discharge hot DRI from the side of a tall bed, two technical problems would have to be solved. The first one is the cooling of the flights of the screw when it is used to discharge DRI of an average temperature of $1400^{\circ} \mathrm{C}$. The second one is to have a retaining wall which would keep pellets in the bed but it would not allow the screw to function as it is.

Some details of the analysis of concerned difficulties and possible solutions are given below:

\section{\$8.1The Use of a Screw Discharger}

The tall bed necessitates longer flights of the screw discharger, compounded with higher temperature; therefore, the cooling of the flights from the shaft would become very challenging. One obvious solution, other than finding a new material for these flights, is to cool down the DRI before discharging. Even though DRI layer remains as thick, but at a cold enough temperature, the screw would be strong to result in an acceptable service life. It should be pointed out that it is not a simple matter to cool down a bed of DRI on a moving hearth. The only practical way appears to have it cooled by radiative heat transfer, which is slow, by subjecting the bed to a cold surface. This will lead to the introduction of a new zone (the cooling zone), in additional to preheating/pre-reduction and reduction zones in the furnace. There will be two significant consequences: (i) the lowering of the productivity of the furnace and the loss of very valuable sensible heat at high temperature for melting. Furthermore, all RHFs are operated under negative pressure. In the cooling zone, in the absence of a strong gas flow, the leaking of oxidants into the cooling zone from the discharging side would cause the re-oxidation of metallic iron in DRI.

\section{§8.2 The Retaining Wall of Pellet Bed}

In existing RHFs, there is a gap between the moving hearth and the stationary furnace wall. Any pellet or briquette, which rolls into the gap, may lead to the jam of the system. Such a risk could be reduced by careful charging. For a shallow bed (about 1.5 layers), it is not very difficult to charge sparsely in the area near the edge of the hearth. The degree of difficulty in this practice increases with the height of the pellet bed. The situation for a bed height of about $120 \mathrm{~mm}$ is illustrated in Fig. 8-1(a). 


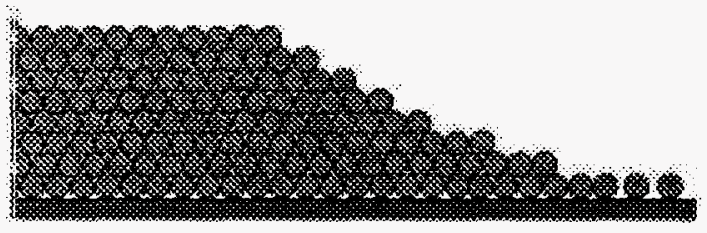

(a) After charging

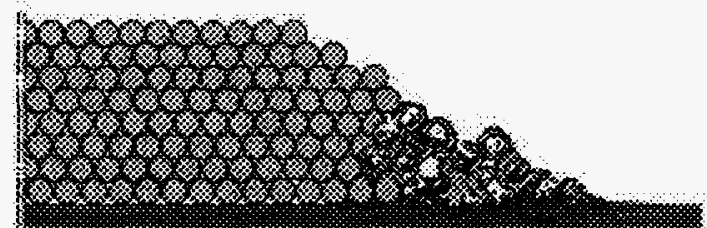

(b) Before discharging

Figure 8-1. Likely situations at outer edge of a rotary hearth furnace with a tall pellet bed

If operation conditions are chosen for a tall bed, the portion of the bed on the slope will be metallized ahead of the main body of the bed and then re-oxidized to various degrees before discharging depending on the local height. DRI in the shallow part of the bed will be heated faster to high temperatures by the flame, followed by re-oxidation to a higher extent. The consequence is likely to be the formation and melting of FeO-rich (i.e., corrosive) slag on the hearth [Figure 9-1(b)].

The affected area of the hearth (as a percentage of the total) and the affected amount of agglomerate (as a percentage of the total charge) can be calculated (see Appendix D). With an assumption that the distance (d) in radial direction over which the bed height decreases from $\mathrm{H}$ to zero is $d=3 H$, the computed results for a tall and a shallow bed of different size are listed in Table 8-1 and Table 8-2. It is a problem, geometric in nature and is relatively more serious for a small plant using tall bed.

Table 8-1. The volume ratios and area ratios, $\mathrm{H}=120 \mathrm{~mm}$

\begin{tabular}{|c|c|c|c|c|c|c|}
\hline RHF Scale & $\begin{array}{c}\text { Outer } \\
\text { Diameter, } \\
\mathrm{R}(\mathrm{m})\end{array}$ & $\begin{array}{c}\text { Inner } \\
\text { Diameter, } \\
\mathrm{r}(\mathrm{m})\end{array}$ & $\begin{array}{c}\text { Hearth } \\
\text { Width } \\
\mathrm{R}-\mathrm{r}(\mathrm{m})\end{array}$ & $\begin{array}{c}\text { Area of } \\
\text { Hearth of } \\
\text { Constant } \\
\text { Height }\left(\mathrm{m}^{2}\right)\end{array}$ & $\begin{array}{c}\mathrm{A}_{\mathrm{PR}} / \mathrm{A}_{\mathrm{C}}{ }^{*} \\
(\%)\end{array}$ & $\begin{array}{c}\mathrm{V}_{\mathrm{PR}} / \mathrm{V}_{\mathrm{C}}{ }^{*} \\
(\%)\end{array}$ \\
\hline Commercial & 45 & 32 & 6.5 & 785.8 & 6.53 & 3.25 \\
\hline Demonstration & 14 & 6 & 4.0 & 125.6 & 12.9 & 6.41 \\
\hline Pilot & 5 & 3 & 1.0 & 12.6 & $\mathbf{4 8 . 2 4}$ & $\mathbf{2 3 . 5 8}$ \\
\hline
\end{tabular}

*: $\quad A_{P R} / A_{C}$ and $V_{P R} / V_{C}$ are the percentage of the area of the "Peripheral Ring", the affected area, to the area of the portion of pellet bed of constant height, and the percentage of volume of the portion of pellet bed on the "peripheral ring" to that of the portion of pellet bed of constant height, respectively. 
Table 8-2. The volume ratios and area ratios, $\mathrm{H}=25 \mathrm{~mm}$

\begin{tabular}{|c|c|c|c|c|c|c|}
\hline RHF Scale & $\begin{array}{c}\text { Outer } \\
\text { Diameter, } \\
\mathrm{R}(\mathrm{m})\end{array}$ & $\begin{array}{c}\text { Inner } \\
\text { Diameter, } \\
\mathrm{r}(\mathrm{m})\end{array}$ & $\begin{array}{c}\text { Hearth } \\
\text { Width , } \\
\mathrm{R}-\mathrm{r}(\mathrm{m})\end{array}$ & $\begin{array}{c}\text { Area of } \\
\text { Hearth of } \\
\text { Constant } \\
\text { Height }\left(\mathrm{m}^{2}\right)\end{array}$ & $\begin{array}{c}\mathrm{A}_{\mathrm{PR}} / \mathrm{A}_{\mathrm{C}} \\
(\%)\end{array}$ & $\begin{array}{c}\mathrm{V}_{\mathrm{PR}} / \mathrm{V}_{\mathrm{C}} \\
(\%)\end{array}$ \\
\hline Commercial & 45 & 32 & 6.5 & 785.8 & 1.35 & 0.68 \\
\hline Demonstration & 14 & 6 & 4.0 & 125.6 & 2.64 & 1.32 \\
\hline Pilot & 5 & 3 & 1.0 & 12.6 & $\mathbf{9 . 5 3}$ & $\mathbf{4 . 7 3}$ \\
\hline
\end{tabular}

\section{§8-3. The Paired Straight Hearth (PSH) Furnace}

In a recent invited paper ${ }^{[7]}$, Lu and Huang outlined the incompatibility between the proposed technology and the existing rotary hearth furnaces which were designed for shallow bed and lower temperature operation. The remaining part of this section is taken from this article with a few changes. Appendix $E$ is much more comprehensive.

At this early stage of the development of a new ironmaking process, certain priorities have to be set. The potential advantages of using high process temperature and tall bed in achieving operational efficiency and product quality can be realized in a hearth furnace, but not necessarily a typical RHF. Once this premise is accepted, problems associated with the protection of screw discharger and uneven bed height will no longer stand in the way of our developmental work.

The basic need for processing ore/coal pellets is not different from that of a bakery, i.e., supplying heat to a chemically self-sufficient object laying on the furnace floor. On the industrial scene and for a continuous operation, there are the tunnel furnaces in ceramic industry, sintering machines, and straight grates for induration of iron ore pellets. Of course, there should be no cross-flow of gas through the bed of ore/coal pellets as the case for iron ore agglomeration; otherwise, the re-oxidation of sponge iron can not be prevented.

We propose that the Paired Straight Hearth (PSH) ${ }^{[8]}$ furnaces are to be used for this purpose. Each of the straight hearth furnaces is made up of detachable pallets, similar to that in sintering machines, and arranged side by side, see Figure 8-2. The pallet is lined with refractory materials as the hearth of RHF. The advantages of such arrangement include the following,

(i) forming a closed loop for the movement of pallets but pellets travel only on one straight hearth furnace,

(ii) forming a controlled gas flow which is originated from one furnace and goes out through the chimney of the other, and

(iii) individual pallet may be taken out for maintenance without stopping the operation.

In Figure 8-3, it is clear that the presence of the retaining wall will make the charging operation conventional, i.e., much simpler than that in a typical RHF. 
After a predetermined time of processing, DRI on a pallet passes through a firewall to reach the discharging end. It may be discharged by a tilt/dump method from the pallets to the receiving container below. The emptied pallet is moved, and is to be attached to the charging end of the adjacent furnace to receive the green balls, as shown in Figure 8-2. There is no need to use water sealing to isolate the combustion chamber if the side wall is extended all the way down to the ground, see Figure 8-4.

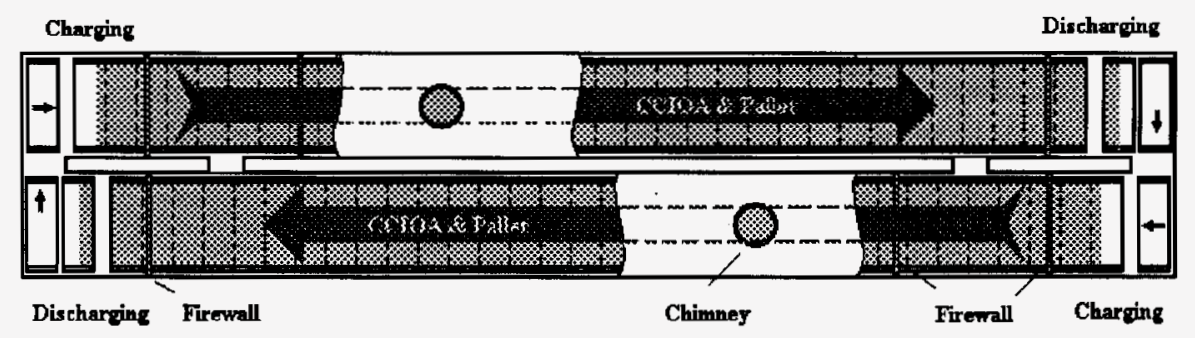

(a) The movement of CCIOA and Pallets

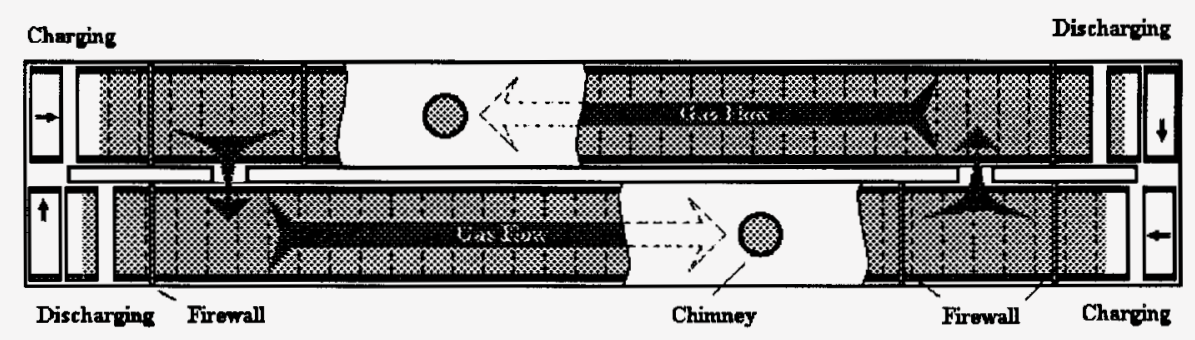

(b) The movement of gas

Figure 8-2. The top view of a PSH furnace and the movements of solids and gas

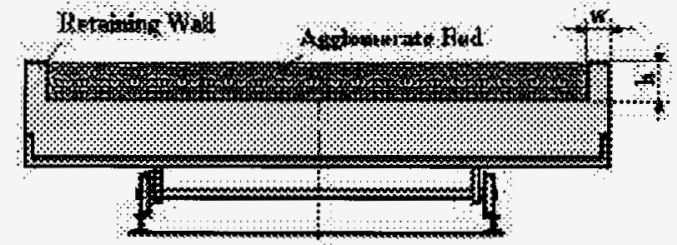

(a) Side view

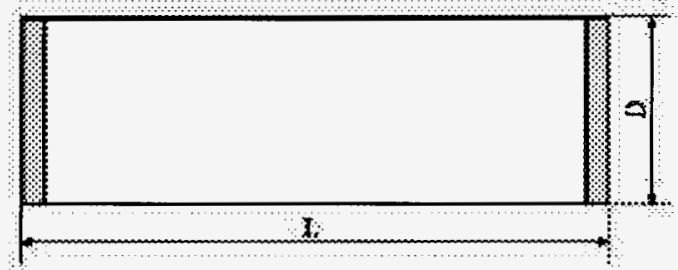

(b) Top view

Figure 8-3. The structure of pallets of PSH furnace 


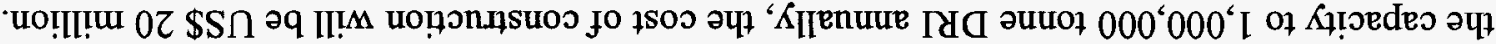

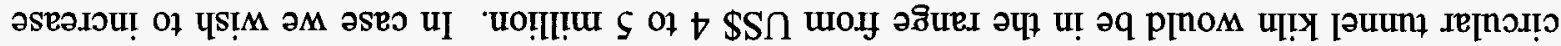

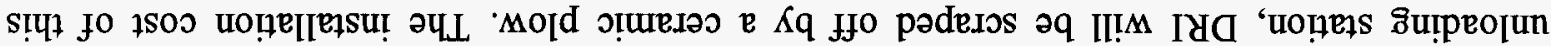

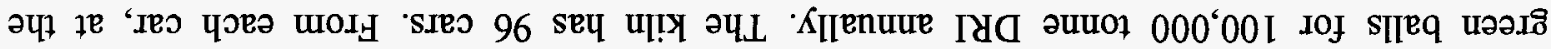

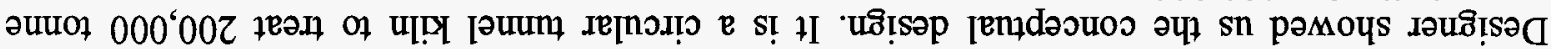

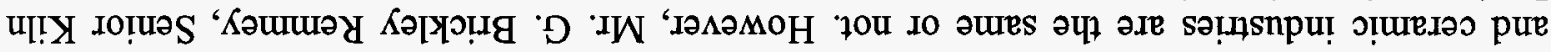

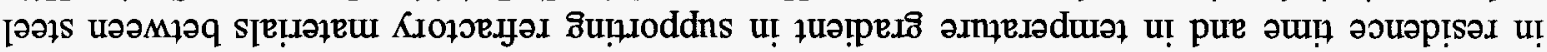

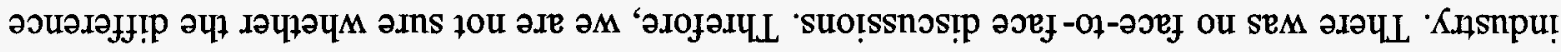

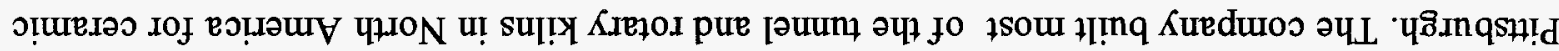

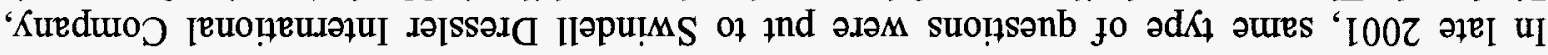

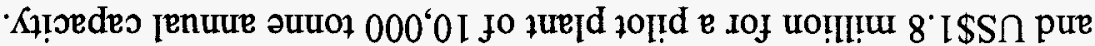

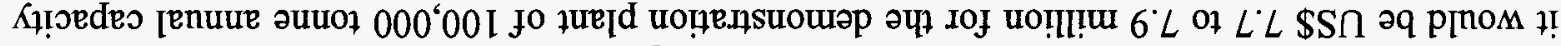

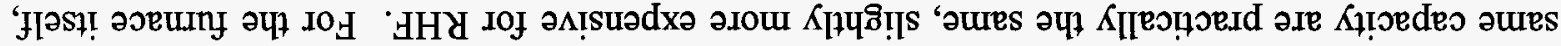

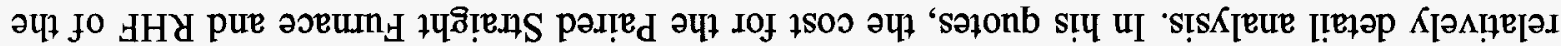

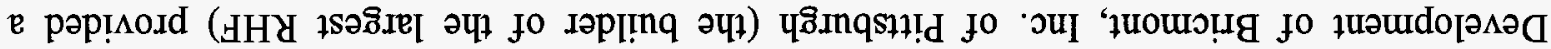

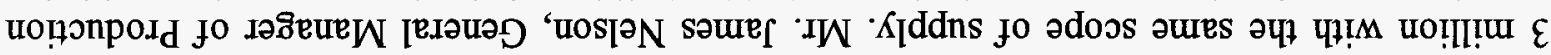

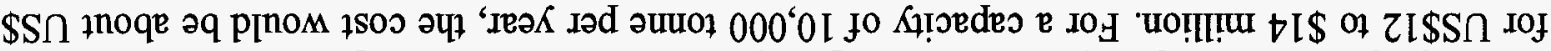

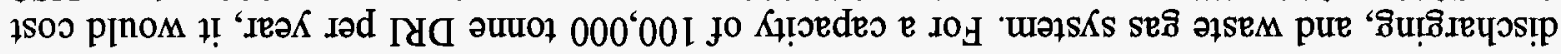

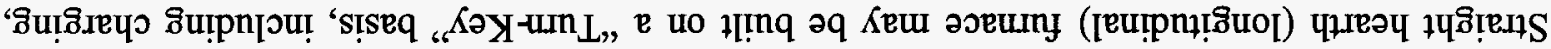

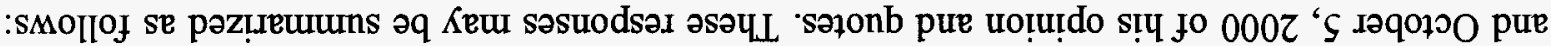

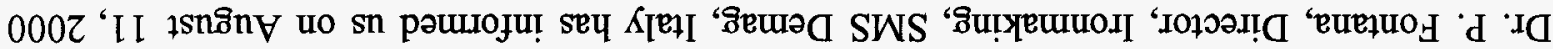

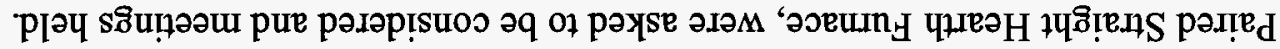

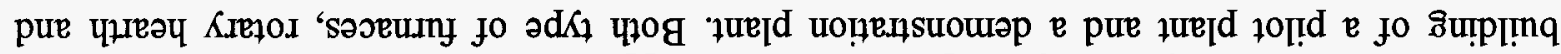

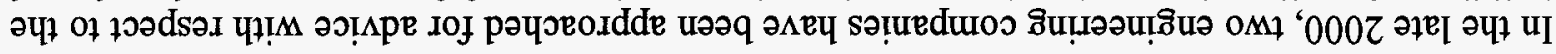

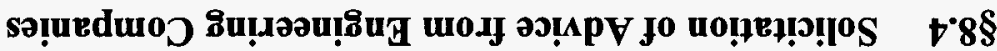

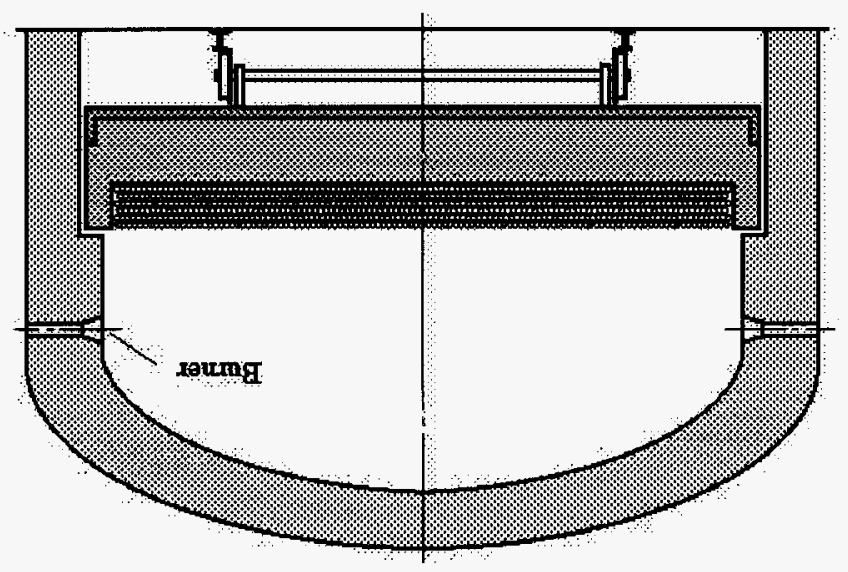




\section{§9 CONCLUSIONS AND RECOMMENDATIONS}

$\begin{array}{lll}\S 9.1 & \text { Conclusions } & 122\end{array}$

$\begin{array}{lll}\$ 9.2 & \text { Recommendations } & 123\end{array}$ 


\section{$\S 9$ CONCLUSIONS AND RECOMMENDATIONS}

The new technology of ironmaking is based on heating the non-traditional feed material, ore/coal pellets, in a hearth furnace. The obvious consequence industrially is the elimination of cokemaking and high temperature agglomeration steps in an integrated steelplant, using the coke oven/blast furnace route. From the view point of engineering sciences, it removes the mass transfer as the rate-limiting step of reduction of iron oxides at high temperatures, and thus, making the overall reaction rate controlled by heat transfer, which has a higher limit. The smoothness of the developmental work of this project is mainly due to the competence of the staff, who collectively have many decades of experience of fundamental studies in the field of iron ore reduction. The pilot plant trials in an industrial setting substantiated experimental findings on campus - the proposed technology is capable to be productive, energy efficient and environmentally friendly, and to produce DRI of best ever qualities. After the establishment of the relevance of methodology and equipment used on campus, a series of systematic experiments have been carried out to generate mathematical models for the selection of optimum conditions for each case of interest to a particular company.

\section{$\$ 9.1$ Conclusions}

1. The thermochemical aspect of the process is well established. The process is stable and tolerant to operational errors and in principle, there is no risk in scale-up. DRIs are of excellent qualities, physically and chemically. The material handling aspect of the process and the exact energy savings have to be established in a pilot plant designed for such tests.

2. Based on experimental data using taconite concentrate as the iron-bearing material, heat and mass balance calculations (with the assumption that air is preheated to $850^{\circ} \mathrm{C}$ with the sensible heat in the exit gas) the following comparison may be made:

- Compared to a blast furnace, the new technology with a melter has a lower total coal rate by $200 \mathrm{~kg}$ per tonne of hot metal.

- Compared to a typical RHF, for an all coal operation, the new technology has a lower coal rate by $110 \mathrm{~kg}$ per tonne of DRI of much better quality. For furnace productivity, the new technology is three to four times higher, in terms of the rigorous definition $(\mathrm{kg}$ of metallic iron made/unit area of hearth/unit time),

3. Three kinds of waste oxides (BOF sludge, BOF sludge/EAF dust, millscale) from carbon steel plants were used as the iron-bearing materials in the pilot plant trials. Experiments with BOF sludge and with millscale yielded excellent results in every way. When EAF dust was in the pellets, the removal of zinc and lead is essentially complete, other than in $4 \%$ to $6 \%$ of DRI at the bottom, due to the design flaw resulting in excessive cooling below. 


\section{\$9.2 Recommendations}

The new technology is based on heating chemically self-sufficient ore/coal agglomerates in a hearth furnace. The heat flux and gas flows from the bed are all in the vertical direction; therefore the process is independent of the size, shape and the movement of the hearth. The existing RHFs may not be used for this new technology because the survival of the screw discharger is in question.

For the great potential of this new technology for ironmaking from ore and coal and for waste oxide recycling, the next phase of activity would be a series of studies in engineering companies. We recommend a feasibility study be carried out for commercialization, engineering design, capital and operating cost estimation, etc. Options will be presented by engineering companies to future owners of the plant. It may be a pilot plant to test equipment for materials handling steps and to evaluate the type and efficiency of burner fuels. It may be just re-building a new hearth furnace at one of the existing RHF plants to take advantage of up-stream and down-stream facilities already in place. We should not, of course, rule out the possibility of building a brand new demonstration plant to accelerate the commercialization of this new technology. 


\section{\$10 REFERENCE}

1. Fruehan, R. J.; Fortini, I.; Paxto, H. W.; and Brindle, R.; "Theoretical Minimum Energies to Produce Steel for Selected Conditions", Sept., 2000, Office of Industrial Technologies, Department of Energy, Washington DC, USA, pp4.

2. R. Stull and H. Prophet, "JANAF Thermochemical Tables", Second Edition, 1971, Office of Standard Reference Data, National Bureau of Standards, Washington, DC, USA.

3. W-K. Lu, 1998 Howe Memorial Lecture, "The search for an economical and environmentally-friendly ironmaking process", Iron and Steel Society, AIME.

4. W-K. Lu and D. (Frank) Huang. Patent Application "Reduction of Iron Ore/Coal Mixtures (4H RHF Reduction)", Provisional Application No. 60/066,078, Filed on Nov. 17, 1997 , Application No. 09/192,927, Filed on Nov. 16, 1998.

5. Thomas J. Lorenzen and Virgil L. Anderson, "Design of Experiments", Marcel Dekker, Inc. 1993, pp323 to 353

6. H. Wakelin and R. Fruehan, "The Making, Shaping and Treating of Steel", $11^{\text {th }}$ Edition (1998), Pittsburgh, PA, AISE Steel Foundation, p791.

7. Lu, W-K. and Huang, D., "The Evolution of Ironmaking Process Based on CoatContaining Iron Ore Agglomerates", ISIJ International, vol. 41(2001), No.8, pp807-812.

8. Lu, W-K. and Huang, D., "Paired Straight Hearth (PSH) Furnaces for Metal Oxide Reduction", USA Patent, No. 60,257879 (Filed on Feb 26, 1999, Issued on July 2001), Chinese Patent 00102679.8 (pending), Canada \& Japan Patent (pending). 


\section{APPENDIXES}

Appendix A

Appendix B

146

Appendix C

148

Appendix D

156

Appendix E

158 


\section{APPENDIX A \\ THE APPERANCE OF DRI COKE MADE IN THE PILOT PLAR TRILAS \\ IN CSM, GENOVA, ITALY}

$\begin{array}{lll}\text { Green Ball : } & \text { Taconite: } & 83.89 \%, \\ & \text { Coal: } & 16.11 \%, \\ & \text { Bentonite: } & 1 \% \\ \text { Pellet Size: } & 16 \sim 19 \mathrm{~mm} & \\ \text { Bed Height: } & 120 \mathrm{~mm} \\ \text { Temperature: } & 1200 \sim 1500^{\circ} \mathrm{C} \\ \text { Time: } & 60 \text { minutes }\end{array}$

Appearance of DRI cake $(230 \mathrm{~mm} \times 190 \mathrm{~mm} \times 70 \mathrm{~mm})$

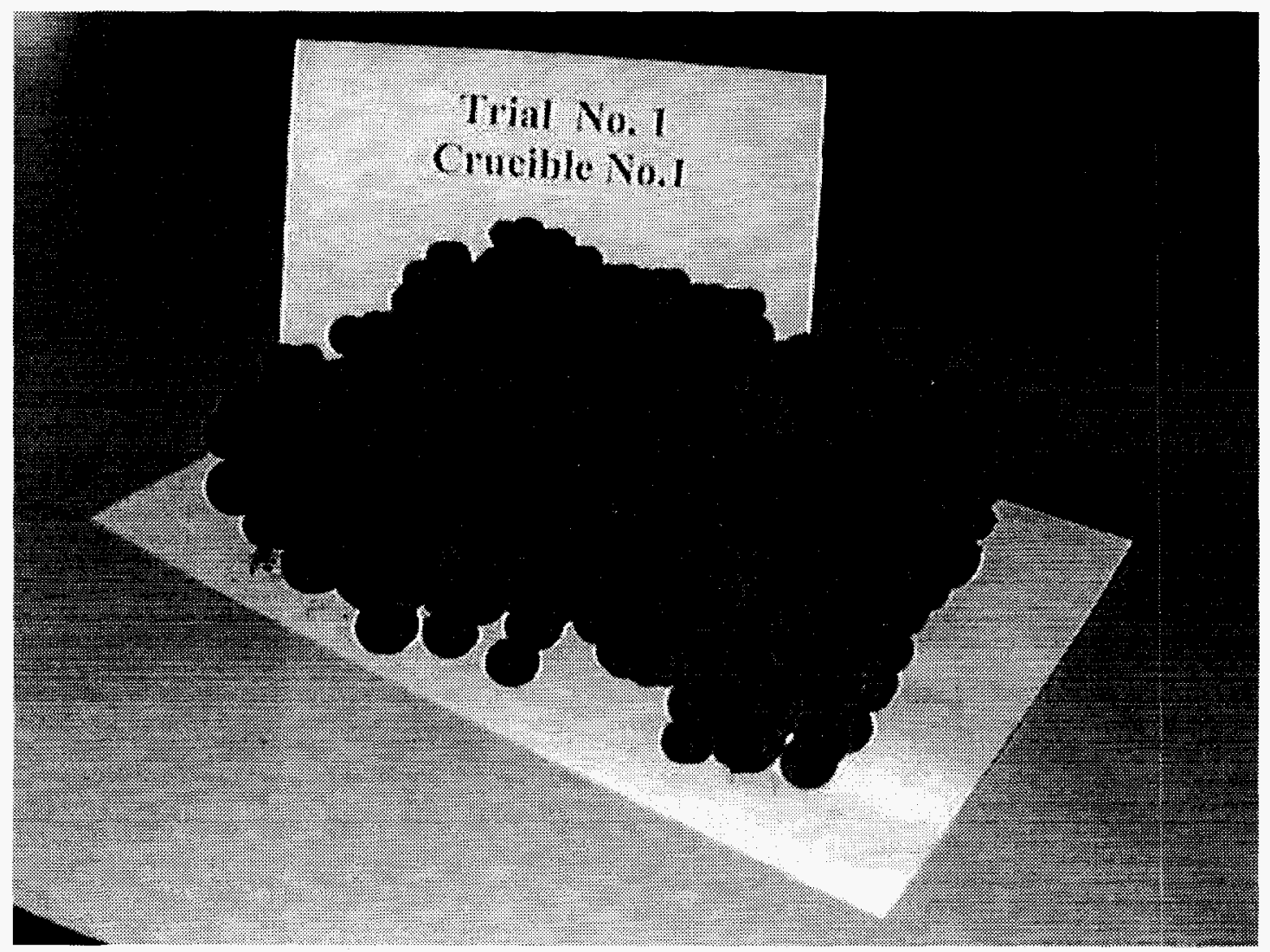

Figure A-1. DRI cake made from taconite concentrate (Crucible\#1 of Trial \#1) 


$\begin{array}{lll}\text { Green Ball : } & \text { Taconite: } & 82.24 \% \\ & \text { Coal: } & 17.76 \% \\ & \text { Bentonite: } & 1 \% \\ \text { Pellet Size: } & 16 \sim 19 \mathrm{~mm} & \\ \text { Bed Height: } & 120 \mathrm{~mm} \\ \text { Temperature: } & 1200 \sim 1500^{\circ} \mathrm{C} \\ \text { Time: } & 60 \text { minutes }\end{array}$

Appearance of DRI cake $(230 \mathrm{~mm} \times 190 \mathrm{~mm} \times 70 \mathrm{~mm})$

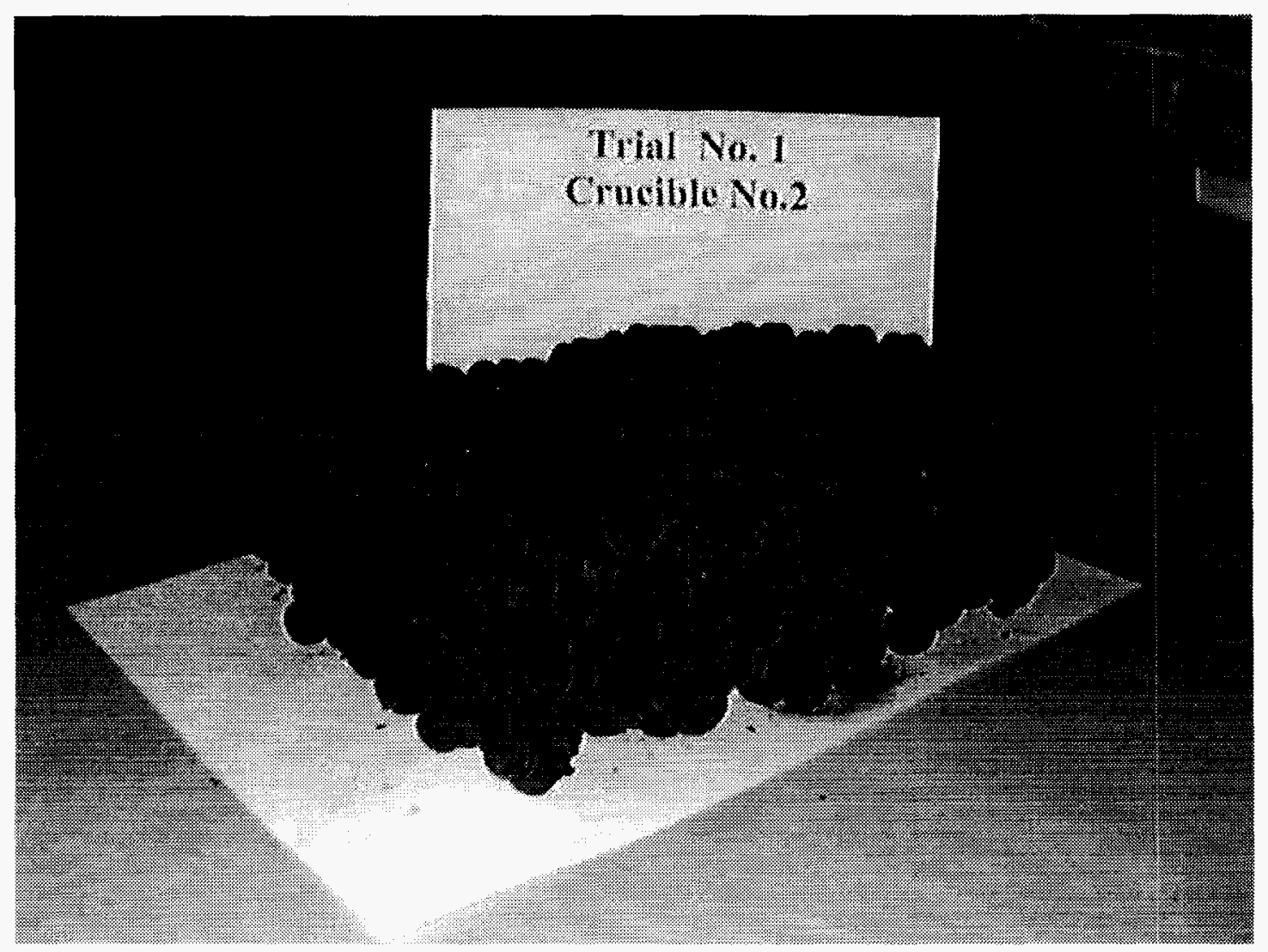

Figure A-2. DRI cake made from taconite concentrate (Crucible\#2 of Trial \#1) 


$\begin{array}{lll}\text { Green Ball : } & \text { Taconite: } & 83.89 \%, \\ & \text { Coal: } & 16.11 \%, \\ & \text { Bentonite: } & 1 \% \\ \text { Pellet Size: } & 16 \sim 19 \mathrm{~mm} & \\ \text { Bed Height: } & 120 \mathrm{~mm} \\ \text { Temperature: } & 1200 \sim 1500^{\circ} \mathrm{C} \\ \text { Time: } & 60 \text { minutes }\end{array}$

Appearance of DRI cake $(230 \mathrm{~mm} \times 190 \mathrm{~mm} \times 70 \mathrm{~mm})$

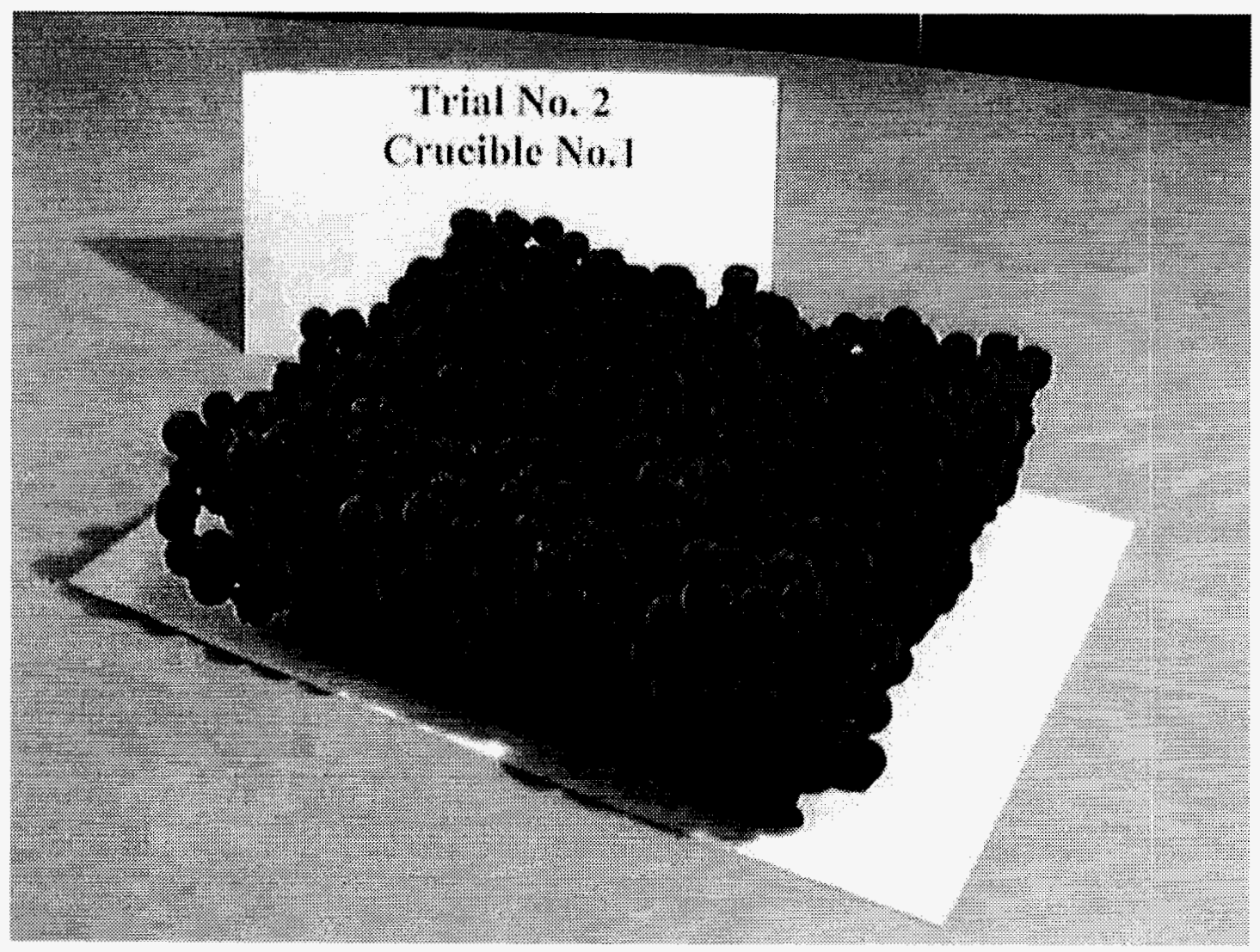

Figure A-3. DRI cake made from taconite concentrate (Crucible\#1 of Trial \#2) 


$\begin{array}{lll}\text { Green Ball : } & \text { Taconite: } & 82.24 \% \\ & \text { Coal: } & 17.76 \% \\ & \text { Bentonite: } & 1 \% \\ \text { Pellet Size: } & 16 \sim 19 \mathrm{~mm} & \\ \text { Bed Height: } & 120 \mathrm{~mm} \\ \text { Temperature: } & 1200 \sim 1500^{\circ} \mathrm{C} & \\ \text { Time: } & 60 \text { minutes } & \end{array}$

Appearance of DRI cake $(230 \mathrm{~mm} \times 190 \mathrm{~mm} \times 70 \mathrm{~mm})$

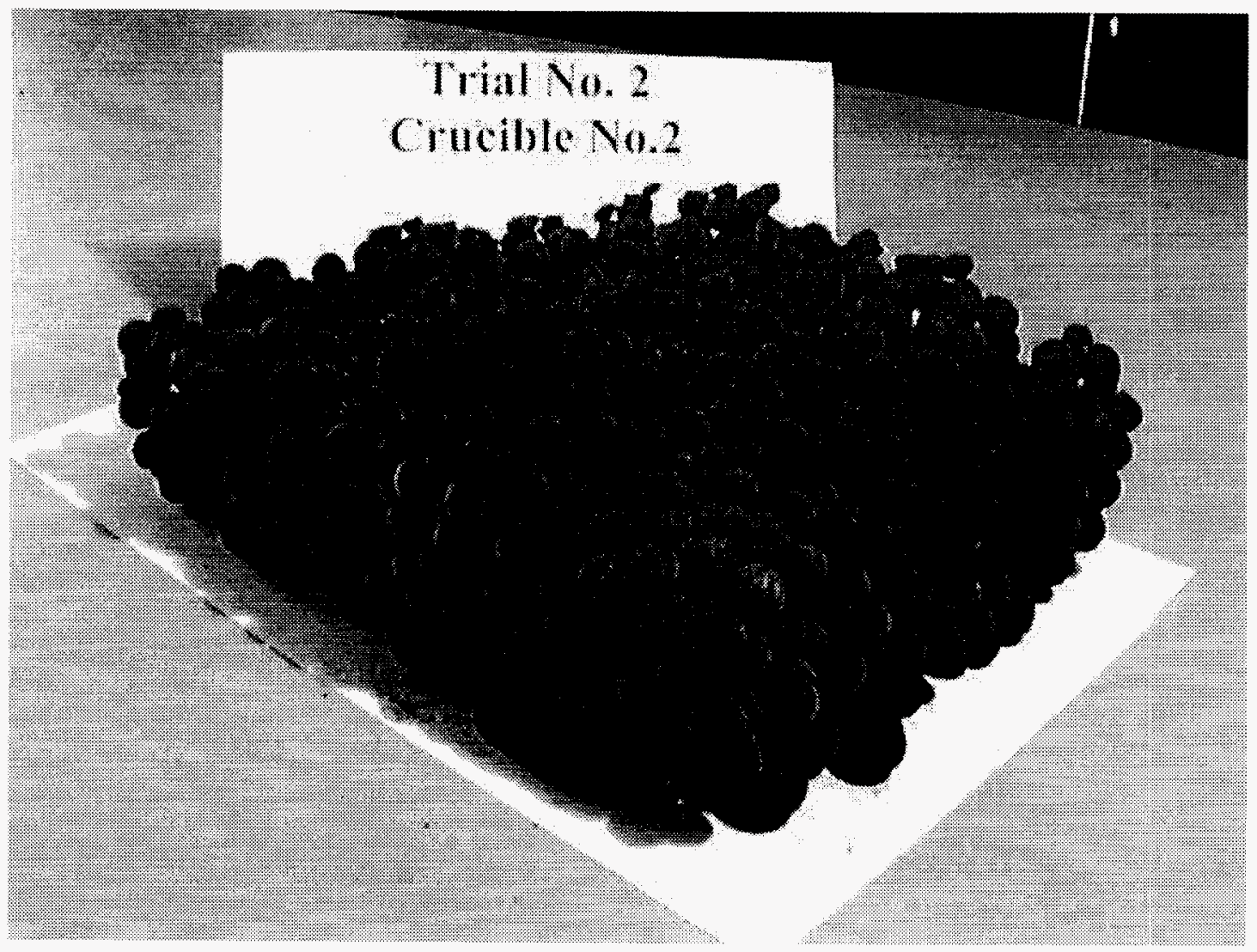

Figure A-4. DRI cake made from taconite concentrate (Crucible\#2 of Trial \#2) 


$\begin{array}{lll}\text { Green Ball : } & \text { Taconite: } & 82.24 \% \\ & \text { Coal: } & 17.76 \%, \\ & \text { Bentonite: } & 1 \% \\ \text { Pellet Size: } & 16 \sim 19 \mathrm{~mm} & \\ \text { Bed Height: } & 120 \mathrm{~mm} \\ \text { Temperature: } & 1200 \sim 1500^{\circ} \mathrm{C} \\ \text { Time: } & 60 \text { minutes } & \end{array}$

Appearance of DRI cake $(230 \mathrm{~mm} \times 190 \mathrm{~mm} \times 70 \mathrm{~mm})$

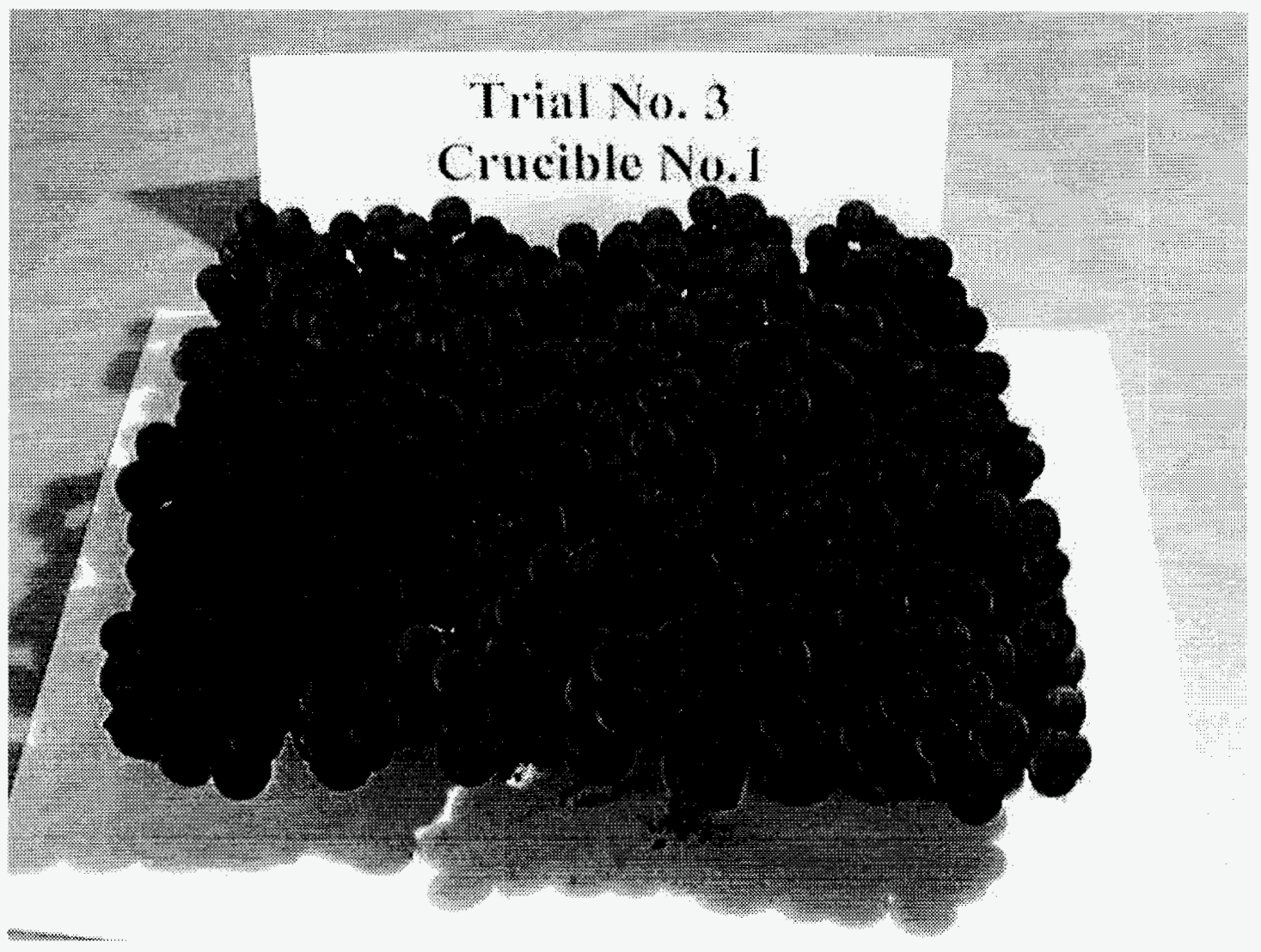

Figure A-5. DRI cake made from taconite concentrate (Crucible\#1 of Trial \#3) 


$\begin{array}{lll}\text { Green Ball : } & \text { Carajas } & 81.52 \% \\ & \text { Coal: } & 18.48 \% \\ & \text { Bentonite: } & 1 \% \\ \text { Pellet Size: } & 16 \sim 19 \mathrm{~mm} & \\ \text { Bed Height: } & 120 \mathrm{~mm} & \\ \text { Temperature: } & 1200 \sim 1500^{\circ} \mathrm{C} & \\ \text { Time: } & 60 \text { minutes } & \end{array}$

Appearance of DRI cake $(230 \mathrm{~mm} \times 190 \mathrm{~mm} \times 70 \mathrm{~mm})$

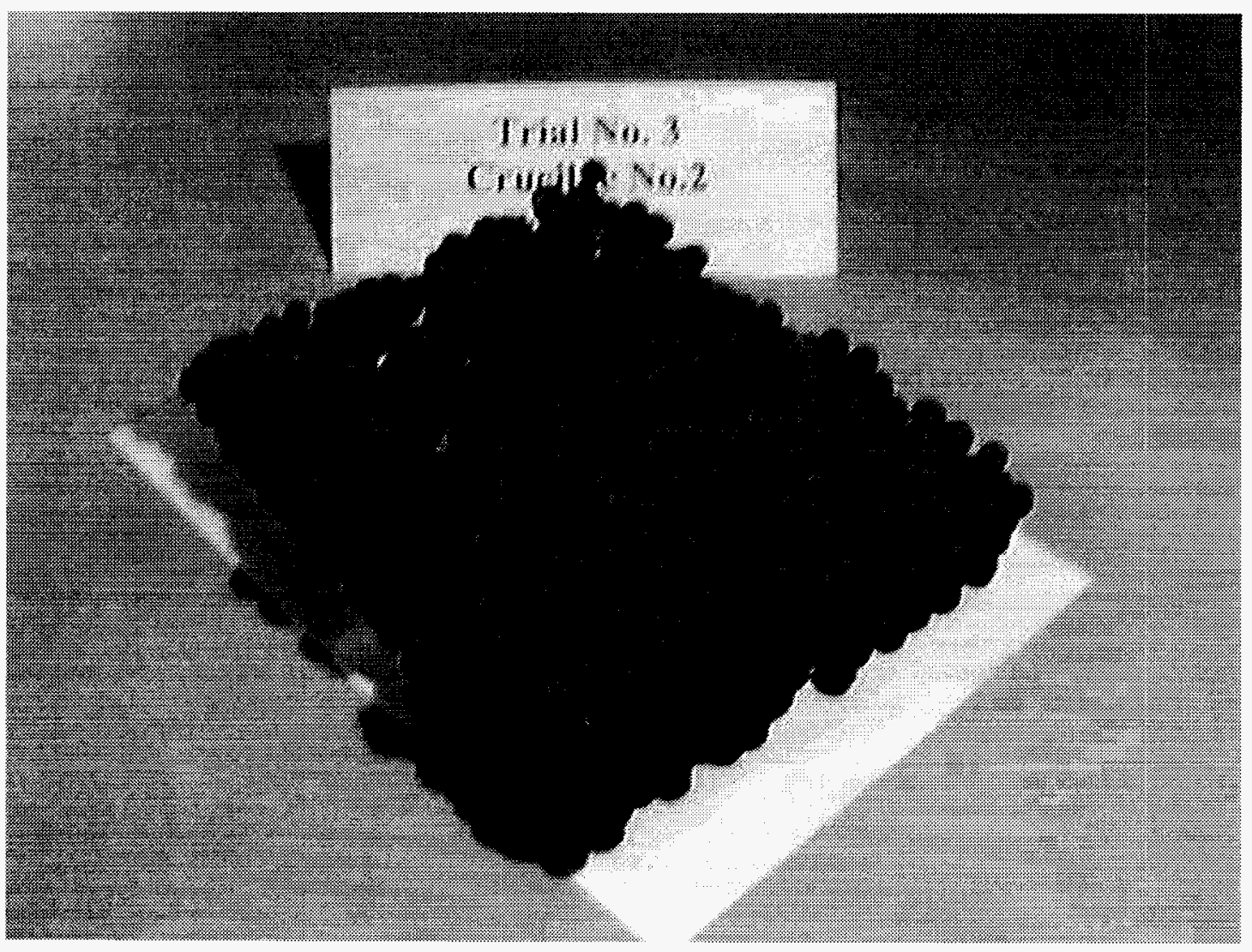

Figure A-6. DRI cake made from Carajas concentrate (Crucible\#2 of Trial \#3) 


$\begin{array}{lll}\text { Green Ball : } & \text { Carajas } & 81.52 \% \\ & \text { Coal: } & 18.48 \% \\ & \text { Bentonite: } & 1 \% \\ \text { Pellet Size: } & 16 \sim 19 \mathrm{~mm} & \\ \text { Bed Height: } & 120 \mathrm{~mm} & \\ \text { Temperature: } & 1200 \sim 1500^{\circ} \mathrm{C} & \\ \text { Time: } & 60 \text { minutes } & \end{array}$

Appearance of DRI cake $(230 \mathrm{~mm} \times 190 \mathrm{~mm} \times 70 \mathrm{~mm})$

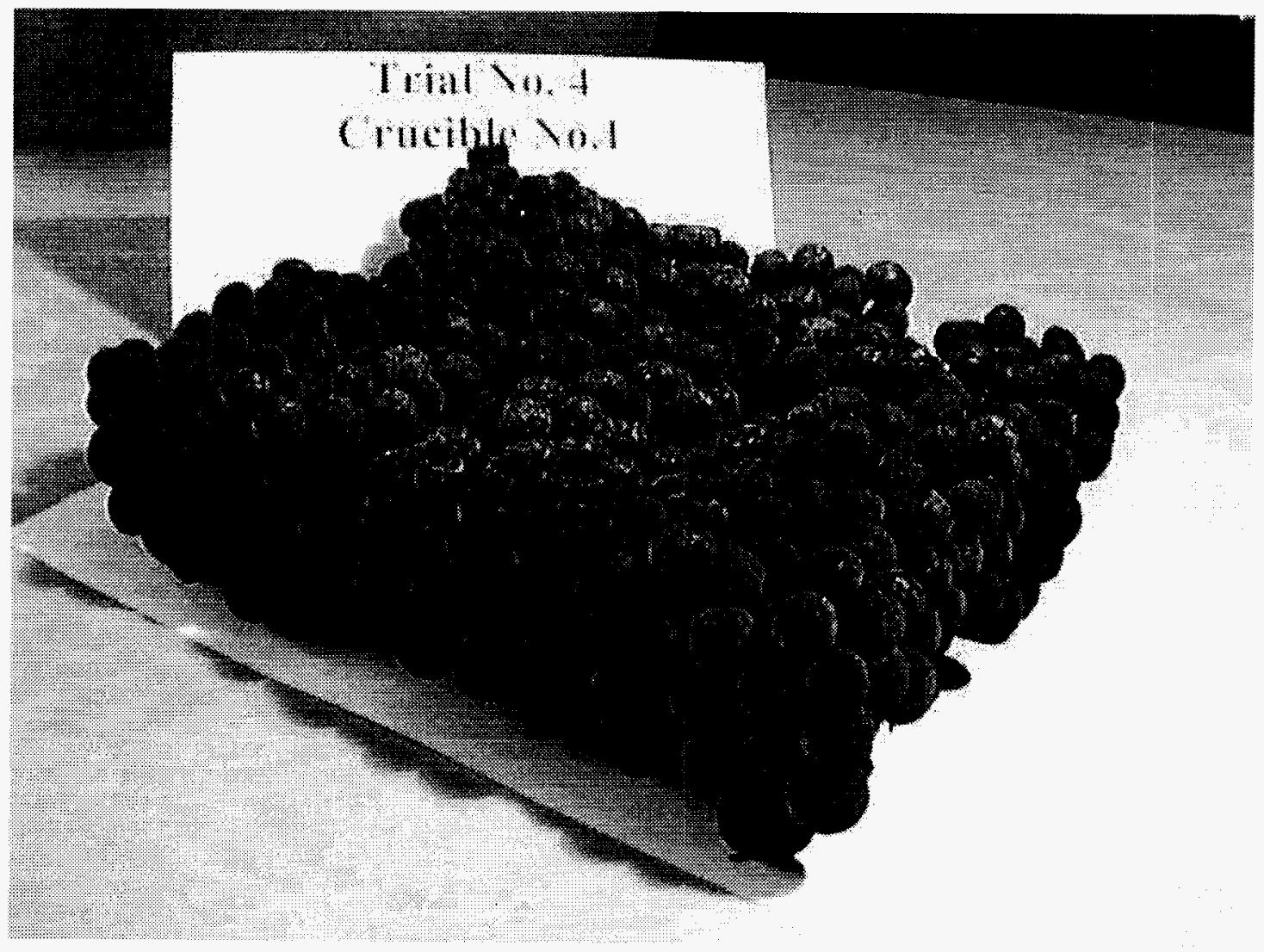

Figure A-7. DRI cake made from Carajas concentrate (Crucible\#1 of Trial \#4) 


$\begin{array}{lll}\text { Green Ball : } & \text { Taconite: } & 83.89 \%, \\ & \text { Coal: } & 16.11 \%, \\ & \text { Bentonite: } & 1 \% \\ \text { Pellet Size: } & 16 \sim 19 \mathrm{~mm} & \\ \text { Bed Height: } & 120 \mathrm{~mm} \\ \text { Temperature: } & 1200 \sim 1500^{\circ} \mathrm{C} \\ \text { Time: } & 60 \text { minutes }\end{array}$

Appearance of DRI cake $(230 \mathrm{~mm} \times 190 \mathrm{~mm} \times 70 \mathrm{~mm})$

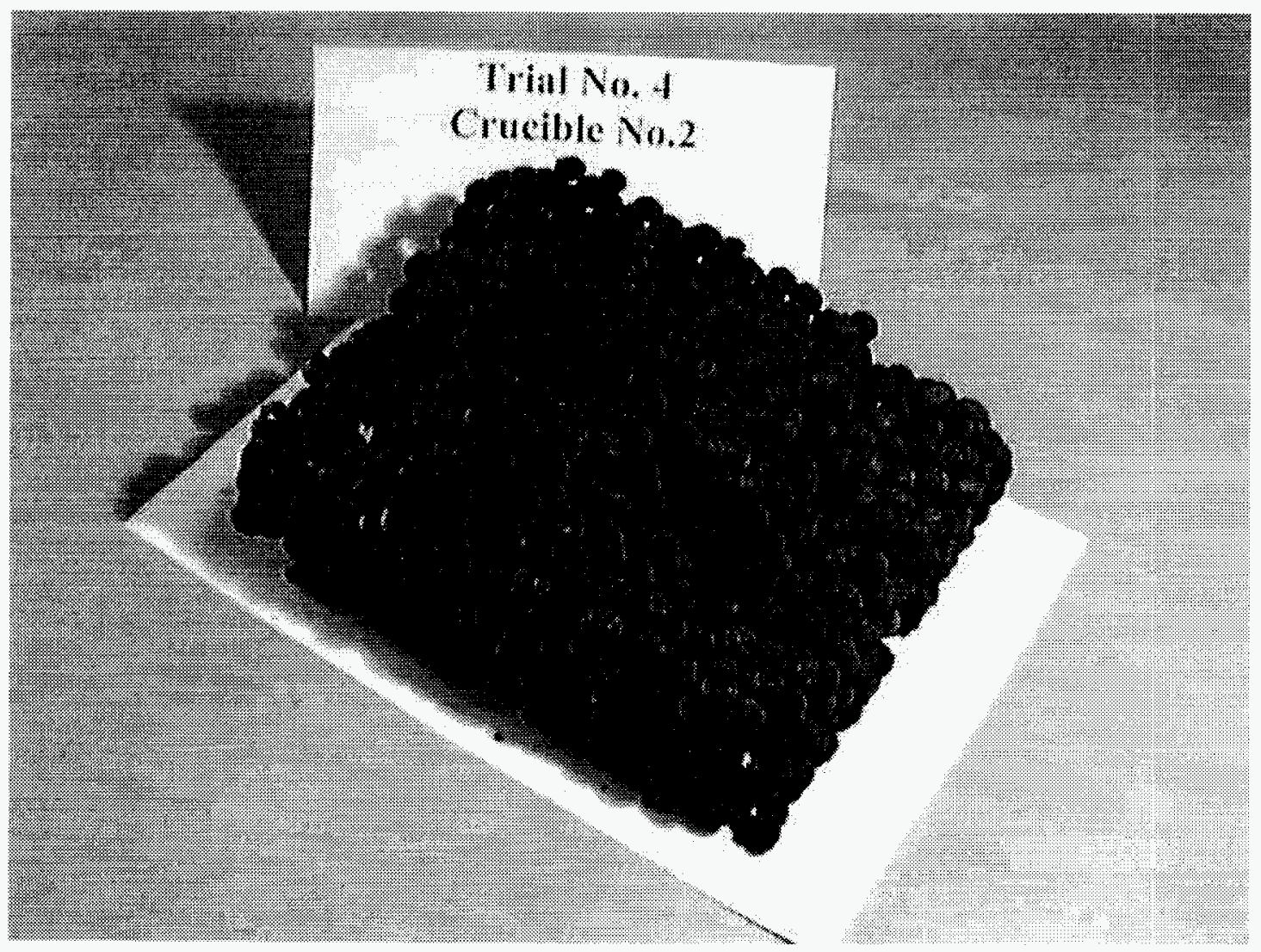

Figure A-8. DRI cake made from taconite concentrate (Crucible\#2 of Trial \#4) 


$\begin{array}{lll}\text { Green Ball : } & \text { BOF Sludge } & 84.50 \% \\ & \text { Coal: } & 15.50 \% \\ & \text { Bentonite: } & 1 \% \\ \text { Pellet Size: } & 16 \sim 19 \mathrm{~mm} & \\ \text { Bed Height: } & 120 \mathrm{~mm} & \\ \text { Temperature: } & 1200 \sim 1500^{\circ} \mathrm{C} & \\ \text { Time: } & 60 \text { minutes } & \end{array}$

Appearance of DRI cake $(230 \mathrm{~mm} \times 190 \mathrm{~mm} \times 55 \mathrm{~mm})$

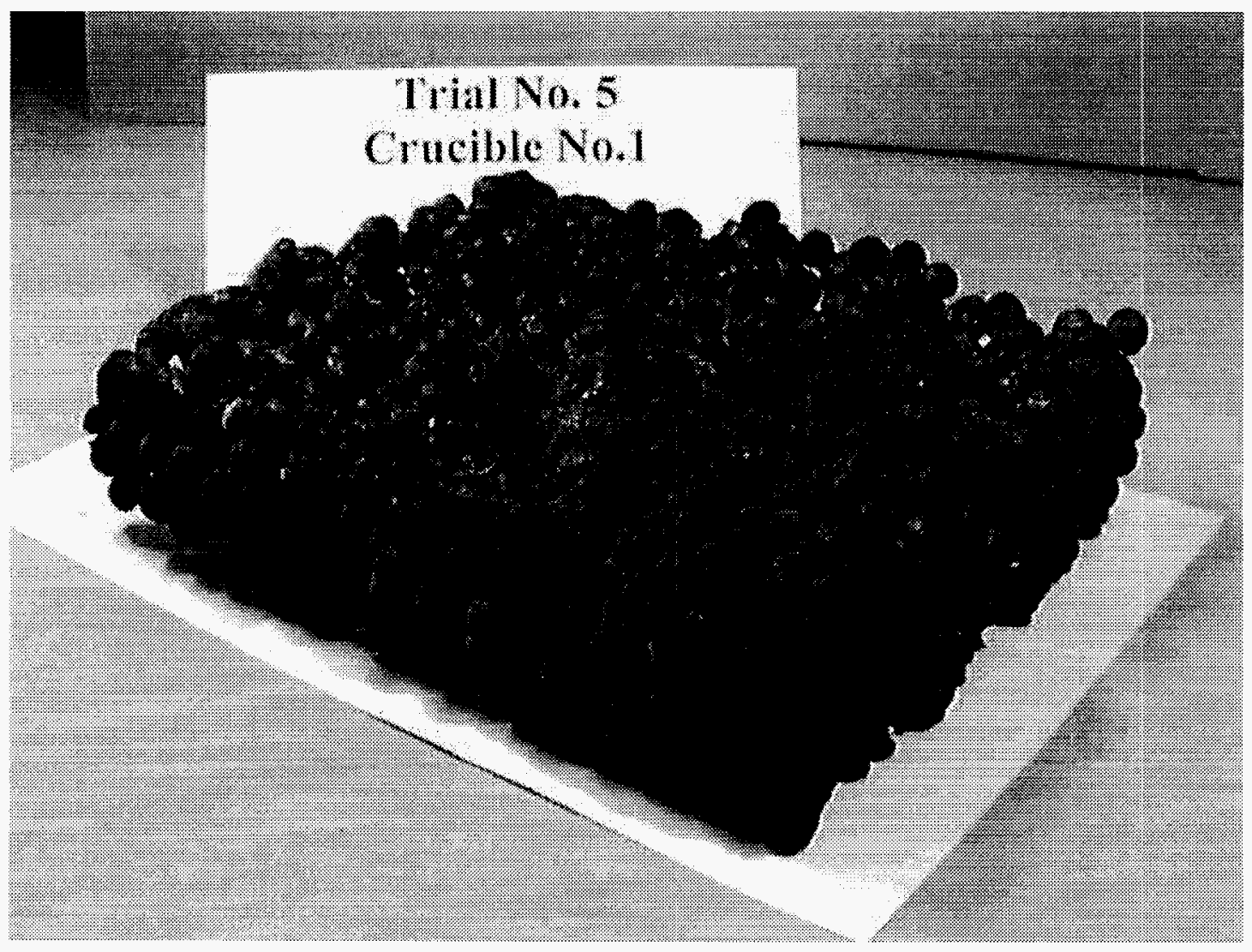

Figure A-9. DRI cake made from BOF sludge (Crucible\#1 of Trial \#5) 


$\begin{array}{lll}\text { Green Ball : } & \text { BOF Sludge } & 83.85 \% \\ & \text { Coal: } & 16.15 \% \\ & \text { Bentonite: } & 1 \% \\ \text { Pellet Size: } & 16 \sim 19 \mathrm{~mm} & \\ \text { Bed Height: } & 120 \mathrm{~mm} & \\ \text { Temperature: } & 1200 \sim 1500^{\circ} \mathrm{C} & \\ \text { Time: } & 60 \text { minutes } & \end{array}$

Appearance of DRI cake $(230 \mathrm{~mm} \times 190 \mathrm{~mm} \times 55 \mathrm{~mm})$

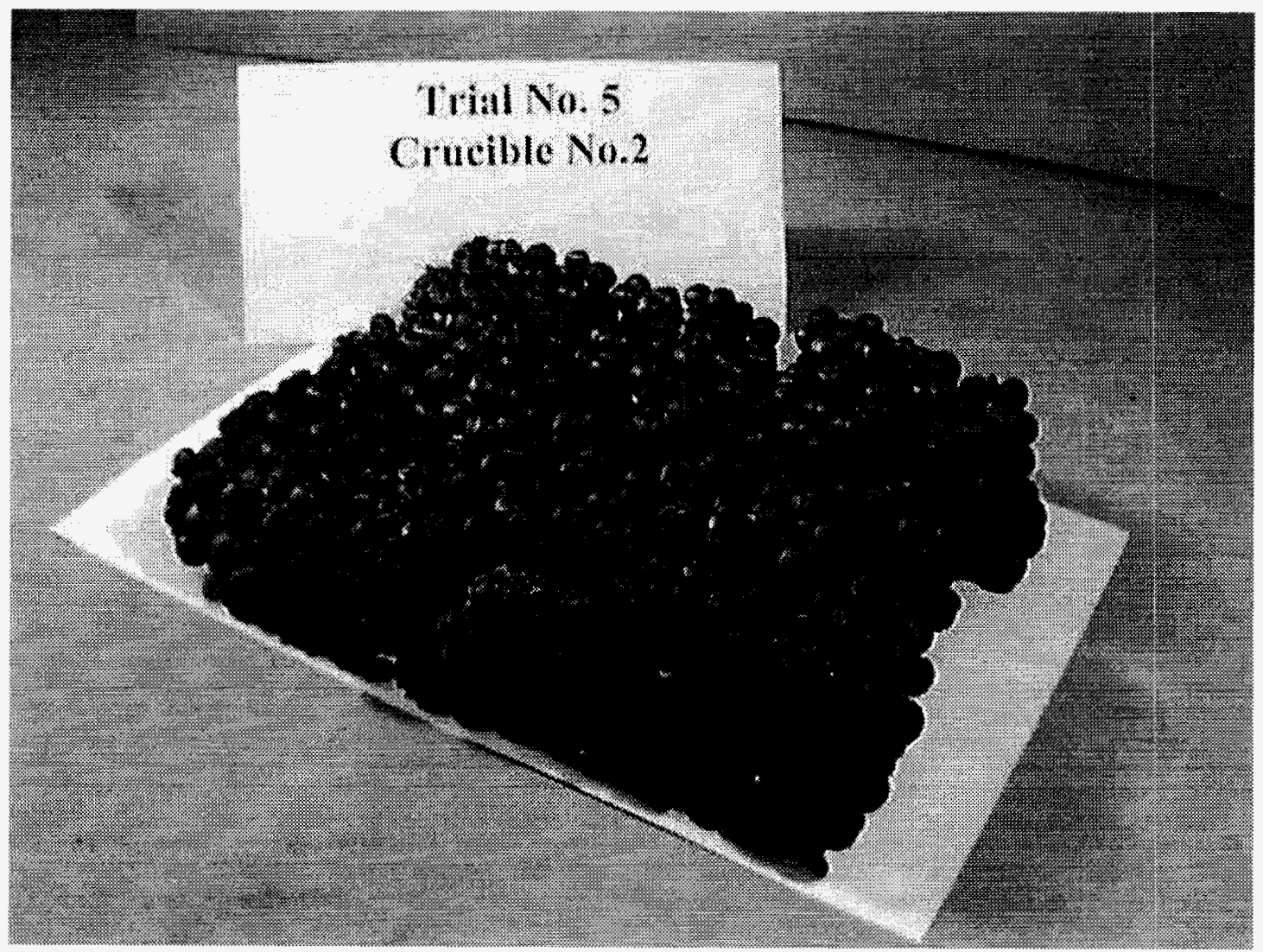

Figure A-10. DRI cake made from BOF sludge (Crucible\#2 of Trial \#5) 


$\begin{array}{lll}\text { Green Ball : } & \text { BOF Sludge } & 83.85 \% \\ & \text { Coal: } & 16.15 \% \\ & \text { Bentonite: } & 1 \% \\ \text { Pellet Size: } & 16 \sim 19 \mathrm{~mm} & \\ \text { Bed Height: } & 120 \mathrm{~mm} \\ \text { Temperature: } & 1200 \sim 1475^{\circ} \mathrm{C} \\ \text { Time: } & 60 \text { minutes } & \end{array}$

Appearance of DRI cake $(230 \mathrm{~mm} \times 190 \mathrm{~mm} \times 61 \mathrm{~mm})$

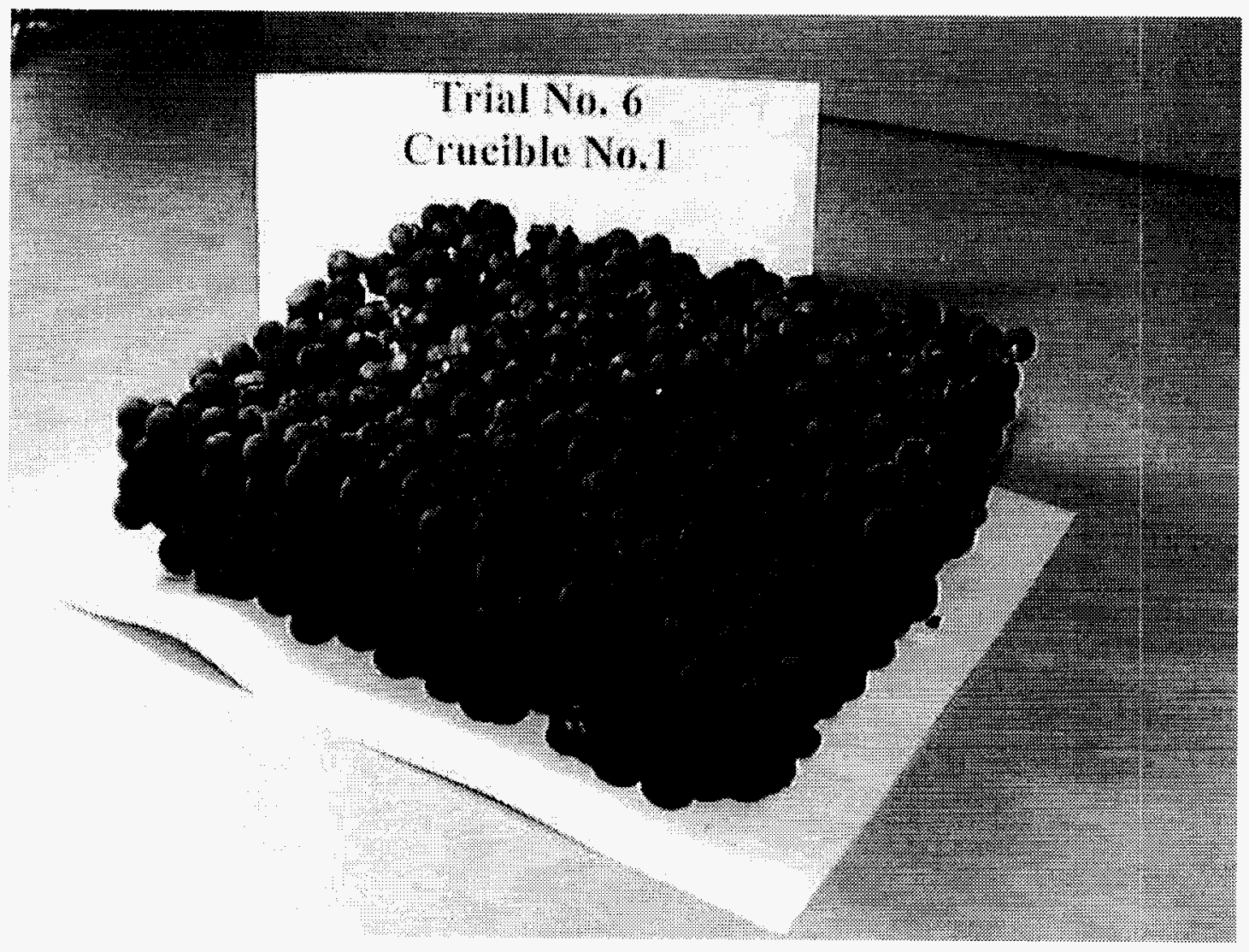

Figure A-11. DRI cake made from BOF slud ge (Crucible\#1 of Trial \#6) 


$\begin{array}{lll}\text { Green Ball : } & \text { BOF Sludge } & 84.50 \% \\ & \text { Coal: } & 15.50 \% \\ & \text { Bentonite: } & 1 \% \\ \text { Pellet Size: } & 16 \sim 19 \mathrm{~mm} & \\ \text { Bed Height: } & 120 \mathrm{~mm} \\ \text { Temperature: } & 1200 \sim 1475^{\circ} \mathrm{C} \\ \text { Time: } & 60 \text { minutes } & \\ & \end{array}$

Appearance of DRI cake $(230 \mathrm{~mm} \times 190 \mathrm{~mm} \times 57 \mathrm{~mm})$

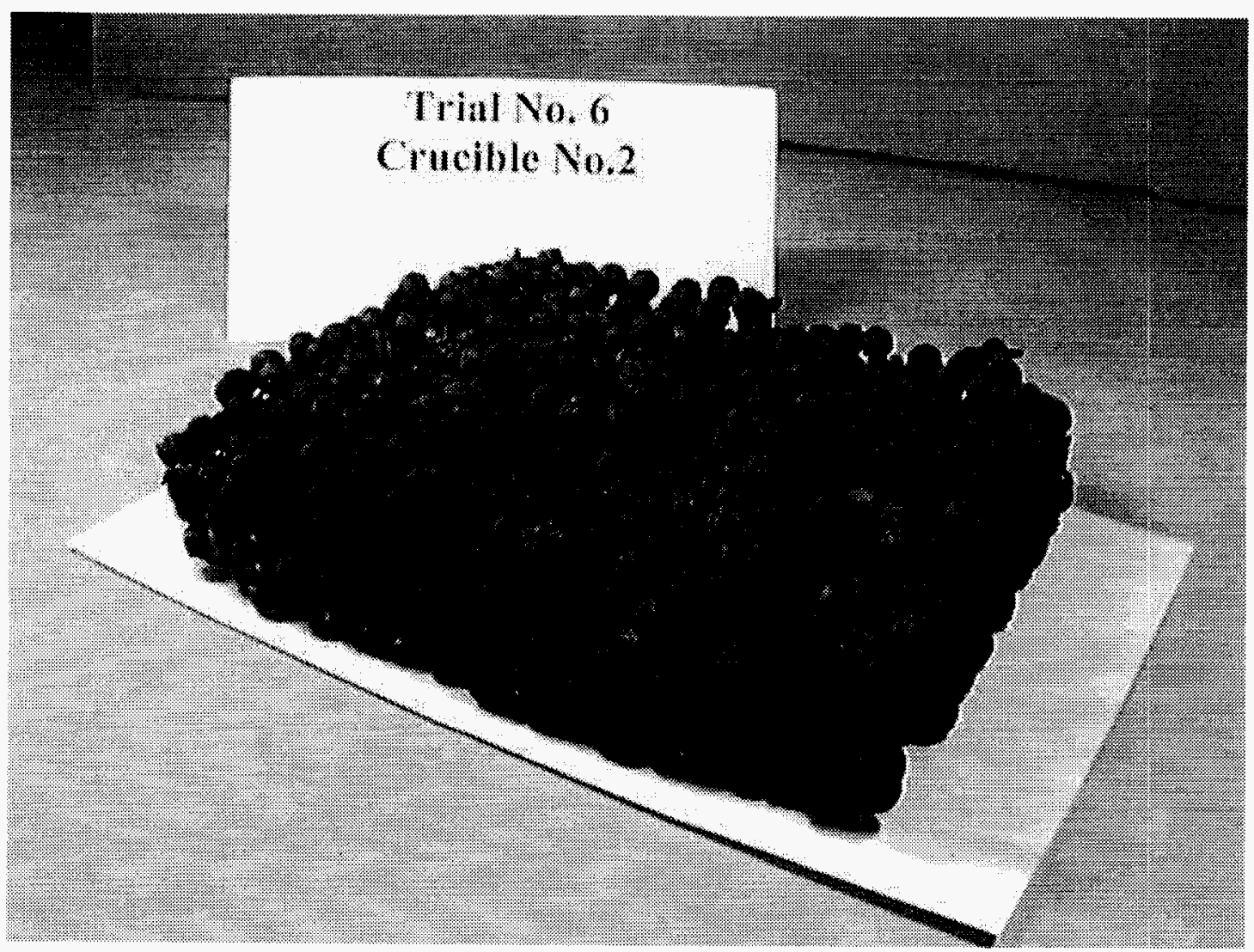

Figure A-12. DRI cake made from BOF sludge (Crucible\#2 of Trial \#6) 


$\begin{array}{lll}\text { Green Ball : } & \text { BOF Sludge } & 59.36 \% \\ & \text { EAF dust } & 25.44 \% \\ & \text { Coal: } & 15.20 \% \\ & \text { Bentonite: } & 1 \% \\ \text { Pellet Size: } & 16 \sim 19 \mathrm{~mm} & \\ \text { Bed Height: } & 120 \mathrm{~mm} & \\ \text { Temperature: } & 1200 \sim 1450^{\circ} \mathrm{C} & \\ \text { Time: } & 65 \text { minutes }\end{array}$

Appearance of DRI cake $(230 \mathrm{~mm} \times 190 \mathrm{~mm} \times 65 \mathrm{~mm})$

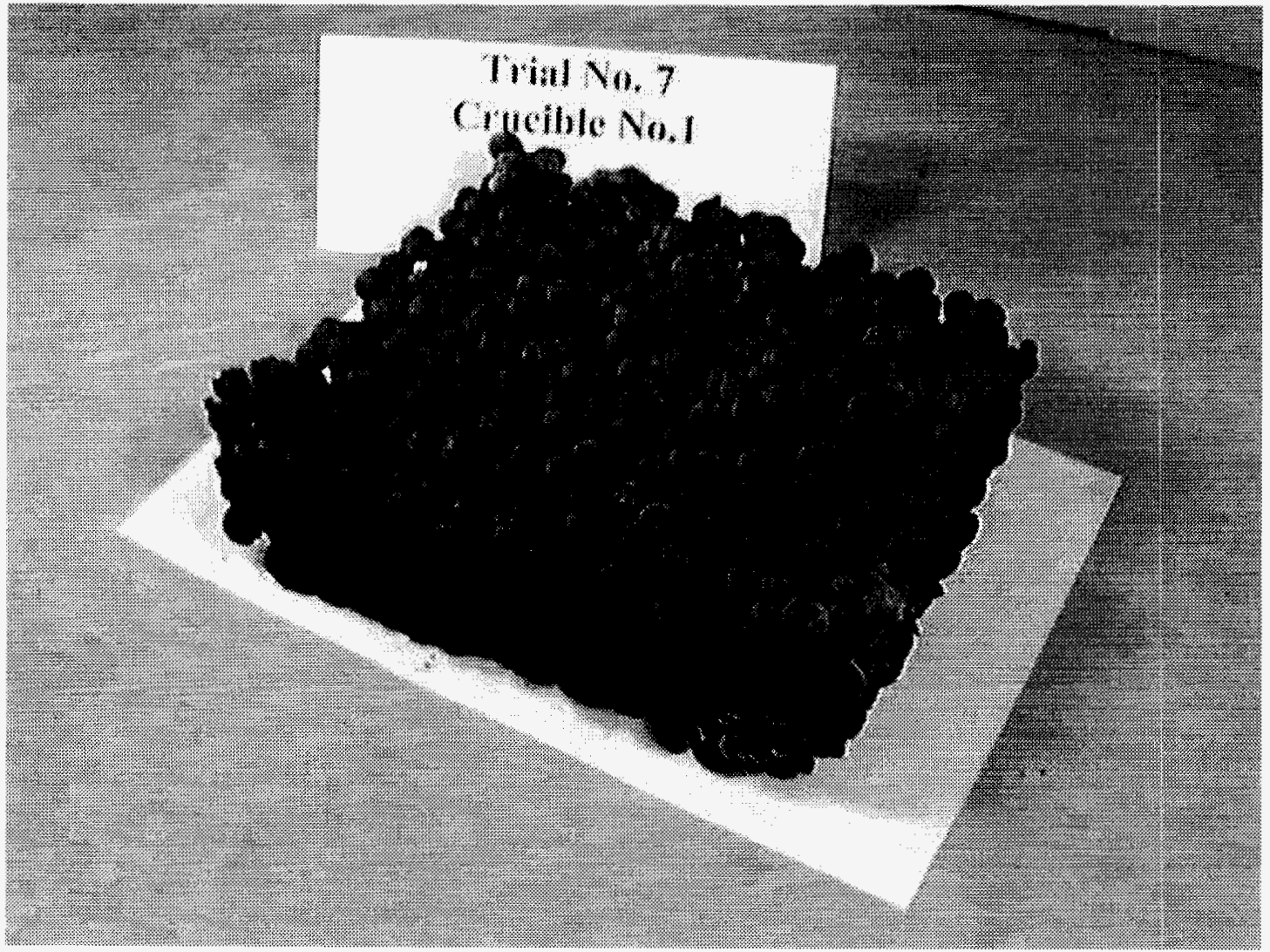

Figure A-13. DRI cake made from BOF sludge and EAF dust (Crucible\#1 of Trial \#7) 


$\begin{array}{lll}\text { Green Ball : } & \text { BOF Sludge } & 59.78 \% \\ & \text { EAF dust } & 25.62 \% \\ & \text { Coal: } & 14.60 \% \\ & \text { Bentonite: } & 1 \% \\ \text { Pellet Size: } & 16 \sim 19 \mathrm{~mm} & \\ \text { Bed Height: } & 120 \mathrm{~mm} & \\ \text { Temperature: } & 1200 \sim 1450^{\circ} \mathrm{C} & \\ \text { Time: } & 65 \text { minutes } & \end{array}$

Appearance of DRI cake $(230 \mathrm{~mm} \times 190 \mathrm{~mm} \times 65 \mathrm{~mm})$

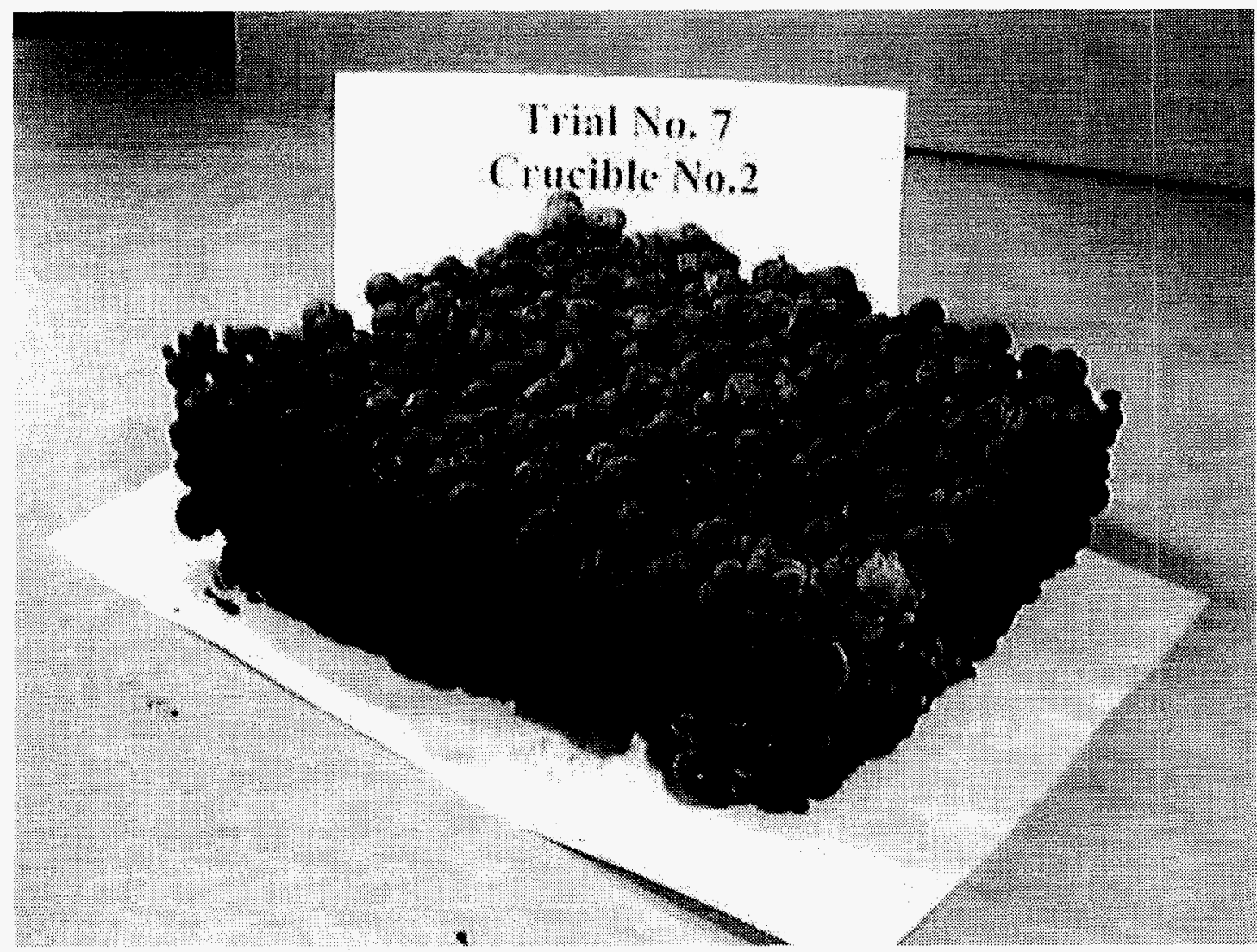

Figure A-14. DRI cake made from BOF sludge and EAF dust (Crucible\#2 of Trial \#7) 


$\begin{array}{lll}\text { Green Ball : } & \text { BOF Sludge } & 42.70 \% \\ & \text { EAF dust } & 42.70 \% \\ & \text { Coal: } & 14.60 \% \\ & \text { Bentonite: } & 1 \% \\ \text { Pellet Size: } & 16 \sim 19 \mathrm{~mm} & \\ \text { Bed Height: } & 120 \mathrm{~mm} & \\ \text { Temperature: } & 1200 \sim 1450^{\circ} \mathrm{C} & \\ \text { Time: } & 65 \text { minutes } & \end{array}$

Appearance of DRI cake $(230 \mathrm{~mm} \times 190 \mathrm{~mm} \times 67 \mathrm{~mm})$

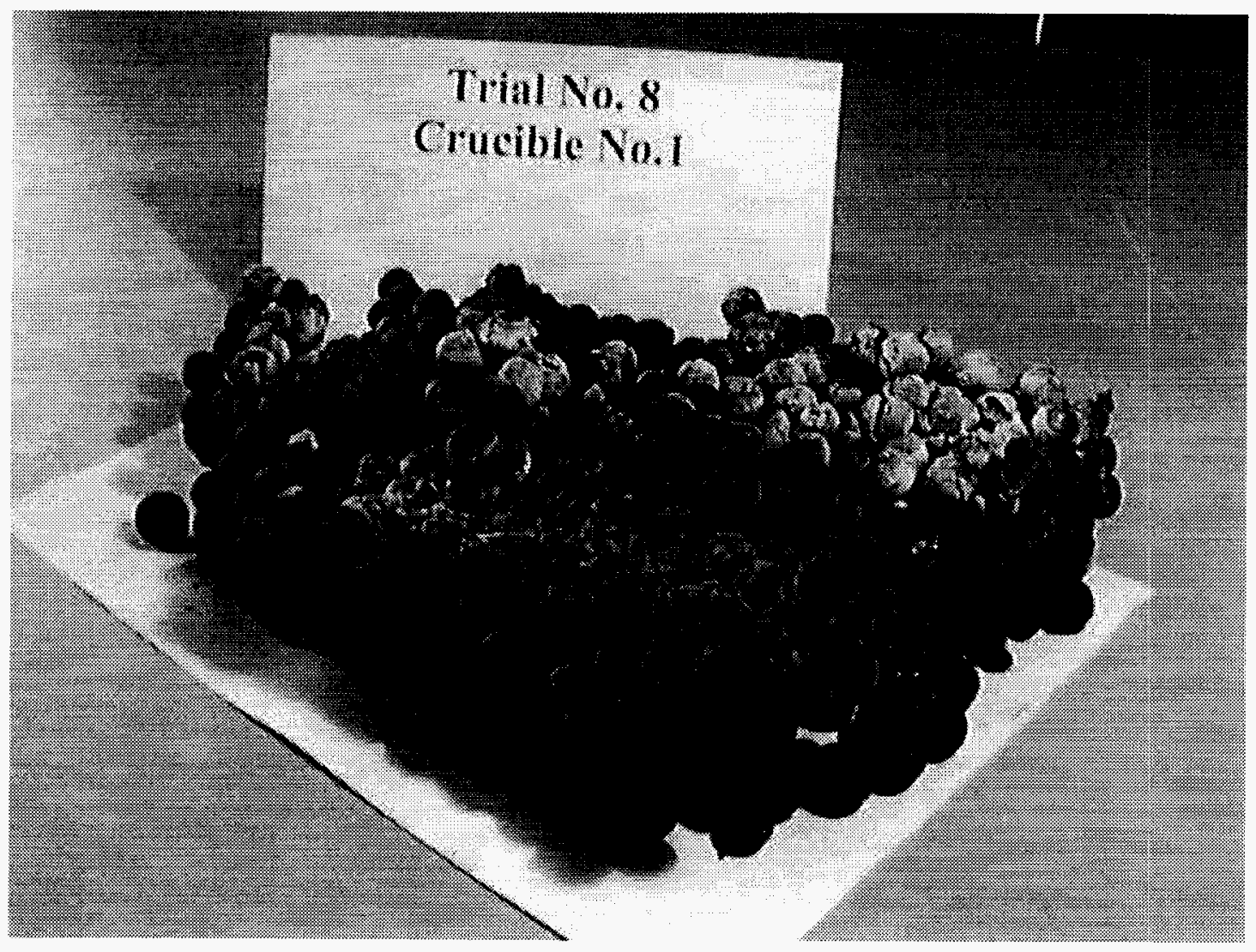

Figure A-15. DRI cake made from BOF sludge and EAF dust (Crucible\#1 of Trial \#8) 


$\begin{array}{lll}\text { Green Ball : } & \text { BOF Sludge } & 59.36 \% \\ & \text { EAF dust } & 25.44 \% \\ & \text { Coal: } & 15.20 \% \\ & \text { Bentonite: } & 1 \% \\ \text { Pellet Size: } & 16 \sim 19 \mathrm{~mm} & \\ \text { Bed Height: } & 120 \mathrm{~mm} & \\ \text { Temperature: } & 1200 \sim 1450^{\circ} \mathrm{C} & \\ \text { Time: } & 65 \text { minutes } & \end{array}$

Appearance of DRI cake $(230 \mathrm{~mm} \times 190 \mathrm{~mm} \times 65 \mathrm{~mm})$

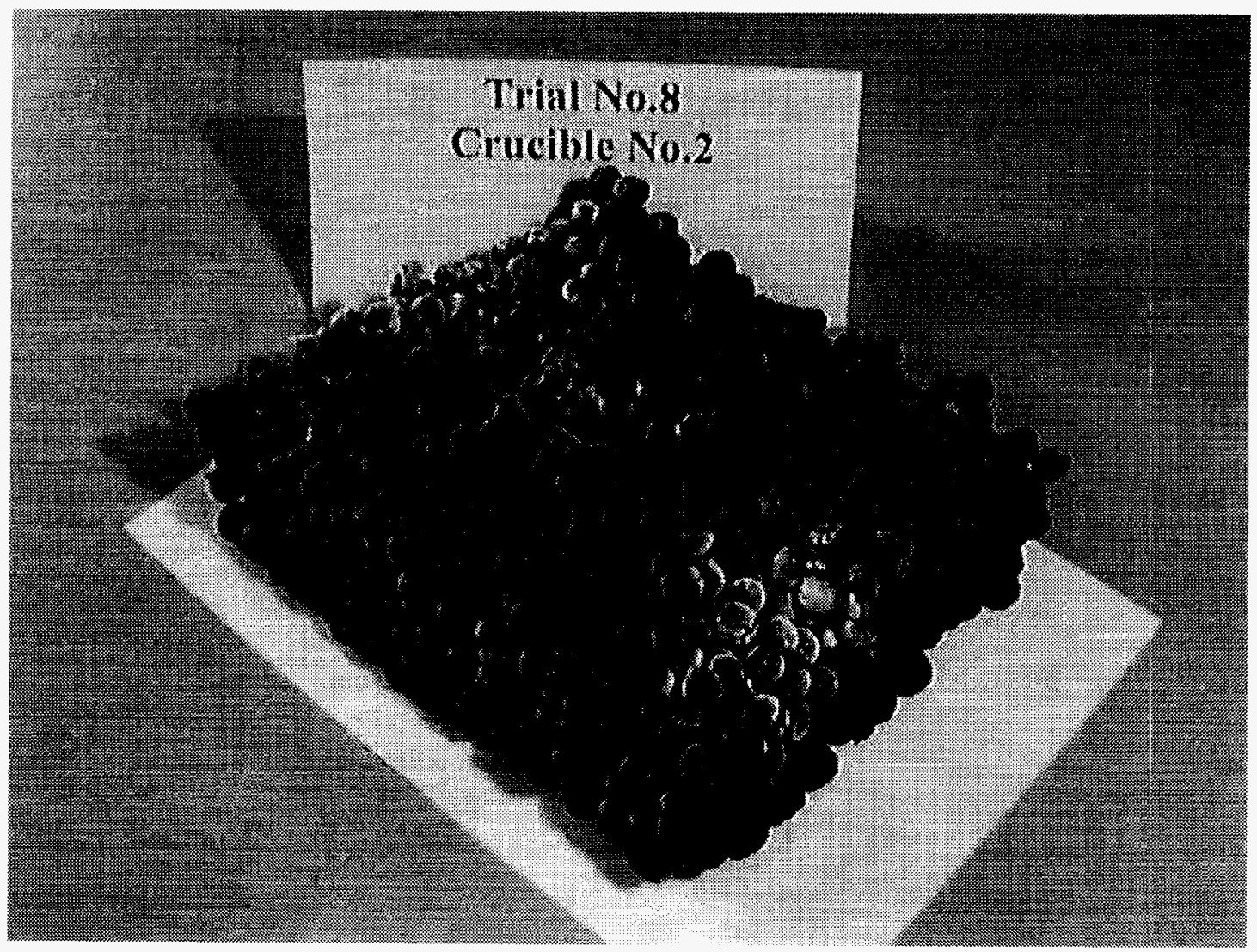

Figure A-16. DRI cake made from BOF sludge and EAF dust (Crucible\#2 of Trial \#8) 


$\begin{array}{lll}\text { Green Ball : } & \begin{array}{l}\text { Carajas } \\ \text { (fine ground) }\end{array} & 82.42 \% \\ & \begin{array}{l}\text { Coal: } \\ \text { Bentonite: }\end{array} & 17.48 \% \\ & 1 \% \\ \text { Pellet Size: } & 16 \sim 19 \mathrm{~mm} & \\ \text { Bed Height: } & 120 \mathrm{~mm} & \\ \text { Temperature: } & 1200 \sim 1500^{\circ} \mathrm{C} & \\ \text { Time: } & 60 \text { minutes } & \end{array}$

Appearance of DRI cake $(230 \mathrm{~mm} \times 190 \mathrm{~mm} \times 65 \mathrm{~mm})$

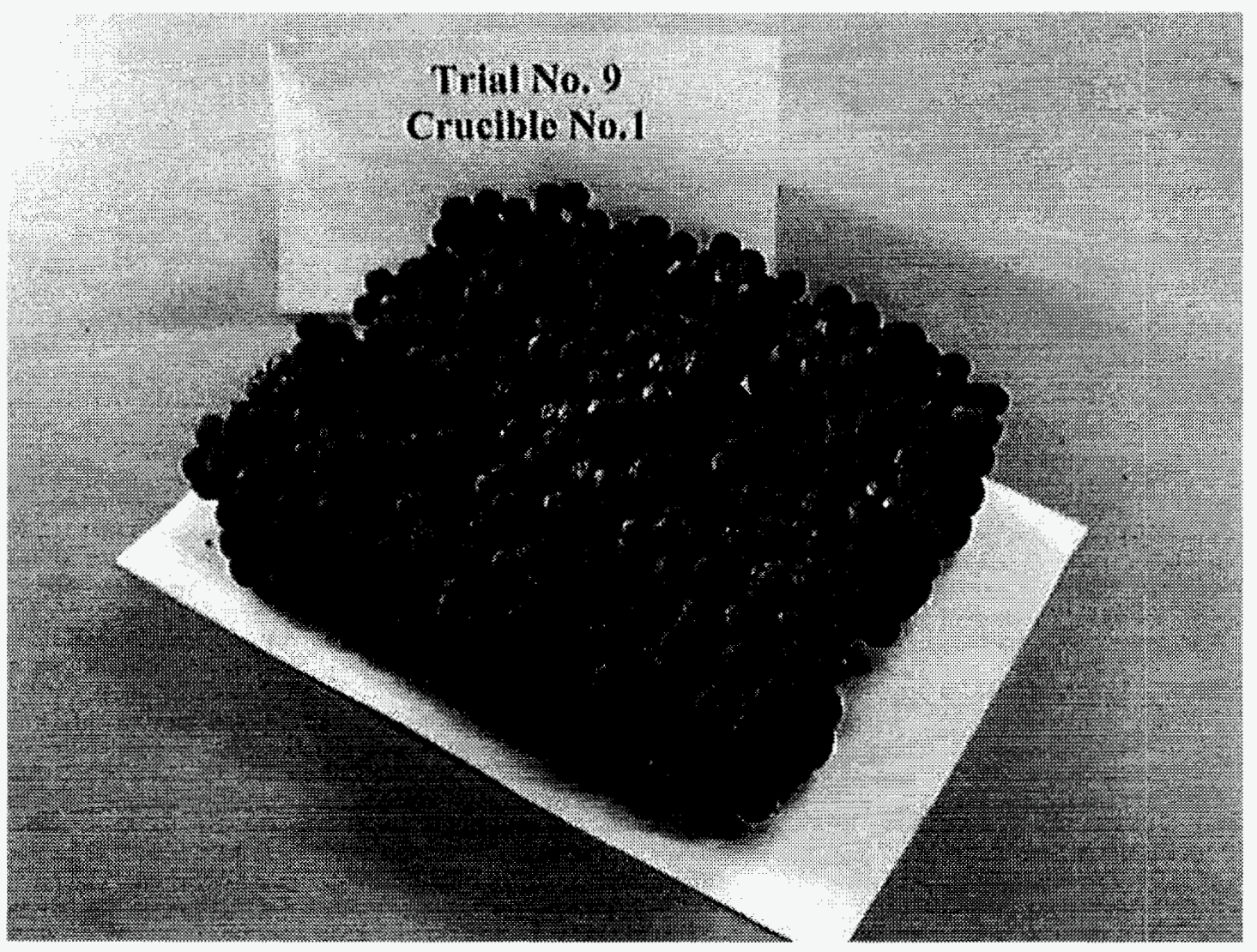

Figure A-17. DRI cake made from Carajas concentrate (fined ground) (Crucible\#1 of Trial \#9) 
$\begin{array}{lll}\text { Green Ball : } & \text { Mill scale } & 81.70 \% \\ & \text { Coal: } & 18.30 \% \\ & \text { Bentonite: } & 1 \%\end{array}$

Pellet Size: $\quad 16 \sim 19 \mathrm{~mm}$

Bed Height: $\quad 120 \mathrm{~mm}$

Temperature: $\quad 1200 \sim 1450^{\circ} \mathrm{C}$

Time: $\quad 65$ minutes

Appearance of DRI cake $(230 \mathrm{~mm} \times 190 \mathrm{~mm} \times 60 \mathrm{~mm})$

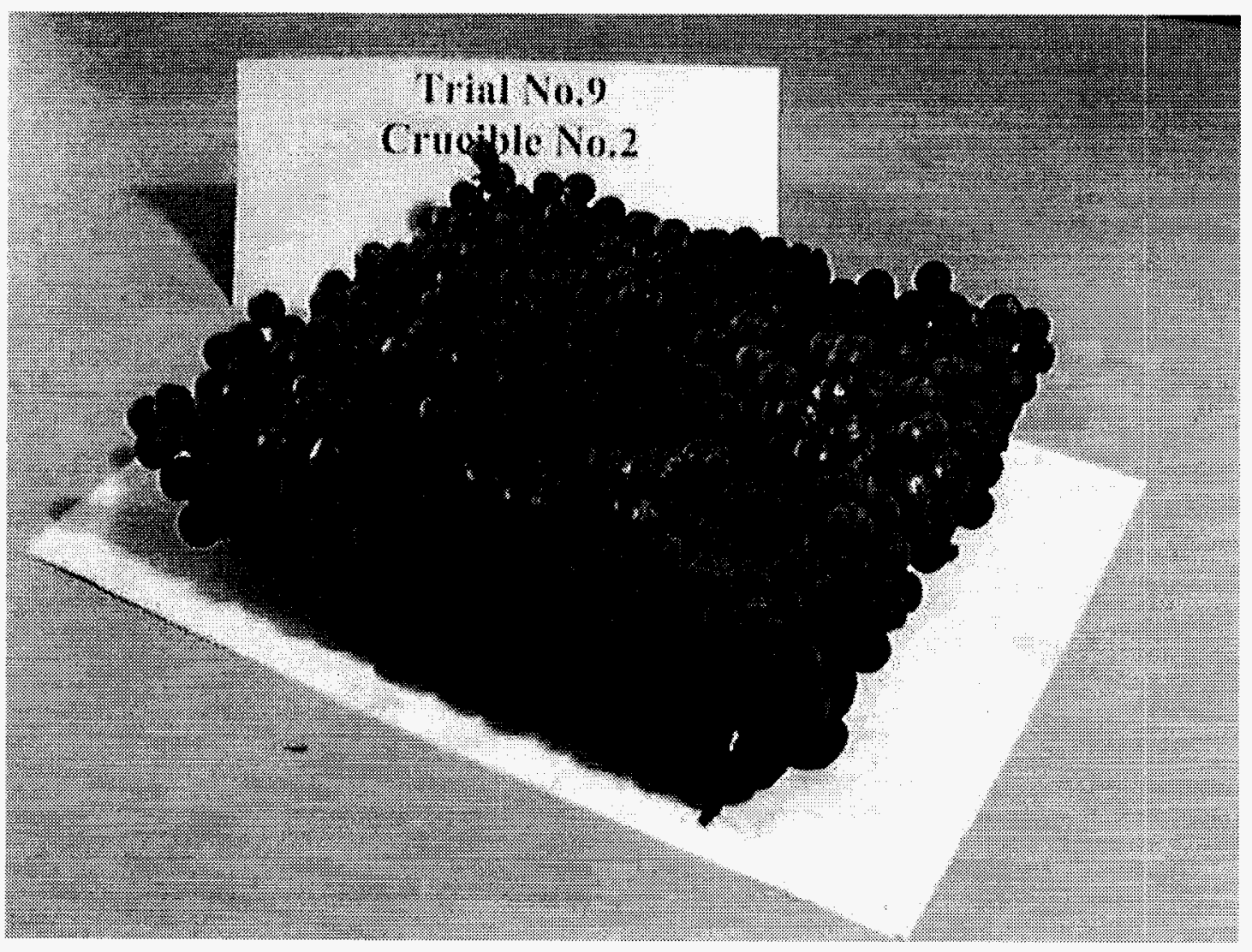

Figure A-18. DRI cake made from mill scale (Crucible\#2 of Trial \#9) 


$\begin{array}{lll}\text { Green Ball : } & \text { Taconite } & 83.89 \% \\ & \text { Coal: } & 16.11 \% \\ & \text { Bentonite: } & 1 \% \\ \text { Pellet Size: } & 16 \sim 19 \mathrm{~mm} & \\ \text { Bed Height: } & 120 \mathrm{~mm} & \\ \text { Temperature: } & 1200 \sim 1500^{\circ} \mathrm{C} & \\ \text { Time: } & 60 \text { minutes } & \\ & & \end{array}$

Appearance of DRI cake $(230 \mathrm{~mm} \times 190 \mathrm{~mm} \times 69 \mathrm{~mm})$

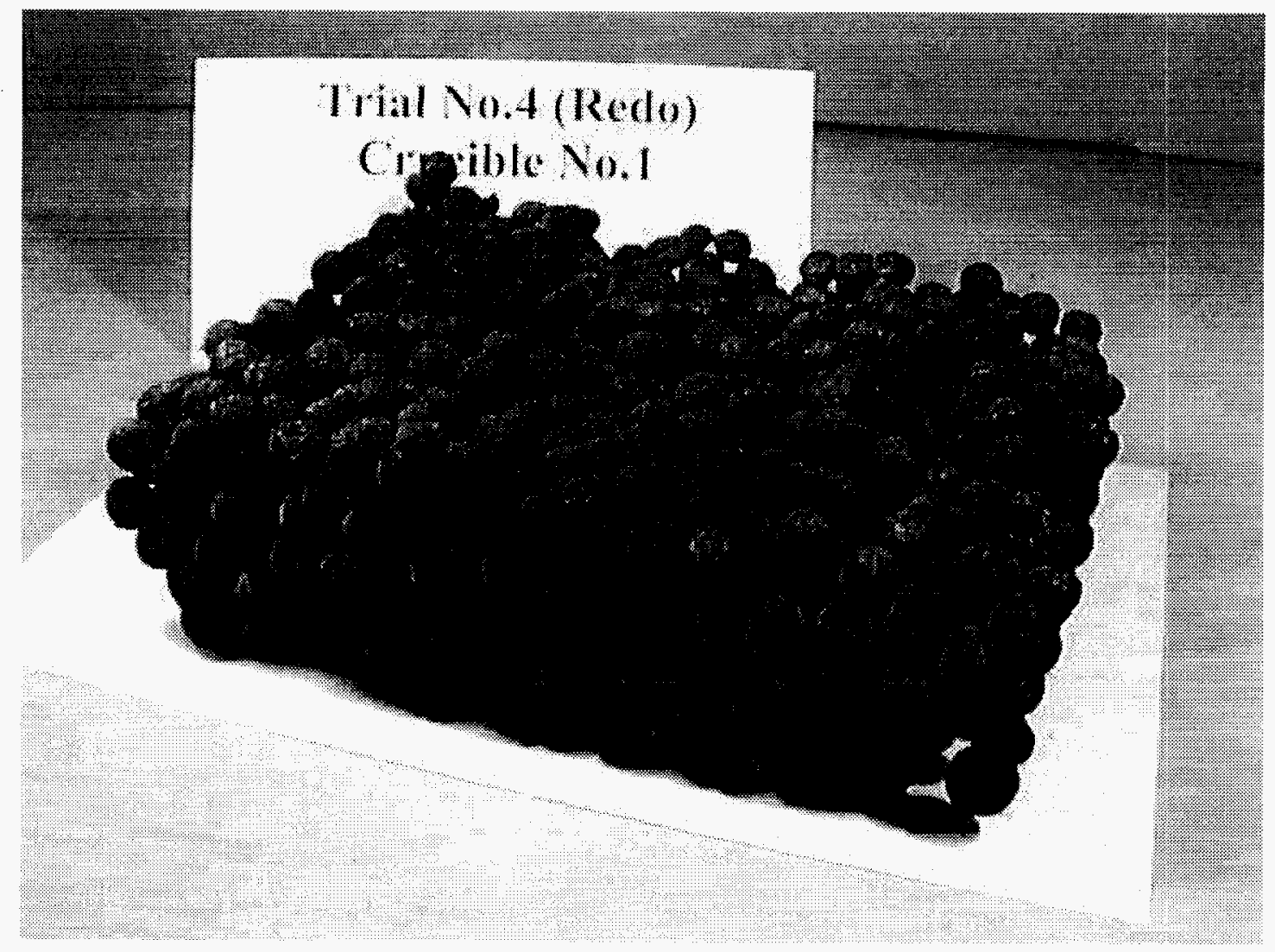

Figure A-19. DRI cake made from taconite concentrate (Crucible\#1 of Trial \#4-Redo) 


$\begin{array}{lll}\text { Green Ball : } & \text { Carajas } & 82.42 \%, \\ & \text { Coal: } & 17.58 \%, \\ & \text { Bentonite: } & 1 \% \\ \text { Pellet Size: } & 16 \sim 19 \mathrm{~mm} & \\ \text { Bed Height: } & 120 \mathrm{~mm} & \\ \text { Temperature: } & 1200 \sim 1500^{\circ} \mathrm{C} & \\ \text { Time: } & 60 \text { minutes }\end{array}$

Appearance of DRI cake $(230 \mathrm{~mm} \times 190 \mathrm{~mm} \times 68 \mathrm{~mm})$

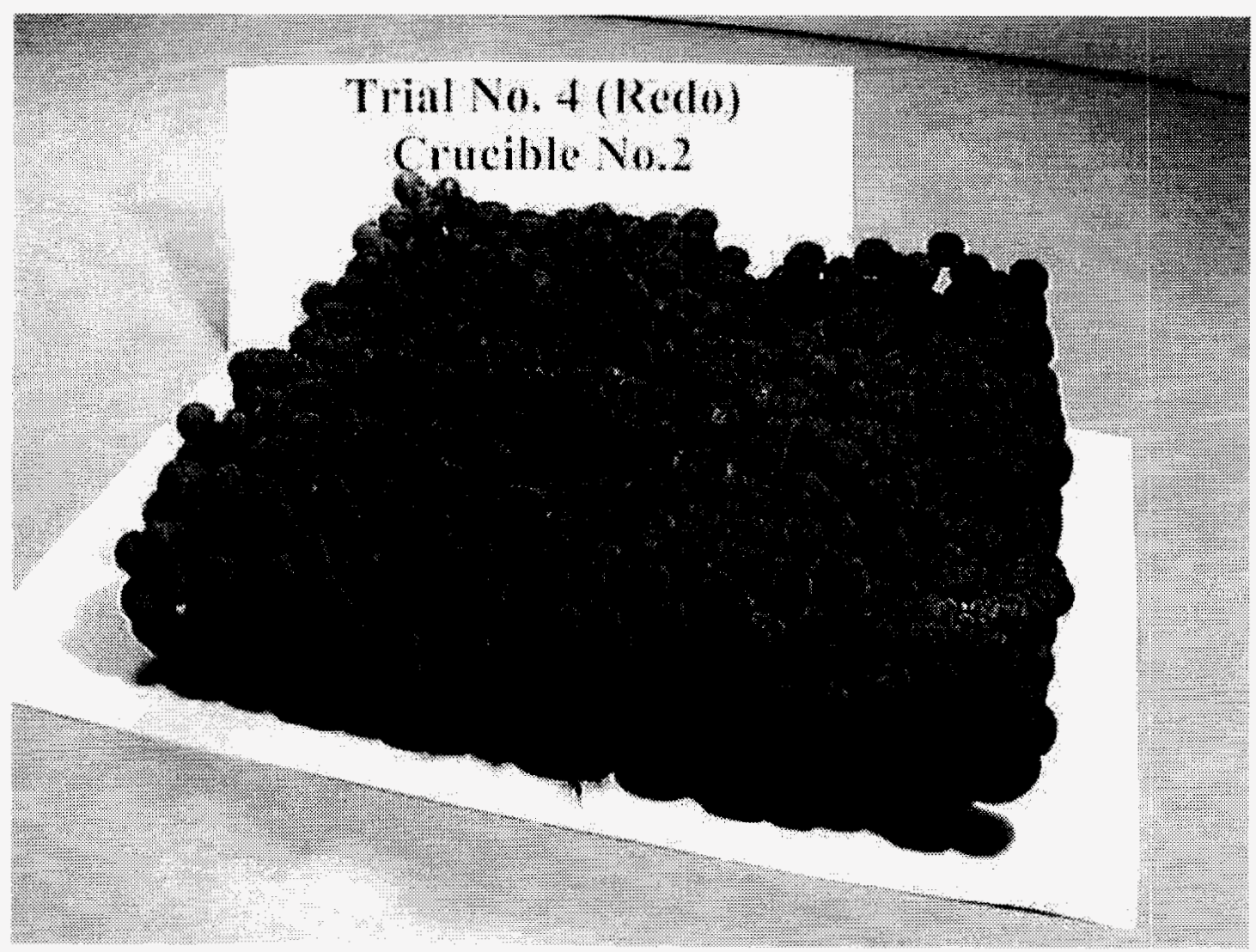

Figure A-20. DRI cake made from Carajas concentrate (Crucible\#2 of Trial \#4-Redo) 


\section{APPENDIX B}

\section{DETERMINATION OF TOTAL, METALLIC, FERROUS AND FERRIC IRON IN REDUCED IRON PELLETS, SPONGE IRON, ORES, SLAG, ETC.}

\section{REAGENTS}

\section{Potassium dicromate $(0.0895 \mathrm{~N})$ :}

Dissolve 4.389 grams of the salt in water and dilute to one litre. Standardize against a standard iron ore, and adjust, if necessary, so that $\mathrm{I} \mathrm{ml} .=0.005$ grains of $\mathrm{Fe}$.

Note: Potassium dichromate (Reagent grade) may be regarded as a primary standard after the following treatment: grind crystals in agate mortar to a fine powder; heat at $140-150^{\circ} \mathrm{C}$ for about an hour and cool in desiccator.

\section{Titration mixture (and indicator):}

To about $300 \mathrm{mls}$. of water (in a 1 litter boiling flask)

add: $150 \mathrm{mls}$. of sulfuric acid (conc.): cool cold

$150 \mathrm{mls}$. of phosphoric acid (conc.)

12 mls. of a $0.3 \%$ aqueous solution $(0.3 \mathrm{gm} / 100 \mathrm{mls}$.$) of$ p-Diphenylaminesulphonic acid, sodium salt.

Dilute to 1 litter and use $30 \mathrm{mls}$. per determination.

\section{Stannous chloride:}

Dissolve $25 \mathrm{gm}$ of $\mathrm{SnCl}_{\mathrm{b}} \cdot 2 \mathrm{H}_{2} \mathrm{O}$ in $50 \mathrm{mls}$. of hydrochloric acid (conc.). Boil for five minutes. Cool. Add $5 \mathrm{gm}$. of mossy tin metal, and $50 \mathrm{mls}$. of water. Shake and transfer to dropping bottle.

\section{Mercuric chloride:}

A saturated aqueous solution of $\mathrm{HgCh}$

\section{Copper sulfate:}

Dissolve $100 \mathrm{qm}$. of $\mathrm{CuSO}_{4} \cdot 5 \mathrm{H}_{2} \mathrm{O}$ in about $300 \mathrm{mls}$. of water, in a 1 litre boiling flask. Add 3-4 gm. of cupric oxide. Allow to stand in a warm place for several hours, with occasional shaking. Filter and dilute filtrate to 1 litre.

Reactions: $\quad \mathrm{Fe}_{2} \mathrm{O}_{3}(\mathrm{~S})+6 \mathrm{H}^{+}=2 \mathrm{Fe}^{+3}+3 \mathrm{H}_{2} \mathrm{O}$

$2 \mathrm{Fe}+3+\mathrm{Sn}++=2 \mathrm{Fe}+++\mathrm{Sn}+4$

$\mathrm{Sn}^{++}+2 \mathrm{HgCl}_{2}=\mathrm{Sn}^{+4}+\mathrm{HgCl}_{2}(\mathrm{~S})+2 \mathrm{Cl}$

$6 \mathrm{Fe}^{++}+\mathrm{Cr}_{2} \mathrm{O}_{7}^{--}+14 \mathrm{H}^{+}=6 \mathrm{Fe}^{+3}+2 \mathrm{Cr}^{+3}+7 \mathrm{H}_{2} \mathrm{O}$

diphenylamine $+\mathrm{Cr}_{2} \mathrm{O}_{7}^{--}=$diphenylbenzidein violet $+\mathrm{Cr}^{+3}$ 


\section{PROCEDURE}

\section{Total iron:}

Weigh $0.25 \mathrm{gm}$. of sample $(0.50 \mathrm{gm}$. if the iron content is less than $50 \%)$ into a $500 \mathrm{ml}$. Berzelius beaker. Add 10-15 mls. of water and bring just to the boil while swirling. Add $20 \mathrm{ml}$. of hydrochloric acid (conc.). Cover and digest at below boiling.

As the iron yellow colour develops add stannous chloride solution dropwise to completely decolorize the solution. This is repeated as long as the colour reappears (except silica or free carbon). Remove from heat, add a dilute solution of potassium permanganate dropwise to restore the iron yellow colour and boil for 4-5 minutes. While still hot, wash off cover glass and sides of beaker, reduce with stannous chloride solution, dropwise, until all yellow is destroyed, and two drops in excess. Cool cold, quickly. Add $10 \mathrm{mls}$. of mercuric chloride solution quickly, and allow to stand with occasional swirling for not less than 3 or more than 5 minutes. Dilute to about $350 \mathrm{mls}$, add $30 \mathrm{mls}$. of titration mixture and titrate immediately with potassium dichromate to violet. Calculate percent of total iron from titration mls. of titrant $\times 2=\% \mathrm{Fe}(\mathrm{T})$. (on $0.25 \mathrm{~g}$ sample)

\section{Metallic iron:}

Weigh 0.25 gm. of sample into a $250 \mathrm{ml}$. beaker. Add $90 \mathrm{mls}$. of copper sulfate solution. Leave sit for 2 hours with occasional stirring until sample has dissolved completely. Cover with watch glass.

Filter through a \# 40 Whatman paper retaining the filtrate in a $500 \mathrm{ml}$. Berzelius beaker. Police the $250 \mathrm{ml}$. beaker twice and also wash 3 times. Wash paper and residue thoroughly with cold water about 8 times. Reserve residue for $\mathrm{Fe}^{++}$. Dilute the filtrate to about 300 with cold distilled water; add $30 \mathrm{mls}$. of titration mixture and titrate with potassium dichromate as before. mls. of titrant $\times 2=\% \mathrm{Fe}(\mathrm{M})$. (on $0.25 \mathrm{gm}$. sample)

\section{Ferrous Iron}

(Abridged)

\section{Ferrous and Ferric Iron}

(Abridged) 


\section{APPENDIX C}

\section{ERRORS IN THE DETERMINATION OF METALLIC IRON CONTENT IN HIGH TEMPERATURE DRI BY BROMINE-METHANOL METHOD.}

The standard method for the determination of metallic iron in DRI used by commercial chemical laboratories including COREM in Quebec City, Quebec, Canada and CSM laboratory, Rome, Italy, is based on bromine-methanol extraction. The typical DRIs to be analyzed are that produced by Midrex and HYL shaft furnaces. The raw materials used for this type of furnaces are direct reduction (DR) pellets which usually has a silica content less than $2 \%$ and the peak reduction temperature lower than $850^{\circ} \mathrm{C}$. This type of low temperature DRI has the following characteristics:

- DRI are of high porosity and metallic iron grains are of fine size.

- The slag phase in DRI is not extensive because the total gangue content is low and after induration at mines, pellets and DRI never see a temperature high enough for slag formation.

- DRI is relatively brittle and can be crushed to very fine size using a shatter box.

Bromine methanol extraction method has been chosen as the standard method for the determination metallic iron content of "low temperature DRI", because it is accurate and efficient.

The high temperature DRI made in our laboratory at McMaster University and in the pilot plant of CSM, Genoa, Italy are of different properties.

- DRIs are of low porosity (very low at the top layer of DRI bed) and heavy iron network due to grain growth.

- DRIs are more ductile than brittle; therefore, it is very difficult to crush them to fine size.

- Gangue in both iron ores may be fluxed by $\mathrm{FeO}$ during reduction. The combination of high temperature and availability of $\mathrm{FeO}$ would cause slag to melt and to coat metal surface due to capillarity.

\section{§C.1 Chemical Analysis Results from COREM}

The report from COREM is attached here as Tables $\mathrm{C}-1, \mathrm{C}-2$ and $\mathrm{C}-3$. About 20 samples made on campus which have been used as control, are not listed in these tables. General observation is that analytical results of degree of metallization are more reasonable for DRI made from waste oxides than that from iron ores. The best DRI judged by the appearance, visual observation and metallographic examination, is the most pronounced in abnormality. One example is the one of the control specimens, Table C-4. The total 
iron content decreases from the top layer to the main body and to the bottom loose pellets due to removal of carbon and oxygen in iron oxide. The trend is right and the numbers are reasonable. On the other hand, the metallic iron content has the opposite trend and is contrary to metallographic observation. The logical conclusion is that the leaching step is incomplete when iron grains are large and dense.

A request to repeat the chemical analysis of a number of specimens was sent to COREM. The supervisor there had checked the procedure which was found to be standard and correct. The repeated results are slightly different but it does not shed light on he systematic nature of the problem.

There might be a problem due to size segregation because the difficulty in the crushing of high temperature DRI. Another request was sent to COREM for them to return the remaining samples (after completing the repeat analyses). Since the analyst followed the procedure, there were large pieces which were deformed but not crushed. These sample were analyzed by Frank Huang on campus using bromine-methanol method. From these results, two important conclusions were reached: (i) The newly obtained results agree, in general, with that reported by COREM, (ii) the size segregation could not be proved to be a cause of concern. 


\begin{tabular}{|c|c|c|c|c|c|}
\hline No & $\begin{array}{l}\text { Crucible } \\
\text { No. }\end{array}$ & $\begin{array}{l}\text { Position of } \\
\text { Sampling }\end{array}$ & $\begin{array}{c}\mathrm{TFe} \\
\text { (wt.\%) }\end{array}$ & $\begin{array}{c}\mathrm{MFe} \\
\text { (wt.\%) }\end{array}$ & $\begin{array}{c}\text { Degree of } \\
\text { Metallization } \\
(\%)\end{array}$ \\
\hline \multirow{6}{*}{1} & \multirow{3}{*}{$\begin{array}{l}\text { 1: Taconite, } \mathrm{C} / \mathrm{O}=0.8 \\
120 \mathrm{~mm} / 60 \mathrm{~min}, \\
1250 \text { to } 1500^{\circ} \mathrm{C}\end{array}$} & Top & 90.4 & 75.4 & 83.4 \\
\hline & & M. B. & 86.6 & 71.5 & 82.3 \\
\hline & & $\mathrm{Bttm}$. & 77.2 & 43.8 & 56.8 \\
\hline & \multirow{3}{*}{$\begin{array}{l}\text { 2: } \text { Taconite, } \mathrm{C} / \mathrm{O}=0.9 \\
120 \mathrm{~mm} / 60 \mathrm{~min}, \\
1250 \text { to } 1500^{\circ} \mathrm{C}\end{array}$} & Top & 89.8 & 77.6 & 86.4 \\
\hline & & M. B. & 85.1 & 68.8 & 80.8 \\
\hline & & Bttm. & 69.4 & 24.4 & 35.2 \\
\hline \multirow{6}{*}{2} & \multirow{3}{*}{$\begin{array}{l}\text { 1: Taconite, } \mathrm{C} / \mathrm{O}=0.8 \\
120 \mathrm{~mm} / 60 \mathrm{~min}, \\
1250 \text { to } 1500^{\circ} \mathrm{C}\end{array}$} & Top & 91.0 & 75.8 & 83.3 \\
\hline & & M. B. & 87.2 & 71.7 & 82.2 \\
\hline & & Bttm. & 69.3 & 20.6 & 29.7 \\
\hline & \multirow{3}{*}{$\begin{array}{l}\text { 2: Taconite, } \mathrm{C} / \mathrm{O}=0.9 \\
120 \mathrm{~mm} / 60 \mathrm{~min}, \\
1250 \text { to } 1500^{\circ} \mathrm{C}\end{array}$} & Top & 91.8 & 78.9 & 85.9 \\
\hline & & M. B. & 87.5 & 74.0 & 84.5 \\
\hline & & Bttm. & 72.0 & 31.2 & 43.3 \\
\hline \multirow{6}{*}{3} & \multirow{3}{*}{$\begin{array}{l}\text { 1: Taconite, } \mathrm{C} / \mathrm{O}=0.9 \\
120 \mathrm{~mm} / 60 \mathrm{~min}, \\
1250 \text { to } 1500^{\circ} \mathrm{C}\end{array}$} & Top & 91.3 & 79.0 & 86.5 \\
\hline & & M. B. & 87.5 & 75.1 & 85.8 \\
\hline & & Bttm. & 71.3 & 30.1 & 42.2 \\
\hline & \multirow{3}{*}{$\begin{array}{l}2: \text { Carajas, } \mathrm{C} / 0=0.85 \\
120 \mathrm{~mm} / 60 \mathrm{~min}, \\
1250 \text { to } 1500^{\circ} \mathrm{C}\end{array}$} & Top & 89.4 & 78.2 & 87.5 \\
\hline & & M. B. & 89.3 & 83.6 & 93.6 \\
\hline & & $\mathrm{Bttm}$ & 78.6 & 56.2 & 71.5 \\
\hline \multirow{6}{*}{4} & \multirow{3}{*}{$\begin{array}{l}\text { 1: Carajas, } \quad \mathrm{C} / 0=0.8 \\
120 \mathrm{~mm} / 60 \mathrm{~min}, \\
1250 \text { to } 1500^{\circ} \mathrm{C}\end{array}$} & Top & 90.4 & 76.6 & 84.7 \\
\hline & & M. B. & 86.7 & 73.6 & 84.9 \\
\hline & & Bttm. & 76.6 & 45.3 & 59.2 \\
\hline & \multirow{3}{*}{$\begin{array}{l}\text { 2: Taconite, } \mathrm{C} / \mathrm{O}=0.8 \\
120 \mathrm{~mm} / 60 \mathrm{~min}, \\
1250 \text { to } 1500^{\circ} \mathrm{C}\end{array}$} & Top & 91.1 & 71.3 & 78.3 \\
\hline & & M. B. & 85.4 & 66.5 & 77.9 \\
\hline & & Bttm. & 68.1 & 17.9 & 26.3 \\
\hline \multirow{3}{*}{9} & \multirow{3}{*}{$\begin{array}{l}\text { 1: Carajas, } \quad C / 0=0.8 \\
120 \mathrm{~mm} / 60 \mathrm{~min}, \\
1250 \text { to } 1500^{\circ} \mathrm{C}\end{array}$} & Top & 89.4 & 76.1 & 85.1 \\
\hline & & M. B. & 89.5 & 83.6 & 93.4 \\
\hline & & Bttm. & 67.7 & 20.6 & 30.4 \\
\hline \multirow{3}{*}{ 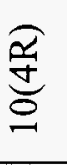 } & \multirow{3}{*}{$\begin{array}{l}\text { 1: Taconite, } \mathrm{C} / \mathrm{O}=0.8 \\
120 \mathrm{~mm} / 60 \mathrm{~min}, \\
1250 \text { to } 1500^{\circ} \mathrm{C}\end{array}$} & Top & 88.7 & 69.9 & 78.8 \\
\hline & & M. B. & 84.2 & 67.3 & 79.9 \\
\hline & & Bttm. & 70.6 & 26.1 & 37.0 \\
\hline
\end{tabular}

Table C-1. The chemical analyses reported by COREM for DRI made in the trials in Italy (DRI made from taconite and Carajas Concentrate) 
Table C-2. The chemical analyses reported by COREM for DRI made in the trials in Italy (DRI made from BOF sludge and millscale)

\begin{tabular}{|c|c|c|c|c|c|}
\hline No & $\begin{array}{l}\text { Crucible } \\
\text { No. }\end{array}$ & $\begin{array}{c}\text { Position of } \\
\text { Sampling }\end{array}$ & $\begin{array}{c}\mathrm{TFe} \\
\text { (wt.\%) }\end{array}$ & $\begin{array}{c}\text { MFe } \\
\text { (wt.\%) }\end{array}$ & $\begin{array}{c}\text { Degree of } \\
\text { Metallization } \\
(\%)\end{array}$ \\
\hline \multirow{6}{*}{5} & \multirow{3}{*}{$\begin{array}{l}\text { 1: BOF Sludge, } \\
\mathrm{C} / \mathrm{O}=1.0 \\
120 \mathrm{~mm} / 60 \mathrm{~min} . \\
1250 \sim 1475^{\circ} \mathrm{C}\end{array}$} & Top & 80.4 & 53.4 & 66.4 \\
\hline & & M. B. & 77.8 & 59.2 & 76.1 \\
\hline & & Bttm. & 80.7 & 63.4 & 78.6 \\
\hline & \multirow{3}{*}{$\begin{array}{l}\text { 2: BOF Sludge, } \\
\mathrm{C} / \mathrm{O}=1.05 \\
120 \mathrm{~mm} / 60 \mathrm{~min} . \\
1250 \sim 1475^{\circ} \mathrm{C}\end{array}$} & Top & 82.3 & 68.1 & 82.7 \\
\hline & & M. B. & 83.1 & 78.2 & 94.1 \\
\hline & & Bttm. & 84.7 & 82.2 & 97.8 \\
\hline \multirow{6}{*}{6} & \multirow{3}{*}{$\begin{array}{l}1: \text { BOF Sludge, } \\
\mathrm{C} / \mathrm{O}=1.05 \\
120 \mathrm{~mm} / 60 \mathrm{~min} . \\
1250 \sim 1475^{\circ} \mathrm{C}\end{array}$} & Top & 83.0 & 699.8 & 84.1 \\
\hline & & M. B. & 83.4 & 78.5 & 94.1 \\
\hline & & Bttm. & 72.0 & 47.7 & 66.3 \\
\hline & \multirow{3}{*}{$\begin{array}{l}\text { 2: BOF Sludge, } \\
\mathrm{C} / \mathrm{O}=1.0 \\
120 \mathrm{~mm} / 60 \mathrm{~min} . \\
1250 \sim 1475^{\circ} \mathrm{C}\end{array}$} & Top & 84.1 & 65.1 & 77.4 \\
\hline & & M. B. & 80.8 & 64.4 & 79.7 \\
\hline & & Bttm. & 80.2 & 66.3 & 82.7 \\
\hline \multirow{3}{*}{9} & \multirow{3}{*}{$\begin{array}{l}\text { 2: Mill Scale, } \\
\mathrm{C} / \mathrm{O}=1.0 \\
120 \mathrm{~mm} / 60 \mathrm{~min} . \\
1250 \sim 1500^{\circ} \mathrm{C} \\
\end{array}$} & Top & 90.6 & 82.3 & 91.2 \\
\hline & & M. B. & 90.7 & 88.4 & 97.5 \\
\hline & & $\mathrm{Bttm}$ & 88.9 & 84.1 & 94.6 \\
\hline
\end{tabular}

The report from the Chemical Laboratory of CSM is not attached here for the following reasons:

- By and large, the chemical analysis reported by COREM and CSM are the same.

- There are some inconsistency obviously due to human errors.

\section{$\S C .2$ The Searching for the Cause of the Systematic Error}

Samples for this investigation were taken at different height from one DRI cake (samples A11, A12 and A13) made from ore/coal pellets at McMaster University and the other DRI cake (samples 5-2-T, \%-2-M, and 5-2-B) made from BOF-sludge/coal pellets in Italy. The experimental conditions for these DRI samples were listed in Table A-5.

In order to find out the reason (or reasons) that caused this serious error, six samples were analyzed by using both the bromine method and copper sulfate method for comparison. 
Meanwhile three pieces of DRI were taken out randomly from every sample, mounted, and polished for metallographic examination.

The degrees of metallization of these samples analyzed, using the bromine method and copper sulfate method, respectively, and those estimated by the metallographic examination are listed in Table C-6.

Table C-3. The chemical analyses reported by COREM for DRI made in the trials in Italy (DRI made from BOF sludge and EAF dust which supplied by SMS Demag Italy)

\begin{tabular}{|c|c|c|c|c|c|c|c|c|c|}
\hline 密 & $\begin{array}{c}\text { Crucible } \\
\text { No. }\end{array}$ & 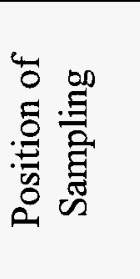 & $\begin{array}{c}\mathrm{TFe} \\
\text { (wt.\%) }\end{array}$ & $\begin{array}{l}\mathrm{MFe} \\
\text { (wt.\%) }\end{array}$ & 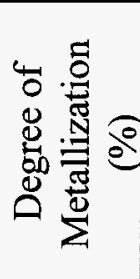 & $\begin{array}{c}\mathrm{Zn} \\
\text { (wt.\%) }\end{array}$ & 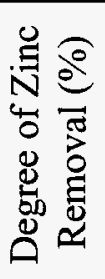 & 全 & 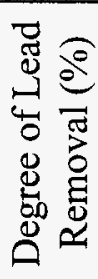 \\
\hline \multirow{8}{*}{7} & \multirow{4}{*}{$\begin{array}{c}\text { 1: (70\%BOF Sludge } \\
+30 \% \text { EAF Dust) } \\
\text { C/O }=1.05, \\
120 \mathrm{~mm} / 65 \mathrm{~min}, \\
1250 \sim 1450^{\circ} \mathrm{C}\end{array}$} & Top & 70.7 & 63.4 & 89.7 & 0.10 & 98.9 & $<1$ & $\sim 100$ \\
\hline & & M. B. & 70.9 & 67.5 & 95.2 & 0.14 & 98.4 & 33 & $\sim 100$ \\
\hline & & Bttm. & 57.9 & 39.0 & 67.4 & 4.25 & 41.0 & 2900 & 44.5 \\
\hline & & Average & & & & 0.28 & 96.7 & 132 & 97.9 \\
\hline & \multirow{4}{*}{$\begin{array}{c}\text { 2: (70\%BOF Sludge } \\
+30 \% \text { EAF Dust) } \\
\mathrm{C} / \mathrm{O}=1.0 \\
120 \mathrm{~mm} / 65 \mathrm{~min}, \\
1250 \sim 1450^{\circ} \mathrm{C}\end{array}$} & Top & 71.8 & 55.8 & 77.7 & 0.13 & 98.6 & $<1$ & $\sim 100$ \\
\hline & & M. B. & 72.2 & 65.3 & 90.4 & 0.29 & 96.8 & 36 & $\sim 100$ \\
\hline & & Bttm. & 56.7 & 23.0 & 40.6 & 4.98 & 30.0 & 3000 & 42.3 \\
\hline & & Average & & & & 0.54 & 93.5 & 200 & 96.7 \\
\hline \multirow{4}{*}{8} & \multirow{4}{*}{$\begin{array}{c}2: \text { (70\%BOF Sludge } \\
+30 \% \text { EAF Dust) } \\
\text { C/O }=1.05 \\
120 \mathrm{~mm} / 65 \mathrm{~min}, \\
1250 \sim 1450^{\circ} \mathrm{C}\end{array}$} & Top & 71.7 & 63.4 & 88.4 & 0.075 & 99.2 & $<1$ & $\sim 100$ \\
\hline & & M. B. & 71.4 & 65.4 & 91.6 & 0.081 & 99.1 & 5 & $\sim 100$ \\
\hline & & Bttm. & 66.6 & 56.0 & 84.1 & 1.39 & 83.5 & 1200 & $>99$ \\
\hline & & Average & & & & 0.13 & 98.5 & 46 & 99.3 \\
\hline
\end{tabular}


Table C-4. The Chemical analyses of DRI made from taconite concentrate for total iron and metallic iron by COREM (wt.\%)

\begin{tabular}{|c|c|c|c|}
\hline & Top Layer & Main Body & $\begin{array}{c}\text { The second layer form } \\
\text { the bottom }\end{array}$ \\
\hline Total Fe & 89.2 & 86.3 & 85.6 \\
\hline Metallic Fe & 62.3 & 68.3 & 77.2 \\
\hline Degree of Metallization & 69.8 & 79.1 & 90.2 \\
\hline
\end{tabular}

Table C-5. The experimental condition of the samples

\begin{tabular}{|c|c|c|c|c|c|}
\hline Sample & Green Ball & $\begin{array}{c}\text { Bed } \\
\text { Height }\end{array}$ & $\begin{array}{c}\text { Heating } \\
\text { time }\end{array}$ & Temperature & Location \\
\hline A-11 & \multirow{3}{*}{$\begin{array}{c}\text { Taconite } \\
50 \% \text { Pinnacle }+50 \% \text { Marford } \\
\mathrm{C} / \mathrm{O}=0.9, \mathrm{CaO} / \mathrm{SiO} 2<0.1\end{array}$} & \multirow{3}{*}{$120 \mathrm{~mm}$} & \multirow{3}{*}{$60 \mathrm{~min}}$. & \multirow{3}{*}{$1250 \sim 1500^{\circ} \mathrm{C}$} & Top layer \\
\hline A-12 & & & & & Main Body \\
\hline A-13 & & & & & $\begin{array}{l}\text { The second layer } \\
\text { from the Bottom }\end{array}$ \\
\hline 5-2-T & \multirow{3}{*}{$\begin{array}{c}\text { BOF sludge } \\
25 \% \text { Pinnacle }+75 \% \text { Marfork } \\
\mathrm{C} / \mathrm{O}=0.9, \mathrm{CaO} / \mathrm{SiO}_{2}>3\end{array}$} & \multirow{3}{*}{$120 \mathrm{~mm}$} & \multirow{3}{*}{$60 \mathrm{~min}}$. & \multirow{3}{*}{$1250 \sim 1475^{\circ} \mathrm{C}$} & Top layer \\
\hline $5-2-\mathrm{M}$ & & & & & Main Body \\
\hline $5-2-B$ & & & & & Bottom layer \\
\hline
\end{tabular}

The results in Table C- 6 show that the degrees of metallization of samples determined by copper sulfate method are much closer to those estimated by metallographic examination compared to those estimated by the bromine method. Errors in the determination of metallic iron content of samples by using the bromine method have following features:

- The error (see the last column of Table C-6) in metallization is larger when the DRI was processed at higher temperature (top layer, see A-11 and 5-2-T in Table C-6)

- The error is larger when the DRI was made from the pellets containing gangue of lower basicity (the basicity of the gangue is listed in the Table C-5).

Based on the above two features, it can be reasoned that the slag coating on the metallic iron in the DRI is likely to be the cause for the serious systematic error on the degree of metallization, determined by using the bromine method, because more molten slag will be generated when the temperature is higher and the basicity is lower. 
Table C-6. The metallization degree of the samples based on the bromine method, copper sulfate method, and estimated metallographically

\begin{tabular}{|c|c|c|c|c|c|}
\hline \multirow[t]{2}{*}{ Sample } & \multirow{2}{*}{$\begin{array}{c}\text { Analysis by } \\
\text { copper } \\
\text { sulfate } \\
\text { method* }^{*} \\
\end{array}$} & \multicolumn{2}{|c|}{ Analysis by bromine method } & \multirow{2}{*}{$\begin{array}{l}\text { Maetallo- } \\
\text { graphic } \\
\text { method }\end{array}$} & \multirow[b]{2}{*}{ Error** } \\
\hline & & $\begin{array}{c}\text { At } \\
\text { McMaster* }\end{array}$ & $\begin{array}{c}\text { Reported by } \\
\text { Corem }\end{array}$ & & \\
\hline A-11 & 86.9 & 70.3 & 69.8 & $85 \sim 90$ & 16.6 \\
\hline A-12 & 93.8 & 82.8 & 79.1 & $>95$ & 11.0 \\
\hline A-13 & 97.4 & 91.0 & 90.2 & $>95$ & 6.4 \\
\hline $5-2-T$ & 91.0 & 83.0 & 82.7 & $90 \sim 95$ & 8.0 \\
\hline 5-2-M & 98.9 & 95.2 & 94.1 & $>95$ & 3.7 \\
\hline $5-2-B$ & 99.5 & 98.2 & 97.8 & $>95$ & 1.3 \\
\hline
\end{tabular}

*Repeated for three times

** Error $=$ the metallization determined by copper sulfate method (column 2) minus the metallization determined by bromine method (column 3 )

In order to substantiate the findings above, the residues of the sample, which are left on the filter paper, after being leached by the bromine-methanol solution were dried, mounted, and polished for metallographic examination. By comparing the photomircograph of the freshly polished specimen of the residues with that of the same specimen etched by the bromine-methanol solution, it was found that etching eliminates many small bright spots, i.e. small metallic iron particles. It appears to be that some of the small iron particles were not dissolved during the standard procedure so that they ended up in the residues.

\section{§C.3 Reliability of Copper Sulfate Method for Determining the Metallic Iron Content}

In order to establish the reliability and accuracy of the copper sulfate method (see Appendix B), the following experiments were conducted (Table G7) for the extreme cases:

- Magnetite for testing the possibility of dissolving $\mathrm{Fe}^{2+}$ in the sample

- Highly de-oxidized steel to ensure that the specimen has a degree of metallization of iron of $100 \%$ 
Table C-7 Experiments for the reliability and accuracy of copper sulfate method

\begin{tabular}{|c|c|c|c|}
\hline Sample & Metallization (\%) & $\begin{array}{c}\text { Leaching time } \\
\text { (hour) }\end{array}$ & $\begin{array}{c}\text { Measured* } \\
\text { Metallization (\%) }\end{array}$ \\
\hline $\begin{array}{c}\text { Magnetite } \\
\left(\mathrm{Fe}_{2} \mathrm{O}_{3} . \mathrm{FeO}\right)\end{array}$ & 0 & 24 & 0 \\
\hline $\begin{array}{c}\text { Magnetite } \\
\left(\mathrm{Fe}_{2} \mathrm{O}_{3} . \mathrm{FeO}\right)\end{array}$ & 0 & 48 & 0 \\
\hline $\begin{array}{c}\text { Freshly polished } \\
\text { and ground } \\
\text { Silicon Steel }\end{array}$ & 100 & 24 & 99.6 \\
\hline
\end{tabular}

* Repeated for three times

It may be concluded that the copper sulfate solution, as described in the procedure (Appendix B), is capable of extracting all metallic iron it can reach and none of the combined iron in oxide phases. Furthermore, copper sulfate solution can break down the barriers around metallic iron grain, supposedly slag coating, which bromine methanol can not. There is no proof that copper sulfate solution can break down all the barrier coating on metallic iron grains, so that there might be, in principle, an error. This error would cause the measured value of the degree of metallization of high temperature DRI to be lower than the true value. It is to say that the possible negative error that we are concerned here, may suggest that the high values of the degree of metallization reported in Table 5-6 to 5-8 are ever more significant in the evaluation of this process. 


\section{APPENDIX D}

§D-1 The ratio of the area of the "Peripheral Ring" to the hearth area for the portion of pellet bed of constant height

- The area of the "Peripheral Ring" on the RHF $\left(A_{P R}\right)$ described on Figure D1 is:

$A_{P R}=\pi\left[(R+d)^{2}-R^{2}\right]$

- The area of the hearth for the portion of pellet bed of constant height $\left(\mathrm{A}_{\mathrm{C}}\right)$

$$
A_{C}=\pi\left(R^{2}-r^{2}\right)
$$

- The area of the "Peripheral Ring" in percentage of the hearth area for the portion of pellet bed of constant height is:

$\frac{A_{P R}}{A_{C}}=\frac{(R+d)^{2}-R^{2}}{R^{2}-r^{2}} \times 100 \%$

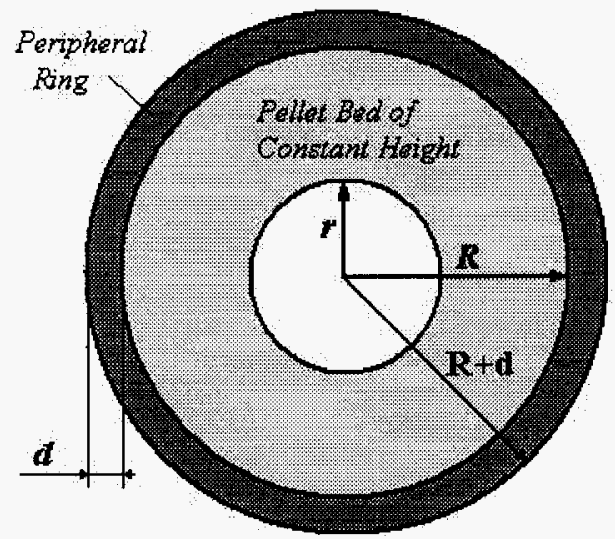

Figure D. 1 The area distribution of the RHF for a tall pellet bed

Where:

$\mathrm{R}=$ the outer radius of the pellet bed of constant height on the RHF (m)

$r=$ the inner radius of the pellet bed on the RHF (m)

$\mathrm{d}=$ the width of the "Peripheral Ring" (m) 
§D-2. The ratio of the volume of the portion of pellet bed on the "Peripheral Ring" to that of the portion of pellet bed of constant height

- The volume of the portion of pellet bed on "Peripheral Ring" on a RHF $\left(V_{P R}\right)$ in Figure D2

$$
\begin{aligned}
V_{P R} & =\int_{R}^{R+d} y d A \\
& =\int 2 \pi x y(x) d x
\end{aligned}
$$

If $y(x)$ is a linear function of $x, y(x)$ may be described as:

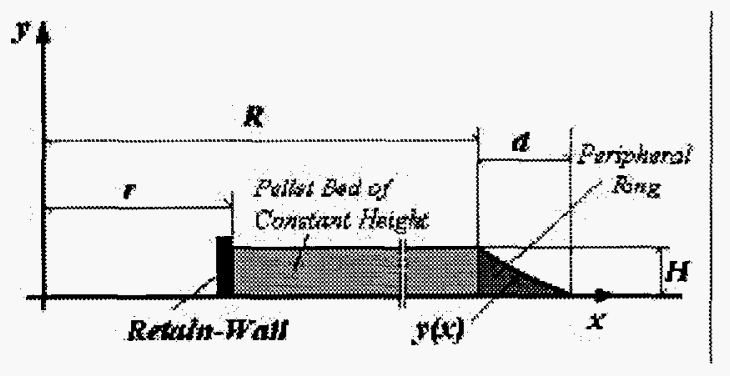

$$
y(x)=H\left(\frac{R+d-x}{d}\right)
$$

Figure D2. The volume of the portion of the pellet bed on the "Peripheral Ring"

and

$$
\begin{aligned}
V_{P R} & =\int_{R}^{R+d} 2 \pi x\left(\frac{H}{d}(R+d-x) d x\right. \\
& =\pi \frac{H}{d}\left(\frac{1}{3}(R+d)^{3}-\frac{1}{3} R^{3}-R^{2} d\right)
\end{aligned}
$$

\section{Where:}

$\mathrm{R}=$ the outer radius of the pellet bed of constant height on the RHF (m)

$r=$ the inner radius of the pellet bed $(\mathrm{m})$

$\mathrm{d}=$ the width of the "Peripheral Ring" (m)

$\mathrm{H}=$ the height of the pellet bed (m)

$y(x)=$ the relationship the height of the pellet bed on the "Peripheral Ring" with its radius $(\mathrm{x})$

- The volume of pellet bed of constant height on the RHF $\left(V_{C}\right)$

For the pellet bed on the RHF described in Figure D2, its volume can be given by:

$$
V_{C}=\pi H\left(R^{2}-r^{2}\right)
$$

- The ratio of volume of the portion of pellet bed in the "Peripheral Ring" to that of the pellet bed of constant height

The ratio of volume of the portion of pellet bed on the "Peripheral Ring" to that of the portion of pellet bed of constant height can be calculated as following:

$$
\frac{V_{P R}}{V_{C}}=\frac{\pi \frac{H}{d}\left(\frac{1}{3}(R+d)^{3}-\frac{1}{3} R^{3}-R^{2} d\right)}{\pi H\left(R^{2}-r^{2}\right)} \times 100 \%
$$




\section{APPENDIX E}

\section{SOME NOTES ON}

\section{THE PAIRED STRAIGHT HEARTH (PSH) FURNACE*}

\section{Introduction}

In order to improve energy efficiency, product quality, and productivity of the coalbased ironmaking process, a new type of furnace, "Paired Straight Hearth (PSH) Furnace", and related technology have been invented. The PSH Furnace Process would produce high quality DRI from iron ore concentrate and steelworks waste oxides. Comparing with the conventional rotary hearth furnace, PSH Furnace has advantages in energy efficiency, productivity, and product quality, and furthermore, in simplicity in its construction and operations.

\section{Basic Designs of a PSH Furnace}

\section{- Furnace Arrangement}

As the name implies, the Paired Straight Hearth (PSH) furnaces are two tunnel-type furnaces placed in parallel, see Figures E-1, E-2, and E-3. In each tunnel, there are three fire walls and one gas exit to control the gas flow in the furnace counter-currently to the movement of pellets. For complete combustion and efficient delivery of its energy inside the furnace, a gas bypath (see Figure E 2 ) is provided, to direct the gas generated by the devolatilization in the pellets, to the high temperature zone of the adjacent furnace for further combustion, see Figure E-3.

Figure E-1. The Side View of PSH Furnace

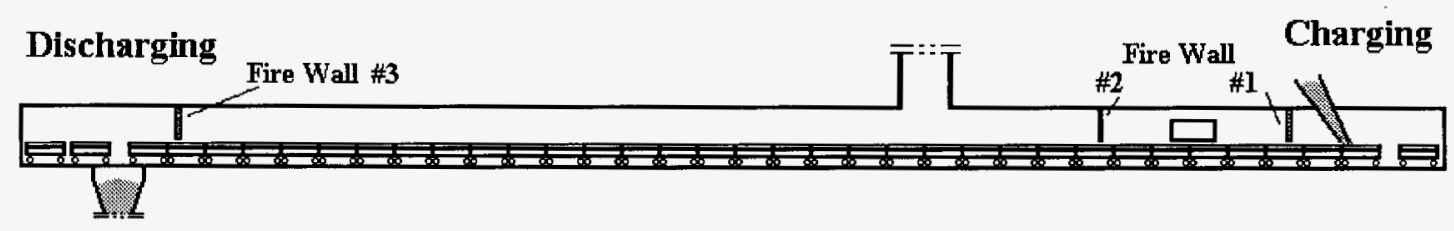

* A USA Patent, No. 60,257879 


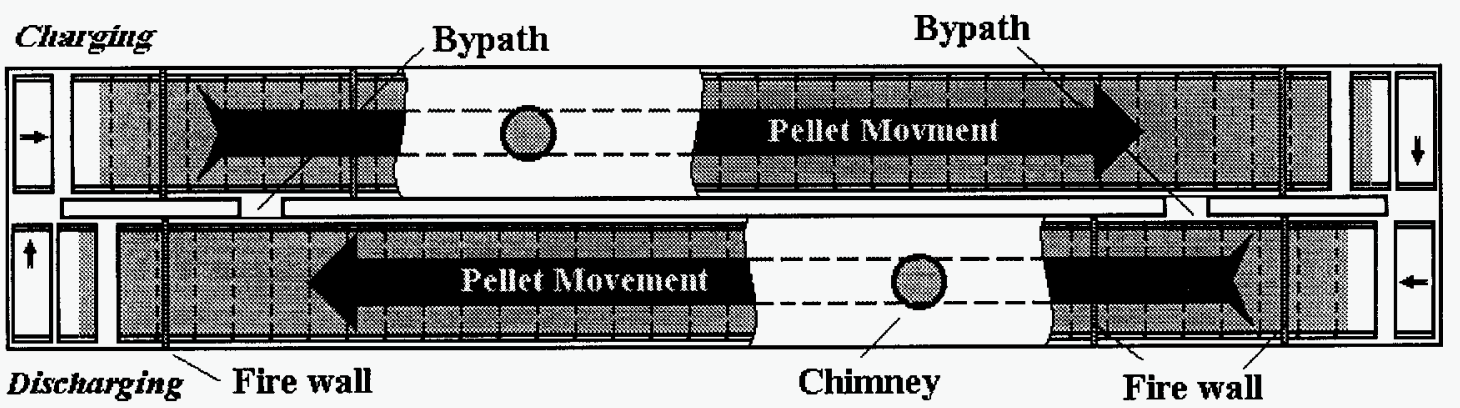

Figure E-2. The Top View of a PSH Furnace and the Movement of Pellets

\section{Charging}

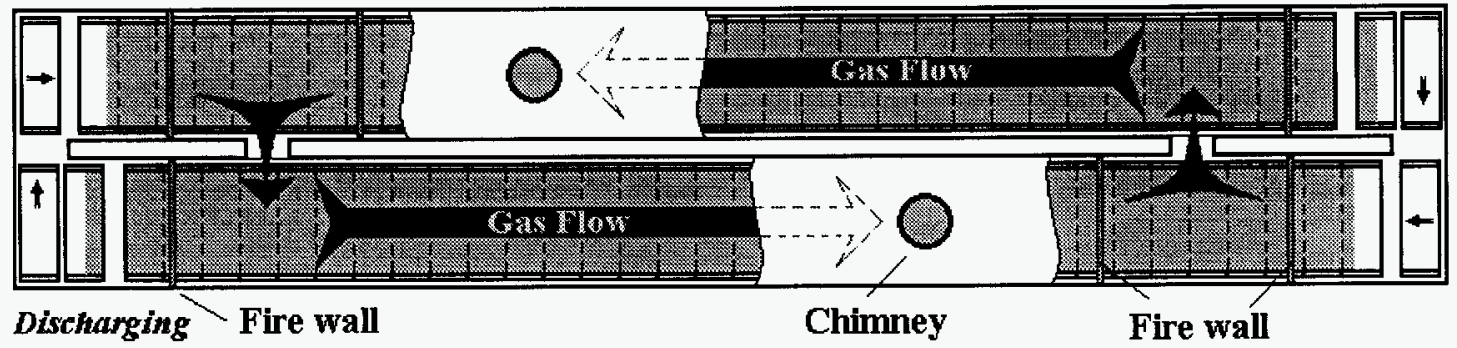

Figure E-3. The Top View of a PSH Furnace and the Gas Flow

\section{- The View of a Vertical Cross Section of a PSH Furnace}

The view of a vertical cross section of a PSH Furnace is shown in figure E-4. The tunnel of a PSH Furnace has an arched roof and straight side-walls. The side walls are all the way down to the ground. To maintain a negative pressure inside to prevent furnace gas from escaping to the environment is one of functions of the side walls of PSH furnace (combining with the roof and the doors at the ends).

\section{- Structure of Pallets}

In each tunneltype furnace, there is a train of detachable sections like a pallet in a continuous travelling grate furnace, see Figure E-2. The detachable pallets of a PSH Furnace are lined with refractory materials, as in a rotary hearth furnace, and unlike the pallets in a travelling grate furnace, the hearth is not permeable to gas flow. The key dimensions of pallets of PSH Furnace are shown in the figure. In our opinion, the ratio of following values $\mathrm{w} / \mathrm{h}=0.8 \sim 1.2, \mathrm{D} / \mathrm{L}=0.3 \sim 0.5$ may be reasonable. 


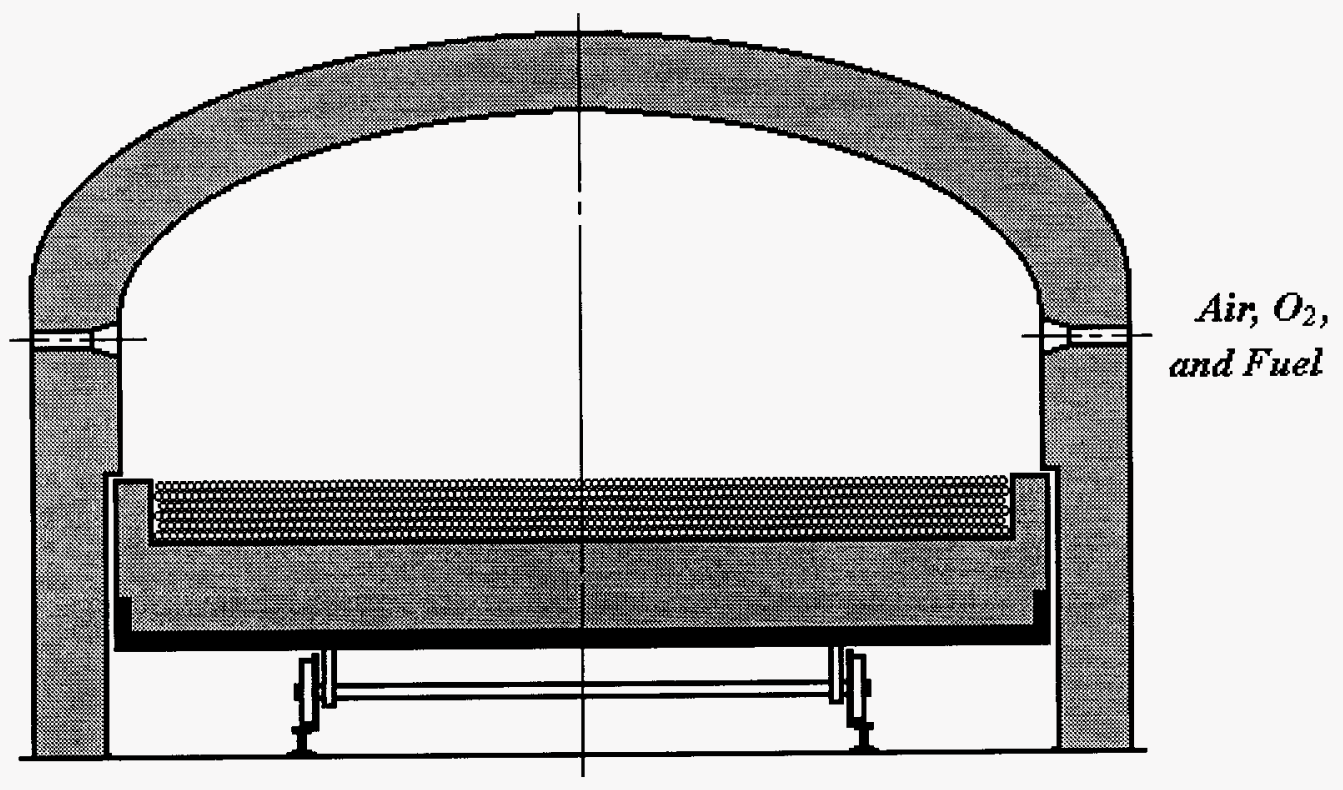

FigureE- 4. The Cross Section View of PSH Furnace
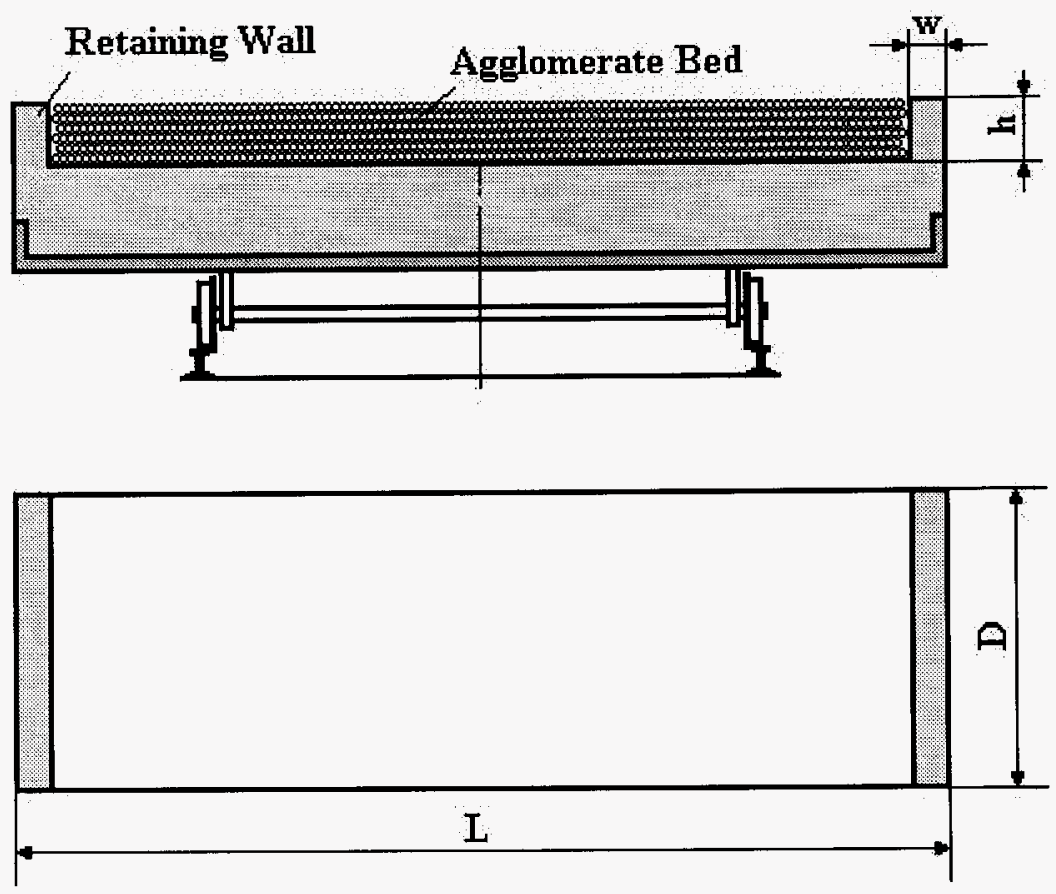

Figure E-5. The Side and Top View of Pallets 


\section{Potential Advantages of PSH Furnace Process in Comparison with RHF}

In a conventional RHF there are two major concerns with the increase of the width of the hearth, the temperature of the furnace, and the height of the bed. The charging rate along the radial direction demands precise control because the rate has to increase proportionally to the value of the radius to achieve uniform loading of the hearth. With a taller bed of DRI at about $1500^{\circ} \mathrm{C}$, the discharging screw of RHF has larger area exposed to more intensive heating. The cooling and the operation of the screw will be very challenging. A PSH Furnace would eliminate above operational problems in addition to the following advantages:

\section{- More Efficient Use of Land}

A PSH Furnace will use the land/space more efficiently than a RHF. The area of land in the middle of a RHF which is not effectively used, is comparable to the total hearth area.

\section{- Better Availability and Simpler Maintenance}

The hearth of a PSH Furnace is made- up of a train of detachable pallets and no moving parts at high temperature for discharging operation. Every pallet, when it needs to be repaired, may be removed from the train and replaced by one in reserve with minimal interruption of the operation. The pallet that is taken off the train may be serviced offline. In the conventional rotary hearth furnace, the furnace hearth is a single unit of refractory material lined steel turntable, and DRI is discharged in the radial direction by a screw discharger. The repair of any part of the hearth necessitates the whole unit to be shut down and cooled to ambient temperature first.

\section{- Wider Acceptable Range of Burner Operation}

Current operation of a RHF with shallow pellet bed needs to control the atmosphere in the reduction zone to be $\mathrm{CO} / \mathrm{CO}_{2} \geq 2$ to facilitate reduction of metal oxides and to minimize the risk of re-oxidization of sponge iron. However, for a hrge chamber with multiple burners, the non-uniformity in temperature and in the atmosphere will cause the ratio of $\mathrm{CO} / \mathrm{CO}_{2}$ to be lower than 2 somewhere in the reduction zone sometimes. It might be the major cause of the re-oxidization of reduced iron and Iquid slag on the hearth floor in some of the current RHF operations.

The operation of a PSH Furnace will not need the reducing atmosphere in the combustion chamber because of the advantage of tall pellet bed. Therefore, the burner design and operation will be less demanding. 


\section{- Lower Construction Cost}

The structure of a PSH Furnace, which has no curved structure other than the roof, will be much simpler because it uses straight hearth, straight walls, and straight roof. These simpler structure of a PSH furnace leads to more conventional design and construction methods.

\section{- The Width of the Hearth}

There is a strong incentive to increase the width of the hearth for more efficient use of the land for the design of a RHF. It will also lead to the problem of non-uniformity of temperature and chemical composition of gaseous phases over the pellet bed. There is no such compromise to be considered in the design of a PSH Furnace.

\section{- Higher Fuel Efficiency}

With the use of a tall pellet bed, the atmosphere can be fully oxidized $(\mathrm{CO} \approx 0 \%)$ in a PSH Furnace, unlike the current RHF process which requires an atmosphere of $\mathrm{CO} / \mathrm{CO}_{2} \geq 2$ in the reduction zone where heat is consumed for chemical reactions.

The heat derived from 1 gram-mole of $\mathrm{CO}$ or carbon under full combustion and partial combustion is shown in Table E-1.

TABle E-1. The Heat D ERIVEd For CO ANd CARbon UNDer DifFerent CONDITIONS

\begin{tabular}{|c|c|c|}
\hline Fuel & $\begin{array}{c}\text { Complete Combustion } \\
\text { (KJ/gm-mole) }\end{array}$ & $\begin{array}{c}\text { Partial Combustion, }\left(\mathrm{CO} / \mathrm{CO}_{2}=2\right) \\
\text { (KJ/gm-mole) }\end{array}$ \\
\hline Carbon & 394 & 205 \\
\hline $\mathrm{CO}$ & 283 & 94 \\
\hline
\end{tabular}

By comparing the data in Table E-1, it is very clear that the fuel efficiency of a PSH Furnace would be higher because more heat is delivered to meet the need of the process, less as waste heat.

\section{- Better Counter-Current Flows}

A counter-current flow of gas and pellets would be better controlled because of the PSH furnace has larger length/width ratio. Therefore control of temperature and composition of the atmosphere should be more effective resulting in an operation with efficient use of energy and free of risk of re-oxidation of DRI. This advantage is very significant for the recycling of waste oxides. 


\section{- Linear Velocity of the Hearth Movement}

Higher linear velocity of the movement of furnace hearth for shallow bed would potentially cause more operational difficulties. In the operation of a PSH Furnace with taller bed, the linear velocity of the movement of furnace hearth would be lower than that in a RHF for comparable hearth productivity.

\section{- Cleaner Hearth}

The operation of a PSH Furnace with tall pellet bed, the bottom temperature of the bed of DRI is about $1200^{\circ} \mathrm{C}$ at the time of discharging. At this temperature, without direct contact with oxidizing atmosphere, the presence of liquid slag on the hearth is very unlikely to happen. In photo E-1 it shows a crucible that was used for the reduction of green balls containing EAF dust for two times. There is no noticeable damage to the hearth, i.e. the bottom of crucible. The black spots visible on the bottom of crucible are colored by soot from cracking of volatile matter.

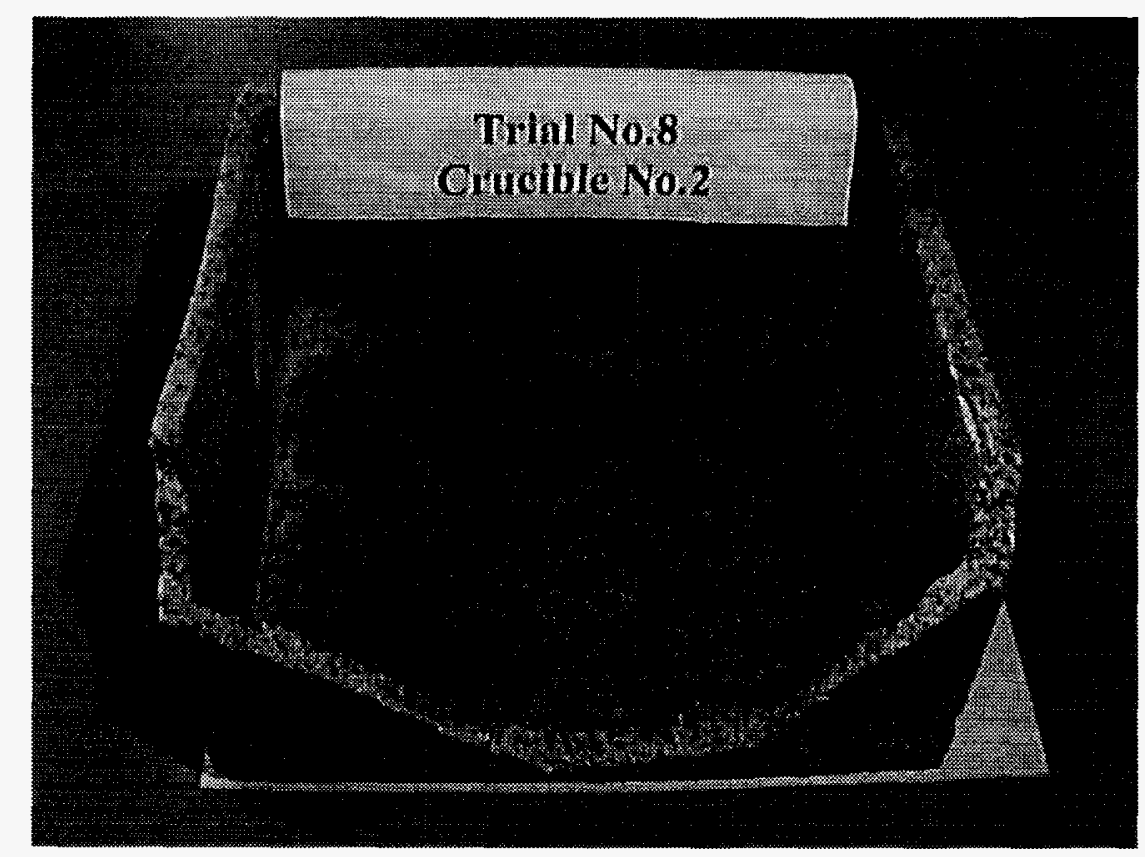

PHOTO E-1. THE “CLEAN” BOTTOM OF USED CRUCIBLE (FURNACE HEARTH) FOR THE REDUCTION OFGREEN BALLS CONTAIN ING EAF DUCT 


\section{The Operations of a PSH Furnace}

\section{- Charging}

At the charging end of the furnace through a charging device ${ }^{[1]}$ (see Figure E-1), dried pellets are charged onto the pallet forming a layer of pellet bed evenly. The height of the pellet bed will be $120 \mathrm{~mm}$ or taller. We recommend that it will be at least $60 \mathrm{~mm}$.

\section{- The Supply of Heat for Reduction}

After charging the pellets, the movement of pallet train is toward to the discharging end (see Figure E-3) and enters the zone with flame temperature at 1300 to $1400^{\circ} \mathrm{C}$ for a few minutes, and then reaches the higher temperature zone with flame temperature of 1600 to $1650^{\circ} \mathrm{C}$. Metal oxides are heated radiatively by he flame and refractory walls, and reduced by carbon and volatile matter of the coal inside the pellet. The total reaction time will be in the range of 50 to 65 minutes if the height of pellet bed is $120 \mathrm{~mm}$. The total time of reaction will vary with the properties of the green balls and its contents, and the quality of DRI required.

\section{- Discharging}

After a predetermined time of processing, reduced pellets pass through firewall \#3 (see Figure E-1) to reach the discharging end and are discharged by the tilt/dump method ${ }^{[1]}$ from the pallets to the receiving container below.

The emptied pallet is moved and attached to the charging end of the adjacent furnace to receive the green balls.

\section{- Burner Operation}

All the burners will be operated for full combustion of the fuel or controlled amount of excess oxygen. The atmosphere can be fully oxidized $(\mathrm{CO} \approx 0 \%$ ), unlike the current RHF process which requires $\mathrm{CO} / \mathrm{CO}_{2} \geq 2$ in the reduction zone. The flame temperature, green balls see in first five minutes, would be in the range of $1300^{\circ} \sim 1400^{\circ} \mathrm{C}$ and in the rest of the system would be between $1600^{\circ}$ and $1650^{\circ} \mathrm{C}$.

\section{Products}

\section{- Degree of Metallization and Density}

DRIs made from these green balls stated above are of a density in the range of 3 to 5 $\mathrm{g} / \mathrm{cm}^{3}$ and a degree of metallization of iron above $94 \%$. 


\section{- The Removal Rate of Zinc and Lead}

For green balls containing EAF dust, our experiments show that the removal rate of zinc is higher than $95 \%$ and that for lead is essentially $100 \%$. The high removal rate of zinc and lead is due to the high temperature and tall pellet bed under conditions that prevails in a PSH Furnace.

\section{- Safety for Shipping}

Photo E-2 shows a cake of reduced pellets, which was made more than one year ago and kept unprotected in laboratory. The surfaces of all pellets are silvery and shining. The DRI, exposed high temperature sintering (about $1500^{\circ} \mathrm{C}$ ), becomes chemically inert for storage and during shipping. The high temperature processing makes the grains of metallic iron grow to big size and densified, see Photo E-3.

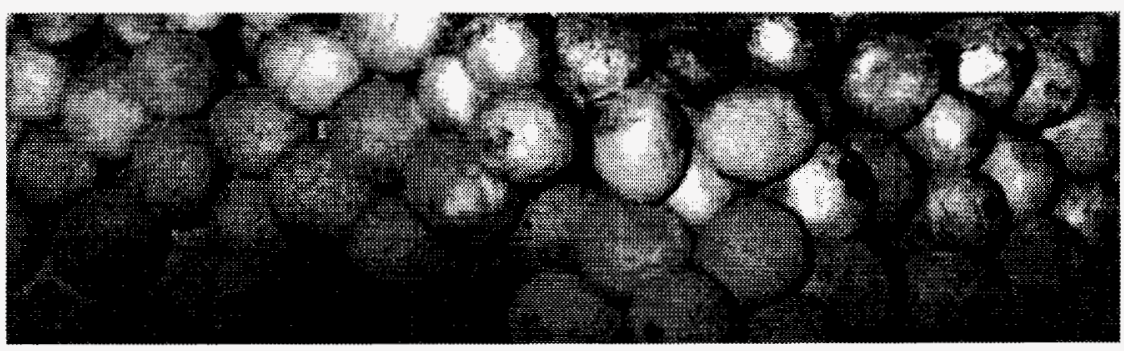

Photo E- 2. The DRI with silvery and shining skin, made from Taconite under $1500^{\circ} \mathrm{C}$

Photo E-3 The Micro-Structure of Reduced Pellet 
- Appearance of Reduced Pellets Bed

The following DRI cakes are $230 \mathrm{~mm}$ long, $190 \mathrm{~mm}$ wide, and 60 to $70 \mathrm{~mm}$ high. The size of the paper on which the cake is siting is A4.

\section{(a) DRI made from Taconite}

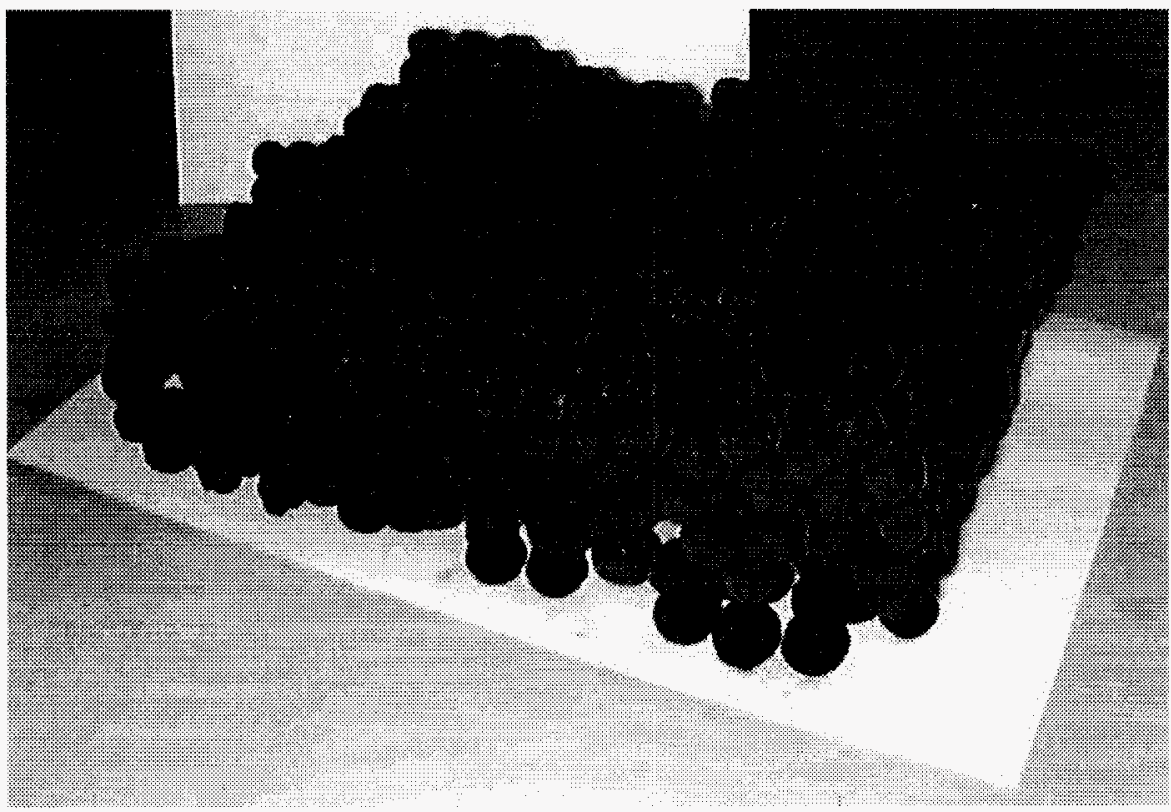

(b) DRI made from Hematite

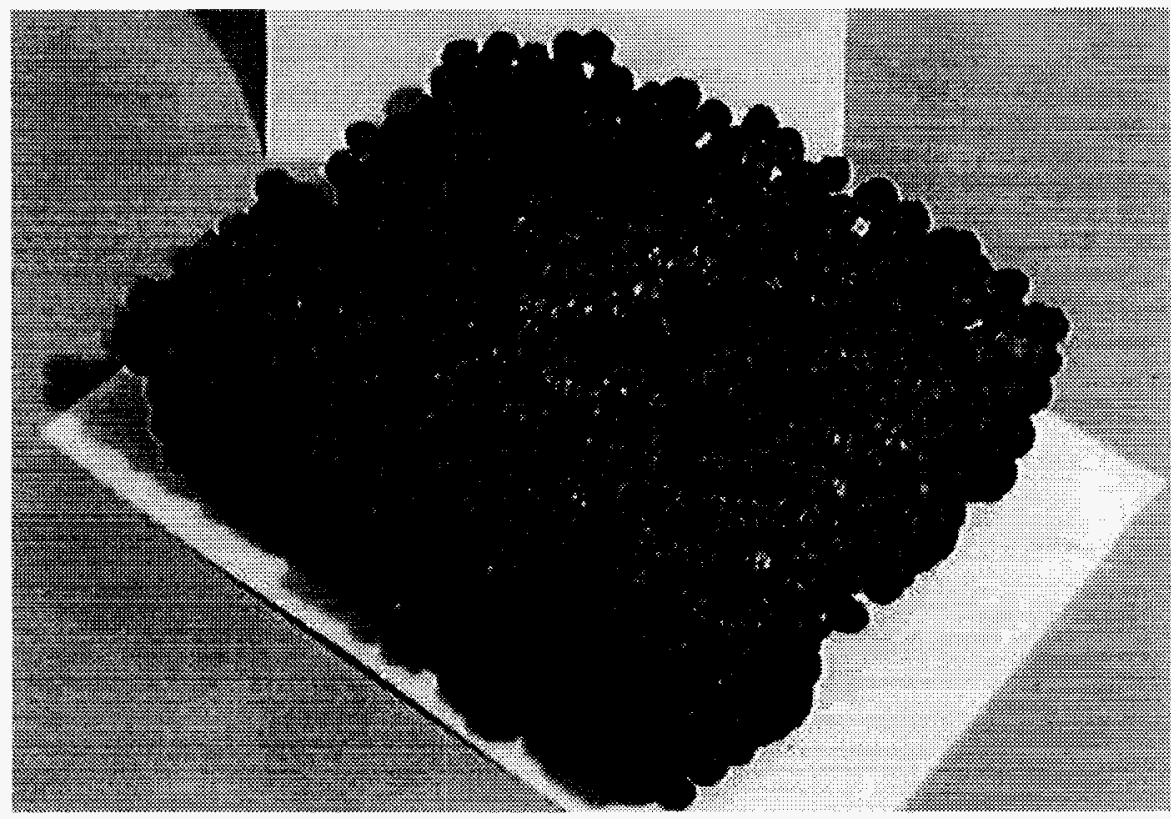


(c) DRI made from BOF sludge

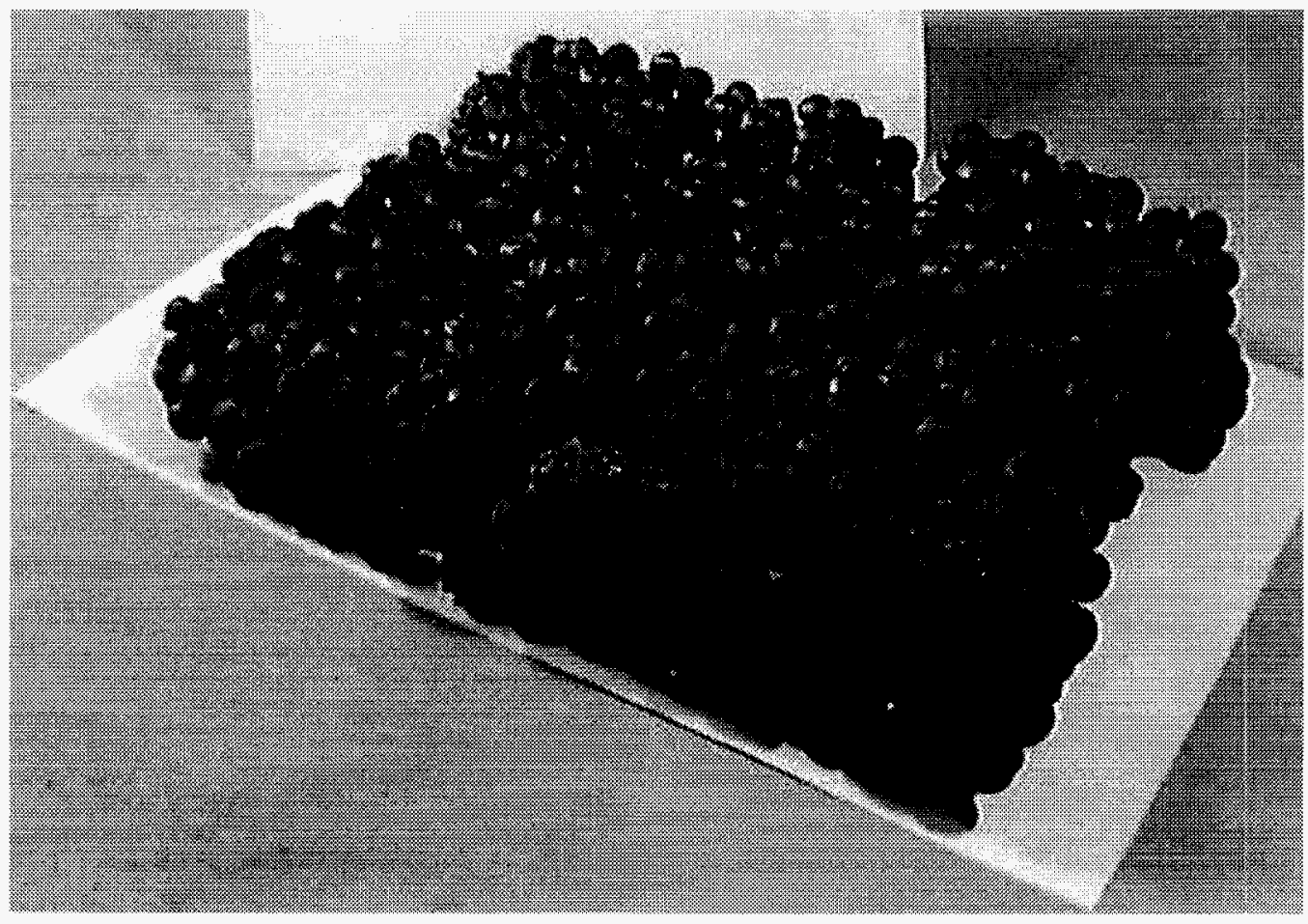

(d) DRI made from BOF Sludge and EAF Dust

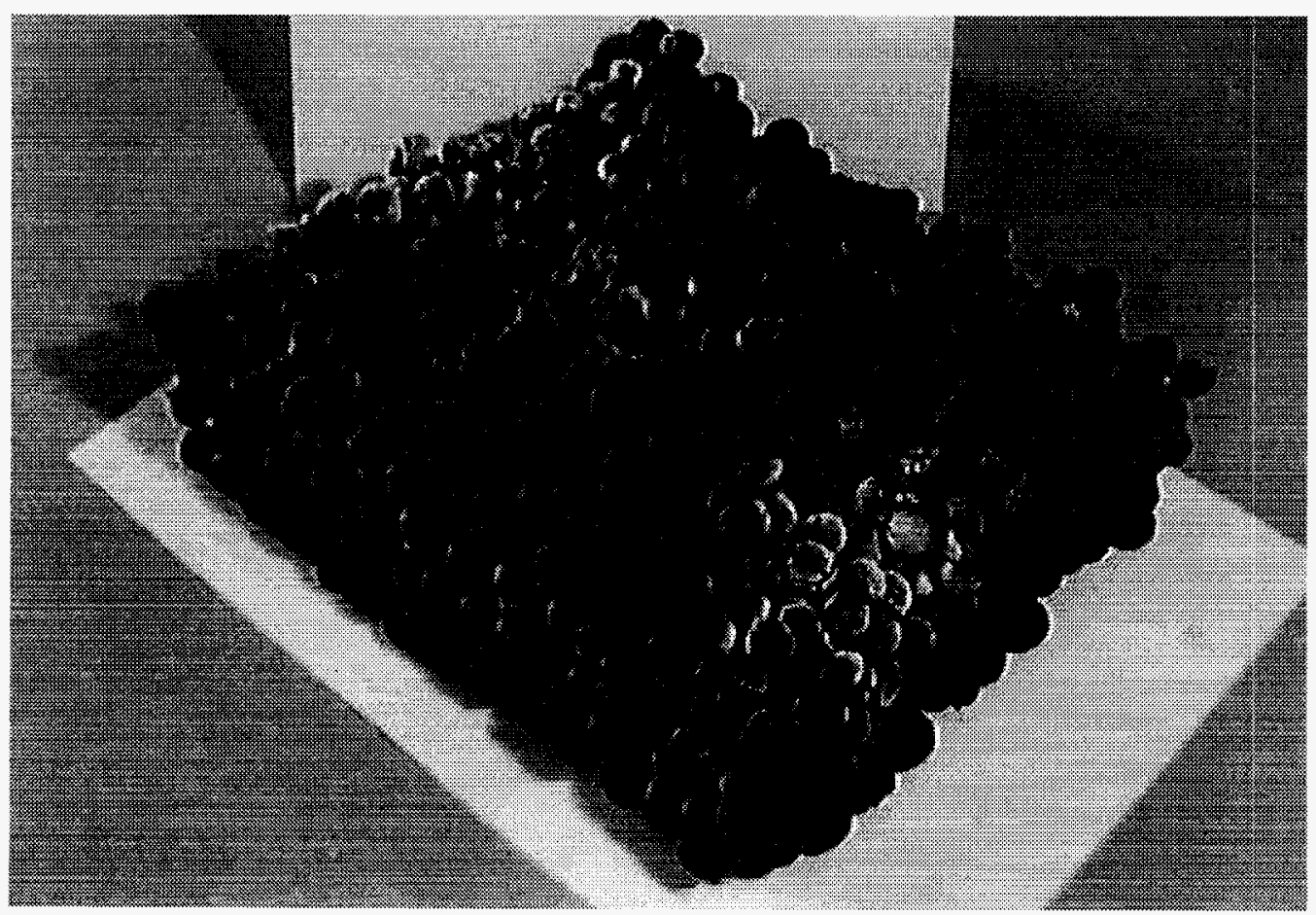


(e) DRI made from Mill Scale

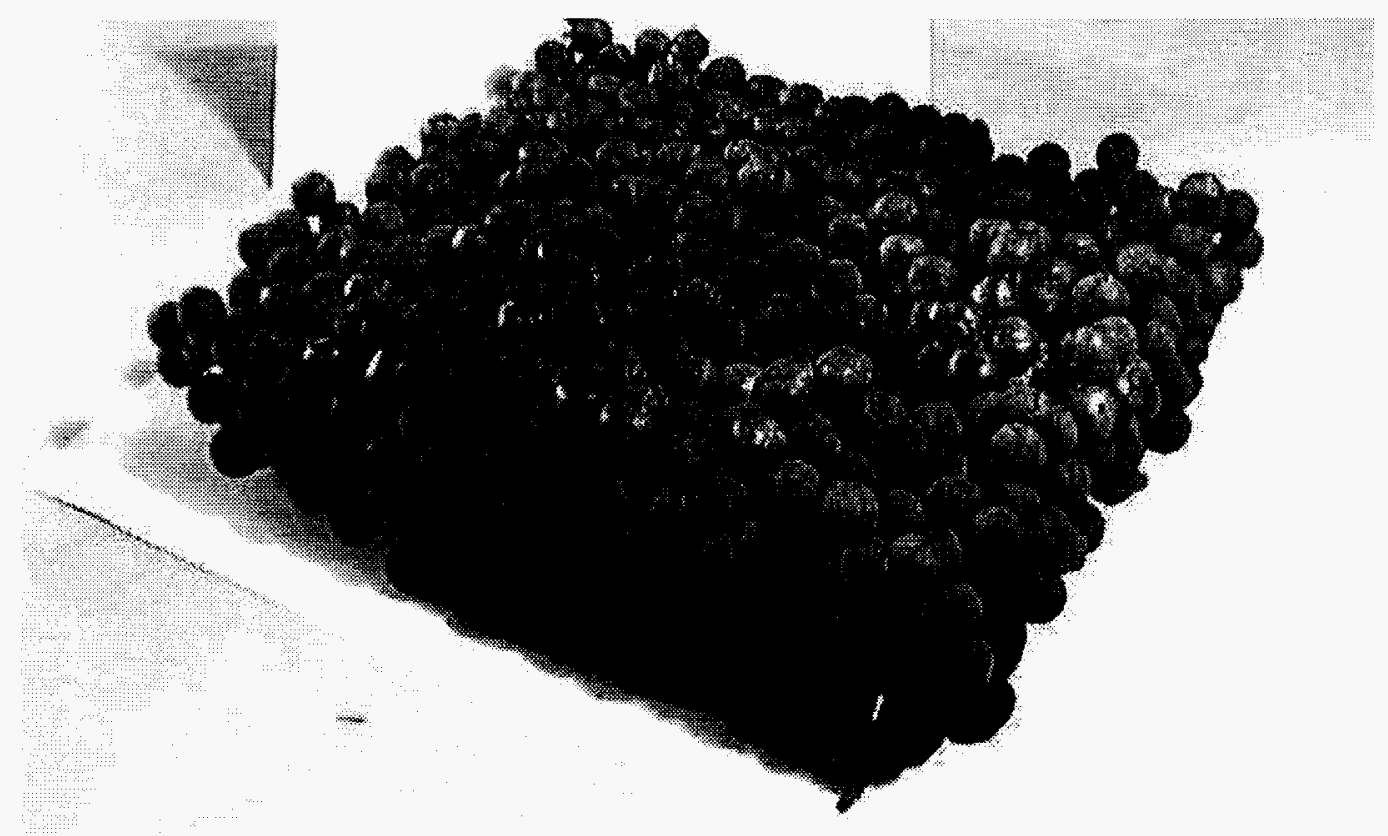

\section{Productivity and Energy Efficiency}

In general, productivity of the equipment depends on the quality of raw materials and the desired properties of the product. A PSH Furnace with the use of tall bed of green balls is most effective in the production of DRI of very high quality. The overall reaction rate in the manufacture of DRI is controlled by the rate of heat transfer to the reaction site to sustain endothermic reactions. The productivity of a PSH furnace would be much higher in comparison with the current operation of an RHF because the radiative heat transfer from a flame of a temperature up to $1650^{\circ} \mathrm{C}$ is much higher. When the height of the pellet bed is $120 \mathrm{~mm}$, the productivity has been established to be 100 to $120 \mathrm{~kg} \mathrm{DRI} / \mathrm{m}^{2} / \mathrm{hr}$. 
Energy efficiency can only be firmly established based on actual operation. A pilot or demonstration plant is often designed to provide such data, among other things. However, a heat and mass balance calculation will establish a solid foundation. We may identify energy-saving factors in the reduction of a tall bed of green balls under a fully oxidized flame at $1600^{\circ}$ to $1650^{\circ} \mathrm{C}$ in a PSH furnace before the computed results are presented. The very important factor is that most of the energy of fuel is released right above the pellet bed where heat is consumed by the process, with very intens ive heat transfer rate. The other two major factors are: (a) less solid reductant is added in green balls, and (b) about $40 \%$ of the sensible heat in exit gas at $1300^{\circ} \mathrm{C}$ is assumed to be recovered in the incoming air at $800^{\circ} \mathrm{C}$. For a summary, see Table E-2. With an assumed heat loss rate of $15 \%$ of total heat input, the estimate of the fuel rate in kilograms of coal equivalent per $1000 \mathrm{~kg}$ DRI is in a range from 350 to $400 \mathrm{~kg}$ coal.

\section{Table E-2 A Summary of Heat and Mass Balance Calculation}

(a) Temperature and Compositions

\begin{tabular}{|c|c|c|c|}
\hline \hline No. & Parameters & Unit & Number \\
\hline 1 & TEMPERATURE OF GREEN BALL & ${ }^{\circ} \mathrm{C}$ & 25 \\
\hline 2 & Average Temperature of DRI & ${ }^{\circ} \mathrm{C}$ & 1400 \\
\hline 3 & Temperature of Exit Gas & ${ }^{\circ} \mathrm{C}$ & 1300 \\
\hline 4 & Temperature of Pre-heated Air & ${ }^{\circ} \mathrm{C}$ & 800 \\
\hline 5 & Average Carbon Content of DRI & wt.\% & 2.5 \\
\hline 6 & Average Degree of Metallization & $\%$ & 95 \\
\hline 7 & Rate of Heat Lost & $\%$ & 15 \\
\hline
\end{tabular}

(b) Mass Balance

\begin{tabular}{||l|c|c||c|c|c||}
\hline \hline \multicolumn{3}{|c||}{ Input } & \multicolumn{4}{c||}{ Output } \\
\hline \multicolumn{1}{|c|}{ Item } & Unit & Amount & Item & Unit & Amount \\
\hline \multicolumn{1}{|c|}{ Taconite } & $\mathrm{kg}$ & 1274.9 & DRI & $\mathrm{kg}$ & 1000.0 \\
\hline Coal & $\mathrm{kg}$ & 374.2 & Exit gas & $\mathrm{kg}$ & 2784.1 \\
\hline Air & $\mathrm{kg}$ & 2135.0 & Exit gas & $m^{3}$ & 2017.3 \\
\hline Air & $m^{3}$ & 1658.3 & & & \\
\hline Total & $\mathrm{kg}$ & 3784.1 & Total & $\mathrm{kg}$ & 3784.1 \\
\hline
\end{tabular}


(c) Heat Balance

\begin{tabular}{||l|r|r||l|r|r||}
\hline \multicolumn{4}{|c|}{ Input } & \multicolumn{4}{c||}{ Output } \\
\hline Heat Derived from & $\mathrm{kJ}$ & $\%$ & Heat Goes to & $\mathrm{kJ}$ & $\%$ \\
\hline $\mathrm{C}+\mathrm{O}_{2} \rightarrow \mathrm{CO}$ & 253560.4 & 2.39 & Iron Oxides Reduction & 3101980.8 & 29.27 \\
\hline $\mathrm{CO}+\mathrm{O}_{2} \rightarrow \mathrm{CO}_{2}$ & 6275400.0 & 59.22 & Other Oxide Reduction & 26492.0 & 0.25 \\
\hline $\mathrm{H}_{2}+\mathrm{O}_{2} \mathrm{O} \mathrm{H}_{2} \mathrm{O}$ & 2220674.0 & 20.96 & Decomposition of Coal & 470087.2 & 4.44 \\
\hline Hot Air & 1812745.1 & 17.11 & DRI & 1109009.9 & 10.47 \\
\hline Green Balls & 33655.5 & 0.32 & Exit Gas & 4299071.0 & 40.57 \\
\hline & & & Heat Lost & 1589394.1 & 15.00 \\
\hline Total & 10596035.0 & 100.00 & Total & 10596035.0 & 100.00 \\
\hline
\end{tabular}

\section{Reference}

1. Lu, W-K. and Huang, D., "Paired Straight Hearth (PSH) Furnaces for Metal Oxide Reduction", USA Patent, No. 60,257879 (Filed on Feb 26, 1999, Issued on July 2001 ), Chinese Patent 00102679.8 (pending), Canada \& Japan Patent (pending). 